

Evaluation of Centres for the Integral

Attention of Children in Dominican

Republic (CIANIs) and Local Community

Organizations for Child Protection (LCOCP)

\author{
Henry Parada \\ Susan Silver \\ Mike Burke
}





\section{Evaluation of Centres for the Integral Attention of Children in Dominican Republic (CIANIs) and Local Community Organizations for Child Protection (LCOCP)}

Henry Parada, Susan Silver, Mike Burke 
Evaluation of Centres for the Integral Attention of Children in Dominican Republic (CIANIs) and Local Community Organizations for Child Protection (LCOCP)

Ryerson University

Principal Investigators

Henry Parada PhD Associate Professor

Susan Silver PhD Associate Professor

Mike Burke PhD Associate Professor

Research Coordinator

Ana Leticia Ibarra Letona

Research Assistants

Meredith Baker de Gutierrez

Tamara Britton

Micely Diaz

Irma Molina

Dominican Republic

Data Collection Coordinator

Julia Hasbún

CONANI Consulting Team

Tilsa Ares Service Manager

Alberto Padilla Public Policy Manager

Design Cover and Diagramming

Jesús Alberto de la Cruz

Printed

Editora Búho, S.R.L.

Santo Domingo, D. R.

\section{Ryerson}

University
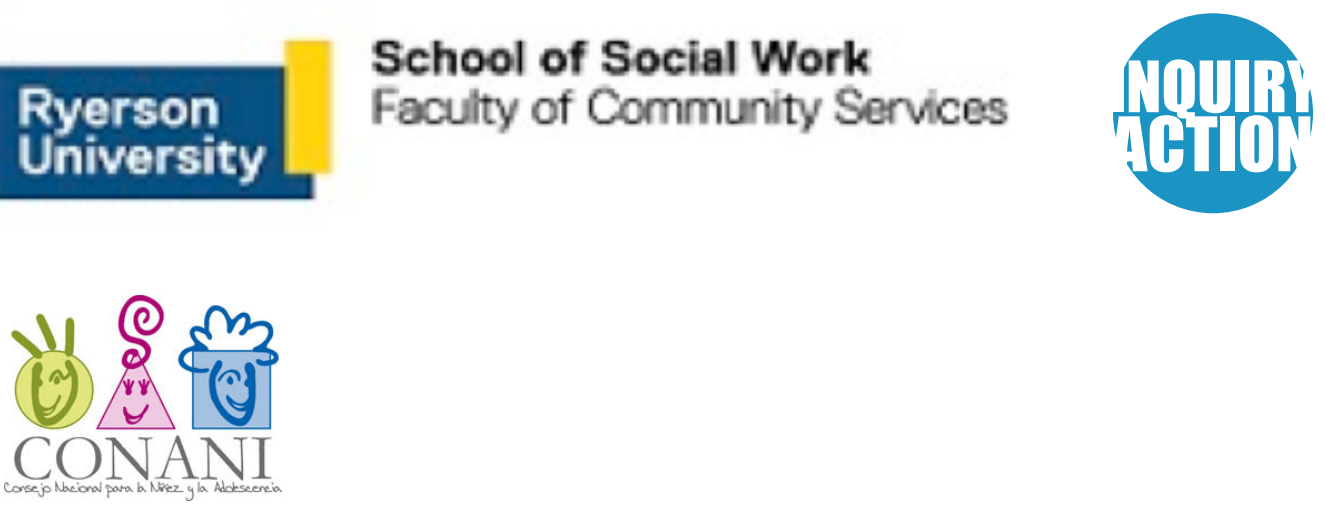


\section{Acknowledgements}

The preparation of this report would not have been possible without the valuable contribution of countless individuals and groups who contributed not only to this final report, but also to the planning, development and implementation of the study.

Sincere gratitude is extended to the Dominican contributors and collaborators, starting with the CIANI families, CIANI employees, and community stakeholders who took the time to share their experiences.

The data collectors in the Dominican who completed the field work on the ground, working tirelessly to collect and organize the data.

To Kirsys Fernandez, for allowing us to partner with CONANI, and who facilitated the work done. To the various CONANI staff, for contributing their expertise and providing guidance and consultation throughout the life of this study. Special thanks to Alberto Padilla who helped facilitate collaboration and data collection.

To INAIPI who took the time to meet with us and review our findings and provide feedback, special thanks to Alexandra Santelises and Eric Gomez who took the time to review the report and findings and meet with us to discuss.

Lastly, to the European Union's Children and Violence Evaluation Challenge Fund, for their financial support. 



\section{Acronyms}

\begin{tabular}{|c|c|}
\hline AEISS & $\begin{array}{l}\text { Administrator of Healthy and Safe Childcare Centers (Spanish } \\
\text { Acronym) }\end{array}$ \\
\hline BCG & Bacillus Calmette-Guerin \\
\hline CAIPI & Centers for Integral Early Child Intervention (Spanish Acronym) \\
\hline CAIPI-T & $\begin{array}{l}\text { Centers for Integral Early Child Intervention in transition (Spanish } \\
\text { Acronym) }\end{array}$ \\
\hline CEN-CINAI & $\begin{array}{l}\text { Centers for Education, Nutrition and Integral Attention for Children } \\
\text { (Spanish Acronym) }\end{array}$ \\
\hline CEPAL & $\begin{array}{l}\text { Economic Commission for Latin America and the Caribbean (Spa- } \\
\text { nish Acronym) }\end{array}$ \\
\hline CESDEM & Center for Social and Demographic Studies \\
\hline CIANI & Centers for the Integral Attention of Children \\
\hline CIPAF & Research Center for Women's Action (Spanish Acronym) \\
\hline CRC & Convention on the Rights of the Child \\
\hline CONANI & National Council for the Protection of Children (Spanish Acronym) \\
\hline DIGEPEP & $\begin{array}{l}\text { Presidents General Directorate of Special Programs (Spanish } \\
\text { Acronym) }\end{array}$ \\
\hline DR & Dominican Republic \\
\hline ECD & Early Child Development \\
\hline ECE & Early Childcare Education \\
\hline ECLAC & Economic Commission for Latin America and the Caribbean \\
\hline HECDI & Holistic Early Childhood Development Index \\
\hline IDB & Inter-American Development Bank \\
\hline ICPHR & International Collaboration for Participatory Health Research \\
\hline INAIPI & $\begin{array}{l}\text { National Institute for Integral Attention for Early Child Intervention } \\
\text { (Spanish Acronym }\end{array}$ \\
\hline JUNGI & National Board of Early Childhood Care (Spanish Acronym) \\
\hline
\end{tabular}




\begin{tabular}{ll|l}
\hline LCOCP & Local Community Organizations for Child Protection \\
\hline LAC & Latina America and Caribbean \\
MEPyD & Ministerio de Economía, Planificación y Desarrollo \\
\hline MMR & Measles, Mumps, and Rubella \\
\hline NGO & Non-Governmental Organization \\
ILO & International Labor Organization \\
\hline INAIPI & $\begin{array}{l}\text { National Institute for Integral Attention for Early Child Intervention } \\
\text { (Spanish Acronym) }\end{array}$ \\
\hline OXFAM & Oxford Committee for Famine Relief \\
\hline PAIPI & Comprehensive Early Childcare Program (Spanish Acronym) \\
\hline PIDI & Integrated Child Development Project \\
\hline SEC & Ministry of Culture \\
\hline SEE & Ministry of Education (Spanish Acronym) \\
\hline SEM & State Secretariat for Women (Spanish Acronym) \\
\hline SESPAS & Ministry of Public Health and Social Assistance (Spanish Acronym) \\
\hline SET & Secretary of Labor (Spanish Acronym) \\
\hline SISDOM & $\begin{array}{l}\text { System of Social Indicators for the Dominican Republic (Acronym } \\
\text { in Spanish) }\end{array}$ \\
\hline SRSG & Special Representative of the Secretary General \\
STI & Sexually Transmitted Infection \\
\hline UN & United Nations \\
\hline UNDP & United Nations Development Programme \\
\hline UNESCO & United Nations Educational, Scientific and Cultural Organization \\
\hline UNICEF & United Nations International Children's Fund \\
\hline USAID & United States Agency for International Development \\
\hline WHO & World Health Organization \\
\hline QAC & Qisqueya Learn With You (Spanish Acronym) \\
\hline QEC & Quisqueya Begins With You (Spanish Acronym) \\
\hline
\end{tabular}




\section{Table of Contents}

1. Introduction . . . . . . . . . . . . . . . . . . . . . . . 15

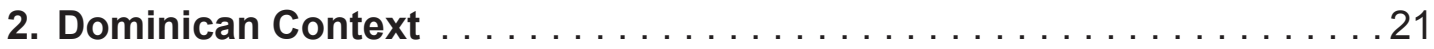

a. Early Childcare Development Focus . . . . . . . . . . . . . 24

b. CONANI - The National Council for the Protection of Children . . . . . 227

c. CIANI - Centres for the Integral Attention of Children . . . . . . . . 29

d. INAIPI - National Institute for Integral Attention for Early Child Intervention . . . . . . . . . . . . . . . . . . . . . . 34

e. LCOCP - Local Community Organizations Child Protection . . . . . . . . 37

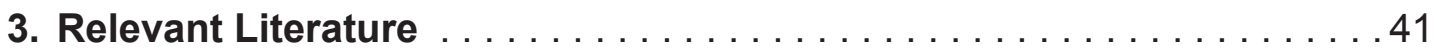

a. Early Child Care Development in Latin America and

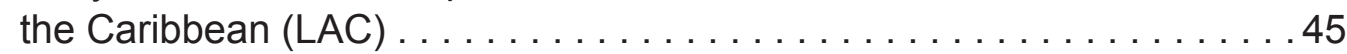

b. Early Child Care Development Interventions and Benefits . . . . . . 46 46

i. Social Capital .................................. 50

ii. Community Trust ........................... 53

iii. Community Engagement ........................ 55

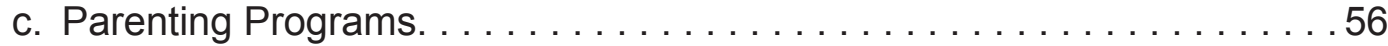

d. Child Maltreatment/Violence . . . . . . . . . . . . . . . 61 
Evaluation of Centres for the Integral Attention of Children in Dominican Republic (CIANIs) and Local Community Organizations for Child Protection (LCOCP)

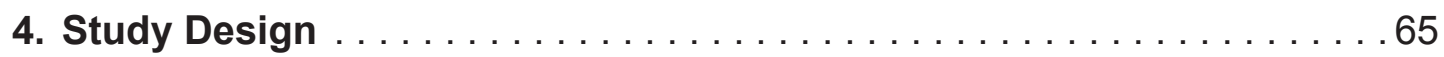

a. Process Review: Qualitative Methods. . . . . . . . . . . . . . . 67

b. Outcome Evaluation: Quantitative Methods . . . . . . . . . . . . 69

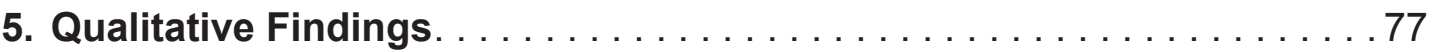

a. Part A: Context, Staff Relationships, and Engagement Strategies . . . . .78

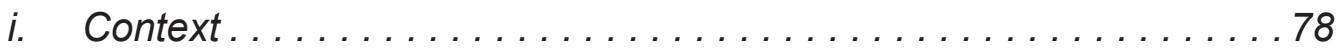

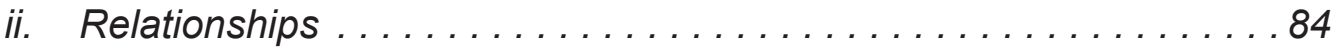

iii. Practice Strategies for Engaging Families . . . . . . . . . . . . . . . . 89

b. Part B: Benefits . . . . . . . . . . . . . . . . . . . . . . . . 98

i. Benefits to the Children . . . . . . . . . . . . . . . . . 98

ii. Benefits to Parents/Families . . . . . . . . . . . . . . . . . . . 106

iii. Benefits to the Community . . . . . . . . . . . . . . . . . . . . . . 112

c. Part C: Challenges . . . . . . . . . . . . . . . . . . . 115

6. Quantitative Findings - Outcome Evaluation . . . . . . . . . . . . 121

a. Social Profile of Survey Respondents in the Three Groups . . . . . . . 123

b. Between-Group Analysis: Comparing All Three Groups . . . . . . . . . . . 133

i. Group Differences on Individual Measures of Discipline . . . . . . . . 134

ii. Building Comprehensive Measures of Discipline . . . . . . . . . . . . 138

iii. Group Differences on the Comprehensive Measures of Discipline . . . . . . . . . . . . . . . . . . . . . . . . . . . . . . 146

iv. Social Characteristics and Discipline . . . . . . . . . . . . . . . 148

c. Within-Group Analysis: Examining the Two Intervention Groups . . . . . 157

i. Satisfaction with CIANI Services . . . . . . . . . . . . . . . . . . . . 157

ii. CIANI Engagement and Physical Discipline. . . . . . . . . . . . . 159

d. Multivariate Analysis . . . . . . . . . . . . . . . . . . . . . . 166

i. Between-Group Multiple Regression Analyses . . . . . . . . . . . . 166

ii. Within-Group Multiple Regression Analyses. . . . . . . . . . . . . . . 179

iii. The CIANI + LCOCP Group . . . . . . . . . . . . . . . . . . . . . 188

7. Stakeholder Consultation Summary . . . . . . . . . . . . . . . . . 193

8. Implications and Recommendations . . . . . . . . . . . . . . . 201 
Evaluation of Centres for the Integral Attention of Children in Dominican Republic (CIANIs) and Local Community Organizations for Child Protection (LCOCP)

9. Reference List . . . . . . . . . . . . . . . . . . . . . . . . . 205

Appendix A: Interview Guides. . . . . . . . . . . . . . . . 225

A - 1: Interview Guide for Parents (Individual Interviews) . . . . . . . 225

A - 2: Interview Guide for Professional Personnel

(Individual Interviews) . . . . . . . . . . . . . . . . . 228

A - 3: Interview Guide for Non-professional personnel

(Individual Interviews) . . . . . . . . . . . . . . . . . . . 230

A - 4: Interview Guide for Key informants \& Community Leaders

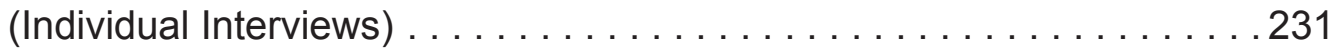

A - 5: Interview Guide for Parents (Focus Group) . . . . . . . . . . 232

A - 6: Interview Guide for Staff (Focus Group) . . . . . . . . . . . . 235

Appendix B: Surveys . . . . . . . . . . . . . . . . . . 237

B - 1: Survey Questionnaire for the Two Experimental Groups:

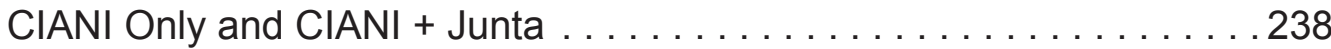

B - 2: Survey Questionnaire for the Control Group.............. . 264 



\section{Introduction}

V

iolence against children in its various manifestations is a worldwide problem. There is a complex mix of both risk and protective factors, which include individual conditions, relationships, and cultural and environmental situations, among others, and which may result in abusive situations. Maltreatment/violence can affect a child physically, emotionally, socially, sexually, academically, and, in extreme cases, can lead to death. Children who have experienced violence at an early age risk having brain development negatively impacted; some may experience learning difficulties and/or perform poorly at school. Further, the experience of violence is linked with a range of mental health problems, including low self-esteem and depression (SRSG, 2013; UNICEF, 2014b; 2014d). Many of these effects are carried well into adulthood.

High levels of violence, which disproportionately affect children and youth, with negative consequences for both their development and well-being, have been found in the Latin America and Caribbean (LAC) region (World Vision, 2014). It has also been reported that the Caribbean has a high prevalence of disclosed violence against children and that the types of abuse faced by Caribbean children include physical maltreatment, which is common and is often regarded as a socially acceptable cultural norm (Jones, Gutman, \& Platt, 2013; UNICEF, 2014c). Physical discipline of children is a widespread practice in the LAC region, and it is generally considered an acceptable form of discipline; a 16 country study in the region found that 33 percent to 83 percent of respondents report personal or family abuse (UNICEF, 2009b). 
Evaluation of Centres for the Integral Attention of Children in Dominican Republic (CIANIs) and Local Community Organizations for Child Protection (LCOCP)

Although the homicide rate worldwide has declined, it has increased by 12 percent in LAC, which also has the highest number of homicide victims under the age of 20 . This increased homicide rate contributes to the violence, crime, and insecurity that continue to hinder development in the region (UNDP, 2013; UNICEF, 2009b; 2011b). Violent acts against children are commonly considered inconsequential, and children are not afforded the same legal protection as adults when they face violence (Covell \& Becker, 2011; UNICEF, 2011b; 2014d).

The region is still developing, and one of the main difficulties in the development of effective responses to violence against children is the lack of information about the real dimensions and nature of this violence, especially when it occurs within the home (UNICEF, 2009b). Although a large proportion of residents in LAC are aware of the existence of violence against children, many are hesitant to report it (Gallup, 2014). The inference is that, of all the violence committed against children, only a small percentage is actually reported and investigated, with only a few offenders taken to trial (UNICEF, 2009b; 2014c). Further, there is a lack of trust and assurance that authorities will respond to these issues (ILO, 2011).

The main risk factor that facilitates domestic violence against children has been identified as the mother's or father's experience of violence during childhood - the phenomenon of intergenerational transmission of violence (UNICEF, 2009b). Violence can become normalized and repeated, and violence is thus passed down from generation to generation (UNICEF, 2014d). In this region, it has been found that many adults believe that the use of physical discipline is a standard means of education and socialization of children (UNICEF, 2009b). Other identified causes of violence include high levels of poverty and unemployment, attitudes of machismo and aggression directed specifically against women and girls, a deficiency of parent education and knowledge, and lack of opportunities (World Vision, 2014).

It is universally recognized that poverty affecting children and young people is one of the major challenges in this region. Poverty impacts the present, but also has long-term consequences throughout childhood and on development that ultimately affect society at large (UNICEF, 2012; 2014c). Almost half of the children in the region are living in poverty - be it moderate or extreme -affecting almost 81 million children under 18 (Silva, Espíndola, \& Jiménez, 2010; UNICEF, 2010b). Many children in these regions are affected by childhood malnutrition, lack of access to adequate housing, lack of access to basic services (potable water), and lack of access to education (Save the Children, 2015; UNICEF, 2010b). Overall levels of 
Evaluation of Centres for the Integral Attention of Children in Dominican Republic (CIANIs) and Local Community Organizations for Child Protection (LCOCP)

households' welfare are linked to educational capital, which can contribute to an individual's achievement of better job placements (Silva et al., 2010).

It has been determined that the quality of education and employment influence an individual's ability to be "lifted from poverty" (UNDP, 2015). Violence has been found to have a negative impact on the educational achievement and performance of children, which can unfortunately have negative long-term economic consequences - including poverty (UNICEF, 2014a; 2014c). Public policies aimed at dealing with this issue may sometimes be limited, and may often stem from inadequate assumptions that do not include the various expressions of poverty in childhood and that are based on a limited approach that ensures compliance with the Convention on the Rights of the Child (Silva et al., 2010).

Inequality in the region is common, and many of these countries rank as low and middle income. These inequalities tend to affect women, children, and infants, who are often poorer and less educated (World Health Organization, 2015). In many low-to-middle income countries, international organizations are among the primary promoters of family and parent support, and the argument has been made that state engagement requires the help of these international organizations (Daly, Bray, Bruckauf, Byrne, Margaria, Pec'nik, \& Samms-Vaughan, 2015).

To deal with the socio-economic gaps in the region, it is imperative that clear priorities be established and that public resources be focused on protecting social rights, for example, education and health, sustainable development, and the elimination of discriminatory patterns (Oxfam, 2014; UNICEF, 2010b). There is a call for the development of public policies aimed at protecting those most affected by violence and crime, including the expansion of opportunities for human development for youth (UNDP, 2013). It is important to note that the leaders of countries where individuals - particularly the new generation - are unable to read, write, or do arithmetic will be ineffective at developing their societies (UNICEF, 2013).

The way these challenges are addressed has major implications for children's welfare. One of the challenges is that the legislation does not always match the local realities and that the laws are not always suited to local contexts, with important gaps in the formal child protection system and the basic services needed to ensure children's rights at the local level. There also seems to be a lack of collaboration and cooperation among key actors, which is necessary for the dis- 
Evaluation of Centres for the Integral Attention of Children in Dominican Republic (CIANIs) and Local Community Organizations for Child Protection (LCOCP)

semination and sharing of initiatives (Parada, 2011; SRSG, 2012; UNICEF, 2009a; World Vision, 2014).

Community-based education has been cited as imperative in dealing with this issue, since children and adolescents are often unaware of their rights, and, in order to increase awareness, strategic action plans for community-level education should be put in place (World Vision, 2014). Prevention of violence requires changing behaviours, which usually involves strategies - such as community-based interventions, raising media awareness, training, and school-based programs - that have been found to be effective (Pinheiro, 2006; UNICEF, 2014b; 2014c). Integration of support in families' everyday lives, for example, has been shown to mitigate a child's risk of physical abuse (UNICEF, 2014). Regarding the prevention of violence against children, experts recommend giving priority to early intervention strategies that are child-centered and that require the participation and strengthening of all institutions dealing with children and adolescents, including those in communities (SRSG, 2013; UNDP, 2013; UNICEF, 2009b; 2014a; 2014b).

The issue of violence against children is multifaceted and thus will require a multifaceted response; efforts to reduce and eliminate it overlap with other issues and actions, such as the effort to strengthen health care and increase the quality of education, which all have the overarching goal of fostering peaceful societies (Pereznieto, Montes, Langston, \& Routier, 2014; UNICEF, 2006; 2014). The majority of interventions currently in place are small in scale and would need to expand in order to increase their scope. Further, there is a need for more in-depth data in relation to their effectiveness (Pereznieto, et al., 2014; UNICEF 2014c).

It is vital that the impact of implemented policies and interventions be properly researched and analysed (SRSG, 2013; 2014). Not all prevention strategies are effective, and research agendas should be established by governments to improve understanding of and the effectiveness of interventions and strategies to reduce violence. It is imperative to raise both the quantity and quality of research and analysis regarding violence interventions and strategies. These programs ought to have evaluations, baselines, targets, and research components built into their design and implementation (Pinheiro, 2006; UNICEF, 2014c).

It is imperative for policy makers to have reliable, high-quality data in order to carry out effective strategies and interventions (UNDP, 2013). Prevention programs need to be informed by evidence (UNICEF, 2014c). Lack of data can unfortunate- 
Evaluation of Centres for the Integral Attention of Children in Dominican Republic (CIANIs) and Local Community Organizations for Child Protection (LCOCP)

ly fuel misconceptions about this issue, and justice is not done in relation to the severity and prevalence of this issue. This lack of data is further exacerbated by the facts that violence is complex, can take many forms, occurs in a variety of settings, and can be perpetrated by various individuals and groups - features that make it hard to measure (SRSG, 2013; UNICEF, 2014b). In addition, there are gaps in the nature and impact of contextual factors and the specifics around the implementation of interventions. Efforts to address these issues tend to not be preventative and do not focus on causes (SRSG, 2013). Unfortunately, very little is known about delivery mechanisms or about what makes these interventions and programs economically, socially, and culturally sustainable over the long term (Daly et al., 2015).

This study aims to develop a thorough understanding through the collection of comprehensive data about a particular intervention, including its implementation and impact. The data will make evident the accomplishments and successes as well as the gaps in services, and also measure effectiveness through a developed tool (survey) that can be replicated to continue monitoring and evaluating for quality assurance and expansion purposes.

Centers for the Integral Attention of Children (CIANIs) and Local Community Organizations for Child Protection (LCOCP) are the two community-based programs that were evaluated in this study. They represent innovative, community-based strategies for addressing the prevention and reduction of the prevalence of violence against children within highly vulnerable and marginalized communities in the Dominican Republic (DR). Given the significance of these community-based interventions to the overall national strategy for prevention, evaluation of these programs was of strategic importance. These interventions form a national strategy for violence prevention against children, and thus demonstration of their effectiveness is critical.

CIANIs operate on the widely accepted theory that healthy Early Child Development (ECD) is critical and influences outcomes throughout the life course, and promote prevention through enhancement of caregiver $\left({ }^{* *}\right.$ note throughout this document, caregiver refers to mothers, fathers, grandparents or any other guardian providing primary parenting care to children in the CIANIs and schools.) capacity, improvement of caregiver-child relationships and family functioning, and strengthening of communities to support families (CONANI, 2011). LCOCPs complement and extend the work of the CIANIs by monitoring and reporting child maltreatment, 
Evaluation of Centres for the Integral Attention of Children in Dominican Republic (CIANIs) and Local Community Organizations for Child Protection (LCOCP)

and also by conducting public education and community outreach to ensure child protection against violence. Consequently, these two interventions aim to effect change at the individual/family level as well as at the community/societal level (CONANI, n.d).

This study intended to undertake an outcome evaluation of the effectiveness of these interventions and also to conduct a process review in order to understand how and why they work. The lessons learned from this evaluation were disseminated extensively within the network of nongovernmental organizations, organizations within the civil society, and other child welfare organizations within the DR.

The study aimed to contribute knowledge about promising community-based strategies and practices geared towards the prevention of violence against children that may influence service providers, community members, and decision makers locally, nationally, and internationally. More specifically, this evaluation will determine whether CIANIs and LCOCPs are effective in reducing violence against children and enhancing well-being. Evaluating the effectiveness of these programs will provide an opportunity to understand the contributions of multiple violence prevention initiatives that are delivered within holistic and integrated environments, and that are geared towards a national prevention strategy. 


\section{Dominican Context}

he DR is the second largest Caribbean nation. It has a Gini Coefficient of 46, which is in the low-middle range (World Bank, 2013). In 2014, the DR ranked 102 out of 187 on the Human Development Index (High Human Development). The positions of countries in the LAC region ranged from the position of Chile, ranked at 41, to Haiti, ranked at 168 (Malik, 2014).

The DR is divided into 3 macro regions, which are further divided into 10 administrative regions. The country is divided into 321 provinces, the capital is (gran Santo Domingo) Santo Domingo de Guzman. There are 154 municipalities, 232 municipal districts, 1,182 political divisions and 9,965 rural areas, 2,621 neighborhoods, and 4,954 sub-neighborhoods (Oficina Nacional de Estadistica, 2011).

The DR is a middle-income country, with the largest economy of the countries in Central America and the Caribbean. In spite of the country's economic progress, some problems are still present, including unemployment, government corruption, and inconsistent electrical services. Further, access to basic public services remains unequal and of low quality, especially for those living in poverty. There is a need for improved program targeting, monitoring, and evaluation, including incentives such as results-based budgeting, which could help improve service delivery (World Bank, 2015). 
Evaluation of Centres for the Integral Attention of Children in Dominican Republic (CIANIs) and Local Community Organizations for Child Protection (LCOCP)

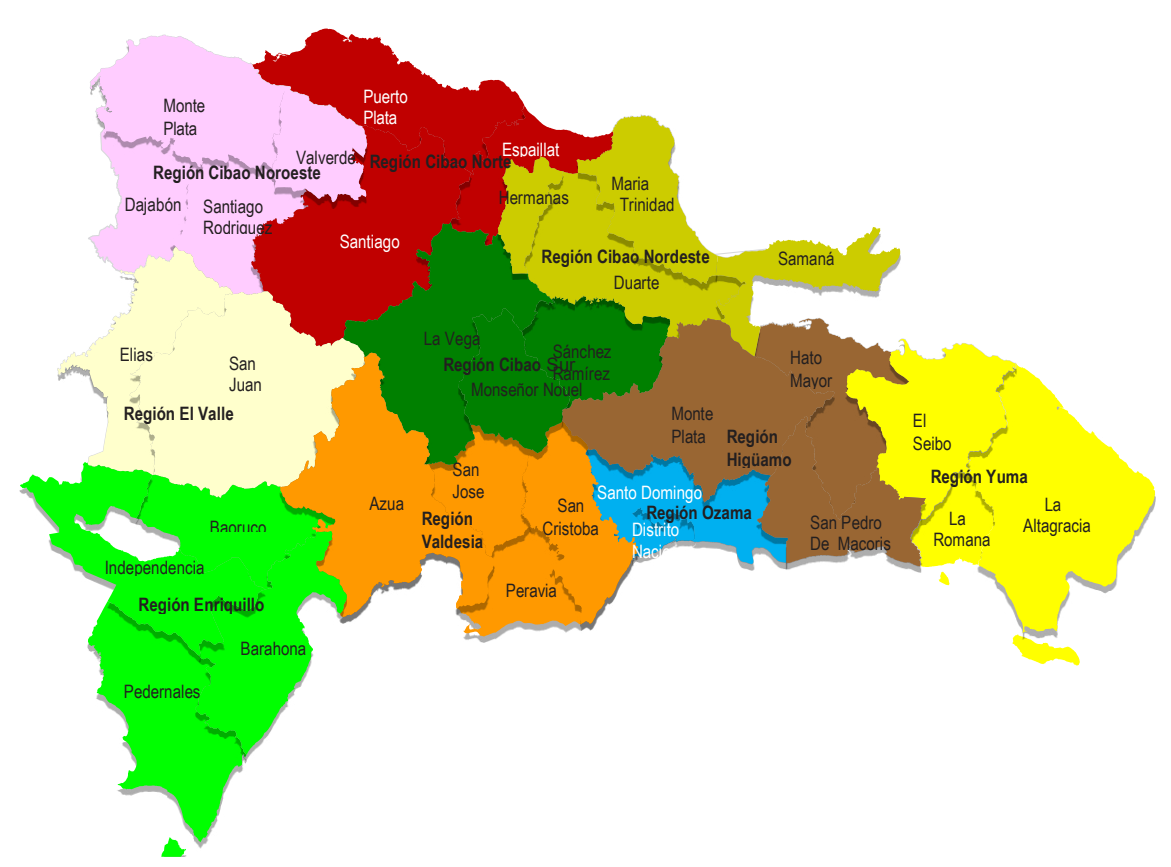

Challenges exist in securing rights for children and youth in the DR. Many young people do not have birth certificates. This issue is more prevalent for those under 15 years of age, with 18 percent of children $0-4,12$ percent of those $5-9$, and 7 percent of those 10-14 being affected (CESDEM \& ICF, 2014). These values are a moderate improvement over the findings from 2002 and 2007 (CESDEM \& ICF, 2014).

One of the most serious problems that affects the population of Dominican children is the level of poverty that exists in the country. The unemployment rate stands at over 6 percent, but more than 40 percent of Dominicans live under the poverty line, with 8 percent living in extreme poverty (MEPyD, 2014a; 2014b). Children under 15 years of age represent more than 30 percent of the population, with most of these children living in female-headed households. Teen pregnancy is another major issue, with 20.6 percent of those 15 to 19 years of age either currently pregnant or already mothers (U.S Global Health Programs, 2014). Early pregnancy limits young women's educational opportunities, consequently increases poverty and inequality, and limits labor opportunities. Poverty is ultimately transferred to the next generation (CEPAL, 2013). Households headed by a single female comprise an estimated 40 percent of the Dominican population, which is a steadily in- 
Evaluation of Centres for the Integral Attention of Children in Dominican Republic (CIANIs) and Local Community Organizations for Child Protection (LCOCP)

creasing number, up from 35 percent in 2007. Further, many of these households live in conditions of poverty (CESDEM \& ICF, 2014). The poverty and extreme poverty levels in the country are high, and the main challenge to the DR's development has been identified as inequality (Social Watch, 2012; Sullivan, 2014).

The situation of children's rights in the DR is varied; children from wealthy families are very privileged, while many other children, such as the children of migrants, those raised by single mothers, and those living in rural areas often end up living in harsh conditions, where many of their rights are violated or at least not upheld (Humanium, 2011). It has been argued that the education system in the DR reproduces inequity, since not all citizens are guaranteed the same access to opportunities (Oficina de Desarollo Humano, 2010; Bellei, Poblete, Sepúlveda, Orellana, \& Abarca, 2015).

It has been suggested that one of the main causes for the high levels of inequality and poverty in the DR is low labour productivity caused by the failure of the education system to impart the minimal skills required by the labour market. Many youth in the DR leave school lacking the skills needed to obtain employment (USAID, 2013). The DR has one of the lowest levels of investment in education in LAC, and, in 2010, the DR was found to have the lowest figures for public spending per pupil in primary and secondary education in the Latin American and Caribbean region (Bellei, Poblete, Sepúlveda, Orellana, \& Abarca, 2015).

The country ranks $132^{\text {nd }}$ in quality of the education system and $138^{\text {th }}$ in the quality of primary education, out of 144 countries worldwide (World Economic Forum, 2014). In the past, many children in the DR lacked the resources needed for a proper education, with insufficient funds being invested in school supplies and infrastructure (Save the Children, 2015). Education services that are available tend to be focused on the population from 6-18 years of age; there is a deficit in early childhood education in the critical first years of life (UNICEF, n.d). This situation has changed since the launch of the Early Childhood Policies introduced in 2015.

The DR has a legal framework which recognizes children and adolescents as subjects with fundamental rights, and as such, require Government action in order to exercise those rights (CONANI, 2011). Areas of particular concern are access to care and maternal child care, including nutrition, general hygiene, and the prevention of sexually transmitted infections (STIs), including HIV and AIDS (Save the Children, 2015). Although the rate of child mortality in the DR has fallen in 
Evaluation of Centres for the Integral Attention of Children in Dominican Republic (CIANIs) and Local Community Organizations for Child Protection (LCOCP)

recent years, it still remains among the highest in the region (U.S. Global Health Programs, 2014). Child malnutrition (chronic and acute) is also a troubling public health issue (Moliné \& Rathe, 2011). The quality of services has been recognized as the main challenge to the health sector, and there is a need to improve the continuum of care.

Efforts have been made to improve both the quality of and access to health care services, but there is high and increasing inequality in the DR, notably in access to both health and education. The outcome of these efforts is indicated by the infant mortality rate, which has fallen considerably, as well as by the overall improvement in hospital care and resources. However, not all children in the DR have been able to benefit from these improvements. Those coming from poor families are relegated to limited access to health care facilities and services (Humanium, 2011).

\section{a. Early Childcare Development Focus}

For many years, the early development of children was in the hands of parents/ families. In the DR like in other countries, the increasing integration of women into the labor market has meant that more and more women have had to leave their children in the care of relatives, neighbours, babysitters and other caregivers. This results in mothers and fathers being increasingly absent in the development processes of children during their first years of life. This, coupled with the large migratory movements, both to urban areas and abroad, has produced a new family environment for early childhood. This affects the guarantee of children's rights, as families (particularly those living in poverty) are forced to cover a much wider range of functions, reflected in an employment extension of domestic work, usually by women (CONANI, 2012a, UNICEF, 2011a).

Comprehensive care of children under the International Convention on the Rights of the Child includes recognition, guarantee, prevention and restoration of rights (Ministerio de Educacion, 2009). In Latin America public policy attention to early childhood is linked to the fact that most countries have become delegates to the Convention on the Rights of the Child, which establishes as a priority the comprehensive care of children under six. Despite this attention to early childhood is at different stages and with different implementation modalities country to country due to the socioeconomic conditions, the level of commitment and the institutional levels of each country (CONANI 2012). 
Evaluation of Centres for the Integral Attention of Children in Dominican Republic (CIANIs) and Local Community Organizations for Child Protection (LCOCP)

The decision to create a government agency with the aim to protect Dominican children emerged from the social, educational, economic, and health situation that was occurring in the country at the time. The decision was realized by the Executive Power, through decree No. 426 on November 23, 1978. The National Council for the Protection of Children, CONANI, was created with the objective of developing coherent, concrete policies to protect children. Initially, it assumed the role of promoting children's well-being, researching different topics relating to children, making policy recommendations, and providing programs and centers for children (CONANI, n.d).

The Convention on the Rights of the Child was adopted in 1989 by the United Nations General Assembly and was ratified two years later by the Dominican state. This facilitated the orientation of national policies towards the construction of a System of Protection of Children's and Adolescents' Rights. The ratification of the convention committed the state to take administrative and educational measures, including social mobilization and legislation, aimed at the dissemination and application of its contents. From that time, a new era began for Dominican children, and there was a move away from viewing children and youth as "minors," subjects of "compassion - repression" and a switch towards seeing them as individuals possessing rights.

Continuing with this commitment, in 1994 the Dominican Republic enacted Law 14 -94, which created the code for child protection, and, with this step, the process of adapting legislation to the requirements of the convention began. Law $14-94$ went into effect in January 1995, introducing important changes in the ways individuals, families, institutions, and the justice system should relate to children and adolescents (CONANI, n.d; Parada, 2011).

Article 320 of Law 14 - 94 created the Governing Body for the System of Protection for Children and Adolescents. The main function of the body is to develop and implement national policies for the protection and assistance of children and adolescents. Although this law was a significant advance in the field, there were still areas for improvement in order to attain full and effective implementation. In response, a board of governors for children and adolescents was created on April 26, 2001, and a proposed amendment was made to law 14 - 94 - Code for the Protection of Minors (CONANI, 2012b)

Implementation was executed in coordination with the Ministry of Education (SEE), the Ministry of Public Health and Social Assistance (SESPAS), as well as with oth- 
Evaluation of Centres for the Integral Attention of Children in Dominican Republic (CIANIs) and Local Community Organizations for Child Protection (LCOCP)

er government institutions, NGOs, and civil society. The proposed reform brought together a number of government institutions, which included the National Council for the Protection of Children (CONANI), the Executive Technical Director of the Governing Body, the Secretary of Labor (SET), the State Secretariat for Women (SEM), the Ministry of Culture (SEC), the Ministry of Public Health and Social Assistance (SESPAS), and the Attorney General of the Republic, and also nongovernmental organizations, such as Children's Way, World Vision, Street Action, Boys and Girls with Don Bosco, Walker Institute of the Family, and Research Center for Women's Action (CIPAF - acronym in Spanish), on behalf of the NGO Coalition for Children, with advice from the Supreme Court and UNICEF. This group took a leading role over a two year period in the drafting of proposed legislation meant to be consensual and, above all, legitimate and consistent with the principles and foundations of the Convention on the Rights of the Child (CONANI, n.d).

The approval and subsequent enactment took place on August 7, 2003, with the Code for the Protection of Fundamental Rights for Children and Adolescents - Law 136 - 03, in compliance with the commitment to human rights, which recognizes children and adolescents as bearers of rights (CONANI, n.d, UNICEF, 2011a).

In its National Development Strategies 2010-2030, the Dominican government expressed its commitment to facing the challenges involved in ensuring the social cohesion and collective development that were needed in order to meet the Millennium Development Goals. Among those goals were:

- the universalization of health, social security, and

- the quality of education for every child and young person

- access to sport, employment, and housing

- equality, poverty reduction, and social inclusion.

All these goals have a direct impact on the well-being of children and youth. The Dominican government national strategic goals for the 2012-2016 period regarding the well-being of children and young people include: (i) protection of children's, young people's, and young adults' rights, (ii) implementation of women's rights, (iii) socio-economic inclusion, (iv) environmental sustainability (CONANI, n.d).

The country has a comprehensive legal framework that establishes regulations for the attention to the Early Childhood. However, there are a lack of guidelines to make these operational as well as a lack of clarity on the implementation which 
Evaluation of Centres for the Integral Attention of Children in Dominican Republic (CIANIs) and Local Community Organizations for Child Protection (LCOCP)

reduce the practical usefulness (UNICEF, 2011a). It has been noted that there is a limited inter-institutional communication among organizations working in the area of Early Childhood in the DR, highlighting the importance of improving the integration of actions to optimize the response to the needs of this population in the country.

The poor integration and systematization of updated data on the status of Early Childhood in the Dominican Republic, produced by the various bodies involved makes it difficult to use for the design and implementation of effective interventions (UNICEF, 2011a). However, it is important to note that there is a National Development Strategy aimed at prioritizing early childhood (CONANI, 2012a). The new "System for Planning and Public Investment" created with Law 498-06, attempts to achieve a long-range vision. The strategic direction was meant to go beyond the "short-sighted" discretionary, patronizing and paternalistic vision that has historically characterized the public sector. The project has a set of objectives aimed at children and youth. The fact that there is express reference made to this population could be a great opportunity not only to promote processes for children, but also to position it within the priority strategic policy of the nation.

\section{b. CONANI - The National Council for the Protection of Children}

Through Article 417, The National Council for the Protection of Children (CONANI) was assigned the lead role in public policies for children and adolescents. CONANI thus became the organization for child and adolescent protection, according to the transitional provision of the law, which allowed for the creation of another institution to assume the service functions (CONANI, 2011).

As a result of decree No. 511 - 06, dated October 17, 2006, decree No. $114-04$ was repealed. This measure formed the Department of Early Childhood Care, which became a Comprehensive Care Program managed directly by CONANI, in order to substantially raise the quality of comprehensive care for children and adolescents (CONANI, n.d).

A process of improvement began in 2006, with a focus on increasing overall quality, extending the schedule, providing children with high-quality educational material, and adapting the daily routine to the curriculum provided by the Ministry of Education. An Early Childhood Program (PAIPI) was developed that incorporated 
Evaluation of Centres for the Integral Attention of Children in Dominican Republic (CIANIs) and Local Community Organizations for Child Protection (LCOCP)

the fields of psychology, social work, education, and nutrition. A team of specialists and experts from these fields was developed, and, from this program and team, the guidelines for the Centres for the Integral Attention of Children (CIANI) were drawn (CONANI, n.d).

CONANI was appointed to coordinate the different issues affecting children under the National Directory for Children's Rights. The following institutions are part of this Directory: governmental institutions, the Ministry of Health, the Ministry of Women's Affairs, the Ministry of Culture, the Ministry of Education, the Ministry of Labour, the Ministry of Attorney General, and also NGOs working with children, churches, and business and labour organizations. This Directory is in charge of developing policies and practices that affect children both regionally and nationally (CONANI, n.d)

CONANI coordinates four kinds of programs:

1. Social Intervention Programs - programs affecting the overall well-being of children, for example children's access to health and community support.

2. Special Protection Programs - programs and services to protect children from maltreatment and sexual commercial exploitation and also to provide temporary group homes for children on the streets.

3. Rehabilitation Programs - programs supporting adolescents in conflict with the law.

4. School-Related Programs - programs to guarantee children's access to education. (CONANI, n.d).

In April 2013, Presidential decree 102-13 declared comprehensive early childhood care of high interest, created the National Institute for Integral Attention for Early Child Intervention (INAIPI), and transferred CIANIs to this new institution, thus dividing the leadership role of CONANI services. This new institute has been in operation since January 1, 2015 (CONANI, n.d). 
Evaluation of Centres for the Integral Attention of Children in Dominican Republic (CIANIs) and Local Community Organizations for Child Protection (LCOCP)

\section{c. CIANI - Centres for the Integral Attention of Children}

The Centers for the Integral Attention of Children (CIANIs) were initially opened with the goal of contributing towards poverty reduction by increasing the coverage and quality of early child care services, ensuring the rights of children, and taking into account the high levels of poverty in the DR (CONANI, 2011).

CONANI (n.d) establishes that the CIANIs were developed using an Ecological Model that integrated a multidisciplinary perspective encompassing education, psychology, health, nutrition, and social work. This approach falls in line with the recommendations made by the International Labour Organization, which advocates a minimal social protection floor that includes (for children) access to essential health care, basic income security, and access to nutrition, education, and care (Jones et al., 2013, p. 17).

Under CONANI management, the program aimed to provide comprehensive care for children from 45 days of age to six years. The goal was to benefit individuals not only in an immediate sense, but also to provide long-term social, political, and economic benefits. The objective was to develop skills during this time that could then be carried on with families, communities, and the country at large. The CIANIs at this time promoted children's development of cultural identity, relationships with their family and social environment, and a sense of belonging, values, attitudes, and personality. CIANI policies and programs were developed and delivered to serve all children, regardless of their gender, ethnicity, religion, and socio-economic status (CONANI, 2014).

The focus was on strengthening family functionality and enabling families to help themselves and their children. CONANI anticipated that this program would work to prevent violence against children and intrafamilial violence (CONANI, n.d). CIANIs worked from the belief that children's rights and needs could be better served by working collaboratively and cooperatively with families and communities. The CIANIs' main goal was to provide high-quality and comprehensive Early Childcare and Development services.

Before opening a centre, CONANI carried out an environmental scan of issues affecting children and families through the use of a previously developed survey that collected important contextual information, such as the number of children in the 
Evaluation of Centres for the Integral Attention of Children in Dominican Republic (CIANIs) and Local Community Organizations for Child Protection (LCOCP)

community, health issues, families, level of education, socio-economic conditions, housing, and other services (World Bank, 2001).

CIANIs employed an interdisciplinary staff consisting of social workers, teachers, teachers' assistants, psychologists, nurses, and educational coordinators in order to facilitate the ecological and holistic approach they employed. The centres were developed as a comprehensive program aimed at addressing all issues that the children may face, with the goal of supporting healthy development in all areas, i.e., educational, emotional, nutritional, and medical.

The centres actively promoted their services and worked towards becoming anchors in the community that encouraged participation from and provided support and resources to families in the community, regardless of whether they had children currently enrolled at the centre. The CIANIs organized social functions, educational opportunities for caregivers, and other events, all of which were open to the community. Well after children had moved on from the program, caregivers reported that they still went to see the staff for support and advice, even after their children moved on to primary school.

\section{i. Program Structure}

Under CONANI management, CIANI registration was primarily handled by the centre's social worker. Caregivers had to fill in pre-registration forms in order to have a child considered for enrolment at the centres. Eligibility was determined through a needs assessment process. After the pre-registration form was filled out, a home visit was conducted, when the family and its socioeconomic condition were assessed, along with living arrangements and any factors that posed potential risks to the child's safety. The technical team would then meet to rank the families, based on the information collected, and would then collaboratively select the children who would enter for the year. The dates for this process were determined by the head office. The demand for the program was always extremely high, with caregivers and CIANI staff reporting long line-ups. Some caregivers were lining up early in the morning and some the night before to ensure they would be able to sign up for registration.

Once a child was accepted into the centre, he or she would undergo an extensive entry physical assessment, which involved a personal hygiene and hand-wash- 
Evaluation of Centres for the Integral Attention of Children in Dominican Republic (CIANIs) and Local Community Organizations for Child Protection (LCOCP)

ing check as well as a skin check. Children were screened for various infectious diseases, including impetigo, scabies, lice, fungal infections, ringworm, rubella, chickenpox, parotitis, measles, dengue, cholera, and leptospirosis. They had their eyes examined for conjunctivitis, visual acuity disorder, and strabismus. Their hearts were checked for any issues, and they also received dental checks for tooth decay and received a cleaning. Children underwent a nutritional evaluation to determine if they were underweight or overweight, and their weights would then be monitored throughout their time at the CIANI (CONANI, 2014).

At the CIANIs, children had health evaluations completed upon entry, throughout their time at the centre, and also when they left the centre. Comprehensive care provided included oral hygiene, deworming, administration of Vitamin A, administration of fluoride, and administration of micro-nutrients (CONANI, 2014).

Vaccines provided to children included:

- Bacillus Calmette-Guerin (BCG)

- Polio

- DPT diphtheria, pertussis (whopping cough), and tetanus.

- Pentavalent vaccine

- Hepatitis B

- Haemophilus influenza

- Rota virus

- Pneumococcus

- Vitamin A

- MMR measles, mumps, and rubella (CONANI, 2014).

Along with vaccines, the CIANIs procured medications for children and families in need through their interagency and community partnerships.

An important aspect of the CIANI program was the continuous support, monitoring, and follow-up of the children and families involved in the program. The centres conducted regular periodic visits as well as emergency visits, as needed, and follow-up through home visits, community visits, follow-up school visits, and follow-up visits for illnesses. Psychological follow-ups were also offered in cases of child abuse, referrals from other institutions, and interfamily violence. 
Evaluation of Centres for the Integral Attention of Children in Dominican Republic (CIANIs) and Local Community Organizations for Child Protection (LCOCP)

The centres opened at 7:45 am, and caregivers were expected to drop children off on time and pick them up on time. Pick-up time varied, depending on the centre and special circumstances. Children were released only to individuals who had been previously authorized by the guardian. Upon arrival, children were welcomed by CIANI staff and checked for any injuries, marks, or signs of abuse and/or neglect. Children were fed breakfast and then would begin the CIANI programming, which included group and individual activities. Children were provided with breakfast, lunch, a small dinner, and two snacks daily. Children who had been identified as overweight or underweight received a special diet (CONANI, 2012b).

The CIANIs provided psychological support to children and families. The psychologists assessed children to detect learning difficulties and to develop modified learning plans that would accommodate any specific learning needs.

The comprehensive care model of service that was used by the centres emphasized working with not only the children but also with the communities and families. The children, who spent the entire day at the centres, were the priority, but the CIANIs worked beyond just assistance to the children by extending their support and expertise to families and communities. The CIANIs paid specific attention to families through home visits, interviews, orientations, and interventions.

The centres actively engaged families through:

- A parents' garden, which aimed to encourage caregiver participation and socialization through a shared goal.

- CIANI from the inside: an orientation for new caregivers, which provided an inside look for the caregivers of newly enrolled children at the content of the CIANI program, the services the centres provide, the daily routine, and an overview of caregiver responsibilities.

- Recreational evenings: the centres would hold parties to celebrate birthdays and holidays.

- Training and educational activities/orientations: occasions when caregivers were invited to hear guest speakers who were brought in to discuss issues of concern for the communities. 
- Parent committee: a group meant to strengthen and facilitate the relationship among the families, the centre, and the community by providing a sense of solidarity among key stakeholders, who worked collaboratively on the committee with the centre.

- Parent school: a program that brought together parents, caregivers, and the community. The program aimed to educate, orient, and work with families and the community as a whole on family and social problems. The school worked to guide and to provide positive parenting alternatives that promote healthy and stable families.

The parent school aimed to:

1. Integrate caregivers in the children's education process.

2. Increase caregiver responsibility.

3. Work to change caregiver attitudes towards better parenting.

4. Decrease child abuse.

5. Manage familial and community conflicts.

(CONANI, 2014).

The topics covered at the parent school were:

- Responsible parenting

- Positive discipline

- Abuse prevention

- The rights and duties of children and adolescents

- No to child abuse - Law 136-03

- Domestic violence

- Values education

- Disaster prevention

- Importance of communication in the family

- Breastfeeding

- Family integration

- The role of women in the family

- Violence against women

- The influence of the media on the family

- Behaviour management

- Mothers of today 
Evaluation of Centres for the Integral Attention of Children in Dominican Republic (CIANIs) and Local Community Organizations for Child Protection (LCOCP)

- Self-esteem in mothers

- Family values

- The role of women in today's society

- How to build healthy families

- Gender education

- The importance of nutrition in early childhood

- Health and hygiene

(CONANI, 2014).

CIANIs worked with an interdisciplinary staff, consisting of social workers, teachers, teachers' assistants, psychologists, nurses, and educational coordinators, in order to facilitate the holistic approach they employed. CIANI personnel worked closely together, maintaining constant communication in order to provide the best service to the children and families (CIANI, 2012). Meetings were regularly held with the technical team/staff, other agencies, the community, and caregivers. The types of meetings held were trainings, talks/presentations, and workshops (CONANI, 2014).

The centres also provided support to community members and families who did not have children enrolled in the program, and those who previously had children enrolled. Psychologists counselled and advised caregivers seeking assistance with caregiving issues, family conflict issues, stress, and any other concern they might have. They were open to answering questions about how to discipline and to simply hearing caregivers vent about stresses. Medical services were also open to the community once a week.

\section{d. INAIPI - National Institute for Integral Attention for Early Child Intervention}

As of January $1^{\text {st }}, 2015$, the management, along with administrative and teaching staff of the CIANIs, were transferred from CONANI to the National Institute for Integral Attention to Early Child Intervention (INAIPI). CIANIs will be known as Centers for Integral Early Child Intervention (CAIPI - [Spanish acronym]), currently they are knowns as CAIPI - T (in transition). INAIPI falls under the jurisdiction of the President's General Directorate of Special Programs (DIGEPEP), which was created under $491-12$ with the objective of reducing poverty and inequality through the promotion and development of opportunities. DIGEPEP takes a com- 
Evaluation of Centres for the Integral Attention of Children in Dominican Republic (CIANIs) and Local Community Organizations for Child Protection (LCOCP)

prehensive, systemic, rights approach and focuses on the importance of social responsibility. The directorate works to foster and strengthen the coordinated efforts and collaboration of government agencies that are geared towards managing early childhood issues (DIGEPEP, 2013b, n.d).

DIGEPEP (2013a) developed the program Quisqueya sin Miseria (Quisqueya Without Misery) to meet these goals, and its broad objectives are:

1. To establish an early childhood system, using the definition of a system of protection and comprehensive care.

2. To establish and implement a high-quality intervention model for protection and comprehensive early child care, which includes educating families, early childhood education, and attention to disabilities and special needs.

3 . To provide early child care services to children.

4. To expand the availability of pre-school services for children up to the age of five.

5. To strengthen the protection and early childhood skills of caregivers and young children.

6. To establish and implement a training program for the provision of protection and early childhood care in agencies, families, and community and homebased programs.

The plan consists of early education, health and nutrition, detection and attention to disabilities and special learning needs, protection against violence and abuse, identity and birth registration, and family participation in the community (DIGEPEP, 2013a).

The plan is comprised of three parts. CIANIs fall under Quisqueya Empieza Contigo [QEC] (Quisqueya Begins With You) (DIGEPEP, 2013a). This plan aims to guarantee the fundamental rights of children and adolescents in vulnerable populations and sectors of the country and in families living in poverty (DIGEPEP, 2013b)

The new administration plan aims to expand the coverage and quality of early childhood services in the country. Much of the structure and many objectives of the CIANIs have been maintained (the centres are open from 7:30 am to 5:00 pm), and are now being improved and systematized. Under INAIPI, the centres continue to provide comprehensive care for children aged 45 days old to 4 years, 11 
Evaluation of Centres for the Integral Attention of Children in Dominican Republic (CIANIs) and Local Community Organizations for Child Protection (LCOCP)

months, through education and health and nutrition services provided by trained professionals. Assistance, guidance, and training for families are also provided (DIGEPEP, 2013a).

The multidisciplinary nature of the team continues to be of great importance. The centres all have:

Psychologist in charge of monitoring child development and psychosocial risks and vulnerabilities through assessments of children and their families done during home visits and group meetings. The psychologist provides family counselling and educational workshops, including mental health workshops with families. The psychologist provides referrals as needed and supports other staff with management of group activities related to the field of psychology and any other related issues that come up (DIGEPEP, n.d).

Social worker in charge of assisting with the enrolment process by identifying eligible children and families based on the established criteria. The social worker participates in home visits, and reviews and updates information provided by families. The social worker engages in follow-up with children and families at risk and provides referrals and follow-ups to other support programs (DIGEPEP, n.d).

Nurse who oversees the monitoring of the weight, height, and nutritional state of the children. The nurse also provides technical support and training about health risk factors and the growth and development of children. The nurse coordinates with primary care networks in the community for follow-up with children in the program and ensures the provision of health care by local health centres for children covered by Quisqueya Begins With You (QEC acronym in Spanish) (DIGEPEP, n.d).

Early childhood educators in charge of carrying out education programs with children, and also planning and evaluating weekly activities. They are assisted by early childhood assistants, who support educators in program planning, implementation, and evaluation (DIGEPEP, n.d).

DIGEPEP (2013) specifies that, under INAIPI management, in order to be eligible for enrolment, potential applicants are ranked on the basis the following criteria: 
Evaluation of Centres for the Integral Attention of Children in Dominican Republic (CIANIs) and Local Community Organizations for Child Protection (LCOCP)

- Children deemed to be living in vulnerable situations (abandonment, neglect, and children of young parents, families facing addiction, or families recommended by CONANI, LCOCPs, or other community-based organizations.)

- Children of single mothers or children who live in mono-parental homes where the individual caregiver has full-time informal work.

- Children 45 days to 5 years of age whose caregivers have full-time informal work.

- Disabled children who require full-time assistance and professional care.

- Children whose caregivers work or go to school and are participating in the Qisqueya Learn With You (QAC - acronym in Spanish) Literacy Plan, second phase.

- Children from families with formal full-time jobs for which wages are below 10,000 pesos a month. Entrance requests must be accompanied by a letter of employment.

- Children from families who are eligible for or who receive other subsidized state services.

- Children 0-4 years of age who are within the geographical area of the centre.

- Caregivers who are able to attend the workshops and trainings offered by the centre.

- Children who are recommended by their neighbours.

- Children who are not receiving services from centres administered by Administrator of Healthy and Safe Childcare Centers (AEISS - acronym in Spanish).

\section{e. LCOCP - Local Community Organizations Child Protection}

According to Law $136-03$, art. 464 and 465 , each municipality is meant to have a Local Community Organizations Child Protection (LCOCP). These Local Community Organizations are the first formal nongovernmental organizations in charge of detecting and reporting any form of child maltreatment to the municipal offices of CONANI and Fiscalias (Offices from the Attorney General). The Judicial Subsystem is made up of the Child and Youth Specialized Courts, the Appeal Court, and the Defense Counsel Office. They receive support from the Attorney General's Office, the Specialized Police department, and the National Support Office for Adolescents in conflict with the law (CONANI, n.d). 
Evaluation of Centres for the Integral Attention of Children in Dominican Republic (CIANIs) and Local Community Organizations for Child Protection (LCOCP)

Local Communities of Child Protection (LCOCP), commonly known as LCOCPs in Spanish, are local entities responsible for maintaining, enforcing, restoring, and ensuring that the rights of children and youth are not violated. They were created by the Code for the Protection of Fundamental Rights for Children and Youth, Law 136 - 03. (CONANI, n.d)

Following the Convention on the Rights of the Child, Law 136 - 03 recognizes the rights of children and youth, and establishes LCOCPs as decentralized agencies at the municipal level. They are expected to act on complaints received about violations of the rights of children and youth (CONANI, n.d)

The objectives are;

1. Caring for, ensuring, protecting, and restoring children and young people's rights.

2. Preventing abuse of children and youth.

3. Strengthening families to promote rights.

4. Following-up with cases until their end.

The agencies receive cases through referrals and reports of children and young people who are having their rights violated, and then work together with families, schools, state institutions, NGOs, community organizations, and communities to restore rights and ensure that children are safe and protected. They also work with public officials to guarantee rights. Relationships with institutions vary according to the region where they are situated (CONANI, n.d)

Cases they receive include:

- Undocumented children/youth

- Gender violence

- Follow-up on support agreements

- Children and young people leaving their homes because of child abuse

- Fraud

- Denial of education rights

- Pregnant youth

- Behaviour problems

- Physical abuse

- Sexual abuse 
Evaluation of Centres for the Integral Attention of Children in Dominican Republic (CIANIs) and Local Community Organizations for Child Protection (LCOCP)

- Psychological abuse

- Sexual harassment

- Negligence

- Bullying

- Trade and trafficking

- Commercial exploitation

- Children and young people living on the street

- Abandoned children

- Panhandling

- Missing children/youth

- Suicide threats

LCOCPs strive to empower communities in relation to the rights of children and young people by raising awareness. They do this through engagement, which includes participating in radio and television programs, working in schools with caregivers and students, and providing training at churches, organizations, schools, and neighbourhood groups.

Article 466 of law $136-03$ states that LCOCPs are comprised of seven members, including three professionals, three substitutes, and one youth representative. The term can be up to three years, but members can be re-elected for a consecutive term in a vote by community organizations, which operate locally. Individual members are known in the community/municipality, and participants work for free as members of a decentralized body. There are selection criteria for members, who are required to have a service vocation in the community, have volunteer experience, have no criminal record, have a good moral character, have working knowledge of Law 136-03, and be honourable and respected members of the community. They also need to be Dominican - by birth or through the naturalization process, be in good physical and mental health, be residents of the LCOCP's municipality, and have at least one year of experience in areas related to health, education, social work, psychology, or law (CONANI, n.d)

Members receive training in Law $136-03$ and child abuse, and receive diplomas in local management, with an emphasis on children and youth and LCOCP roles and objectives. They participate in workshops conducted by World Vision on how to work with issues related to complaints, human trafficking, and disability awareness. 



\section{Relevant Literature}

$\mathrm{t}$ is now universally acknowledged that the risks associated with poverty and vulnerability fall disproportionately on children (Wessells, 2009, p.8). For instance, The World Health Organization estimates that around 40 million children worldwide are victims of abuse and neglect (Save the Children, 2012). Therefore, various child-centered fields are becoming increasingly aware of the need for innovative perspectives and solutions to issues that directly affect the well-being of children.

The United Nations Office of the Special Representative of the Secretary-General on Violence against Children (2013) defines protection as preventing and responding to violence, exploitation, and abuse of children. Addressing these issues requires a commitment from all states to uphold the stipulations outlined in the Convention of the Rights of the Child (1989).

In particular, Article 4 (Protection of Rights) states that all governments have the responsibility to take all measures possible to make sure "children's rights are respected, protected and fulfilled." By ratifying the Convention, countries agree to review their laws and policies related to children, including social and legal policies, and health and educational services. Through this international agreement, governments are obliged to take the steps needed to ensure that the minimum standards set by the Convention are being met. They are therefore committed to the creation of an environment where children can grow and reach their potential. 
Evaluation of Centres for the Integral Attention of Children in Dominican Republic (CIANIs) and Local Community Organizations for Child Protection (LCOCP)

(UN, 2009). According to UNICEF (2006), "improving survival, growth and development requires three interventions: quality basic services, good care practices within the family and community, and the implementation of Early Child Development policies. If these components are combined, there will be greater impact on children's wellbeing" (p. 4).

In specific terms, Curry and Heykoop (2012) view child protection systems as a "web of interconnected elements that create layers of safety nets to prevent violence, exploitation and abuse. This requires all states to provide appropriate care for children at risk of, and who have experienced violence" (p.14).

Recent estimates claim that "nearly 200 million children under five years in impoverished countries are not attaining their full potential, suffering from profound deficits in nutrition, health, fine and gross motor skills, cognitive development, and socio-emotional development" (WHO, 2012, p.8). It is becoming clear that there is a significant gap between policy and practice with regard to the protection and well-being of children worldwide. Unfortunately, initiatives that address violence without a supportive policy and legislative environment are incapable of succeeding (Irwin, Siddiqi, \& Hertzman, 2007; Save the Children, 2012; The Consultative Group on Early Childhood Care and Development, 2013; Tinajero \& Loizillon, 2012; UNICEF, 2014b; World Bank, 2006;). Awareness of this gap indicates that there is a need for increased international enforcement and monitoring of CRC (Convention on the Rights of the Child) standards (Ruiz-Casares, 2010; Santos Pais, 1997; Shier, 2001; Skelton, 2007). The UN Committee on the Rights of the Child (2009) has acknowledged that meeting these requirements will not be an easy task for all states, but has also stated that the goal is attainable through systematic implementation and a culture of respect.

Government investments in Early Childhood Development policies and programs are not only steps in the right direction toward meeting the obligations of protection as stipulated in the CRC, but also creators of the potential for high returns in the long term, with regard to facilitating labour market participation and human capital. Substantial improvements occur in the situations of children from families with low socio-economic status. (Attanasio, Maro, \& Vera-Hernández, 2004; Behrman, Cheng, \& Todd 2004; Berlinski \& Galiani, 2005; Cunha, Heckman, Lochner, \& Masterov, 2005; Levy \& Schady, 2013; Schady, 2006; Tinajero \& Loizillon, 2012; USAID, 2011). According to UNICEF: 
Evaluation of Centres for the Integral Attention of Children in Dominican Republic (CIANIs) and Local Community Organizations for Child Protection (LCOCP)

Evidence from paediatrics, psychology, nutrition, child development and anthropology tells us that survival, growth, and development are inter-linked, and recent evaluations of comprehensive interventions for young children and families showed that they improved children's physical, psychological and social development and that they were cost-effective for the individual and for society. (UNICEF, 2006, p.7)

Schady (2006) states that the improvements in developmental deficits in the region indicate a high impact from early childhood programs over the past few decades (UNESCO, 2010). The largest benefits are seen in poor households, "as positive effects of early childhood development programs [in the United States] were twice as large for children from the poorest and least educated families as for other children" (Schady, 2006, p.194). Therefore, studies have shown that an investment in crucial skills early in life makes it easier to acquire professional skills later in life (Attanasio et al., 2004; Cunha et al., 2005; IDB, 2013; Levy \& Schady, 2013; Tinajero \& Loizillon, 2012; Vegas \& Santibáñez, 2011).

In the LAC region, in particular, social and economic inequality is very high in relation to other parts of the world (IDB 2013; Vegas \& Santibáñez, 2011). "The region is second only to Sub-Saharan Africa in terms of the inequality [with] ... an estimated 20 percent of the population living below the poverty line and the number of poor children in some countries is greater than 40\%" (De Ferranti, 2003; Vegas \& Santibáñez, 2011, p.xxv).

According to Levy \& Schady (2013), many children in Latin America begin "formal schooling with serious deficits in health and development. Rates of chronic malnutrition, for instance, low height-for-age, or stunting are extremely high in some countries, particularly among poor families" (p.198). Several researchers have discussed the effects "poor nutrition in early childhood can have on cognitive functioning, and the damage may be largely irreversible" (Attanasio et al., 2004; Levy \& Schady, 2013, p.198; Vegas \& Santibáñez, 2011). The evidence also suggests that many poor Latin American children begin schooling already behind, a lag that puts them at a significant disadvantage in relation to their peers (Levy \& Schady, 2013).

Although UNESCO (2012) states that the signs of children's cognitive-language and socio-emotional development are strongly debated in various cultural contexts, there is an agreement across cultures regarding the developmental skills 
Evaluation of Centres for the Integral Attention of Children in Dominican Republic (CIANIs) and Local Community Organizations for Child Protection (LCOCP)

children need to succeed in school (Fernald, L.C., Kariger, P., Engle, P. \& Raikes., A, 2009). "School readiness is now used as a measure of developmental health, and the domains that appear to be most relevant to the child's success at school are: physical health and well-being, social and emotional competence, approaches to learning, cognitive and language competence, and communication skills" (Tinajero \& Loizillon, 2012, p.9). The view through this lens shows that investments in early childhood education (ECE) have proved to create measurable results; for instance, "ECE can be a critical reading readiness intervention for children, particularly for the disadvantaged whose mother tongue is different from the officially taught language in school" (USAID, 2011, p.2).

Other studies have revealed that early childhood interventions can equalize opportunities for children and reduce the intergenerational grip of poverty and inequality (Vegas \& Santibáñez, 2011; Currie 2001). A holistic approach to early childhood development has been shown to improve income-earning capacity, productivity, longevity, health, and cognitive ability (IDB 2013; Levy \& Schady, 2012; Schady, 2006; USAID, 2011; Vegas \& Santibáñez, 2011). UNICEF (2006) defines the "holistic approach to Early Child Development" as "policies and programming that ensure that child rights to health, nutrition, cognitive and psychosocial development and protection are all met. All interventions should reach the same children, including the most marginalized" (p.3).

According to UNESCO (2012), "The Holistic Early Childhood Development Index (HECDI) is used as a critical and analytical tool to review existing early childhood indices and indicators in the areas of child development, developmental care and education from birth to the age of 8"(p. 2). A holistic approach to early childhood education "requires good health care and nutrition for children and mothers, clean water and proper sanitation, psychosocial care, opportunities for early learning and emotional security, protection from abuse and exploitation, and equal rights for boys and girls" (UNICEF, 2006, p.4).

Early childhood development specifically refers to "the stage of life from conception to age 5 as a period of experience-based brain development and as a critical stage for the programming of neurobiological pathways" (Tinajero \& Mustard, 2011; UNESCO 2012, p.4). Research has established that "the brain continues to develop and form neural connections during the early years of childhood; therefore nutrition, cognitive stimulation, and nurturing care during these early years strongly influence the extent to which a child's health, as well as her or his cogni- 
Evaluation of Centres for the Integral Attention of Children in Dominican Republic (CIANIs) and Local Community Organizations for Child Protection (LCOCP)

tive and socio-emotional abilities, may develop to their fullest potential" (Vegas \& Santibáñez, 2011; Young-Wolff, Kendler, \& Prescott, 2012). "The sense of touch - particularly in the early stages of life - seems to play a crucial role in the development of the brain and the biological pathways" (Mustard, 2006; UNESCO 2012, p.4). For these reasons, later-in-life capabilities such as language and mathematics skills, self-discipline, and social skills are strongly linked to early childhood experiences (IDB, 2013; Schady, 2006). This evidence supports the need to implement high-quality early child development programs during the early stages of life, since, according to the World Health Organization (2008), experience during the early years of life is seen, across countries in the world, as one of most significant social determinants of health (Tinajero \& Loizillon, 2012, p.4). USAID (2011) states that "where possible, countries should be examining methods to deliver developmentally appropriate educational content to their youngest children" (p.10).

\section{a. Early Child Care Development in Latin America and the Caribbean (LAC)}

According to UNESCO (2010), early childhood care programs in Latin America began in the late 19th century with a nursery school in Argentina named Jardines de Infantes, but services did not become public until the mid-20th century. Across the LAC region, public child care services vary widely, with programs beginning about 25 years ago in Central America, the Caribbean, and the Southern Cone, but only as recently as 16 years ago in the Andean regions. (IDB, 2013; UNESCO, 2010). According to Levy \& Schady (2013), Argentina, Ecuador, Mexico, Uruguay, and Venezuela reported an enrolment rate for pre-primary levels above 80 percent by the late 2000s, while Paraguay, El Salvador, Nicaragua, and Honduras had pre-school enrolment rates of less than 50 percent. However, during the past two decades, the coverage of early childhood programming in Latin America and the Caribbean has increased significantly (IDB, 2013). In specific terms, statistics show that in "1990-98 the coverage level for children aged 3-5 increased in the region to almost 50 percent. In the Caribbean, progress has been faster as it is estimated that currently, 95 percent of children in Jamaica are served by early childhood education services offered from 3 to 5 years of age" (IDB, 2013, p.35; UNESCO, 2010).

It is important to note that much of the literature indicates that many of the first early childhood development programs were originally geared to promote more female participation in the workplace (Currie, 2001; IDB, 2013; Kamerman, 2006; 
Evaluation of Centres for the Integral Attention of Children in Dominican Republic (CIANIs) and Local Community Organizations for Child Protection (LCOCP)

Reimers, 1993; Vegas \& Santibáñez, 2011). However, during the past few decades, there has been a transformation, and now there is a greater diversity of programs aimed at promoting children's well-being from various perspectives. (Attanasio et al., 2004; Behrman, Cheng, \& Todd, 2004; Berlinski \& Galiani, 2005; Cunha et al., 2005; IDB, 2013; Levy \& Schady, 2013; Vegas \& Santibáñez, 2011).

The Inter-American Development Bank's (2013) report on early childhood education in Latin America and the Caribbean provides an example of this transformation through Hogares Comunitarios de Bienestar (Community Welfare Homes [HCBs]) in Colombia, which began in 1974. This particular type of child care service was common in Andean countries and was designed to facilitate the entry of economically disadvantaged mothers to the workforce by creating a safe environment for children in urban areas affected by violence (IDB, 2013). However, today these programs are now offered under the Instituto Colombiano de Bienestar Familiar (Colombian Family Welfare Institute [ICBF]), the largest child care organization in Latin America, serving more than 1.2 million children. The program serves pregnant women, mothers, and children living in poverty through a combination of parental education and child services (Attanasio et al., 2004). Recent improvements have been made to ensure staff professionalism and better-quality infrastructure and care of the children. There are also community parenting programs working with mothers (Vegas \& Santibáñez, 2011).

While many early childhood development (ECD) programs are still run by private or community level organizations, there has been a trend during the past few decades in the direction of the nationalization of these programs (Kamerman, 2006). This is evident in the IDB (2013) analysis of over 40 early childhood development programs across the LAC region, with a total of 28 operating at the national level. The institutionalization of programs also varies across the region; "in the Southern cone child care services are almost exclusively institutional in nature, while in the Andes and, to some extent, Central America, a community-based model prevails" (IDB, 2013, p.40). However, according to Vegas \& Santibáñez (2011), despite these changes, the coverage of these programs still remains low, especially in the rural sectors of society.

\section{b. Early Child Care Development Interventions and Benefits}

Early childhood development programs can be beneficial in a variety of areas that affect a child's well-being. Given that slightly over 10 percent of children under five 
Evaluation of Centres for the Integral Attention of Children in Dominican Republic (CIANIs) and Local Community Organizations for Child Protection (LCOCP)

in Latin America today live on less than \$1 per day (Vegas \& Santibáñez, 2011), there is a desperate need for strategies to create a more equal playing field for all. Children who are born into poor families are much more likely to have parents who have low levels of educational attainment, low-quality jobs, and low wages, factors that often perpetuate cycles of poverty (Currie, 2001; Cunha et al., 2005; IDB, 2013; Levy \& Schady, 2013; Schady, 2006). Therefore, according to Currie (2001), governments' work towards the reduction of inequalities through ECD programs may be more effective than efforts to compensate for differences in outcomes later in life (Tinajero \& Loizillon, 2012).

As demonstrated earlier, early childhood development is a multidimensional field that requires a holistic array of perspectives to address the diversity of issues present across the Latin America and Caribbean region. The most common types of ECD strategies are indicated below, including child care programs, parenting interventions, nutritional programs, home visits, health programs, and cash transfer programs. In many cases, various programs will combine numerous approaches in order to produce a more holistic outcome. The programs that incorporate various strategies appear to be having the most successful outcomes. For instance, evidence from programs in Guatemala, Jamaica, Colombia, Nicaragua, and Bolivia suggests that programs that incorporate parenting practices, nutritional supplements, and child care have positive results in relation to cognitive and noncognitive skills (Cunha et al., 2005; Cunha \& Heckman, 2007; Heckman, 2006; Vegass \& Santibáñez, 2011; Tinajero \& Loizillon, 2012).

Child care programs are the most common form of ECD with the widest degree of coverage, especially within urban areas. "In several countries, there has been a movement away from the community modality toward the institutional modality for these types of services. This process is part of the major effort to improve the quality of care provided to children" (IDB, 2013, p. 70). Behrman, Cheng, \& Todd (2004) report the significant effects of daycare programs on motor skills, psychosocial skills, and language attainment in Bolivia, and Berlinski \& Galiani (2005) show how increased pre-school enrolment rates led to better performance on cognitive and behavioral outcomes among pre-school participants in Argentina (Vegas \& Santibáñez, 2011).

While child care programs vary considerably across the region in terms of whether or not they are state or privately run, their size, facilities, the length of daily service, the number of meals given per day, and the teacher-to-student ratio, etc., 
Evaluation of Centres for the Integral Attention of Children in Dominican Republic (CIANIs) and Local Community Organizations for Child Protection (LCOCP)

the struggles faced by these services are often quite similar. A total of " $80.6 \%$ of programs reported that their centers have a waiting list due to a lack of slots ... $26.5 \%$ of programs acknowledged that they have inadequate staffing, and $64.7 \%$ admitted that they face funding constraints (IDB, 2013, p. 47). Parents also report that they face various barriers to these services, often due to difficulty accessing the location and/or inability to produce the necessary documents required to enroll their children, such as birth certificates, vaccination records, health certificates, identity cards, and proof of residency (IDB, 2013, p.47).

Although female access to the workforce is obviously connected to the availability of affordable, suitable, and reliable child care services, many of the modern centres offer far more than simply child care. Many incorporate nutritional programs, and prenatal and parenting education into their service provision. For example, the LCOCP Nacional de Jardines Infantiles (JUNJI or National Board of Early Childhood Care) in Chile operates as a "network of daycare and preschools that offer parent education, child-centered early education, nutritional services and support for working women" (Vegas \& Santibáñez, 2011, p.146).

In terms of child care programs, many include a comprehensive approach consisting of health checkups, vaccines, and nutritional supplements as part of their programming. The most common supplements, particularly found in Latin America, are subsidized milk and milk fortification programs (IDB, 2013). Evidence suggests that the nutritional components of Early Childhood Development interventions are particularly beneficial when targeted towards low-income children (Vegas \& Santibáñez, 2011). In Guatemala, for example, the rate of malnutrition among indigenous children under five is 80 percent, and among ladino children, 43.5 percent. This malnutrition is due to an unbalanced diet lacking in fruits, vegetables, and proteins. In addition, there are cultural practices that support feeding babies' sugar water or powdered supplements when they have trouble sucking breast milk, and also introducing whole foods before six months of age. Since the first five years of development are crucial, those who do not have adequate nutrition often suffer severe growth, cognitive, motor skills, and other assorted deficiencies later in life (Benfirrez, personal communication, June 2015).

Early childhood development programs that focus on nutrition, Attanasio et al. (2004) show improvements in the nutritional status of children in community nursery programs in Colombia. In addition, Behrman, Cheng, \& Todd (2004) found overall improvements in children's height, cognitive development, and school per- 
Evaluation of Centres for the Integral Attention of Children in Dominican Republic (CIANIs) and Local Community Organizations for Child Protection (LCOCP)

formance through their study in Bolivia of the Proyecto Integral de Desarollo Infantil (PIDI) full-time nursery school and nutritional program.

Several sources also found positive effects from programs that conditioned benefits on health controls and growth monitoring (Gertler \& Fernald, 2004: Fiedler, 2003: Tinajero \& Loizillon, 2012). For example, in Costa Rica, The CEN-CINAI program provides direct care to children through an interdisciplinary team consisting of doctors, physical therapists, and audiologists, who identify problems and follow up with cases as needed (IDB, 2013).

Home visit programs are regularly paired with parenting programs and are often used as a strategy to reduce violence in the home. According to Schady (2006), home visit programs can offer disappointing results if they are not followed up with other approaches. The program design often tries to convince parents to change behaviours that the parents may not agree are negative, and this difference of opinion causes tensions. There also tends to be a high rate of staff turnover with these programs, making it difficult for families to build a relationship of trust with the program.

Therefore, it is crucial to design programs that are attractive to the households that they are trying to benefit, and also to use an innovative combination of programs, since there is potential for high returns when parenting and the home environment are effectively improved (Schady, 2006; Fontes, 2002).

In terms of government programs that offer family and parenting support, "conditional cash transfers are especially popular in the Latin American region - the UN has indicated that some 25 million households (equivalent to some 133 million people) in 18 LAC countries receive conditional cash transfers" (UNCIEF, 2015, p.16). According to UNICEF (2015), mostly low-income families are targeted through these programs, and "in most countries, the conditions relate to school attendance and/or health-related progress on the part of the child, or indeed the parents' attendance in parenting programs" (p. 17). However, cash transfer programs have been criticized for reinforcing gender roles by targeting women as the primary recipients, and have been subject to both positive and negative feedback (Daly et al., 2015).

Monitoring the level of the quality of early childhood development programs also remains a challenge "especially among those indirect and non-formal programs 
Evaluation of Centres for the Integral Attention of Children in Dominican Republic (CIANIs) and Local Community Organizations for Child Protection (LCOCP)

and providers with ad hoc reporting mechanisms. Selecting the aspects to monitor which would proxy the quality of early childhood services is also a matter of concern, as the literature is emerging in this field" (Tinajero \& Loizillon, 2012, p.35). This monitoring is crucial, since poor quality programs can be detrimental to child development (Barnett, 1995; Cunha et al., 2005; Engle et al., 2011; Nusche, 2009; Paxson and Schady, 2005; Tinajero \& Loizillon, 2012, p.35).

Schady (2006) explains how severe behavioural problems in early childhood have been proven to predict dropping out from high school and delinquency later in life; high-quality programs produce "children who are appropriately socialized, [who] tend to turn into better-adjusted adults. [Thus] labor market returns, various non-cognitive skills, including motivation, enthusiasm, cooperation, and teamwork, may be as large as or larger than the returns to intelligence and other dimensions of cognitive development" (Attanasio et.al., 2004; IDB, 2013; Levy \& Schady, 2013; Schady 2006, p.191; UNESCO 2012; Vegas \& Santibáñez, 2011).

It is also stated throughout the literature that countries that implement early child development policies and programs have higher levels of overall health status among their populations (Bernard Van Leer Foundation, 2009; Save the Children, 2012; Siddiqi, Irwin, \& Hertzman, 2007; USAID, 2011), and these higher levels not only contribute to savings in public investment, but have also been shown to strengthen the democratic system (USAID, 2011; Vegas \& Santibáñez, 2011). Despite these benefits, "providing young children with a safe and healthy environment that fosters their motivation and stimulation to learn and engage socially is often not high on the list of priorities for developing countries, as many governments and donors in these countries continue to neglect ECCE investments at the expense of other education and social policies" (Tinajero \& Loizillon, 2012, p.11).

\section{i. Social Capital}

Social capital is the "social fabric" of a community (Chilenski et al., 2013) which refers not only to the various types of relationships among individuals and among organizations, but also to qualities such as trust, cooperation, and leverage (Petersen, 2002; Putnam, 1993; Chilenski et al., 2013). According to Abom (2004), social capital theory can be viewed in terms of "'bonding' capital, which exists among kin

and extended family or work members, and 'bridging' capital, which exists among wider and more general social networks" (p. 343). Application of this framework is 
Evaluation of Centres for the Integral Attention of Children in Dominican Republic (CIANIs) and Local Community Organizations for Child Protection (LCOCP)

useful when violence prevention strategies are looked at, since it can unveil power dynamics, as well as the ways information and resources are passed back and forth in order to work towards the common goal of well-being within a community.

Social capital has been accepted as an important component that contributes to a child's well-being by assisting parents in coping with stress and in accessing resources; the capital can ultimately be utilized for a child's success (Furstenberg, 2005; Hernandez \& Grineski, 2012). These networks are vital to understanding the structure of a community's social organization since they reveal the ways community members utilize their capital to improve their own livelihoods and the community as a whole. Social capital is vital because it affects other forms of capital, such as human, financial, physical, political, cultural, and environmental capital, and because, through its impacts on health and education, it contributes to well-being and development (Green \& Haines, 2015). In Latin America, the evidence suggests that young people who were lacking social capital in their neighbourhoods not only performed poorly in school, but were also more likely to drop out (Hernandez \& Grineski, 2012). By expanding social relations across various socio-economic levels, individuals acquire opportunities to share and gain life skills and contacts. Research shows that a "higher level of social capital is associated with higher productivity of individuals and groups, better health outcomes, higher educational achievement, and lower crime rates" (Foxton \& Jones, 2011; Green, Grimsley, Suokas, \& Halpern, 1999; Prescott, Jowitt, \& Lincacre, 2000; Sampson, Raudenbush, \& Earls, 1997).

Social factors such as unemployment, poverty, and violence do not merely stand alone, but are intertwined in a myriad of relationships governed by one's exposure to social networks. For instance, Abom (2004) discusses how low levels of broadbased social capital in urban Guatemala are due to a complex and diverse range of social, cultural, political, and economic issues. He explains that fear of violence and corruption, and also of a top-down authoritarian state has hindered social capital and fostered a dependency on northern-led NGO service provision. This problem indicates a need for more community-based participatory interventions to foster the growth of social capital networks within the population.

It is also important to note that, when violence prevention is looked at through a social capital lens, "lower income parents are likely to have lower income members in their social networks which often relates to culturally acceptable forms of child maltreatment" (Sabol et al., 2004). This social reality is supported and further 
Evaluation of Centres for the Integral Attention of Children in Dominican Republic (CIANIs) and Local Community Organizations for Child Protection (LCOCP)

explained by Dominguez \& Watkins (2003), who state that networks that consist of "socio-economic homogeneity" can limit members' chances of advancement, because the same types of information and resources are often circulated throughout the group.

According to Dominguez \& Watkins (2003), social capital can generate social support, such as advice and encouragement, through friendship, family networks, and also non-profit organizations. Institutional support, for instance, can be a valuable resource, particularly when family and friends are ineffective or unavailable (Dominguez \& Watkins, 2003). Institutional networks often offer various advantages in comparison to traditional sources of capital by providing reliable, efficient resources and contacts "that are less stressful and burdensome in terms of reciprocity than relationships with family and friends. For example, service professionals can serve as social mobility bridges, connecting low-income mothers with appropriate strategies and tools" (Dominguez \& Watkins, 2003, p.19). While social capital tends to be viewed as a ground-up alternative to top-down policies (Portes \& Landolt, 2000). Portes (1998) explains how social support can also be viewed as a sort of as social control, which occurs when individuals' freedoms are restricted because of the networks they rely on. For example, "emotional reliance on support systems that can discourage the development of other forms of social capital" (Portes \& Landolt, 2000, p.15). In addition, the existence of high levels of social capital in countries such as Guatemala, which is rampant with corruption, can also mean that larger social networks provide more opportunities for extortion.

Social capital is a useful concept in the analysis of community structures that can help both individuals and service providers to expand their resources, and, in turn, attain better community livelihoods by creating efficient violence prevention networks. Still, Portes and Landolt (2000, p.19) insist that "social capital is not a substitute for the provision of credit, material infrastructure, and education." At an institutional level, Portes and Landolt urge community members to be cautious and critical of social networks and power dynamics, and explain that, in order for a project to be successful, it must be combined with grassroots approaches and be embedded in the local context.

Authentic parental participation in violence prevention programs led by local professionals and community members can generate immense benefits for both the parents involved and their children. Through their participation in these programs, relationships are built among parents, children, and staff, which not only expand 
Evaluation of Centres for the Integral Attention of Children in Dominican Republic (CIANIs) and Local Community Organizations for Child Protection (LCOCP)

and diversify social networks, but also equip families with a support system of educators, professionals, and other community members in similar situations. Participation in a community of individuals working towards the common goal of violence prevention helps to build bridges among neighbours who are otherwise isolated and to draw out common concerns and struggles in order to create a positive environment for learning, sharing, and personal growth.

However, looking at violence prevention strategies in terms of social capital only provides a limited picture of social relations within a community. Social capital, especially within developing countries, is often misunderstood and is difficult to measure. "The purpose of giving centrality to social networks is not to suggest that social networks are the sole or primary agent contributing to family violence but to broaden the context in which family violence is viewed beyond that of the perpetrator, the victim/survivor, or the violent dyad" (Gracia \& Musitu, 2003, p.154; Korbin, 1995). Therefore, for these relationship to have meaning and for these types of programs to create a lasting effects, the building of trust and collective efficacy among community members is crucial.

\section{ii. Community Trust}

Sampson et. al (1997) suggest that it is perhaps more effective to look at community violence prevention in terms of collective efficacy, which refers to mutual trust among neighbours, combined with the willingness to intervene on behalf of the common good, specifically, to supervise children and maintain public order. It can also be described as the likelihood that neighbours would intervene in situations requiring assistance. Collective efficacy or community trust is crucial to establishing common goals and solutions to community issues, and, according to Sampson et. al (1997), rates of violence are lower in urban neighborhoods that exhibit these characteristics. Eriksson, Hochwälder, \& Sellström (2011) maintain that there should be a focus on promoting community trust and safety, since they found that perceived community trust and safety had a positive impact on children's subjective well-being.

Gracia and Musitu (2003) support this notion by arguing that positive social networks can provide important protection from child maltreatment. They explain that, when child rearing is a shared concern within a supportive network, the chances of a child having an "inadequate or aggressive parent are diminished. [This is 
Evaluation of Centres for the Integral Attention of Children in Dominican Republic (CIANIs) and Local Community Organizations for Child Protection (LCOCP)

because] networks built on community trust create an environment of consensus, scrutiny, and enforcement of standards of child care" (Gracia \& Musitu, 2003, p.155). Ohmer (2007) points out that citizen participation cultivates collective efficacy in a neighbourhood, which fosters the development of trusting relationships that are imperative; in neighborhoods with mistrust, residents are less likely to take action and work together, and social efficacy is reduced (Van Der Land \& Doff, 2010).

According to Halpern (2001), "survey data for Chicago neighbourhoods showed that mutual trust and neighborly altruism were key factors in explaining inter-neighbourhood differences in crime rates, which improved levels of trust, respect and self-esteem within and between community members" (p. 237). Research by Gracia and Musitu (2003) in both Spanish and Colombian studies largely supports the connection between social isolation and child maltreatment. They state that "maltreating parents are not only frequently isolated from informal networks of social support such as relatives, neighbors and friends, but also from institutions and formal systems of social support" ( p. 154).

Since these parents tend to receive less community support, they have a tendency to feel lonely, and thus often lack coping mechanisms to deal with day-to-day stressors. UNESCO (2012) suggest that "healthy child development (including socio-emotional and cognitive development) is highly dependent on the mother's well-being and the social support she receives from her significant others and her community. Thus, the absence of significant others and a mother's inability to exchange emotional signals with the child are early risk factors that can affect the child's overall development" (Tinajero \& Loizillon, 2012, p.7). DiLorenzo, White, Morales, Paul, \& Shaw (2013) state that because children and families face such complex issues, the best way to approach child protection is through community-based initiatives that reach out to various members and support families. "Strong community bonds and socially, economically, and environmentally vibrant communities would produce healthier individuals and families who would be less prone to violent behavior" (Bowen, Gwiasda \& Brown, 2004).

Unfortunately, poverty has been found to weaken levels of perceived trust, a development that decreases social interaction (Lenzi, Vieno, \& Santinello, 2013). Usher emphasizes that trust is a coping resource and "cornerstone of productive social capital" and that individuals need to be involved with others to gain the benefits. These social ties allow for access to resources and opportunities (2007, p. 37). 
Evaluation of Centres for the Integral Attention of Children in Dominican Republic (CIANIs) and Local Community Organizations for Child Protection (LCOCP)

\section{iii. Community Engagement}

Research also indicates that community engagement and participation in local activities, social events, and programs, etc., can greatly contribute to violence prevention and a reduction in cases of child maltreatment (Bowen et al., 2004; Chaskin, Brown, Venkatesh, \& Vidal, 2001; Garbarino \& Sherman, 1980; Gracia \& Musitu, 2003; Green et al., 2000; Halpern, 2001). This reduction occurs because higher levels of community integration, participation in community social activities, and use of formal and informal organizations provide parents the social and emotional support they need to deal with family stressors, and to help them provide adequate care for their children (Gracia \& Musitu, 2003, p.153). Kotzé, Seedat, Suffla, and Kramer promote the practice of "community conversations" for community engagement. They argue that the activity is a great benefit to a community because it not only promotes community interactions, but also connects both people and ideas and can serve a source of co-learning and social transformation (2013).

Polansky et al. (1985) found that "neglectful parents who perceived their community as non-supportive tend to isolate themselves from any type of social contact, and, more significantly, other members of the community tended to avoid contact with abusive parents, thus strengthening the vicious circle of negativity and isolation" (Gracia \& Musitu, 2003, p.155). Gracia \& Herrero (2004) link community engagement with psychological well-being, and they argue that that community support is associated with a reduction of the symptoms of depression after six months. Community participation helps to develop more positive attitudes toward other community members, and "research shows that neighbours who take part in community activities express a higher degree of satisfaction and sense of community" (Gracia \& Herrero, 2004, p. 62). Engagement in the community can foster the perception of the community as being welcoming and supportive, and these beliefs can convert into actions (Kimbrough-Melton \& Melton, 2015). This environment can foster a mutual commitment to shared goals and ideals, as the very "concept of sense of community refers to the perception of belongingness and feeling that one is part of a larger structure, as well as the feeling of interdependence with others which is maintained by supporting or being supported" (Gracia \& Herrero, 2004, p. 7).

In communities where intergenerational cycles of violence are common, in terms of connections between the perpetuation of violence by local young people and 
Evaluation of Centres for the Integral Attention of Children in Dominican Republic (CIANIs) and Local Community Organizations for Child Protection (LCOCP)

the abuse of those young people as children, Bowen et al. (2004) suggest that there is a need for the community as a whole to address violence in the home in order to make the community a safe place to live. This suggestion is supported by Sabol et al. (2004), who argue that successful community violence prevention programs need to be structured in ways that 'contribute to the communities' own capacity to prevent violence" (Bowen et al., 2004). Sabol et al. (2004) also suggest that state institutions are often central to promotion of community violence prevention efforts, yet, in order to promote the healthy development of children, families themselves need to search for new and creative ways of supporting interpersonal relationships. Community capacity is unique since it consists of both social capital and formal and informal organizations that can be used to reduce violence in a variety of ways that are suited to the context of a particular community (Chaskin et. al 2001; Sabol et. al 2004). Kimbrough-Melton \& Melton (2015) state that, in order to improve child safety in communities, it is imperative to build and capitalize on community assets as movement is made towards a broader focus on healthy development.

This section has demonstrated the connections among social capital, community trust, and community engagement as crucial perspectives to consider when violence prevention programs in local community settings are planned. Understanding of the important role each has in the successful functioning of a community environment makes it clear that real change is in the hands of community members, and that harnessing these theoretical concepts can break the cycle of violence and improve the quality of life for all families involved.

\section{c. Parenting Programs}

Parenting programs are "a much more recent concept with the average age of parenting programs in the Latin American and Caribbean region being nearly 12 years" (IDB, 2013, p. 33). According to UNICEF:

Families, parents and caregivers play a central role in child well-being and development. They offer identity, love, care, provision and protection to children and adolescents as well as economic security and stability. Families can be the greatest source of support for children but also - under unfortunate circumstances - the greatest source of harm. Children's well-being is therefore inextricably linked to parental well-being (2015, p.5). 
Evaluation of Centres for the Integral Attention of Children in Dominican Republic (CIANIs) and Local Community Organizations for Child Protection (LCOCP)

Therefore as Gardner, Montgomery, and Knerr (2015) state, "parenting interventions are increasingly being recommended and implemented in diverse regions of the world (UNODC, 2009; WHO, 2010), as part of strategies for preventing violence-both-to and by children-and enhancing children's development" (p.10).

Bornstein \& Cote (2004) explains that parenting knowledge includes learning and understanding how to care for children, how children develop, and the numerous roles parents play in raising a child. Parenting knowledge directly affects parents' ability to make decisions about how to care for their children and this in turn affects the child's development. Thus, investment in parenting programs is crucial to realizing the rights of the child.

The engagement of parents "in activities with their children is important for stimulation of child development and is considered an indicator of parental concern for overall child well-being and development" (Nonoyama-Tarumi \& Ota, 2009; UNESCO 2012, p. 38). These programs are often designed to help intercept intergenerational cycles of poverty and abuse by better equipping adults for the challenges of parenthood in modern society. Many of these programs are combined with child care services, nutritional programs and home visits. "In a study in Ecuador, parenting activities, such as time spent reading to the child, and parental responsiveness, increased cognitive outcomes among poor children aged three to five" (Paxson \& Schady, 2005; Tinajero \& Loizillon, 2012, p.38).

Webster-Stratton (2009) explain that during parenting interventions it is often favoured that parents rather than professionals set the goals they want for their children, and then the teacher responds by suggesting a "range of strategies which parents are free to adopt or reject according to their belief systems and needs" (Scott et al., 2010, p.7). "Among the main outcomes targeted by these programs are the promotion of positive discipline and the amelioration of child maltreatment and child related risks" (Daly et al., 2015, p.18).

Thus there are various forms of parenting programs. Some may be delivered through such diverse channels as group educational programs, one-to-one counselling, and coaching or peer mentoring in a community context around parenting-relevant information, education and skills.... In some countries, for example, parents attend information, coaching and training sessions at the early education and care centres which their children are attending (Daly et al., 2015, p.18). 
Evaluation of Centres for the Integral Attention of Children in Dominican Republic (CIANIs) and Local Community Organizations for Child Protection (LCOCP)

According to Weaver \& Maddaleno (1999) another approach to parenting programs is to teach parenting skills to young people in school before they become parents, which can improve knowledge and realistic expectations among young men and women. This type of community level parenting education can also change attitudes and skills in violence prevention among young people and adults.

Various sources state how interactive parenting programs have been shown to improve the quality of the relationship between parent and child as well as between parents, (Cowan et al. 2011) by improving parental competence and reducing stress as well as maternal depression (Gross et al. 2003; Nixon, Sweeny, Erickson, \& Touyz, 2003; Sanders \& McFarland 2000; Gardner, Montgomery, \& Knerr 2015). "A call for interventions in developing countries was recently made by the World Health Organization (WHO, 2009), specifically to prevent behavioral difficulties and child maltreatment through the development of stable relationships between children and their parents" (Mejia, Calam, \& Sanders, 2012, p. 164).

Parenting programs have also been shown to be useful in the prevention of a wide range of issues such as anti-social behaviour, low school attendance, unhealthy peer group associations and other precarious choices later in life (Scott et al., 2010). This is in addition to the fact that successful parenting programs can create considerable long term clinical, public health and financial benefits for society (Loeber \& Farrington, 2000; Scott et al., 2010).

Numerous sources draw attention to cultural applicability of parenting interventions arguing that the consideration of culturally appropriate measures is essential (Mejia, Calam and Sanders, 2012; Kotchick \& Grover 2008). For instance, Belfer and Rohde (2005) claim that traditionally in Latin American and Caribbean countries the family has played a major role in society, so no prevention program has a chance of success without fully involving families in the process.

Fontes (2002) supports this model and explains how early childhood development strategies can have an important role to play in addressing abusive parenting in order to prevent subsequent violence. However, she notes that changing deeply rooted traditional child-rearing practices has many obvious challenges, and many studies have shown that efforts to introduce new strategies can clash with the dominant cultural views and cause tensions (Fontes, 2002; Longman-Mills et al., 2011; Moestue \& Mugglah, 2013). 
Evaluation of Centres for the Integral Attention of Children in Dominican Republic (CIANIs) and Local Community Organizations for Child Protection (LCOCP)

Research reveals that parents are less likely to feel criticized by members of their own cultural community for new parenting strategies if they are surrounded and supported by others in their own community. Support may be expressed through affirmation from peers within their own cultural group, open discussion, or assistance from counsellors to cope with this divide (Fontes, 2002; Longman-Mills et al., 2011; Moestue \& Mugglah, 2013). Professionals are often ill equipped to handle harsh punishment in a family that differs from their own cultural norm. It is important for counsellors to engage with families in the language that is most comfortable for them (Fontes, 2002). Fontes (2002) also outlines new culturally competent ways to approach teaching parenting techniques by:

Explaining new disciplinary strategies from a position of ambition - (i.e. without hitting children they are more likely to be successful later in life- achieve higher status positions etc.). Physical punishment creates more aggressive adults and higher likelihood they will become criminals. [Therefore, it is important to teach]... values of respect without fear (p.36).

However, it is interesting to note, Gardner, Montgomery, and Knerr (2015) argue that there are in fact more similarities than differences across cultures in regards to parenting practises. They claim that there are cross-cultural basic principles which are universal, thus only minor adaptations to transporting programs to other countries is needed to ensure success.

Through their study of the global distribution of parenting interventions across countries with varying cultural-economic compositions, they argue that contrary to popular belief, parenting programs that have been duplicated in countries that differ culturally, can be as effective as in the countries where they were originally designed.

Scott (2010) agrees with Gardner et al. (2015) on this point by stating that cross-cultural studies show that "warm involved relationships between parents and children backed by firm limits are associated with better child outcomes regardless of culture" (Steinburg, 2001). While this statement is supported across various studies, in developing countries there remains many factors which can influence the effectiveness of these programs. This includes factors such as poverty, access to resources, inequality, differing family structures and the quality of service provision.

Several studies draw attention to the obstacles to implementing effective parenting programs, particularly in middle to low income countries. For instance, the lack 
Evaluation of Centres for the Integral Attention of Children in Dominican Republic (CIANIs) and Local Community Organizations for Child Protection (LCOCP)

of skilled and trained professionals in developing countries can create substantial difficulties in creating effective parental interventions. Gardner, Montgomery, and Knerr (2015) also add to this by stating that due to limited local professional capacity, foreign nongovernmental organizations are often utilized in training local professionals or even in implementing the programs.

Studies indicate that in order to remedy this issue, it is necessary not only to investigate "the needs and preferences of practitioners in these countries, as they may provide valuable insight to inform the dissemination process, [but also the]... need to develop local research and evaluation expertise" (Mejia, Calam and Sanders, 2012, p.171). As many parenting programs in developing countries will likely be operated by staff with low levels of training, it is particularly crucial that programs are designed clearly and by using strong materials, to ensure their effectiveness.

It is also crucial to note that Mejia, Calam and Sanders (2012) bring attention to the fact that while there is a large body of research surrounding parenting programs, the majority is based in a small number of high-income countries (WHO 2004).

Other common obstacles consist of financial constrains as developing countries generally have fewer resources to allocate towards social programs. Thus implementing cost-effective interventions which can be sustained long term and can also create economic benefits for participants in the future, is essential. Finally, sources discussed the importance of regular attendance for participants in parenting programs, as higher attendance directly corresponds to higher effectiveness. However, qualitative studies indicate that the overwhelming reason for not attending sessions regularly was "being too busy" (Scott et al., 2010). Reid, Webster-Stratton \& Baydar (2004) adds to this issue by stating that attendance is poorer for parents whose children lack problems. In order to remedy concerns regarding lack of attendance, scheduling programs during convenient times of the week as well as an appropriate location are crucial. It may also be valuable to have participation in the program as a requirement for receiving other family benefits and assistance.

In addition to these concerns, a recent review of the dominant literature on parenting programs by Mejia, Calam and Sanders (2012) proposes that the main challenges of these programs consist of the following:

1) The focus tends to be on the preventions of physical difficulties in children rather than managing behavioural or emotional problems, 2) a lack of 
Evaluation of Centres for the Integral Attention of Children in Dominican Republic (CIANIs) and Local Community Organizations for Child Protection (LCOCP)

rigours methodological evidence to support the effectiveness of parenting programs, 3) mixed evidence regarding the effects of these programs, and 4 ) the measurement of outcomes in many studies remains unclear (p. 175).

They discuss how some studies only focus on parental outcomes, and how this is problematic because as the main goal of parenting programs is to make a change in the child; which as a result confines the conclusions that can be made.

While parenting programs in low-income countries present a number of challenges, they also show the high rates of positive outcomes. For instance, parenting programs in Jamaica, Bolivia, Honduras, and elsewhere suggest that parents do generally improve their child-rearing and child stimulation techniques, and the result is children with improved development of cognitive, language, motor, social, and other skills (Behrman, Cheng \& Todd, 2004; Fiedler, 2003 Grantham-McGregor, Powell, Walker, \& Himes, 1991; Vegas \& Santibáñez, 2011).

Certain difficulties such as "accessing geographically remote populations can be remedied using technological advancements via remote interventions that show promise in terms of being a valuable low-cost solution to these barriers " (Mejia, Calam and Sanders, 2012, p.172).

It is also important to note that parenting programs offer an excellent opportunity for interdisciplinary research and collaboration across various fields such as social work, psychology, public health, international development, anthropology, law and economics. (Mejia, Calam and Sanders, 2012).

While parenting interventions have often had mixed success in improving children's behaviour in the long term, there are many studies which highlight the effectiveness of these programs in improving parental competence, and relationships between parents and children, as well as parental knowledge about child development.

\section{d. Child Maltreatment/Violence}

The United Nations' 1989 Convention on the Rights of the Child (CRC) and recommendations in the 2006 United Nations World Report on Violence against Children - Latin American Report both characterize acts of violence against children and youth as human rights violations (Pinheiro, 2006; Borht, Mendez, Villalobos, 
Evaluation of Centres for the Integral Attention of Children in Dominican Republic (CIANIs) and Local Community Organizations for Child Protection (LCOCP)

2012). Within the UN Study, 12 major recommendations focused on the need for strengthening national and local commitment and action, prohibiting violence against children, prioritizing prevention, promoting nonviolent values and awareness, supporting people who work with and for children, providing recovery and social reintegration services, ensuring child and youth participation, creating accessible and child-friendly reporting systems and services, making perpetrators accountable, addressing gender dimensions of violence against children, and strengthening international commitment. This was the first UN study to widely consult children and young people and, in this way, treat them as subjects with rights (Blanchet-Cohen, 2009).

Various international human rights and children's committees continually encourage the collecting and analysing of data based on adolescents' experiences in areas of safety, risk, and participation in order to "build the capacity of States parties - government, academia [and] civil society" to ensure adolescents' well-being (Banati \& Alexander, 2012, p. 12). Despite ongoing concern and the need for better empirical research, human rights and protection studies regarding children and youth that have been completed since the release of the CRC and UN Report have several shortcomings. In Central American and Caribbean countries, in particular, the research of international organizations has produced only national estimates of violence against children and youth, making it impossible to determine various factors that support or hinder the process of implementing children and youth rights, or to identify the types of protection against different forms of violence at the regional level (Blanchet-Cohen, 2009; Borht et al., 2012; Glendford, 2012).

The success of child protection measures is determined by: laws, policies, and standards; services and service delivery mechanisms; human and fiscal resources and management; communication and advocacy; collaboration and coordination; and evidence and data for decision-making (UNICEF, 2014b). If evidence-based policies that protect children and youth across the regions are to be created, researchers must simultaneously gather comparable national and regional-level data that helps researchers and policy makers to understand the unique factors that support and hinder children's and young people's rights. ECD child protection programs are most successful when they are developed and implemented through a systems approach.

Other limitations to LAC research include lack of consensus on the definition of violence and the fact that 50 percent of studies focus on Mexico and Brazil (Con- 
Evaluation of Centres for the Integral Attention of Children in Dominican Republic (CIANIs) and Local Community Organizations for Child Protection (LCOCP)

treras Bott, Guedes, \& Dartnall, 2010). While prevalence studies have been conducted in Argentina, Bolivia, Chile, Colombia, Ecuador, Peru, Mexico, Costa Rica, and Nicaragua, cross-national comparison is often impossible since the studies do not examine the same things or focus on the same areas (e.g., physical, sexual) and/or age groups (UNICEF, 2009b). For example, the population study by Speizer, Goodwin, Whittle, Clyde, \& Rogers (2008) explored only the prevalence of sexual abuse of children before the age of 15 in three Central American countries (Guatemala, Honduras, and El Salvador). Some Central American and Caribbean countries do not officially register cases of violence and those that do fail to capture prevalence (Arteaga, Mendez, \& Munoz, 2011; Contreras et al., 2010). Reports from Central America and the Caribbean lack thorough comparative analyses and are completed without sufficient time in the field to examine how various actors and the society at large contribute to violence against children and youth (Gonzalez, 2002; USAID, 2005).

The IDB (2013) reports that the rate of child abuse in Latin America is twice as high as the world average; "violence is seen as a key impediment to development, with an estimated 80,000 children dying each year as a result of intra-family violence" (IDB, 2013). This number has also been named by the UN (2007); an estimated 40 million children under the age of 15 in Latin America and the Caribbean experience violence, abuse, or neglect. (ECLAC-UNICEF, 2011; UN, 2007; UNICEF, 2011b). There is also an "increasing body of research which documents the significant effects of stress, abuse, and violence on the life of very young children, and their impacts over a lifetime" (UNICEF, 2006, p.40). The research indicates a strong need for more intensive early childhood education programs.

The important role of the parental environment in promoting, for instance, human capital and success later in life is also discussed to a considerable extent throughout the literature (Vegas \& Santibáñez, 2011; IDB, 2013; Levy \& Schady, 2013; Schady, 2006; Attanasio et al., 2004; Behrman, Cheng, \& Todd 2004; Cunha et al., 2005; Berlinski \& Galiani, 2005). According to Zayas (1992), rates of child maltreatment can be directly related to parents who are younger and less educated, and who have lower salaries and poor living conditions (Whipple 1991; Zolotor and Runyan et al., 2006). Berk (2001) explains that "culturally accepted violence as discipline creates a challenge to child protection programs" (Longman-Mills et al., 2011, p.13). 
Evaluation of Centres for the Integral Attention of Children in Dominican Republic (CIANIs) and Local Community Organizations for Child Protection (LCOCP)

Studies in both Mexico and Colombia, for instance, show a "strong correlation between past and present abuse in terms of intergenerational cycles" (Knaul \& Ramirez, 2005, p.10), which indicates that child rearing is highly influenced by ethnic cultural norms that are passed down through generations. Fontes (2002) explains how many Latino families strive to preserve customs and beliefs, such as traditionally authoritarian parenting styles (Longman-Mills et al., 2011; Moestue \& Mugglah, 2013). Frequent use of corporal punishment often leads to child abuse as the effectiveness of such techniques decreases. The higher the number of disciplinary encounters, the higher the risk of abuse (Fontes, 2002). In order to reduce levels of abuse, the frequency and severity of disciplinary encounters must be reduced. A study by Moestue \& Mugglah (2013) on the prevention of violence among youth in Latin America indicates a need for long-term early childhood education programs and family-oriented interventions in order to combat this cycle. "The challenge now is for countries to adopt best-practice and program models to ensure that all children, especially those marginalised and excluded, not only survive, but thrive" (UNICEF, 2006, p.52). 


\section{Study Design}

\section{Introduction}

his report will examine whether CIANIs and LCOCP are effective in reducing violence against children. Evaluating the effectiveness of these two policy interventions will provide an opportunity to understand the contributions of multiple violence prevention initiatives that are delivered within holistic and integrated environments and that are geared towards a national prevention strategy. Thus, the report has national implications.

The main purpose of our research, then, is to undertake an outcome evaluation of the effectiveness of these interventions. We also conducted a process review/formative evaluation to understand how and why these interventions work. A process review will allow us to better comprehend the actual program activities, processes, relationships, and other delivery and management aspects that define the intervention and contribute to its effectiveness.

Consistent with the empowerment philosophy underlying CIANIs and LCOCPs, our methodology in conducting this evaluation is informed by a participatory and collaborative approach (Cousins \& Whitmore, 1998; Fetterman, 2002; Guba \& Lincoln, 1989; ICPHR, 2013; Papineau \& Kiely, 1996). In line with this approach, we sought extensive and meaningful dialogue and knowledge exchange with all stakeholder groups throughout this evaluation project. This approach ensures 
Evaluation of Centres for the Integral Attention of Children in Dominican Republic (CIANIs) and Local Community Organizations for Child Protection (LCOCP)

that the research design and the data collection tools and methods are culturally sensitive, and also respectful of organizational values and local practices. Our participatory approach helps to ensure that the evaluation tools that we develop will provide a relevant template for ongoing program review and renewal. Consultations with stakeholder groups were undertaken during each phase of the project, and these consultations informed the design of each subsequent phase. All data collection instruments, qualitative and quantitative, were developed in consultation with all partners and with the project's Advisory Group. Each instrument was pilot tested, and respondent feedback was collected and incorporated into the final instruments. Further, knowledge mobilization strategies were developed and delivered in collaboration with local partners. Consequently, all possible efforts were made to maximize the degree of stakeholder input in all aspects of the project. Including the development of the final report, where various multidisciplinary members from six different CIANIs were consulted with to assess the findings and contribute their knowledge, opinions and ideas.

Our study design is a mixed-methods approach, one that combines both qualitative and quantitative methods. ${ }^{1}$ For the process review, the design uses qualitative techniques to conduct semi-structured interviews with various stakeholder groups. For the outcome evaluation, it applies quasi-experimental research logic to survey three distinct groups of respondents, using a standardized questionnaire.

Each part of the study design addressed a specific set of questions. The process review questions are:

\footnotetext{
1 The literature on mixed-methods research is voluminous. See, for instance, Creswell, J. W. (2014). Research design: Qualitative, quantitative, and mixed methods approaches (4 ${ }^{\text {th }} \mathrm{Ed}$.). Sage publications; Tashakkori, A., \& Teddlie, C. (2010). Sage handbook of mixed methods in social \& behavioral research ( $2^{\text {nd }}$ Ed.). Sage; Creswell, J., \& Clark, V. (2011). Designing and conducting mixed methods research $\left(2^{\text {nd }}\right.$ Ed.). Thousand Oaks, Calif.: SAGE; Denzin, N. K. (2010). Moments, mixed methods, and paradigm dialogs. Qualitative inquiry, 419-427; Bergman, M. M. (2010). On concepts and paradigms in mixed methods research. Journal of Mixed Methods Research, 4(3), 171-175; Leech, N. L., \& Onwuegbuzie, A. J. (2009). A typology of mixed methods research designs. Quality \& Quantity, 43(2), 265-275; Morgan, D. L. (2007). Paradigms lost and pragmatism regained. Methodological implications of combining qualitative and quantitative methods. Journal of Mixed Methods Research, 1(1), 48-76; Mertens, D. M. (2010). Transformative mixed methods research. Qualitative Inquiry, 469-474; and Sweetman, D., Badiee, M., \& Creswell, J. W. (2010). Use of the transformative framework in mixed methods studies. Qualitative inquiry. 441-445.
} 
Evaluation of Centres for the Integral Attention of Children in Dominican Republic (CIANIs) and Local Community Organizations for Child Protection (LCOCP)

1. What are the operational mechanisms that link CIANIs and LCOCPs to their outcomes? What are the various roles played by the holistic cluster of service components, the programs' organizational and administrative structures, the forms of engagement pursued, and the nature of stakeholder relationships?

2. How are the CIANI and LCOCP programs experienced by caregivers? Does the nature and intensity of parental engagement in the program contribute to decreasing violence and enhancing children's well-being?

3. How are these programs perceived or recognized within the broader community in relation to community-level indicators of violence prevention?

The outcome evaluation questions are:

1. What are the key indicators (attitudinal, behavioral, and psychological) of violence against children in the family?

2. Are municipalities with CIANIs effective at reducing the rates of violence against children, as compared to municipalities without CIANIs?

3. What are the added contributions of LCOCP in municipalities with both a LCOCP and LCOCP, as compared to municipalities with neither a CIANI nor a LCOCP?

4. What are the specific contributions of the determinants of violence against children within municipalities that have a CIANI and within those that have both a CIANI and a LCOCP?

The next two sections discuss in detail the qualitative methods of the process review and the quantitative methods of the outcome evaluation. Addressing both process questions and outcome questions allowed us to undertake a comprehensive evaluation.

\section{a. Process Review: Qualitative Methods}

The intention of process reviews, also referred to as formative evaluations, is to understand how the program actually works. When combined with an outcome evaluation, a process review provides program-specific information to which the findings of an outcome evaluation can be attributed (Dudley, 2014; Patton, 1998; Rossi \& Freeman, 2004; Weiss, 1998). Common types of questions that inform a process review would include inquiries pertaining to program implementation, such as the services available and the patterns of service use. Process reviews 
Evaluation of Centres for the Integral Attention of Children in Dominican Republic (CIANIs) and Local Community Organizations for Child Protection (LCOCP)

also address staffing relationships, administrative policies, intervention strategies, and service user satisfaction. Process reviews are thus intended to provide data that can be used to enhance and improve programs. As such, process evaluations tend to rely on qualitative research methodologies such as individual interviews and focus groups.

Process reviews are also very useful when outcome data is interpreted, particularly when there are discrepancies in findings across different sites or groups of participants. For example, the qualitative data from the process review provides specific information about the types of services provided, the duration and intensity of the services, and the nature of the relationships established. This qualitative data can thus be useful in interpreting outcome variations or inconsistencies. ${ }^{2}$

Our process review was undertaken with three municipalities: Santo Domingo, Santiago, and Boca Chica. Table 4.1 provides selected characteristics of these municipalities, along with the remaining six municipalities included in this project. Semi-structured interviews and focus groups were conducted with a purposive sample of caregivers, professional and nonprofessional CIANI staff, as well as with key informants and community leaders.

In terms of the specific methodologies used, 11 focus groups with 61 participants reflecting the following distribution of stakeholder groups were conducted: one focus group with CIANI staff, one with key informants/community leaders, and nine with caregivers. A further 110 individual interviews were conducted with the following stakeholders: 41 with CIANI staff, eight with CIANI nonprofessional staff, 10 with key informants/community leaders, and 51 with primary caregivers. A total of 171 participants were interviewed during the process review.

Interviews and focus groups with caregivers were intended to discover the nuanced, detailed, and contextual understanding of valued practices, experiences, and outcomes.

Interviews and focus groups conducted with CIANI personnel included: teachers, teaching assistants, social workers, educational coordinators, psychologists, doctors, nurses, centre directors, kitchen staff, cleaning staff, and security staff.

2 For further examples of the use of process reviews see: Weiss, Carol H. (1998) Evaluation: Methods for Studying Programs \& Policies (2nd Ed.). Upper Saddle River, New Jersey: Prentice-Hall Inc., p. 9. 
Evaluation of Centres for the Integral Attention of Children in Dominican Republic (CIANIs) and Local Community Organizations for Child Protection (LCOCP)

These interviews were intended to provide information on: the values and goals of the program, the operations of the program, staff complement and responsibilities, services and intervention, and approaches to the reduction and prevention of physical discipline.

The group of individuals identified as community leaders/key informants who were also interviewed included LCOCP members and public school teachers. In these interviews, we were able to gather information regarding issues of reputation, ease of transition for children from the CIANI to their local public schools, and overall impressions.

All interviews were conducted in Spanish and later translated into English. A grounded theory approach, supported by the capacity of NVIVO 10 software, was used to reveal themes of significance and valued practices. Grounded theory facilitated an inductive approach to the discovery of conceptually relevant themes, experiences, and contexts of significance (Charmaz, 2006; Glasser \& Strauss, 1967; Strauss \& Corbin, 1994). NVIVO 10 software conducts a line-by- line and sentence-by-sentence analysis. This analysis led to the development of 176 open codes and 44 axial codes, and resulted in the following final themes: contexts of practice, benefits and outcomes, and challenges. The qualitative findings in section five of this report are organized and presented in terms of these three final themes.

As part of a mixed method design, our process review was further used to inform the construction of our two standardized questionnaires, which we used to survey primary caregivers in the outcome evaluation. More specifically, the individual and focus group interviews with caregivers allowed us to understand the dynamics of change that participants attributed to: the nature and intensity of their engagement with the CIANI, the relationships that they valued, and the services that mattered most to them. These understandings allowed us to construct and shape our questionnaires in a relevant and accessible manner.

\section{b. Outcome Evaluation: Quantitative Methods}

We use a quasi-experimental research design and survey research to answer questions four through seven, pertaining to the development of methods to measure violence against children and the effectiveness of the CIANI and LCOCP 
Evaluation of Centres for the Integral Attention of Children in Dominican Republic (CIANIs) and Local Community Organizations for Child Protection (LCOCP)

interventions in reducing violence. Generally speaking, quasi-experiments are structured like experiments except that research subjects are not randomly assigned to treatment (intervention) and control groups. According to the work of Donald Campbell, quasi-experimental research designs are especially appropriate to understanding the impact of social reforms and public policy interventions. ${ }^{3}$

Our design uses three "similar" groups: two Intervention Groups and one Control Group. And recall that our broad purpose is to develop standardized surveys to administer to primary caregivers in each of the three groups. The specification of the three groups is as follows:

1. The first Intervention Group-the CIANI Only Group-consists of survey respondents who live in one of three municipalities that have CIANIs but no LCOCP, and who have at least one child registered in the municipality's CIANI.

2. The second Intervention Group - the CIANI + LCOCP Group-consists of respondents who live in one of three municipalities with both CIANIs and LCOCPs, and who have at least one child enrolled in the municipality's CIANI.

3. The third group, the Control group, has two subgroups. The first subgroup consists of respondents who live in one of the two municipalities that have neither CIANIs nor LCOCPs, and who have at least one child registered in a pre-school or initial education program at their local public school. The second subgroup consists of respondents who live in one municipality that has a CIANI but no LCOCP, who have had no direct contact with that CIANI, and who have at least one child registered in the pre-school program of their local public school. ${ }^{4}$

3 For a comprehensive account of quasi-experimental research see: Shadish, W.R., Cook, T. D., \& Campbell, D. T. (2002). Experimental and quasi-experimental designs for generalized causal inference. Wadsworth Engage learning. See also Campbell's two classic treatments that relate quasi-experimental research design to policy interventions: Campbell, D. T., \& Ross, H. L. (1968). The Connecticut crackdown on speeding: Time-series data in quasi-experimental analysis. Law and Society Review, 33-53, and Campbell, D. T. (1969). Reforms as experiments. American psychologist, 24(4), 409.

4 Our original information was that the municipality of Herrera had neither a CIANI nor an LCOCP. We were later informed that Herrera in fact had a small CIANI. Our survey results showed that none of the respondents in Herrera had any direct contact with the CIANI. In this sense, the Herrera respondents retain the characteristics of a control group in which we would expect neither a CIANI nor an LCOCP effect. 
Evaluation of Centres for the Integral Attention of Children in Dominican Republic (CIANIs) and Local Community Organizations for Child Protection (LCOCP)

Below, we first examine our quasi-experimental logic at the group level of analysis. Then, we move to the individual level of analysis to discuss the design of our survey of primary caregivers in the three groups.

One of the biggest challenges in quasi-experimental research is to find groups that are "equivalent" or, more precisely, "sufficiently similar" to yield meaningful comparisons. The quasi-experimental search for equivalent groups is meant to imitate the function of randomly assigning subjects to control and treatment (intervention) groups, an option that is available in experimental designs, but generally not possible in quasi-experiments that assess real policy initiatives and organizational interventions. Comparing equivalent groups can be understood as "holding constant" plausible rival hypotheses to the explanation of interest, in this case that CIANIs and LCOCPs effectively reduce violence against children and thus contribute to children's well-being.

In our study, the causal logic of equivalent group comparisons can be briefly explained, at least in an ideal-typical way. To the extent that our three groups are "equivalent" on all "other" variables that shape violence against children, any group differences we find could be tentatively attributed to the impact of the two policy interventions under study, the CIANI and LCOCP programs, since these programs are the two major factors that differentiate the three groups. That is, if CIAN/s and LCOCPs work to lower the physical punishment of children in families, we should find the following pattern:

- The use of physical punishment is highest in the Control Group, in which we expect there is neither a CIANI nor an LCOCP effect.

- Compared to the Control Group, the use of physical punishment is lower in the CIANI Only Group, a difference that reflects the impact of the CIANI program.

- The use of physical punishment is lowest in the CIANI + LCOCP Group; this low level reflects both the CIANI effect of the previous group and any added impact of the LCOCP program.

Table 4.1 lists the nine municipalities included in our study, according to their membership in the three quasi-experimental groups. For the CIANI Only Group, a purposive sample of three municipalities with the most established CIANIs was selected from the population of 56 municipalities that had only a CIANI at the time of our study. By "most established," we mean not only those CIANIs that have 
Evaluation of Centres for the Integral Attention of Children in Dominican Republic (CIANIs) and Local Community Organizations for Child Protection (LCOCP)

been in place for a considerable period of time, but also those that demonstrate significant institutional capacity. Since a main focus of the research is the effect of CIANIs on the reduction of violence against children, we concentrate on those CIANIs that are sufficiently established to produce an effect. As Table 4.1 shows, the municipalities and associated CIANIs in the CIANI Only Group are La Romana, Santo Domingo, and Santiago.

\section{Table 4.1: Selected Characteristics of the Municipalities in the Study*}

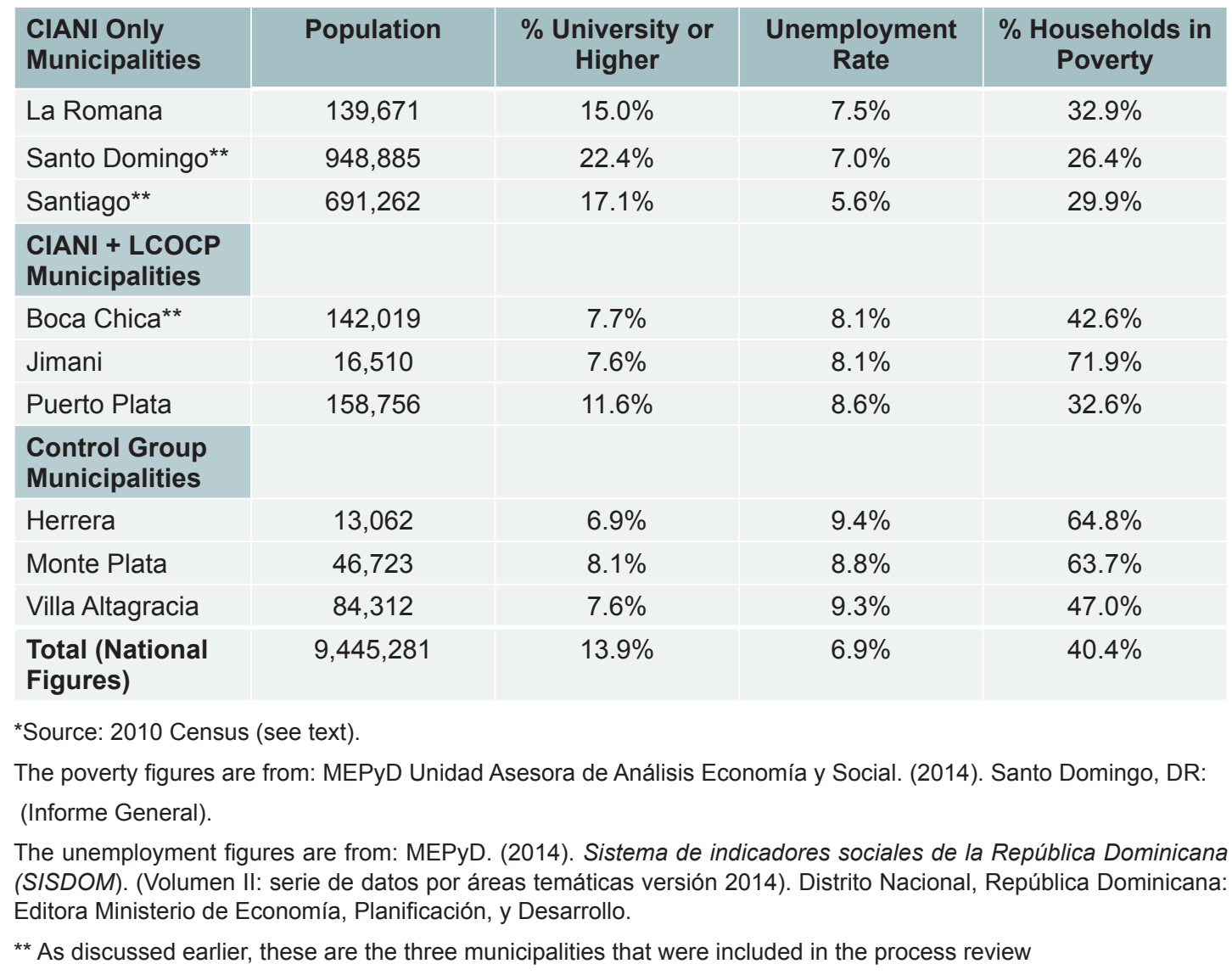

Similarly, for the CIANI + LCOCP Group, a purposive sample of three municipalities with the most established CIANIs was selected from the population of nine municipalities that had both a CIANI and a LCOCP at the time of our study. 
Evaluation of Centres for the Integral Attention of Children in Dominican Republic (CIANIs) and Local Community Organizations for Child Protection (LCOCP)

The three municipalities/CIANIs in this group are Boca Chica, Jimani, and Puerto Plata. The three municipalities in the Control Group are Herrera, Monte Plata and Villa Altagracia. Monte Plata and Villa Altagracia have neither a CIANI nor an LCOCP; Herrera has no LCOCP but does have a small CIANI.

A purposive sample is a nonprobability sample in which units "are selected because they meet criteria that have been predetermined by the researcher as relevant to addressing the research question" (Given, 2008, p. 252). Two criteria were used to determine which municipalities were selected for the study. First, as mentioned above, for the two Intervention Groups, municipalities were selected because they contained the "most established" CIANIs. Second, for all three Groups, municipalities were chosen because they were "similar" on a series of municipal-level socio-economic characteristics.

Table 4.1 also gives some selected characteristics of the nine municipalities in the study, drawn from the 2010 DR census (Banco Central de la República Dominicana, 2012; Oficina Nacional de Estadistica, 2013; Oficina Nacional de Estadistica, 2015). As can be seen, the three groups are made up of municipalities that are only very roughly similar. In particular, the municipalities in the CIANI Only Group are much larger, and have higher levels of education, lower unemployment rates, and lower levels of poverty than do the municipalities in the CIANI + LCOCP Group and the Control Group.

The fact that our three groups are not really "equivalent" is the kind of problem that is common to quasi-experimental research. To reiterate, we could not ensure equivalency ${ }^{5}$ by randomly assigning subjects to the CIANI Only, the CIANI + LCOCP, and the Control Groups, as experimental researchers do. Rather, the three groups were in a sense "defined" prior to our research by the diffusion of the CIANI and LCOCP programs throughout the DR. ${ }^{6}$ Given this important limitation, we selected municipalities to make the three groups as similar as possible. As we discuss below, the nature of our research design does allow us to address the problem of the non-equivalence of our groups.

5 That is, ensure average equivalency. See Cook, T. D., \& Campbell, D. T. (1979). Quasi-experimentation: Design and analysis for field setting. MA: Houghton Mifflin.

6 To be more precise, the separate universes of CIANI Only, CIANI + LCOCP, and Control Groups were defined by the diffusion of the programs. 
Evaluation of Centres for the Integral Attention of Children in Dominican Republic (CIANIs) and Local Community Organizations for Child Protection (LCOCP)

Once the qualitative interviewing was completed, we developed two standardized questionnaires to administer to respondents in the three groups: one for the two Intervention Groups and one for the Control Group. There were many common questions in both versions of the questionnaire, with the Control Group version comprised almost entirely of a subset of questions from the Intervention Group version. The Intervention Group questionnaire was the longer of the two versions because it contained a series of additional questions about the CIANI experience.

In addition to probing respondents' experiences with CIANIs and LCOCP, the questionnaire asked a series of questions about caregivers' social backgrounds and family characteristics, their experiences in the community, and their attitudes and behaviours relating to the physical disciplining of children. The questionnaires are reproduced in Appendix B.

The Intervention Group questionnaire was pre-tested on 29 April and 1 May 2014. As a result of a long debriefing with the Dominican team of interviewers, we made numerous changes to the wording, format, and sequence of questions. The actual interviewing for the study took place from 12 August to 5 September 2014.

In the two Intervention Groups-the CIANI Only Group and CIANI + LCOCP Group-we administered face-to-face surveys to virtually all the primary caregivers who had children registered in their municipality's CIANI. Each CIANI provided a list of registrants to the interviewers, which allowed the interviewers to make the first contact with caregivers at the CIANI, as they dropped off or picked up their children. The field supervisors worked closely with the CIANIs to revise and update the lists in order to ensure that they were an accurate representation of program registrants. While we cannot say with certainty that we interviewed the entire population of CIANI registrants, we can say that we came as close as possible to a survey of the population.

A similar protocol was followed for interviewing primary caregivers in the Control Group. In each of the three Control Group municipalities, a purposive sample of three or four public schools with a pre-school/initial education program was selected for study. The field supervisors and teachers together compiled comprehensive lists of caregivers who had children five years of age or younger in the pre-school program. This age range is equivalent to the age of children enrolled in the CIANIs. Interviewers first contacted caregivers at the school to arrange for an interview, with almost all interviews being conducted in the home. Once again, we came as 
Evaluation of Centres for the Integral Attention of Children in Dominican Republic (CIANIs) and Local Community Organizations for Child Protection (LCOCP)

close as our detailed lists allowed to conducting interviews with all the caregivers enrolled in the program.

Overall, we completed 1,690 interviews in the three Groups. ${ }^{7}$ In the section below on quantitative findings, we provide more detailed information about the survey.

Causal inference is an important component of outcome evaluation. To ask questions about the effectiveness of programs is to ask about the nature of the relationship between cause and effect. If the evaluation question is - are the CIANI and LCOCP programs effective in helping to reduce violence against children? - then the concomitant causal question is - are the CIANI and LCOCP interventions significant determinants of caregivers' disciplinary attitudes and behaviours?

Our research design addresses the question of causal inference in three complementary ways. First, we attempted to make the three groups as similar as possible in relation to a series of municipal-level characteristics, such as education and unemployment. As discussed above, given the limitations of the quasi-experimental research design, we did not attain equivalency among the groups. Still, we can use the overall between-group differences with regard to violence against children as a first approximation of the impact of the CIANI and LCOCP interventions. That is, if we find the expected pattern-that caregivers' use of physical discipline is lower in the CIANI only and the CIANI + LCOCP Groups than it is in the Control Group-we can tentatively conclude that the interventions appear to be working. This pattern is, however, a weak basis for drawing a causal inference about the effectiveness of the programs.

The logic of our design allows a second form of causal inference. Due to the problem of the nonequivalency of groups, quasi-experimental designs do not allow the strength of causal inference that experimental designs allow. To compensate for this limitation of the quasi-experimental design, we can supplement the weak causal inferences drawn from our first approximation described above with the kind of causal inferences that our survey of 1,690 primary caregivers allows. With our survey data, we can statistically control for numerous variables to isolate the independent impact of CIANIs and LCOCPs in the reduction of the physical punishment of children. In effect, statistical controls address the problem of the nonequivalency of our quasi-experimental groups.

7 Ten primary caregivers started but did not complete the questionnaire. 
Evaluation of Centres for the Integral Attention of Children in Dominican Republic (CIANIs) and Local Community Organizations for Child Protection (LCOCP)

The mixed-methods component of our study design, which combines qualitative and quantitative modes of inquiry, gives us the opportunity to probe a third, additional element of causality. The literature on causal inference is devoting increasing attention to the importance of causal mechanisms (Gerring, 2005; Maxwell, 2004; Mahoney, 2001). That literature suggests that qualitative research is especially well-placed to examine the operation of causal mechanisms. As opposed to the "effects of causes" approach taken by experimental, quasi-experimental, and survey designs, causal mechanisms focus on understanding the "causes of effects." That is, causal mechanisms seek to answer "how" and "why" questions about the relationship between cause and effect. These mechanisms seek to go beyond the finding of a robust correlation or statistically significant relationship to uncover the mechanisms and sequences that link cause to effect. In this study, our qualitative approach will try to elucidate how and why CIANIs and LCOCPs may lead to the intended effects of decreasing violence and enhancing the well-being of children. What is the mechanism linking the CIANI/LCOCP to these outcomes? What role does the nature and intensity of parental engagement play? How important are the kinds of relationships that develop among program staff, caregivers, and children? Is the holistic structure of organizations crucial?

The next two sections of the report examine the qualitative findings of the process review and the quantitative survey findings of the outcome evaluation.

8 On the difference between "effects of causes" and "causes of effects," see Mahoney, J., \& Goertz, G. (2006). A tale of two cultures: Contrasting quantitative and qualitative research. Political Analysis, 14(3), 227-249. 


\section{Qualitative Findings}

$\mathrm{n}$ this part of the report, we present the qualitative findings of the individual and focus group interviews that were conducted with CIANI staff, caregivers, community leaders, and representatives of the LCOCPs. These interviews address the process/formative review of the CIANI and allow us to understand the "lived experiences" of those working in the CIANI and those with children/grandchildren in the CIANI. More specifically, the objectives informing this process/formative review are:

1. To determine the operational mechanisms that link CIANIs/LCOCPs to their outcomes, by reviewing the holistic cluster of service components delivered, the forms of engagement pursued, the nature of stakeholder relationships, and their organizational and administrative structures.

2. To understand how these programs are experienced by caregivers and how the nature and intensity of parental engagement contribute to decreasing violence and enhancing children's well-being.

3. To understand how these programs are perceived or recognized within the broader community.

As described in Section 4, a total of 110 individual interviews were conducted with the following stakeholder groups: 51 with caregivers, 41 with CIANI staff, eight 
Evaluation of Centres for the Integral Attention of Children in Dominican Republic (CIANIs) and Local Community Organizations for Child Protection (LCOCP)

with CIANI nonprofessional staff, and 10 with key informants/community leaders. In addition, 11 focus groups were conducted with a total of 61 participants; the groups were organized as follows: one focus group with CIANI staff, one focus group with key informants/community leaders, and nine focus groups with caregivers. Thus a total of 171 participants contributed to the qualitative findings that we present in this part of the report.

Narrative-based interviewing allowed participants to tell us about the significance they attributed to the CIANI, the intensity of their engagement with the CIANI, the impact of this engagement, and the role that it plays in their lives and in the lives of their communities. In selecting the sample of narratives for this report, we endeavored to include narratives that reflected the diversity of the stakeholder groups as well as the common themes that emerged in the qualitative analysis. In Part A of this chapter, we present the narratives that describe the context of the $\mathrm{CIANI}$, the nature of the relationships that are established, and the strategies for engaging families, including the role of the "Parent School." In Part B, we present the benefits that are attributed to involvement with the CIANI, including benefits related to children's development, as well as benefits related to parental stress, child discipline, and their narratives of change. In Part $\mathrm{C}$, we outline the challenges facing CIANIs that respondents identified.

\section{a. Part A: Context, Staff Relationships, and Engagement Strategies}

\section{i. Context}

(a) Positon in Community

Our first set of narratives reveal the manner and ways CIANIs are regarded within their communities.

People want to have their children here. It really is a good service that they offer. (Community Leader)

It is fundamental service they are giving the community. (Mother)

In many ways, the Centre is practically a treasure for those that are called 
Evaluation of Centres for the Integral Attention of Children in Dominican Republic (CIANIs) and Local Community Organizations for Child Protection (LCOCP)

[admitted], because therein lies the problem, it facilitates, like it's a comprehensive care that we provide to the community. (CIANI Director)

People want to have their children here. It really is a good service that they offer. (Community Leader)

Super good, everyone wants their children here. (Focus Group Parent)

We provide what the community needs. If we did not have such a good service and quality of the service too, people would not demand it. (CIANI Educational Coordinator)

Provides children and parents and all the community a service that is like no other. (CIANI Teacher)

These narratives reflect the very high regard and respect attributed to the CIANIs. Respondents describe CIANIs as a service for both enrolled families and the broader community. These narratives suggest that this service is highly valued by all families, including those that are selected and those that are not enrolled.

The narratives further reflect the extensive vulnerability of the families and children within the CIANI communities. Respondents spoke of the depths of poverty, unemployment, parents' lack of education, inadequate housing, unmet basic needs, and situations of abuse. Respondents also spoke of the ways in which the CIANI contributes to lessening some of these vulnerabilities and ensuring the safety of the children.

The main objective of CIANI is to take care of the boys and girls with little resources, to give them an integral education, it could be psychological, because we are in an environment in which the system is very vulnerable, for education, you know that, the majority of children, they come from parents who don't receive education. (CIANI Educational Coordinator)

... taking in the children who are most vulnerable. (CIANI nurse)

You know a lot of poor families ... the majority of the parents that are here cannot pay for a private school, here they do not charge a single penny and 
Evaluation of Centres for the Integral Attention of Children in Dominican Republic (CIANIs) and Local Community Organizations for Child Protection (LCOCP)

here from one year to five years we take care of them, without them bringing any resources. (CIANI Assistant Teacher)

I needed it. I am a poor woman, my son when he works helps me out and gives me money, there is no one working at home, so I wanted to be put on the list, for her to be here. (Grandmother)

With this economy it has really helped us. (Grandmother)

The children who are here are the ones who need the service, that same woman I told you about. When I went to visit her, I was feeling bad because of the condition, going in a latrine outside. With that small girl in that room, in a house made of wood with no floor. Just one bed and nothing else, and she and her husband and child all sleep on it. Now as things are, it is a difficult situation, they are living somewhere else, and their condition is a little better than it was before. You can see the difference, and although they are not living in an ideal situation for any family, compared to what it was, they are doing better, it is more stable for the girl. Before she would go to the alley, into a ditch or hole. At least here the house is under construction but I do not see any hole close by. (CIANI Social worker)

Here we have children who need so much more than other families. Children who live with grandparents who cannot properly care for them. They cannot even take care of themselves. Unfortunately, and it is sad to say, but the girls these days have children so young and leave them with the grandparents. (CIANI Educational Coordinator)

They worry about the children who are wandering the streets, they concern themselves with that. (Public School Teacher)

Yes, of course, those children because there is vulnerability because of the way that they have been brought up. With the mistreatment if the mother leaves them alone, or with smaller children so we - well there is all kinds of abuse, not just hitting. So those with any sort of mistreatment, we go and rescue them. (CIANI Social Worker)

Many of them are abused, they are not respected, because when a child, a mother or father speaks to him in an inappropriate tone, when a parent does something inappropriate in front of the boy or girl, it's already disrespecting 
Evaluation of Centres for the Integral Attention of Children in Dominican Republic (CIANIs) and Local Community Organizations for Child Protection (LCOCP)

their rights, and the majority of boys and girls live with parents who have substance abuse problems, who physically abuse each other in front of the children, verbally as well. The majority, not physically, they don't come with physical abuse, but theirs is emotional, emotional abuse when a child sees a father hit a mother and that is confusing their mind, that in reality here we tell them that you shouldn't hit another person because it is abuse. Then they are at home and the people they have as leaders are doing it. (CIANI Educational Coordinator)

(b) Narratives Describing the Staff

Our interviews included extensive narratives related to the CIANI staff. We begin with the narratives about how the caregivers describe the staff.

Respect

They are very respectful. (Parent Focus Group)

Friendly

Very good, very good they are all good, very friendly. (Mother)

... they are all very friendly and treat everyone good. (Mother)

They are very friendly, very educated I cannot say one bad thing about them. (Mother)

Very well, they are very friendly, they are very good. (Mother)

Trust

Trust? I feel that they should receive badges, merits, each one. (Mother)

Yes, I feel that I can trust them. (Mother)

Yes, one hundred percent. (Mother)

Completely. (Grandmother) 
Evaluation of Centres for the Integral Attention of Children in Dominican Republic (CIANIs) and Local Community Organizations for Child Protection (LCOCP)

I feel trust like family, as I would have left him with my mother, which was who cared for him before. (Mother)

Professional

They are very educated. (Parent Focus Group)

Good. In my neighbourhood, clean, hygienic, very responsible, the staff here is very prepared and take good care of the children. (Parent Focus Group)

A highly trained staff, very dedicated. (Mother)

Well, the staff I would say the people directing it, they are aware, prepared, very professional in all they do and they try and do the best for the children's education. So the children feel good. (Mother)

Clearly, the staff create an environment of service that is highly valued by the parents. It is an environment that is described as respectful, professional, trusting, and friendly.

(c) The Interdisciplinary Team

The staff members describe their relationships within the interdisciplinary team in a manner that is consistent with the characteristics that the caregivers attribute to them. These narratives speak to the collegiality, mutual support, respect, and effectiveness of working together as an interdisciplinary team.

In this unit we need to work together, not only in technical team meetings but in personal meetings we have together. Where everyone can express themselves freely, without being afraid of anyone. Because there are times that you want to say something but you feel restrained, you say: "no, no, no I will not say anything because maybe they will take it wrong and hit me," but here that is not the case. Here we discuss problems of all kinds. (CIANI Director)

The working team is excellent, the director is someone who is well prepared with a lot of knowledge, and we are always growing and learning. That is another thing we are grateful to the CIANI for, the CONANI's which worry about that part need to deal with maintaining this feedback in a constant manner 
Evaluation of Centres for the Integral Attention of Children in Dominican Republic (CIANIs) and Local Community Organizations for Child Protection (LCOCP)

that keeps that happening here. So each and every one of us is doing a job, but when we are a team, we guarantee that the education, the training, that integration reaches the children as well as the parents. We give the parents education and training too. (CIANI Psychologist)

Up until this point, I have had no problems with anyone, at least no one has said anything to me. I feel like I have a good relationship with the teachers and psychologists. We work jointly, the psychologist and me. If she needs me to do a home visit I do it, I write down everything that I observe so that when the parents come for a meeting with her, she has a more or less good idea of what is happening. (CIANI Social Worker)

We always try to get along well. If I need something, someone will help me, if someone else needs something, I will help them. We are always communicating to see if anyone needs anything. (CIANI Teacher)

It is phenomenal, in that sense I feel very good. I feel that they are very good people, those women. They are very cooperative, the teachers when I need to, for example, I am alone as the nurse here, there used to be two of us, but now it is just me. So when the children come to be weighed and measured it can be a lot for me alone, but it is easier because they are really cooperative. (CIANI Nurse)

Here we are not so segregated, that is psychology, that is social work. It is not like that. For example, I am not too good with writing; the coordinator will help me out. We are like a family, and if something affects one it affects us all. (CIANI Social Worker)

Well, up until this point I get along well with them, I try. I always say my colleagues are more like family because, as I said, if you need anything you can always go there. There should always be companionship and harmony with coworkers - that is how I like to work. (CIANI Teacher)

My work relationships, well thank God, up until this point good. When I first started here, that was one of the things that I most liked and noticed, how the treatment there is between everyone. I mean there are always issues with different characters, personalities, opinions, but the issues are always quickly and successfully dealt with. (CIANI Psychologist) 
Evaluation of Centres for the Integral Attention of Children in Dominican Republic (CIANIs) and Local Community Organizations for Child Protection (LCOCP)

Up until now it is good, we generally do everything in a coordinated manner, and we always support each other. Even though I am the psychologist, let's say if tomorrow a teacher is not here or something happens to them, if I have to go to the classroom while it gets sorted out, I would go. (CIANI Psychologist)

We are like a family and if something affects one, it affects us all. (CIANI Social Worker)

United, all of us working and looking after anyone who comes looking for assistance. Here we have a team where everyone gets together to analyze how we should do things, and we listen to everybody's opinions, all the staff and from there we make the decisions. (CIANI Director)

Consequently, as revealed by these narratives, the CIANI staff have successfully established an environment of service that is respected by the families, the staff, and the broader community. The CIANI is held in high regard by all those who participated in this evaluation. Within this environment, key relationships are established and fostered among the staff, the caregivers, and the children.

\section{ii. Relationships}

(a) Staff Relationships with the Caregivers

A key aspect attributed to the success of the CIANI is the capacity of the staff to create engaging and effective relationships with the caregivers and the children. We present below narratives that describe the relationship between the staff and the caregivers.

\section{Respectful}

They respect me and I respect them, they are good. They know what they are doing. (Mother)

Very good. I belong to the parents association, and if you ask anyone in here they would tell you the same. Very good relationships with the staff. Yes, they are very respectful because when I arrive they greet me with deference: 
Evaluation of Centres for the Integral Attention of Children in Dominican Republic (CIANIs) and Local Community Organizations for Child Protection (LCOCP)

“Hello, Doña Ramona.” (Grandmother)

I have good relations with them. The times that I have been here they treat me with cordiality. Yes, they are respectful. (Mother)

The staff here, well it is like a family interaction, no one feels like a stranger. (Mother)

Excellent, whatever concerns I tell them, that's fine, there is never... I always try to get along well with people, more with the people who are helping me with my girl, I cannot say disrespectful things, not on my part nor on theirs, I have no complaints. (Mother)

\section{Collaborative}

Well the parent relationships are good because we always have open doors and have let them know that this centre is for them, and the service is for them. (CIANI Social Worker)

They are successful because every time the parents are invited, there is a relationship between the teacher and the parent, so when the child sees the relationship, they feel more trusting, so those are the positive parts of relating and those moments. (CIANI Teacher)

Good, because I try to from the beginning when the children come we meet with the parents and discuss norms. I always try and make it a good relationship. I tell the parents your child will be spending 9-10 hours with us so we need to have a relationship. So when you come in the morning you need to say good morning. And we are polite to them too. (CIANI Teacher)

They treat me very good; I help in the kitchen sometimes. (Mother)

The staff is always looking for the children's welfare, then accompanied with the welfare that the parents always wanted to be combines and merges very well. (Focus Group Parent) 
Evaluation of Centres for the Integral Attention of Children in Dominican Republic (CIANIs) and Local Community Organizations for Child Protection (LCOCP)

Supportive

If I need help with anything, I can ask them and they are there for me. (Mother)

The staff, I would never change it. That staff from here, good, good, good, because they treat you with respect, they give you confidence, and they give you the space for you to de-stress, many times one comes here with problems and, if the psychologist is not there, she is in social work, if [the Director] is not there, there is always a shoulder to cry on. (Mother)

They have always treated me very well, if she is sick or anything they help me. One day, she was bit by a dog in the street and they helped me. They sent me to different places and they gave her a lot of vaccines, they took good care of me. (Mother)

Up until now, in my opinion they are all excellent, all of them. I have no complaints about them. (Grandmother)

Excellent, excellent, I would not change them for anything. I am always here and I see. I always ask if they need anything. (Mother)

These narratives clearly demonstrate that the relationship between the staff and the caregivers is exceedingly positive, in the sense that it is respectful, collaborative, and supportive. Parents can count on the staff being there for them, promoting a sense of confidence and empowerment. The relationship is grounded in a sense of mutuality, as this mutuality relates to their concerns for the care and well-being of the children. We now turn to the staff's relationships with the children.

(b) Staff Relationships with the Children

The nature of the relationship between the staff and the children is critical to the successful development and well-being of the children. As we see in the following narratives, this relationship is described by caregivers in a manner that captures the care, compassion, and dedication that permeates relationships at the CIANI. 
Evaluation of Centres for the Integral Attention of Children in Dominican Republic (CIANIs) and Local Community Organizations for Child Protection (LCOCP)

\section{Trusting}

Left my child safely, I'm calm with him in their care, I feel trust like family, as I would have left him with my mother, which was who cared for him before. (Mother)

It is not a tense atmosphere, the people come here with confidence they leave the children with confidence and trust you see it. (CIANI Priest)

\section{Loving and Dedicated}

They treat the children well, they are dedicated to them, and they show them love and attention. (Mother)

I liked the dedication that they have to the children. (Mother)

The staff is always looking for the children's welfare, then accompanied with the welfare that the parents always wanted to be combines and merges very well. (Focus Group Parent)

I have seen a lot of the teachers, without them noticing that I am watching them, I have seen them giving so much love, giving them kisses, "don't fight," putting their shoes on for them when they take them off, and I have noticed that and I think that is good. The affection that they give the children, I would not change that. I think that matters for real. So much love they give the children. (Mother)

Very good, she sees the secretary she treats her with care, everyone, I believe that even the cleaning lady gives her love. (Mother)

She is not shy. She likes to talk and sing, she is always doing things like bringing the tias flowers. And you know that is because they treat her well and she feels loved. Even at home when she is misbehaving I tell her I will tell tia Maria, and she will calm down. (Grandmother)

They are very affectionate. (Mother)

The children are attached to her [Director] leg. (Mother) 
Evaluation of Centres for the Integral Attention of Children in Dominican Republic (CIANIs) and Local Community Organizations for Child Protection (LCOCP)

\section{Safety and Security}

I saw the security that is there, the love and dedication to the children. (Mother)

She [daughter] knows all the employees at the center and they know her too. As soon as she gets there, they hug her they treat her very well. (Mother)

\section{Caring and Attentive}

Lots, lots of attention, they take care of the children, they are outstanding to the children, and something very important: they give love. (Mother)

The centre is not their home, but they treat the children as if they were home. It's very important. (Mother)

The tias take good care of them. As if they were their kids. Sometimes they care about my grandchildren better than me. (Grandmother)

All the staff have been the absolute best with all the children here, because I see it I always come. I come most often to pick the girl up more often than her father, and they treat her very well. (Grandmother)

I thank God that CONANI exists; here they treat the children better than in your own home. (Parent Focus Group)

The women here are excellent with the children. I always come and I have seen the children crying and I have seen how they go and carry the children like they were their own children and attend to them, and, if they need to call the parents for them to come if the child does not want to stop crying, they look to comfort them. (Parent Focus Group)

At first I was afraid they would mistreat her, but after I went picking her up and I realized how well they treat them, very good teachers, anyway, the truth is, excellent treatment. (Mother)

And when they [children] are sick and cannot attend to school, they cry because they want to go to the centre. (Focus Group Parent) 
Evaluation of Centres for the Integral Attention of Children in Dominican Republic (CIANIs) and Local Community Organizations for Child Protection (LCOCP)

In these narratives, caregivers tell us of the depth of affection, dedication, attention, trust, and security that is engendered by the staff in their relationships with the children. The caregivers speak of the bond between their children and the "tias," with some caregivers suggesting that this bond might be similar or perhaps stronger than the bond between caregiver and child. Caregivers further describe the CIANI in terms of creating a sense of "home" for the children, one that is safe and infused with love.

\section{iii. Practice Strategies for Engaging Families}

\section{(a) Service Environment}

In our interviews, a number of practice strategies were identified that create an engaging and effective environment of service.

\section{Welcoming practices}

I was made very welcome, they came to my house to visit me, and I felt great because also when you come here, one parent feels that the teachers, the teachers, including the principal, who welcomes one well, you feel confident here, they are very sociable with parents, everyone. (Father)

They are always doing innovative things here. The children do not miss the parents or cry. The centre is always looking for something to do. They dress up and are always doing things to make the child feel good and not be missing and crying. They really work to make the child happy, they sing and yeah. (Mother)

Well the parent relationships are good because we always have open doors and have let them know that this centre is for them, and the service is for them. (CIANI Social Worker)

\section{Caring Practices}

Yes, in all of them. Yes, the nurse came to my home. I was sick and couldn't bring the children, and I had high fever and could not take the phone. They were calling me, and then the nurse came. (Grandmother) 
Evaluation of Centres for the Integral Attention of Children in Dominican Republic (CIANIs) and Local Community Organizations for Child Protection (LCOCP)

The teacher sent me a letter congratulating me for my kid. I'm very grateful to this centre. (Focus Group Parent)

\section{Availability}

Yes the psychologist is always available, the nurse, the director is always around. (Mother)

If I see that I cannot deal with the child what I do is to call [the Director] and tell her to put me with the psychologist and make an appointment and tell her, "the child is behaving like this and I do not know how to deal with her." She treats her and tells me how I should treat her at home. (Mother)

\section{Communicating and meeting}

Whenever I have called them over for meetings regarding a child it is very few the percent that do not come. I work with them, develop strategies to work with the child and things like that. (CIANI Psychologist)

Yes because, as I said, we do the follow-up and maintain communication with the parents, we are close so we notice any little thing. (CIANI Social Worker)

We have parent meetings and there I give different presentations. I also do some outside the meetings because some cannot make it to all the meetings. I deal with topics that I know will benefit them, that they are struggling with. I ask them how things are going in their family, if they are having a hard time with work. Sometimes there are some that earn their part, and there is a frustration that they are no longer working, and that can be passed on to their children. In those meetings, I start seeing that, in the parent school you also get to know them. The psychologist also gets together with them, in the couples one, I call them on the telephone and they call me back when I do not reach them, asking if it is something serious, and I tell them no, I just wanted to discuss this or that with you, and that is how we connect. (CIANI Social Worker)

We do monthly meetings at what is called the parent school. But we take the opportunity to invite them daily for their work, their participation to meet with them. As I mentioned, if there is a specific issue, and we need a per- 
Evaluation of Centres for the Integral Attention of Children in Dominican Republic (CIANIs) and Local Community Organizations for Child Protection (LCOCP)

sonal meeting, we will arrange it. If not, whenever the circumstance allows it. (CIANI Director)

Well, one of the challenges is trying to involve the family, make them aware so that they can support us. Because we cannot do it alone it needs to be done together. So a challenge of ours is the integration of the family to the centre. (CIANI Psychology)

We work on a personal level, what is the situation of that couple? Sometimes the husbands come. Sometimes they do not come because they think meeting with a psychologist is for crazy people. You have to work on that with them, the idea that not just people with mental health illnesses see a psychologist. That it is to help the family, so that they pass that on to their children who are coming here. It is a test of patience, because there are some parents who come and say "How much longer?" "How long does this go until?" and you have to tell them, no, dear, it has barely begun, but remember that this is for your child's development, and also yours, and she will say "Yes, but you talk too much," and then you have to be make them see that this is something good for them, and not just a benefit for them, but on a social level. (CIANI Social Worker)

Because when you talk with a parent regarding behaviour, be it positive or not so positive, with their child and then you see the change, then you know they have learned. If you tell the parents, for example, that they need to wake up earlier so that the child can be at school on time, and the next day the child is there on time, well, then they have learned. When you tell them, please help with this, maybe posture, and the child comes with good posture, then the parent has made that effort and you can see it. Bit by bit, but it is so worth it. (CIANI Educational Coordinator)

These narratives suggest an environment that is welcoming and caring. Staff members are readily available and create a sense of familiarity, inclusion, and belonging. Respondents spoke of the importance of building communication between the staff and the caregivers, and also of the many ways in which communication is facilitated. There are daily informal encounters, private meetings with staff and caregivers, and monthly meetings of the Parent School (discussed below). Issues or difficulties that families experience can thus be addressed in multiple ways. Open and frequent communication leads to the development of a partnership between 
Evaluation of Centres for the Integral Attention of Children in Dominican Republic (CIANIs) and Local Community Organizations for Child Protection (LCOCP)

the staff and the caregivers in relation to achieving the healthy development and well-being of the children. Consequently, deep engagement is a central practice strategy of the CIANI service model.

\section{(b) Practices for Suspected Child Maltreatment}

CIANIs play an important role in the detection of violence against children and within families. Staff identified existing protocols for detecting any possible signs of maltreatment. When suspected, the initial strategy is to work closely with the caregivers to stop this behaviour. However, CIANIs are also willing to involve the LCOCP and outside officials when necessary. These narratives further reflect their concern with emotional as well as physical abuse.

The following narratives describe some of their practices when maltreatment is suspected.

Yes, there is a protocol for suspected child abuse. If the child comes, let's say with a mark - well then we ask how that happened. The child will say, and, if they come more than one time, then we call the parents, have a meeting - with the psychologist. (CIANI Social Worker)

The teacher, who is the first to begin to detect, talks to the coordinator, and the coordinator makes a report for the psychologist, and the psychologist moves to observe, then when he sees the teacher, whenever he does something, he'll always make annotations in the book of everything that happens in the day, then he sent for the family. (CIANI Director)

There are parents who hit them, and you know those parents need to be guided even on how to raise their children. We have brought them and cited them, precisely we do more or less 15 days or more. We had to cite a mother, and they came and told us - it was the head of the community - the president of the Neighbourhood LCOCP, she came and sat down and said: I need to talk about something with you, ok tell me, ok but, come, I do not want you to tell anyone that I came. No, there were no immediate problems she said, and that mother went, and if you want to talk to the child, so we immediately went to the child and conversed. The child she had was four years old or five, hurt by the belt, by the strappings that .... severely marked, yes, and we spoke with her, and we let her know that it was not ok, and that the next time we would denounce her 
Evaluation of Centres for the Integral Attention of Children in Dominican Republic (CIANIs) and Local Community Organizations for Child Protection (LCOCP)

to the provincial office that we have there, and that she could be charged and that it would be the last time she would do that. We try first to ensure that it does not happen again, and we try here like a family to do the follow-up. We do not take all cases, the ones we can resolve with our psychologist, we resolve here before taking them somewhere else. (CIANI Director)

In every aspect, many of the children who are abused are withdrawn. They withdraw from school, they are fearful; you see them always like that. Hunched over, they do not interact with the others. When you go to say something, they pull back, you can see what a huge impact it has on them. (CIANI Social Worker)

Of course, we have been successful, because, if you take action, if you communicate with the authorities, they do what they have to and the parents are going to have to restrain themselves, they say, no, you cannot abuse your child, you cannot send them to wherever to do whatever, no you cannot put them to work. (CIANI Teacher)

We get together with them and tell them that things cannot continue like that. (Mother)

CIANIs further engage in a number of preventive strategies through their Parent Schools, which are discussed below.

\section{(c) The Parent School}

As described earlier in the report, the Parent School is a central strategy for caregiver engagement and education. Staff members describe the purpose of the Parent School in the following manner:

Well the purpose of the parent school is for the children to have better parents, better families than when they come in. Better families and, for the child, if before coming here were mistreated, for them to no longer be mistreated. (CIANI Social Worker)

The purpose is to make the families intelligent, that the families educate their children. (CIANI Psychologist)

To empower the parents to know. (CIANI Psychologist) 
Evaluation of Centres for the Integral Attention of Children in Dominican Republic (CIANIs) and Local Community Organizations for Child Protection (LCOCP)

These narratives speak to the significance of caregiver education as a strategy that promotes children's and families' well-being. In fact, reference to this engagement strategy as a "School" for caregivers clearly reflects the importance attributed to educating caregivers.

The Parent School is structured in a manner that includes educational events and presentations, informal opportunities for caregivers to share concerns and learn from each other, as well as a social space that encourages caregivers to get to know each other. Presentations and events are also open to members of the community, and this practice indicates that outreach and inclusion strategies extend beyond the families of the CIANI.

The parent school is to train the parents in the functioning of the center. Also depending on the necessity that there is, we have different presentations, such as the family experience, on child abuse - it depends on the needs at that moment. (CIANI Psychologist)

Right when we get there, they have their activities, games, to entertain us. Then when they begin talking about how we need to treat our children, about how we at home need to be so with the children, they talk to us about everything. Not just for the children, but also for us parents. (Mother)

The psychologist works directly with the parent school, and I help and assist her there. (CIANI Social Worker)

The parent's school, the class is open, if one as a parent cannot come, one has the right to send a tutor, a relative, a cousin, someone who takes care of the child, someone you can trust. Also you have the right to invite someone from the community. (Mother)

They cover different topics. They have pamphlets. They work with the families. They socialize there too. (Public School Teachers)

Even about mammograms, our bodies. They give us presentations about health, about... in reality they give us knowledge. This is a center that is caring for our children, there are presentations for parents, and I am truly amazed. On nutrition, so they are not overweight, to keep them fit; they give different ones. On the founding fathers, when there is a holiday. In these 
Evaluation of Centres for the Integral Attention of Children in Dominican Republic (CIANIs) and Local Community Organizations for Child Protection (LCOCP)

days, they teach us as if we are the children, things we may have forgotten because many people forget. (Grandmother)

The parents get invited to talks, that they like them, invited to courses, courses for the parents. For them to be speakers too, when they go to those neighbourhoods of whatever they learn here, that is part of this too. (Focus Group Parent)

Part of it is to orient them to the different areas and different themes. For example, like I said, the maternal and child, teen pregnancy, violence, that one is given more than once a year. We do not wait for the violence against women day, but it also depends on what issue is on the table. The one against violence, the AIDS one, and, like that, we do the programming for the parents at the school and also with the Parent Committee. The parents learn many things. (CIANI Nurse)

The purpose is to prepare parents in regards to different issues related to families. For example, communicable diseases, the relationships between couples, relationships with children, relationships with community. Many topics, children's rights, child abuse, so many. (CIANI Educational Coordinator)

\begin{abstract}
A broad range of topics and themes are presented at the Parent School. These include health, nutrition, relationships, children's rights, national holidays, community resources, and many other topics. In addition to the various topics, caregivers also indicate that they value the opportunity to get together, to share their experiences, and to support each other.
\end{abstract}

The parents here have the opportunity to bring up issues that concern us, and that way we learn with each other, share with each other, and positive things come from that. Since there is a parent school, we (parents) can share like a family. We know each other and everything like that. We went there, hear each other, it's neat, good. (Focus Group Parent)

Us parents talk about our children, meet each other, discuss any anxieties we may have, we vent, and they tell us things we need to improve in order to be better people and parents to our children. (Mother)

They give us a lot of advice that really helps us, the couple. You know? The 
Evaluation of Centres for the Integral Attention of Children in Dominican Republic (CIANIs) and Local Community Organizations for Child Protection (LCOCP)

advice is sometimes things I have not heard before, and I learn it from there. (Mother)

... they speak, for example, of self-esteem, received a makeup workshop, received a workshop of violence with a guest they had, we received workshops with the psychologist. I mean that each date they have a specific topic. (Mother)

Education that supports good parenting practices is a central theme of the Parent School. Topics within this theme focus on effective and nurturing parenting practices that promote strong parent-child relationships and healthy child development and well-being. Caregivers also see this area as an opportunity for their own self-development and growth. Thus, education around parenting practices is an important strategy for the prevention of child maltreatment. This was a major theme in the narratives describing the activities of the Parent School. We start with the narratives of the CIANI Psychologists, who work with the Parent School, as they describe their focus on the treatment of children.

Well, here they always have the parent meetings, and the parents are oriented on the treatment of the children, discipline, and the behaviour that needs to take place between parent and child. (CIANI Psychologist)

Well, in the parent school there are different themes. Now, the last time we talked about the prevention of child abuse, and we give them work so they prepare - I mean it is not just us talking to them, but we also have them come up and present, and that is something so they can see and be a part of. (CIANI Psychology)

What we always try to do is work on how parents should manage their children, treat them, deal with them, act in front of them so that they can learn to behave from it. (CIANI Psychologist)

These narratives reveal the importance of offering information, supporting caregivers in modelling appropriate behaviour, and engaging caregivers in the delivery of this information. These approaches comprise the key strategies used by the staff in promoting positive parenting.

Parents, in their narratives, elaborate on some of the learnings that they value. 
Evaluation of Centres for the Integral Attention of Children in Dominican Republic (CIANIs) and Local Community Organizations for Child Protection (LCOCP)

In the caregiver school, they give presentations. How to treat your child, how the indifference with your child, for those with various children, you cannot be indifferent with one and not with the other. They also talk about and explain what it means to be a good father, and a father that is good. The difference, as well as other things, like how to treat your child at home, not to fight with your partner in front of your child, a lot of things. (Parent)

They explain to us how we should treat our children, how we should act in front of them to ensure that they are learning good things from us. (Mother)

You know, they have had people coming from the capital, and they gave a really good presentation on how to treat the children. Not to abuse them, if you are going to the supermarket tell them not to touch things because you do not have money, how to manage the child. Those are things that people with parents should hear so that they do not abuse the children. (Mother)

For me, the experiences are good because they educate me and teach me how to deal with my child, correct him in a manner that is positive if I have a negative way. I learn a lot of things you never knew, even terms and names and things. (Mother)

Everything is useful because the conversations that take place there help the parents to learn how they should correct their children. And they learn what abuse is and what is not abuse, they acquire experience, so there are parents who talk about experiences, and they are lived experiences about good treatment, and so you can see with whom you should leave your child, whom you should trust. You also are guided in the moment to look for who can pick them up and who cannot, everything is useful. (Grandmother)

They provide you with a lot of things that are useful because there are a lot of things you think you know, but you really don't. (Mother)

... how to behave in front of your children, because sometimes you talk about inappropriate things that should not be talked about in front of children. (Mother) 
Evaluation of Centres for the Integral Attention of Children in Dominican Republic (CIANIs) and Local Community Organizations for Child Protection (LCOCP)

In the meetings, the nurse tells us to bathe the children, to dress them well. Some children come here dirty. The nurse always insists in that. (Grandmother)

They tell you that you have to give them love, and to talk to them with love. (Focus Group Mother)

I am a first time mom, and there are a lot of things that they teach you. How to discipline them without hitting them or yelling at them. Sometimes they want something, and you just have to distract them so they forget about what they wanted. (Focus Group Mother)

As these narratives reveal, caregivers clearly articulate what they learned about how to treat children as a result of their engagement with the Parent School. Caregivers identify the significance of understanding what constitutes abuse, how to manage children's behaviour in the home and in public spaces, the importance of modelling appropriate behavior, the importance of knowing whom you should trust with your child, and many more vital aspects of positive parenting. Caregivers clearly value the learnings that they attribute to their engagement with the Parent School.

\section{b. Part B: Benefits}

In this part of the report, we present the benefits and outcomes attributed to the work of the CIANI. The narratives reflect the opinions of the professional staff working at the CIANI, as well as those external to the CIANI, such a public school teachers and community leaders. We also heard extensively from caregivers, who told us about the changes they have realized in relation to their children and to their own development. In the sections that follow, we describe the benefits in relation to the children, the caregivers, and to the broader community.

\section{i. Benefits to the Children}

We begin by examining the narratives that describe the benefits to the children. These benefits can be groups into the following categories: academic benefits, social benefits, and benefits that relate to overall well-being. The first set of narra- 
Evaluation of Centres for the Integral Attention of Children in Dominican Republic (CIANIs) and Local Community Organizations for Child Protection (LCOCP)

tives reflect the opinions of the staff at the CIANI and the public school teachers who will work with the children once they complete their time at the CIANI.

\section{Academic}

When they leave here, they know to read and write, from here they go to another school. (CIANI Staff)

From here the child will go to school. The children who have come out of here, some of the best meritorious children, even the teachers coming out of here - the teachers fight for them because they have that first step already. (CIANI Teacher)

When our children come here they are just one year old, and, like I said, sometimes they cannot even walk. When they leave, they are so much more capable. They are developed in terms of education and personality. They are so much more advanced. It is a marvelous experience to see a child capable of expressing themselves. (CIANI Educational Coordinator)

When we go to do the follow-up with the children who leave here, in the majority of the schools they rave about the children. (CIANI Psychologist)

They are well prepared, they communicate fluidly. (Public School Teacher)

They do a wonderful job educating them even if they are so young. It's like the basement of a building. If the basement is wrong the building will stumble and fall. (Public School Teacher)

It is good. Very good. They are children who already know, it is easier to work with them. Normally five year olds who do not have the opportunity to be in educational institutions come crying, they want to be at home and not at school. But if they have been at CONANI they are more adapted even in the learning and behaviour because it is continuing. If they are starting from zero, you have to work more. (Public School Teacher)

Socially, they are very good. They are more capable and able. They know what school is and behaviour and how things are. It is easier. Sometimes, with the others, you spend the first week calming them down, they are crying 
Evaluation of Centres for the Integral Attention of Children in Dominican Republic (CIANIs) and Local Community Organizations for Child Protection (LCOCP)

the whole time wanting their moms. But the ones who come from there are ready to learn, play and share. They know about routine and are ready to follow direction. (Public School Teacher)

Well, when they come from the CIANI, they come with an understanding. For example, when you have children who come for the first time away from home here, you see it. The ones who come from there, they have an understanding. They know what paint is, they know numbers and everything like that. (Public School Teacher)

The schools like to have children who are coming from the CIANI because they are more educated, less wild and unsociable compared to the ones who were just at their homes. (Community Leader)

It is clearly evident that the children are exceedingly well prepared academically. Public school teachers speak of the rivalry among the teachers in trying to secure these "meritorious" CIANI graduates for their classrooms. These narratives suggest that children attending the CIANI acquire an early advantage in terms of both their capacity for learning and the substantive knowledge that they gain.

The caregivers' narratives identify similar benefits and outcomes.

When the children come to the education centres and are different as well, you see the difference. Even when the children are in the street, you know they are from CONANI. (Grandmother)

You notice in the behavior they have, they are different, when they come there they know the anthem, they know when you tell them to sit, stand. They are not rowdy like the ones who do not come here, they have the habits, they are disciplined, they go to the community disciplined. (Grandmother)

After being here, it is like their minds are open, they learn faster, so then it is like they have a different understanding. (Father)

CONANI is a place where children acquire learning at an early age and start organizing ideas, because, since they are organizing, since they are organizing because when they arrive at school they are different, very different. (Focus Group Parent) 
Evaluation of Centres for the Integral Attention of Children in Dominican Republic (CIANIs) and Local Community Organizations for Child Protection (LCOCP)

My daughters, both of them are the best testimony of what the centre has done. Even the teachers at the school where my daughter is now at are so happy with her because of her behavior and her discipline, she wants to learn. (Parent)

This is a boost to life, huge, in all, I think early education and early child brain development are the first five years, and the child leaves super advanced from here. (Father)

They understand you better. They are prepared to receive instructions. (Focus Group Mother)

They listen more and are more attentive to what you tell them, compared to the ones outside, those who are in other places. (Focus Group Parent)

She knows, you ask her something and she gives me an elaborate tale, she tells me the colours, she has learned a lot there. (Mother)

He knows how to count already from one to 12. He is three years old, turning four now in March. He can count from one to 12. One to 12. He knows the colours, the names of the founding fathers, the national anthem he knows almost all of it. Here they have worked miracles with him. (Grandmother)

She knows a lot, has learned a lot. She counts, she knows the founding fathers, things a 10 year old knows, she knows the month of the year, days of the week, she knows the whole national anthem, she draws, she sings. She is only four years old but she has learned all those things here. Ten year olds, you ask them who the founding fathers are and they do not know, you ask them to sing you the national anthem and they do not know that either. (Parent)

They learn here more than at school. My girl of one year and a half knows all the colours, and there are kids at school in third grade who don't know. (Focus Group Parent)

He knows how to distinguish colors, if we are at the light he asks, "why are we stopped?" and he will say "because the light is red." He knows. They learn so much it is incredible. (Mother) 
Evaluation of Centres for the Integral Attention of Children in Dominican Republic (CIANIs) and Local Community Organizations for Child Protection (LCOCP)

She talked but here she learned to speak clearly and correctly. Now she speaks better than I do, she corrects me. I will say something and she will say "no mami, it is said like this." (Mother)

He has changed a lot, he knows things. He says that is medium or that is large. He tells me he cannot touch the glass cups because he could cut himself. When he is going to eat he prays, everything. I really enjoy it. (Mother)

The manners, he knows a lot, he is educated. He says please, he is friendlier, and he has learned a lot. He speaks better. (Mother)

My baby is 10 months, she sings, claps, and says "mama" too. You can see that they are teaching them very good. (Focus Group Parent)

Caregivers speak about the capacity of the CIANI to instill in their children both the desire for learning and the readiness for learning. As one father remarks, "their minds are open, they learn faster." These narratives also indicate the types of early childhood learning that the children have acquired. This learning includes colours, sizes and shapes, numbers, months and days, the names of the founding fathers, and the national anthem. Like the perspectives of the staff, the view of the caregivers is also that their children's academic development is much further advanced than the development of their peers who are not at the CIANI. Consequently, the children acquire a solid academic foundation and meet this very important goal of early childhood development.

\section{Social}

Caregivers further described the emotional and social benefits that their children had gained while at the CIANI.

... she can put on her clothing, she can distinguish the food, she can more or less speak well, normal, she is two years old and is developing, because at home they mostly learn to fight with their friends, and they learn a lot of things that they do not learn there - offensive words. (Mother)

I see that he is more alert, more social with his peers. (Mother)

Her behaviour, now she is better at sharing with other children. She did not talk much before, now she talks more. (Mother) 
Evaluation of Centres for the Integral Attention of Children in Dominican Republic (CIANIs) and Local Community Organizations for Child Protection (LCOCP)

He is more social, he gets along with everyone. (Father)

The manners, he knows a lot, he is educated. He says please, he is friendlier and he has learned a lot. He speaks better. (Mother)

Everyone asks me if it's true that my son is only two years old because he talks in complete sentences. He interacts with other children. (Parent Focus Group)

My child was shyer before. He changed. (Focus Group Mother)

Mine talks a lot now. (Focus Group Mother)

The socialization is very good. (Focus Group Mother)

My boy didn't talk. And now he said to his sister, "you have to ask permission." And one day that one of his aunts was having lunch with us, he said to her: you don't eat with your hands. (Focus Group Parent)

You love to see your child knowing how to behave with the others. (Focus Group Parent)

These narratives describe the social and behavioural changes that caregivers witnessed as their children attended the CIANI. As the caregiver indicate, since attending the CIANI, their children are now able to speak, are well behaved, are friendlier and get along well with the other children.

\section{Well-being}

The caregivers further spoke of the significant contributions that the CIANI makes to the overall well-being of the children. Caregivers greatly value the safe environment, the food that their children receive, and the medical attention they provide.

The main benefit is that children have safety; they have good care and love. (Mother)

They are not roaming the streets, and we don't have that fear that they will be hit by a car or motorcycle. (Focus Group Parent) 
Evaluation of Centres for the Integral Attention of Children in Dominican Republic (CIANIs) and Local Community Organizations for Child Protection (LCOCP)

This is a help when you are poor and do not know if you will be able to give your child food. Here there is a lot of poverty. (Father)

They get their meals in here. This is a poor area, so feeding is really important. (Mother)

Sometimes I don't have money to give my child a juice or yogurt. In here, he has all those things. (Focus Group Parent)

They feed them, and that is a great help. As I said, I have four children, and the ones at home, it is not much what I can give them. (Mother)

It has benefited me because I save on milk and pampers. They feed them here so they do not need so much at home. I save on a lot. (Mother)

The crisis, we have to go to work and leave the children. So apart from that, it really helps me economically because I am very poor, and I have three children. The other is a private school where I have to pay. I have to pay for school and make monthly payments so they can be there. So here they help me with the food as well as the health when they are a bit sick. They medicate them and this has been the best thing to happen to me. (Mother)

Here, at the meetings, there are mothers who stand up and say "I live in gratitude of CONANI because, I do not have to give to my child, and I bring them here and they feed them." That is one of the reasons that I think. (Grandmother)

Sometimes I do not have food to give her, here she is well taken care of, she eats, having dinner the things they give her, and it helps me economically. I just have to give her a little something and that's it. (Mother)

Perfect, a meal with dairy, which is what a child needs. You will see that the children are never missing milk. (Mother)

The staff of the CIANI further describe the state of need and malnutrition of many of the children when they arrive. With proper food and medical attention, the children quickly thrive in the CIANI. 
Evaluation of Centres for the Integral Attention of Children in Dominican Republic (CIANIs) and Local Community Organizations for Child Protection (LCOCP)

There are many cases, as we have discussed, who I believe have nothing to eat on the weekends. (CIANI Director)

The children, aside from being cared for, are being fed. (CIANI Director)

Also food is given because there are children with little food in the environment. (CIANI Educational Director)

... give the food, the snacks ... at least they are here five days and like I tell the director, here it is five days and they are home for two ... Is there a lot made, does it make up a lot, because even if they do not find what to eat at home, listen, a pasta at four in the afternoon, here they get the snacks, and those who are malnourished get extra. (CIANI Doctor)

With the nutrition program we always work with that program, we always work to succeed. Last year, we had 38 children entering who were underweight, and we finished with just 10. We did as much as possible, it is those children who are bad eaters, they do not eat enough. (CIANI Nurse)

She came so malnourished that the psychologist told me she thought the girl had hepatitis because the whites of her eyes were yellow. She had two colours in her eyes, and now that girl looks happy - she is a whole new girl. (CIANI Director)

Apart from the education we provide, the nutrition, the medical - here we provide a lot of medical help. We have a dentist as well as a doctor, and we provide dental care to the children. They have their teeth cleaned if they have cavities, all of that. There are many parents who cannot take their children to a dentist, and here they have that opportunity. (CIANI Social Worker)

They bring the children to the doctor and the dentist. Sometimes the doctor and the dentist have to go out to the community. (CIANI Director)

If they are sick, they will take them to the doctor. (Public School Teacher).

As succinctly summarized by a CIANI teacher, "When you drop off your child from the morning till the evening, the child has all their needs met. Be it food, health and education." With this full service approach, the children's conditions of vulnerability 
Evaluation of Centres for the Integral Attention of Children in Dominican Republic (CIANIs) and Local Community Organizations for Child Protection (LCOCP)

are significantly decreased by the various services made available in the CIANI. In fact, the CIANI's contributions to their academic skills and capacity, to their social skills, and to their overall well-being create advantages for these children and position them ahead of their peers in the community. They are the children who are sought by the teachers in the public schools that they subsequently attend.

As stated by a CIANI staff member, "When they [the children] leave here they know to read and write, from here they go to another school, they are good people in the society. It is something of pride for us." Consequently, CIANI children are the envy and pride of the community.

\section{ii. Benefits to Parents/Families}

While CIANIs work very closely with the children, their relationship with the families, as explored earlier, is also a very significant focus of their work. In this section, we reveal the benefits that caregivers attribute to their relationships and involvements with the CIANIs. The narratives reveal the significant contributions that the CIANI has made in relation to their employment capacity, reduction in levels of stress, and movement towards their self-development. We begin with the narratives describing the benefits to their employment capacity.

\section{Employment Capacity}

It has contributed to the working mothers. Now they can work. (Grandmother)

It helps many mothers who need it, be it that they are working and do not have someone to leave the child with, or be it that they work and cannot afford to pay the child care. That is a priceless assistance. (CIANI Teacher)

I can say that the opinions that I have heard are good. The mothers really need the space, because they go to work and have no one to leave their children with. They feel safe knowing their children are there, they pick them up no problem, and we have not heard of any kind of difficulties. Of course, if we were in the same situation, we would also leave our children there, because we know they would be in good hands, which is the point. (Community Leader) 
Evaluation of Centres for the Integral Attention of Children in Dominican Republic (CIANIs) and Local Community Organizations for Child Protection (LCOCP)

Yes, they are helping mothers who couldn't work before, and now they can work in some other place than home. (Focus Group Mother)

It is something to help mothers, poor ones. You at least have the chance to start work or look for a way to bring bread home. (Mother)

Parents can rest assured that their children are being well taken care of there. It is beneficial because the parents have the opportunity to do a course or to work, knowing the children are taken care of. (Public School Teacher)

It allows parents to work, if there is a child at home they cannot work, but the parents bring the children here. That is the best support, it allows the family to sustain themselves, because it is work, and they can have a better quality of life. (CIANI Psychologist)

A lot of mothers who don't have the chance to work because they have to take care of the children -- the CIANI gives them the opportunity to go work without worrying about their children. (Public School Teacher)

Parents who cannot take care of their children need to work and can have their child taken care of. It is a great help. (Mother)

I have to go out to do my work, and without the CIANI, I would have no place to put him, besides the fact that he is learning so much. (Mother)

There are mothers who work, thanks to this place. There are not many requirements, we do not pay. So for the community that is great. This center should have been opened a long time ago, that way I could have avoided paying child care for my children. Thank God my grandson is here so I do not have to pay. I am thankful; this center has been the right hand providing for the community. (Grandmother)

Well it helps many mothers and fathers who cannot pay child care and that is a help for us because, when I have to go to work, it is sometimes 15-20 days, and if I did not have the CONANI here watching him all day, I would have to pay a lot of money. (Mother) 
Evaluation of Centres for the Integral Attention of Children in Dominican Republic (CIANIs) and Local Community Organizations for Child Protection (LCOCP)

If I have somewhere to have my children, well then I can go and work. (Focus Group Parent)

These narratives clearly reveal how the CIANI has promoted employment options for many caregivers who would not otherwise have options. Given the economic vulnerability that families face, their ability to pay for private day care is very limited. Having this "free" child care service, caregivers are able to look for employment outside the home and thus contribute to their household income. Caregivers also mentioned the difficulty and stress they feel when they must leave their children in situations that might not be safe or that they do not trust. The next set of narratives speak to the peace of mind that caregivers have, knowing that their children are safe and well cared for while at the CIANI.

Stress Reduction ... peace of mind

... left my child safely, I'm calm with him in their care, I feel trust like family, as I would have left him with my mother, which was who cared for him before. (Mother)

I can go to work in peace. I know they are in good hands. (Parent Focus Group)

So people can work and go to school, they want to reach goals, with these sorts of problems and in minor cases, couples who want to and cannot pay, they do not have family to watch the children but they need someone to. (Focus Group Parent)

The most important benefit that a family with their children at the CIANI can receive is the peace of mind. The peace of mind that comes with that, knowing that you can buy bread for your children and knowing that you are leaving your children well taken care of. Not having to worry, that is number one. Nothing else can replace that. It's hard leaving at five in the morning, leaving your child in God's grace and worrying. (Community Member)

I feel satisfied, leaving her here I feel calm, I feel sure, that my girl is ok, they are taking care of me, I feel good with the centre. (Focus Group Parent)

When a parent brings their child here to the CIANI they have peace of mind knowing that the child is getting a good education. (CIANI Psychologist) 
Evaluation of Centres for the Integral Attention of Children in Dominican Republic (CIANIs) and Local Community Organizations for Child Protection (LCOCP)

I am more calm, I am not worrying for the boy. His mother works, so the boy is well taken care of. (Father)

This is a peace of mind when you leave her here and have that confidence, you feel safe. Sometimes you pay a fortune, there are people who pay a fortune and looks like they sent them unwashed, looks like they left them, you understand me? You spend a fortune and you do not get the service that you are paying for. (Mother)

I did not have anyone to watch my son, and now I have someone and I can leave my child and have peace of mind. (Focus Group Parent)

We can work in peace knowing our child is safe here, he is getting taken care of. I do not leave him with just anyone that is dangerous. You leave them with someone and you have to pay them and, on top of that, they treat them badly. (Father)

Single mothers can be found where they work, and they are calm and happy because they left their children in good hands. If they are mothers who, even if they have a husband, but they have low salaries, they can go with peace of mind that their children are in good hands. (CIANI Social Worker)

When a mother goes to work in peace, I am a working mother and I work in peace knowing he is taken care of and it is free. (Mother)

It has helped me a lot, it has helped me grow. Even with my studies, in everything, because it gives me tranquility. Leaving your child in someone else's care is not easy. (Parent)

These narratives clearly describe the significant benefit of the CIANI in reducing the stress that caregivers feel when leaving their small children in the care of others. Parental stress reduction results from the trust established between the staff and caregivers through the various engagement strategies identified earlier. Stress is also reduced by the exemplary changes and outcomes that caregivers see in their children. CIANIs provide a safe, trusting, and nurturing space, and thus allow caregivers to take up employment opportunities, go back to school, or pursue other options that they feel will lead to a better life for their family. 
Evaluation of Centres for the Integral Attention of Children in Dominican Republic (CIANIs) and Local Community Organizations for Child Protection (LCOCP)

The final benefits to caregivers, and perhaps the most powerful, are the changes that caregivers reveal in relation to physical discipline. In these narratives of change, caregivers tell us about how the parenting education that they received has had a profound impact on their relationships with their children. They tell us that they now understand what it means to be a "good" parent. In many cases, they share how much they regret their past actions, such as yelling, hitting, and other disparaging behaviours. Instead, they talk of loving and valuing their children, using positive discipline, and playing an important educating role with their children.

\section{Narratives of Change}

Before when she upset me, I would grab her and hit her hard. But now I sit with her and tell her she knows how she should be behaving. (Mother)

I correct her and discipline her, I do not abuse her. Sometimes we think we are correcting and we are mistreating. (Parent)

I didn't know what was required to educate a child. There are things that I have cried when I came to know it. (Focus Group Parent)

\section{Parent Focus Group:}

They tell you that you have to give them love and to talk to them with love.

They tell us how to speak to children.

We are being educated the same as the children. When I was a child my parents used to hit me. But they explain to us that this is not educating children.

Yes, we don't yell at them and call them "damned boy."

And hitting them is not good.

My husband has learned a lot about how to educate children.

We women are softer with kids. That is why it is so important that men attend to the talks. They are stronger and more violent. 
Evaluation of Centres for the Integral Attention of Children in Dominican Republic (CIANIs) and Local Community Organizations for Child Protection (LCOCP)

They need more information than we do.

I have learned to value children more. I made a lot of mistakes when I had my children, and those mistakes I made, I would not make them now. Although now I can help other parents, but it is not the same because I wish my children could have enjoyed and benefited from what I have learned now. (CIANI Nurse)

To enjoy the children to not tell them "no you're worthless, you're good for nothing" so they explain how all that is damaging. So I liked that and I took it in little by little. (Mother)

They help me to discipline myself. Before I liked to fight. Now I have a new and different mind. I talk with them, without yelling at them. (Mother)

Talk to them, hitting does not solve anything. No now I do not hit her. (Mother)

Sometimes your children can drive you crazy, always talking, so you hit them and you shouldn't. You need to talk to them so they understand better. (Mother)

I used to hit my kids. One day, I hit my oldest kid with an aluminum jar and I cut her and had to go to the doctor to get stitches for her head. (Grandmother)

We learn how to not hit them, but instead talk to them and punish them but not abuse them. (Mother)

We work specifically on how to talk to your child, what the relationship between parent and child is, so it is one where the child trusts the parents and tells them everything that happens. It is sad to say, but often it is the own family who do the damage. There are some parents who do not come from a normal family, they are families where the father lives with the child, the mother lives with the child so we give presentations on how it does not matter that a parent is missing, but what matters is that the child has stability. (CIANI Social Worker) 
Evaluation of Centres for the Integral Attention of Children in Dominican Republic (CIANIs) and Local Community Organizations for Child Protection (LCOCP)

I think that I have changed. I was not so tolerant to a child crying, but I observed that when kids are new here they are crying and very softly they accommodate to the new situation. For example, my child sleeps here at certain hour, and on weekends she does not sleep at that hour. But I know that if she can do it here, she can do it at home too. We just have to try. (Mother)

I am a first time mom, and there are a lot of things that they teach you. How to discipline them without hitting them or yelling at them. Sometimes they want something, and you just have to distract them so they forget about what they wanted. (Mother)

I did not know how to deal with her, and after the child got here, I have learned and I even learned how to live with my own frustrations, with my daughter. (Mother)

It has improved my family relationships, which is the most important. I have improved as a person. I have grown as a human, because there are taboo topics that often times parents do not understand. (Parent)

These narratives of change dramatically attest to the changes in the treatment of children by their caregivers. Caregivers recognize these changes in their own behaviours and attitudes in relation to the physical discipline that they relied on in the past. Caregivers further acknowledged improvements in their relationships with other family members and with their partners/spouses.

The caregivers we spoke with are profoundly appreciative of their involvement with the CIANI and the benefits that they have realized through this involvement. As succinctly stated by a father, "Because of the benefits, you can give a better life to your children".

\section{iii. Benefits to the Community}

As we have heard repeatedly, the CIANI is recognized as a vital community resource. In the sections above, the narratives speak of the multiple benefits that the children and caregivers gain through their participation in the CIANI. However, as a community resource, CIANIs extend their reach beyond the families that are members by offering support and providing instrumental assistance. In the 
Evaluation of Centres for the Integral Attention of Children in Dominican Republic (CIANIs) and Local Community Organizations for Child Protection (LCOCP)

narratives below, we hear of the "accessible" nature of this community space, a space that invites engagement and participation. Members of the community are encouraged to attend events hosted at the CIANI and to participate in Parent School activities. Pamphlets and resource materials are distributed by CIANI members to their neighbours and to the broader community; these resources encourage discussion and sharing about topics such as child abuse and physical discipline. Many of the local families in their communities are vulnerable, and CIANIs will also provide medical services and medications to these community members. The narratives below describe these community engagement practices and benefits.

It is an institution with a strong community impact ... the impact is very positive. (CIANI Psychologist)

I think that's one of the first benefits we provide to the community, the children are safe. (CIANI Director)

Provides children and parents and all the community a service that is like no other. (CIANI Teacher)

And the community sees CONANI like that space where children are welcome, where their children are educated, that they acquire learning. (Focus Group Parent)

Giving their services to these children; it is a fundamental service that they are giving the community. (Mother)

Not only do they lend themselves here in the center, but if there is a problem out in the community, they also take it into account and do follow-up. (LCOCP Member)

Here they come and think we have a hospital, and we need to give them the medication. There are poor families whom often we see. They are so poor that we also give them some rations. (CIANI Director)

Sometimes the doctor and the dentist have to go out to the community. (CIANI Director) 
Evaluation of Centres for the Integral Attention of Children in Dominican Republic (CIANIs) and Local Community Organizations for Child Protection (LCOCP)

Yes, I have shared with two fellow workers, my sister who I invited, because it is also for the community, the workshops. (Mother)

CIANI has always tried to get the community to participate in all the activities that happen here. (Mother)

We duplicate materials, so that the material will remain for parents, but that they also duplicate them, we suggest they make groups with their neighbours, we ourselves were responsible for delivering this material so they can reach their community. (CIANI Psychologist)

I go with the social worker and then you are encouraged, we always give promotion, "The center is for you." We have a daycare for the community, although you don't have children there, you can come if you need to come and hear a talk at the school, a meeting of neighbours. We try to show it is accessible, here anyone is received and they notice that. Over there in the street, whichever place we greet them and also, ah look, she works in CONANI, and this is really good. (CIANI Psychologist)

With the talks that they give, you take it to the community, to the neighbour, like always around here, if you cannot go, you send the neighbour, the friend, the grandmother, it is just a matter that the community gets soaked with the actual topics, the more legal topics about the child, abuse, that make you conscious how to treat the child in each situation. (Focus Group Parent)

Not only do they lend themselves here in the centre, but if there is a problem out in the community, they also take it in account and do follow-up. (LCOCP Member)

Consequently, CIANIs are recognized as essential community institutions that offer key family-centered resources and benefits to members of the community. As mentioned in one of the above narratives, "the centre is for you." CIANIs can be characterized as a community hub, a welcoming space that brings together professional staff, local families, and community members. It is through the sharing of information, providing an array of services, and organizing events that the CIANI is able to enhance the well-being of the community. 
Evaluation of Centres for the Integral Attention of Children in Dominican Republic (CIANIs) and Local Community Organizations for Child Protection (LCOCP)

\section{c. Part C: Challenges}

In this final section of the qualitative findings, we outline the challenges and recommendations that respondents discussed. While respondents have attributed tremendous value and benefits to their involvement with the CIANI, there are some aspects of the CIANI that respondents would like to see expanded and improved. Some of the challenges mentioned by our participants include: limited space/capacity; insufficient staff; physical space, equipment, and toys; and food supplies.

Space

They should expand it, because there are so many children who are in the street who need it and cannot access it. They should have more and should also expand the ones they have. (Public School Teacher)

The CIANI's capacity is much too limited. (Community Leader)

There should be more centres because they are a great help to the community. (Focus Group Parent)

Well, the amount of children we have is one. Because sometimes the classrooms are too full, and it makes it hard. We have 29 per classroom. It should be 25 ideally to be more manageable. There are two educators in the classroom. Also the ages, because that is a challenge. It is a bit complicated. (CIANI Teacher)

Now we need more centres, the demand that the community has, that's to say there are many people who cannot get in. (Focus Group Parent)

There are needier people, but they cannot get in. (Public School Teachers Focus Group)

I think that they should also do a more careful selection of children entering the CIANI. They should work with the children who are in most danger of something bad happening to them. I am not saying that the ones in there are not in need. Everyone needs it, but outside there are many children with dangerous parents who are not included in the CIANI. But they (CIANI) go through the neighborhood and try to find out what happened. (Community 
Evaluation of Centres for the Integral Attention of Children in Dominican Republic (CIANIs) and Local Community Organizations for Child Protection (LCOCP)

Leader)

The schedule. It must be extended. They leave at 4:15pm, and you work until $5 p m$ or later. So it's difficult. (Mother)

\section{Staff}

There is not sufficient staff, for me that is the most ... what we would need to get first and foremost. I mentioned to the technical team that, in this centre, with four more people, assistants that can be in the classroom, it would be marvelous. We would really benefit with four more people, we do not need any more than that, in terms of the classroom, three or four people. (CIANI Director)

... we need staff, we need another nurse ... there is a medical intern who changes and that is something Public Health deals with, we need the staff, there is no fixed medical assistant the interns change every month. (CIANI Nurse)

Having a fixed doctor, having another nurse because there are two, but, if there is an emergency, she is alone, the other is on leave, I think if an emergency were to arise she would not be able to deal with it alone, and there are a lot, many children. They also need more teachers because they should open the space, and, if there are more teachers, they can have more children from the community, and they could also improve the salary, they work from 8am, 7:30am up to 5pm, that is more than eight hours, I do not think they get paid overtime and they are here all day. (Grandmother)

\section{Physical Space, Equipment, and Toys}

Focus Group Parents:

They have to get a computer and internet.

Also there is problem with the electricity. We don't have a lot of electricity in this barrio. So they have to work without lights and with a lot of heat. They are always fanning the kids with a piece of paper. This is sad. 
Evaluation of Centres for the Integral Attention of Children in Dominican Republic (CIANIs) and Local Community Organizations for Child Protection (LCOCP)

Water dispensers. At least two. The refrigerator is full of food, and there is no space for drinking water.

Anti-slip for the steps.

We ask for UNAP to have a comprehensive service, for it to be expanded. We need a bathroom because the patients from the community use the children's bathrooms, so we need that. An electrical generator to be able to work when the electricity is gone. They have a small one. (CIANI Nurse)

The children's toys are in bad shape, they need more toys because that is their first amusement, in order to keep them from eight in the morning until five, they really need more toys, really, like the tias say, their mattresses to sleep on are very important, and they are in very bad shape. (Parent Focus Group)

The bathrooms, they are too far. I would prefer for every classroom to have a bathroom, because it is too far, and the teachers cannot even when the children are a bit older - they have to send them alone sometimes. (Mother)

We need a bigger fridge for the food, there are two, but one is damaged. Things would be better, things would be organized in the fridge, the things that need to stay cold, and it would be more organized. We give water out in punch bowls. (CIANI Kitchen Staff)

\section{Food Supplies}

CONANI fights to maintain the maximum services to provide, be it from the psychologist, be it from health, from nutrition and food. I am not going to tell you that, in the same nutrition and food, there are months that we run out and the groceries have not come, just as we are now waiting for them to come ... (CIANI Director)

As one would expect, given the array of benefits attributed to the CIANIs, the demand far exceeds their capacity. Further, these narratives identify staffing needs, that is, those pertaining to classroom staff and medical staff. Improvements to their physical spaces are also mentioned, with a concern for adequate electrical power, water dispensers, bathrooms designated for 
Evaluation of Centres for the Integral Attention of Children in Dominican Republic (CIANIs) and Local Community Organizations for Child Protection (LCOCP)

the children that are close to the classrooms, anti-slip mats for the stairs, and the need for new toys. Food security was also mentioned, and we heard that there are times in the month when the food runs short.

We also heard that parents are very willing to support the operations of the CIANI and are very responsive to requirements that the Director makes of them. The following narratives describe some of the ways parents voluntarily contribute their support.

The parents cooperate a lot. Last year we had a program one Saturday a month. I got a list of chores like cleaning the ravine in the back because is very big, pulled the weeds. I put up a schedule, and they registered for the Saturdays they could. But anything that I ask, they help, like helping in the meetings. The participation in the meetings is massive. (CIANI Director)

I think more support from us the parents, because there are many things that are missing here for the children. For example, if we do not help, they cannot have more amenities, because the staff does enough with all the affection and love they care for the children with, for example, look at the seats, the stools over there. They just need a helping hand for someone to cut with a chisel, those stools, and to bring blocks and make some chairs for the children, and the parents do not at any moment - I like when they ask me for things, do you know why? Because then I know what is needed for my child, and the others to be comfortable, if we do not help, then we cannot be comfortable, and the children cannot be comfortable and safe. (Parent Focus Group)

Well, I got along very well with everyone. The teachers, the director, they have never had a complaint about me. I always come when they ask for my help. If I do not have work, I come. When [the Director] tells me to come, I come. One time I came and spent the week here, the whole week helping out with the children, babies, or in the kitchen or the yard. (Parent)

\section{Conclusion}

Our qualitative findings have demonstrated a number of significant operational mechanisms and practices that are associated with outcomes that enhance the well-being of children and families. These operational mechanisms and processes include: 
Evaluation of Centres for the Integral Attention of Children in Dominican Republic (CIANIs) and Local Community Organizations for Child Protection (LCOCP)

- The capacity to establish a welcoming, inclusive, and engaging environment of service;

- An effective and professional interdisciplinary team that works in a collegial and mutually supportive manner;

- A respectful, friendly, trusting, supportive, and collaborative relationship between the staff and the caregivers;

- High levels of caregiver engagement and participation;

- A loving, trusting, caring, safe, and attentive relationship between the staff and the children;

- Established protocols for detecting and addressing violence against children and within families;

- A vibrant and highly valued Parent School committed to providing education that supports good parenting practices and healthy communities.

The significant benefits/outcomes that are associated with these processes are listed here:

- Children are exceptionally well prepared academically, socially, and behaviorally;

- CIANI children are the envy and pride of the community and are sought after by teachers in the public schools that they attend;

- The benefits expressed by caregivers include enhanced employment capacity and reduced stress and peace of mind;

- Changes in caregivers' attitudes and behaviours lead to a reduction in incidents of physical punishment;

- Relationships between caregivers and their children improve.

Consequently, CIANIs are recognized as a vital community resources and play an essential role in the daily lives of the children, caregivers, and members of the community. They are the heart and soul of their community. Their operational processes and practices lead to reductions in physical punishment and violence against children. CIANIs enhance all aspects of well-being for children and their families. Given these outcomes, it comes as no surprise that the major limitation discussed by respondents was the need for an expansion of existing CIANIs and establishment of new CIANIs so that all vulnerable children, families, and communities would have access to these services. 
Evaluation of Centres for the Integral Attention of Children in Dominican Republic (CIANIs) and Local Community Organizations for Child Protection (LCOCP)

In the next section of the report, we apply quantitative measures and a quasi-experimental design to survey data in order to further test the strength of these correlations of practices and outcomes and to establish the extent to which these are particular to CIANIs. 


\section{Quantitative Findings - Outcome Evaluation}

$\mathrm{T}$

his part of the report examines the results of the standardized survey we administered to 1,690 primary caregivers in nine municipalities in the late summer of 2014 . Originally a sample survey was planned for data collection, however, during the administration of the pilot survey it became clear that this would be difficult if not impossible to do. Logistically speaking it was difficult to contact parents/caregivers as landlines are uncommon in the country and cell phone numbers are regularly changed. The phone numbers on file with the centers were not up to date, and we were informed that caregivers changed numbers frequently and that centers communicated with parents through home visits or when parents came by the center in person.

The survey design changed to a census survey with survey administrators going to the centers in the morning and evening and making direct contact with caregivers when they dropped off and picked up their children. Times were scheduled with caregivers to conduct the surveys based on participant availability. Participants were also informed that the surveys could take place at a location of their choosing, the centers provided a private room within the centers for the survey 
Evaluation of Centres for the Integral Attention of Children in Dominican Republic (CIANIs) and Local Community Organizations for Child Protection (LCOCP)

administration, but the option of completing the survey elsewhere was also made clear to parents. The majority choose to complete the surveys after dropping their children off at the centers.

Surveys were administered face-to-face as opposed to having participants fill them in themselves taking into consideration the cultural norm of oral transmission of stories and histories as well as the low literacy rate of those caregivers involved with the centers.

The first section offers a social and demographic profile of the people we interviewed for the survey. It also describes the various indices we have constructed to capture levels of family stress, community trust, and community engagement. The second section discusses our measures of caregivers' attitudes towards disciplining children and of their disciplinary behaviours. It also begins the between-group analysis that explores the extent to which survey respondents in the three groupsCIANI Only, CIANI + LCOCP, and Control-differ systematically in the ways they discipline their children. In the next section, we examine patterns within the two Intervention Groups, CIANI Only and CIANI + LCOCP. This within-group analysis focuses on caregivers' specific experiences with the CIANI. Here, for instance, we determine if respondents' disciplinary attitudes and behaviours differ according to how engaged they are in the CIANI, how satisfied they are with the services provided by the CIANI, and how long they have been associated with the CIANI.

The final section performs a series of multiple regression analyses using our measures of discipline as dependent variables, that is, as the outcomes to be explained. This multivariate analysis estimates the independent impact that a given factor has on disciplinary attitudes and behaviours while taking into account the influence of other shaping factors. Crucially, for this study, we can see if child discipline patterns remain different in the two Intervention Groups, as compared to the Control Group, after we have adjusted for other factors that might explain such patterns. This kind of analysis, of course, attempts to answer the question: are the policy interventions working? Our quasi-experimental research design enables us to go a step further, to begin to answer the question about why the policy interventions might be working. This exploration of why concludes the section on survey results. 
Evaluation of Centres for the Integral Attention of Children in Dominican Republic (CIANIs) and Local Community Organizations for Child Protection (LCOCP)

\section{a. Social Profile of Survey Respondents in the Three Groups}

As outlined in the earlier description of our methodology, we used a quasi-experimental research design in order to survey three distinct groups of primary caregivers:

1. The CIANI Only Group includes caregivers who live in a municipality where there is a CIANI but no LCOCP and who have at least one child registered in their municipality's CIANI.

2. The CIANI + LCOCP Group includes caregivers who live in a municipality where there is both a CIANI and a LCOCP, and who have at least one child registered in their municipality's CIANI.

3. The Control Group includes two subgroups of caregivers: (1) those who live in a municipality without a CIANI or a LCOCP, and who have at least one child registered in a pre-school or initial education program at their local public school, and (2) those who live in a municipality that has a CIANI but no LCOCP, who have had no contact with that CIANI, and who have at least one child registered in the pre-school program of their local public school. The pre-school programs are for children under the age of six.

Here, it is also useful to recall the broad research design logic of the three groups:

- If the CIANI program is working to reduce violence against children, we would expect that, other factors being equal, the CIANI Only Group to have lower inclinations to physical discipline than the Control Group, other factors being equal.

- If the LCOCP program is working similarly, we would expect that, other factors being equal again, the CIANI + LCOCP Group to show the lowest inclination toward corporal punishment of all three groups, since it carries both the "CIANI effect" and any additional "LCOCP effect."

Recently, the number of CIANIs and LCOCPs has increased, as the Dominican government has expanded the breadth of these programs. The designation of municipalities-as having a CIANI only, a CIANI and LCOCP, or neither-refers to their status at the time the survey was conducted, from mid-August to early September 2014. 
Evaluation of Centres for the Integral Attention of Children in Dominican Republic (CIANIs) and Local Community Organizations for Child Protection (LCOCP)

As Table 6.1 shows, we surveyed caregivers in a total of nine municipalities, i.e., three municipalities in each of the three groups. We interviewed a total of 1,690 respondents across these nine municipalities. Table 6.2 lists the public schools surveyed in the three municipalities that make up the Control Group. To ensure an equivalent number of interviews of sufficient size for subgroup analysis, we surveyed three schools in Villa Altagracia and Herrera, and four in Monte Plata.

\section{Table 6.1: Municipalities Surveyed By Group}

\begin{tabular}{|c|c|c|c|c|c|}
\hline $\begin{array}{c}\text { CIANI Only } \\
\text { Municipalities }\end{array}$ & N & $\begin{array}{c}\text { CIANI + LCOCP } \\
\text { Municipalities }\end{array}$ & N & $\begin{array}{c}\text { Control Group } \\
\text { Municipalities }\end{array}$ & N \\
\hline La Romana & 223 & Boca Chica & 206 & Herrera & 193 \\
\hline Los Mina & 171 & Jimani & 182 & Monte Plata & 171 \\
\hline Santiago & 171 & Puerto Plata & 208 & Villa Altagracia & 165 \\
\hline Group N $=$ & 565 & Group N $=$ & 596 & Group N = & 529 \\
\hline
\end{tabular}

Table 6.2: Schools Surveyed By Municipality (Control Group Only)

\begin{tabular}{|c|c|c|c|c|c|}
\hline $\begin{array}{c}\text { Municipality of } \\
\text { Herrera }\end{array}$ & N & $\begin{array}{c}\text { Municipality of Monte } \\
\text { Plata }\end{array}$ & N & $\begin{array}{c}\text { Municipality of } \\
\text { Villa Altagracia }\end{array}$ & N \\
\hline Club 16 de Agosto & 86 & Cruz de Pela & 47 & Estiliano Susana & 54 \\
\hline Cristobalina Batista & 67 & Estrella Vieja & 37 & Javier Angula Guridi & 55 \\
\hline El Buen Pastor & 40 & Luisa Blanca & 36 & Juan Pablo Duarte & 56 \\
\hline Municipality N $=$ & 193 & Luisa Prieta & 51 & & 165 \\
\hline
\end{tabular}

The survey included a battery of questions on the social background characteristics of the respondents. Table 6.3 provides a social profile of the primary caregivers in the three groups. The three Groups are similar in relation to most social characteristics.

The vast majority of caregivers in the study are women, some 84 percent overall. A total of 77 percent are mothers. Mothers and fathers together account for at least 89 percent of respondents in each of the three groups. The marital status of most respondents is "free union" (59.3\%), and this figure is especially high in 
Evaluation of Centres for the Integral Attention of Children in Dominican Republic (CIANIs) and Local Community Organizations for Child Protection (LCOCP)

the CIANI + LCOCP Group (69.5\%). Four times as many respondents are in free unions as are married (14.6\%).

The average (mean) age of respondents is 32.1 years, with little variation by group. The average number of children in the household is 2.2 , and their average age is 4.4 years old. The average age of the children in the Control Group (5.7 years old) is higher than the age in the two Intervention Groups (3.7 and 3.9), a difference that is to be expected, given that all the families in the Control Group are registered in schools and have many more school-age children than do the families in the two Intervention Groups. Generally, respondents have lived in their neighbourhoods for a long time, over 12 years on average. Some 20 percent have lived in their neighbourhoods for two decades or more.

The income and education profiles of respondents in the three groups are similar. Overall, the median personal monthly income is 4,000 to 6,999 pesos, with slightly higher medians in the CIANI Only Group and the Control Group. The survey measured household income as well as personal income; that is, we asked respondents to give their "best estimate of the total monthly income of all household members ... from all sources of income." For all respondents, the median monthly household income is 7,000 to 9,999 pesos. The pattern for median household income is similar to that for median personal income, with a slightly higher figure in the CIANI Only Group.

In our social profile of respondents in the three groups, we went beyond the conventional social and demographic variables of sex, marital status, age, income, education, and so on. We also wanted to draw an attitudinal and behavioural portrait of the groups. In particular, we wanted to examine how the three groups differ on levels of family stress, community trust, and community engagement. We were interested in these three measures because of their potential impact on the way caregivers discipline their children. Our literature review pointed to research showing that high levels of stress in the home can put children at risk. The review also summarized the extensive literature showing that trust in the community, sometimes referred to as social capital or collective efficacy, and the level of participation in the community are associated with a host of positive outcomes that provide a safe family environment for children. 
Evaluation of Centres for the Integral Attention of Children in Dominican Republic (CIANIs) and Local Community Organizations for Child Protection (LCOCP)

Table 6.3: Selected Social Characteristics of Respondents by Group

\begin{tabular}{|c|c|c|c|c|}
\hline \multirow[b]{2}{*}{$\begin{array}{l}\text { Social Characteristics of } \\
\text { Primary Caregivers }\end{array}$} & \multicolumn{3}{|c|}{ Group } & \multirow[b]{2}{*}{ Total } \\
\hline & CIANI Only & $\begin{array}{l}\text { CIANI + } \\
\text { LCOCP }\end{array}$ & Control & \\
\hline Percent Female & $83.5 \%$ & $79.7 \%$ & $88.7 \%$ & $83.8 \%$ \\
\hline Percent Mothers & $76.5 \%$ & $76.3 \%$ & $78.1 \%$ & $76.9 \%$ \\
\hline Percent Fathers & $15.6 \%$ & $19.8 \%$ & $10.8 \%$ & $15.6 \%$ \\
\hline Percent Married & $14.2 \%$ & $13.6 \%$ & $16.3 \%$ & $14.6 \%$ \\
\hline Percent in Free Union & $52.7 \%$ & $69.5 \%$ & $54.9 \%$ & $59.3 \%$ \\
\hline Mean Age & 32.0 & 30.5 & 34.0 & 32.1 \\
\hline $\begin{array}{l}\text { Mean Number of Children in the } \\
\text { Household }\end{array}$ & 2.1 & 2.2 & 2.4 & 2.2 \\
\hline $\begin{array}{l}\text { Mean Age of Children in the } \\
\text { Household }\end{array}$ & 3.7 & 3.9 & 5.7 & 4.4 \\
\hline $\begin{array}{l}\text { Mean Number of Years in } \\
\text { Neighbourhood }\end{array}$ & 13.1 & 11.5 & 12.3 & 12.3 \\
\hline Mean Number of Years in CIANI & 1.1 & 1.1 & Not applicable & 1.1 \\
\hline $\begin{array}{l}\text { Median Monthly Personal } \\
\text { Income (pesos) }\end{array}$ & $7,000-9,999$ & $4,000-6,999$ & $7,000-9,999$ & $4,000-6,999$ \\
\hline $\begin{array}{l}\text { Median Monthly Household } \\
\text { Income (pesos) }\end{array}$ & $\begin{array}{c}10,000- \\
12,000\end{array}$ & $7,000-9,999$ & $7,000-9,999$ & $7,000-9,999$ \\
\hline Median Level of Education & $\begin{array}{l}\text { Completed } \\
\text { high school }\end{array}$ & $\begin{array}{l}\text { Completed } \\
\text { high school }\end{array}$ & $\begin{array}{l}\text { Some high } \\
\text { school }\end{array}$ & $\begin{array}{l}\text { Some high } \\
\text { school }\end{array}$ \\
\hline Percent High on Family Stress & $5.8 \%$ & $7.2 \%$ & $21.2 \%$ & $11.1 \%$ \\
\hline $\begin{array}{l}\text { Percent High on Community } \\
\text { Trust }\end{array}$ & $22.7 \%$ & $21.1 \%$ & $12.1 \%$ & $18.8 \%$ \\
\hline $\begin{array}{l}\text { Percent High on Community } \\
\text { Engagement }\end{array}$ & $15.5 \%$ & $20.6 \%$ & $12.8 \%$ & $16.4 \%$ \\
\hline$N=$ & 565 & 596 & 529 & 1690 \\
\hline
\end{tabular}


Evaluation of Centres for the Integral Attention of Children in Dominican Republic (CIANIs) and Local Community Organizations for Child Protection (LCOCP)

Figure 6.1 shows the percent of primary caregivers who reported experiencing various stressful situations in the past year. The most frequently experienced stressors are economic: almost half of respondents (44.4\%) had problems paying household expenses, and 21.7 percent reported that they had experienced a significant amount of time without income during the past year. Another 14 percent said that there was a period during the past year when their children were unable to receive the food they needed. Personal relationships are also a source of stress for some respondents. Over 18 percent reported that they had "significant problems" in their relationships with their spouses or partners, and almost 17 percent had experienced a divorce, separation, or breakup. These two variables regarding relationships are related, of course, but they also seem to be measuring different situations: 43 percent of those who experienced relationship problems during the past year had not undergone a divorce, separation, or breakup. Other stressful experiences reported by respondents include moving (11.1\%) and experiencing violence in the neighbourhood $(10.5 \%)$ or household (5.3\%).

Figure 6.1: Family Stress*

Percent saying "Yes," they have had these experiences in the past year All Three Groups $(\mathrm{N}=1,690)^{*}$

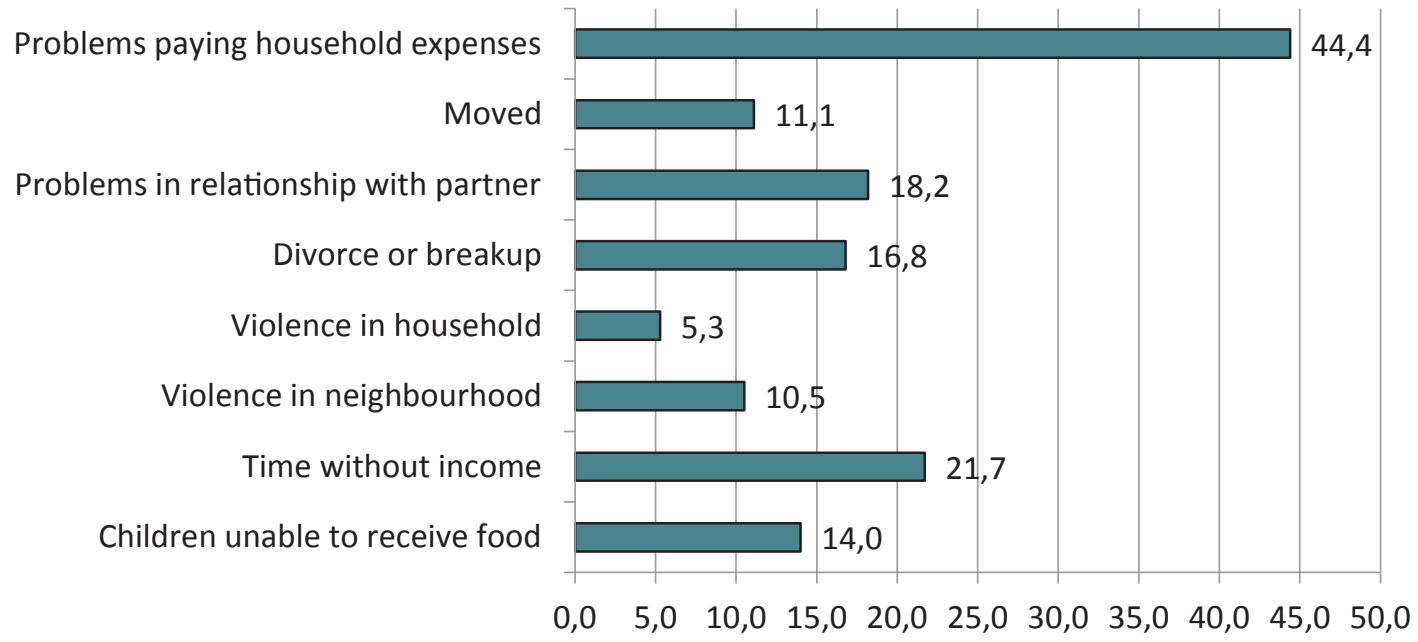

${ }^{*}$ For this and all subsequent figures in this section, the $\mathrm{N}$ for each individual item in the figure will vary slightly because of variations in the amount of missing data. 
Evaluation of Centres for the Integral Attention of Children in Dominican Republic (CIANIs) and Local Community Organizations for Child Protection (LCOCP)

To construct a comprehensive measure of these stressful experiences, we added the number of times respondents said "yes" to each of the eight questions in Figure 6.1. This additive Index of Family Stress ranges from a low score of zero, for those respondents who never answered "yes" and therefore did not experience a single stressful episode, to a high score of eight, for those who said they had experienced all the various stressful situations. Table 6.4 displays the full distribution of the Index. Most respondents fall near the low end of the Index of Family Stress, with $38.2 \%$ experiencing none of the stressful situations and $24.3 \%$ experiencing one kind of stressful episode. Only 10 respondents $(0.6 \%)$ scored seven on the Index and just five (0.3\%) scored the maximum of eight.

Table 6.4: Index of Family Stress

\begin{tabular}{|c|c|c|}
\hline Level of Stress & Index Score & Percent \\
\hline Lowest & 0 & 38.2 \\
\hline & 1 & 24.3 \\
& 2 & 14.8 \\
& 3 & 11.5 \\
\hline & 4 & 6.0 \\
\hline Highest & 5 & 2.6 \\
\hline & 6 & 1.7 \\
& 7 & 0.6 \\
& Total Percent & 0.3 \\
\hline & $\mathbf{N}=$ & $\mathbf{1 0 0 . 0}$ \\
\hline
\end{tabular}

${ }^{*}$ In this and subsequent tables, percentages may not add up exactly to 100 because of rounding error.

In the next section, we use a series of figures, constructed from contingency tables, ${ }^{9}$ to explore the nature of the relationship between Family Stress and various measures of physical discipline. There we begin to address the question about

9 Contingency or bivariate tables show the joint distribution of two variables and are a basic way to explore bivariate relationships between categorical variables. Healy, J., \& Prus, S. (2015). Statistics: A Tool for Social Research (3rd Canadian Ed.). Toronto: Nelson Education., chap. 10. 
Evaluation of Centres for the Integral Attention of Children in Dominican Republic (CIANIs) and Local Community Organizations for Child Protection (LCOCP)

whether caregivers in highly stressed families are more likely to discipline their children physically than are those in low stress families. Our tabular analysis and figures use a variation of the Index of Family Stress displayed in Table 6.4. Since there were so few respondents at the high end of the Index, we combined some of the high scores to form a recoded or grouped version of the Index, with the following distribution:

No Stress (score of 0 ) Low Stress (score of 1 ) Moderate Stress (scores of 2 and 3) High Stress (scores of 4 through 8 )
$38.2 \%$

$24.3 \%$

$26.3 \%$

$11.1 \%$

Looking back at the social profile in Table 6.3, we see that there is marked variation by group in the number of respondents experiencing high levels of family stress. The differences are especially evident in a comparison of the two Intervention Groups, on one hand, and the Control Group, on the other hand. Only 5.8 percent of respondents in the CIANI Only Group and only 7.2 percent in the CIANI + LCOCP Group score high on the Index of Family Stress. In the Control Group, however, levels of family stress are three to four times higher, with 21.2 percent of respondents experiencing high stress. In the multivariate analysis below, we'll return to this very strong relationship between family stress and respondents' groups.

The Community Trust Index is the second comprehensive measure that we examine. The survey questionnaire included a section asking interviewees to "strongly agree," "agree," "disagree," or "strongly disagree" with a series of eight statement designed to measure the level of trust in the community. Respondents were asked, for example, whether they agreed or disagreed with statements such as "children are safe in my neighbourhood," "we take care of each other's children in my neighbourhood," and "I feel part of a group of people in my neighbourhood who share my attitudes and beliefs." 
Evaluation of Centres for the Integral Attention of Children in Dominican Republic (CIANIs) and Local Community Organizations for Child Protection (LCOCP)

Figure 6.2: Community Trust

Percent saying "strongly agree," "agree, "disagree," or "strongly disagree" All Three Groups $(\mathrm{N}=1,690)$

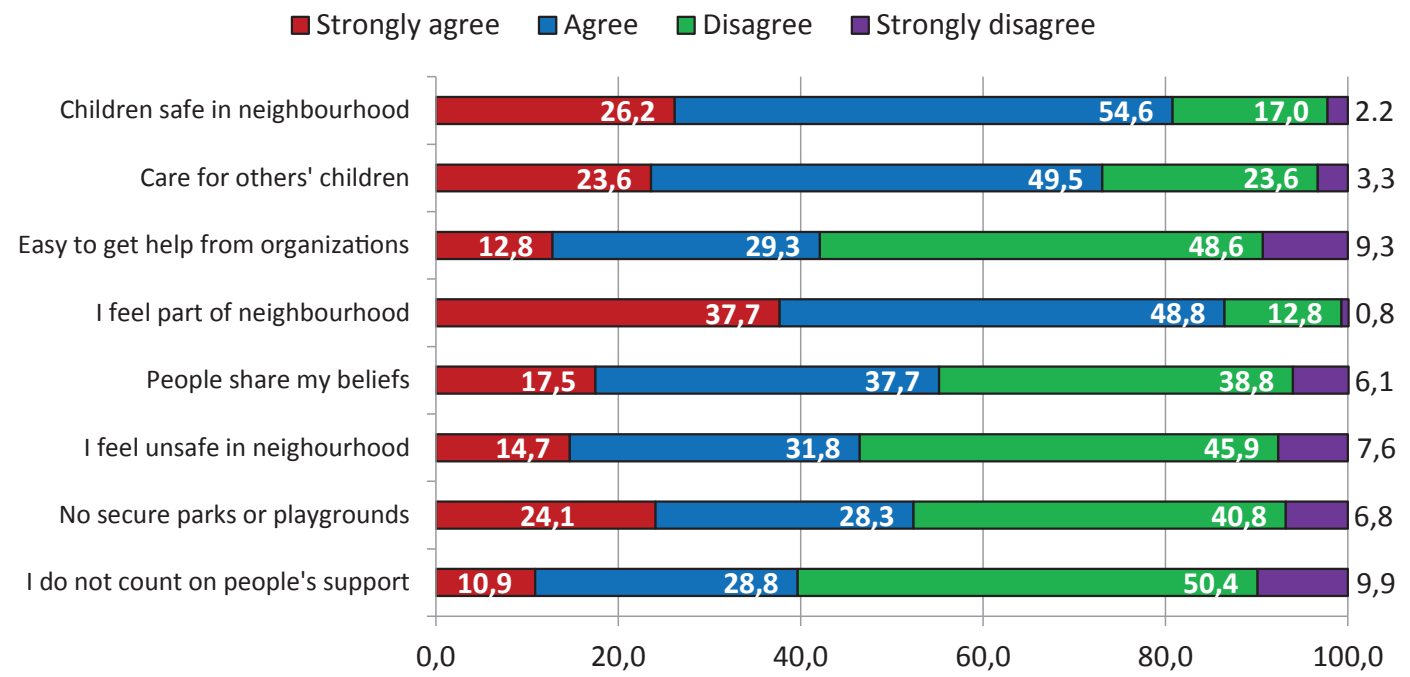

Figure 6.2 displays the distributions of the individual variables from which this index was constructed. The first point to note about the figure is that respondents show a relatively high degree of trust in the community. On six of the eight statements, a majority of respondents gave the "trustful" response. Over 86 percent strongly agreed or agreed that they felt part of the neighbourhood, 80.8 percent that children are safe in the neighbourhood, and 73.1 percent that we take care of others' children. The last three statements in the figure-"I feel unsafe in my neighbourhood," "there are no secure parks or playgrounds," and "I do not count on support from many people"-are worded negatively, meaning that the trustful response is "strongly disagree" or "disagree." On two of these three indicators, a majority of respondents are trusting: 60.3 percent strongly disagree or disagree that they cannot count on people's support, and 53.5 percent strongly disagree or disagree that they feel unsafe in the neighbourhood.

To construct a comprehensive measure of community trust, as we did with family stress, we added how many times respondents gave a "trustful" response to the eight statements in Figure 6.2. It is important to recall that the trustful response could be strongly agree or agree, or it could be strongly disagree or disagree, depending on the wording of the statement. This summation yields an Index of 
Community Trust ranging from a low of zero to a high of eight, as displayed in Table 6.5. This index, unlike the Index of Family Stress, is weighted towards high values, with two thirds of respondents scoring five or greater. Only 3.6 percent of caregivers (60 people) have a score of zero, indicating that they never gave a trustful response to any of the eight statements.

Table 6.5: Index of Community Trust

\begin{tabular}{|c|c|c|}
\hline Level of Trust & Index Score & Percent \\
\hline \multirow[t]{8}{*}{ Lowest } & 0 & 3.6 \\
\hline & 1 & 2.0 \\
\hline & 2 & 3.3 \\
\hline & 3 & 8.7 \\
\hline & 4 & 15.9 \\
\hline & 5 & 27.9 \\
\hline & 6 & 19.9 \\
\hline & 7 & 11.7 \\
\hline \multirow[t]{3}{*}{ Highest } & 8 & 7.1 \\
\hline & Total Percent $=$ & 100.0 \\
\hline & $\mathbf{N}=$ & 1,690 \\
\hline
\end{tabular}

To ensure that we would have a sufficient number of respondents in the various categories of the index for tabular analysis, we recoded Community Trust into the following three groupings:

Low Trust (scores of 0 through 4)

Moderate Trust (scores of 5 and 6 )

High Trust (scores of 7 and 8)
$33.4 \%$

$47.8 \%$

$18.8 \%$

To see the extent to which levels of community trust differ among the three GroupsCIANI Only, CIANI + LCOCP, and Control-refer again to Table 6.3. Once again, we find significant variation between the two Intervention Groups, on one hand, and the Control Group, on the other hand. More respondents in the CIANI Only and CIANI + LCOCP Groups display high levels of Community Trust $(22.7 \%$ and $21.1 \%$, respectively) than do respondents in the Control Group (12.1\%). 
Evaluation of Centres for the Integral Attention of Children in Dominican Republic (CIANIs) and Local Community Organizations for Child Protection (LCOCP)

The third and final additive measure is the Index of Community Engagement. Survey respondents were asked how often they attended neighbourhood meetings or events and how often they worked with others in the neighbourhood to solve problems. Figure 6.3 displays the results. The level of community engagement is relatively low, much lower than the level of community trust, for instance. Only 6 percent of respondents report that they "very often" attend community meetings and work with others to solve neighbourhood problems. For each of the two questions in the figure, the largest group of respondents is in the "hardly ever" category, with 39.4 percent saying they hardly ever attend neighbourhood meeting or events, and 44.8 percent saying they hardly ever work with others to solve local problems.

Figure 6.3: Community Engagement

Percent saying "very often," "often," "sometimes," or "hardly ever" All Three Groups (N=1,652)

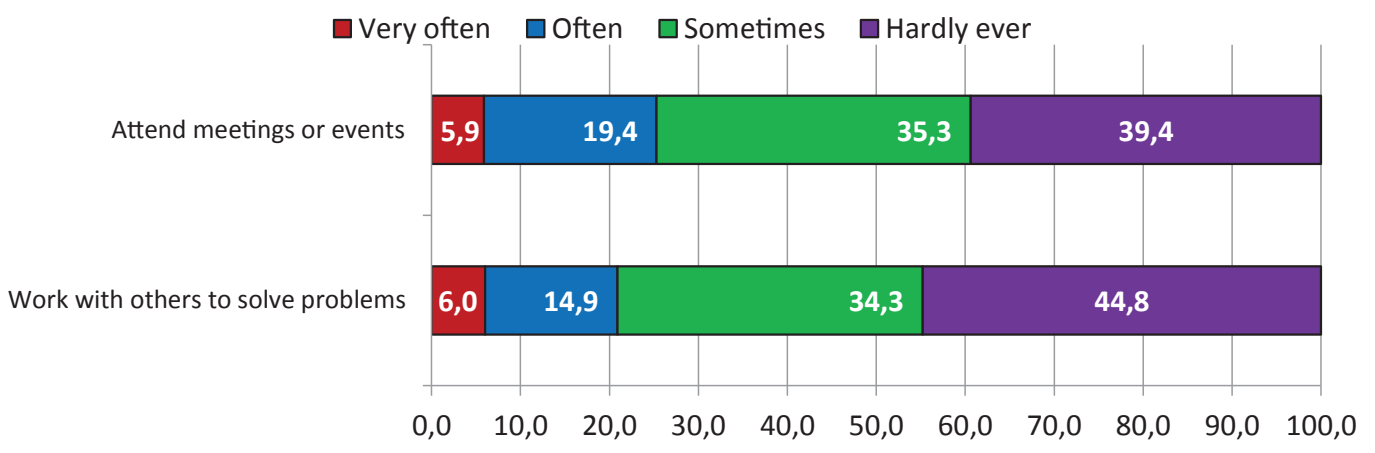

Table 6.6: Index of Community Engagement

\begin{tabular}{|c|c|c|}
\hline Level of Engagement & Index Score & Percent \\
\hline Lowest & 0 & 70.3 \\
\hline Moderate & 1 & 13.3 \\
\hline Highest & 2 & 16.4 \\
\hline & Total Percent $=$ & 100.0 \\
\hline & $\mathbf{N}=$ & $\mathbf{1 , 6 5 2}$ \\
\hline
\end{tabular}


Evaluation of Centres for the Integral Attention of Children in Dominican Republic (CIANIs) and Local Community Organizations for Child Protection (LCOCP)

The low level of participation is reflected in Table 6.6, which gives the distribution of the Index of Community Engagement. This index counts the number of times that respondents answered "very often" or "often" to the two questions about how frequently they participated in their community. As the table shows, a total of 70 percent of respondents have a score of zero on the index, indicating that they did not answer "very often" or "often" to either of the two questions. Only 16.4 percent have an index score of two, meaning that they replied "very often" or "often" to questions about both attending community meetings and working with others in the neighbourhood. Given the nature of the distribution of Community Engagement, there is limited scope to recode the index. In the tabular analysis and figures, then, we use the three-category index displayed in Table 6.6, which differentiates low, moderate, and high levels of engagement.

Reference to Table 6.3 again allows us to see the extent to which the three groups differ with regard to Community Engagement. The percent of respondents with high levels of Community Engagement in the CIANI Only Group (15.5\%) and in the Control Group (12.1\%) are slightly below the overall figure of 16.4 percent. The percent of respondents with high community engagement in the CIANI + LCOCP Group (20.6\%) is above the overall figure.

\section{b. Between-Group Analysis: Comparing All Three Groups}

This section begins the analysis of caregivers' attitudes towards disciplining children and the various modes of discipline they report using. It is a "between-group analysis" because the primary focus will be comparing the three groups to determine if there are significant differences in disciplinary attitudes and behaviours across the groups. In other words, the principal question we begin to address in this section is: are there observable differences between the two Intervention Groups (CIANI Only and CIANI + LCOCP), on one hand, and the Control Group, on the other hand, that may indicate that the policy interventions are working? To assess properly the influence of the group variable on caregivers' discipline patterns, we need to take into account other factors that might affect discipline; that is, the impact of the group is best assessed relative to the impact of these other factors. In this section, therefore, we also examine the impact of some of the social and demographic variables discussed in the previous section. At this point, we examine "bivariate" or "two-variable" relationships; we look at the influence on discipline of the group variable and then the influence of other variables, one vari- 
Evaluation of Centres for the Integral Attention of Children in Dominican Republic (CIANIs) and Local Community Organizations for Child Protection (LCOCP)

able at a time. Every relationship we examine in this section, then, contains two variables: discipline and some factor, like group, that might influence discipline. Our "multivariate" analysis is in the last section of this part of the report, and, in this analysis, we examine simultaneously all the various factors that might influence the disciplinary attitudes and behaviours of caregivers.

\section{i. Group Differences on Individual Measures of Discipline}

The qualitative interviews we conducted with primary caregivers and also with the professional CIANI staff and key informants underlined the importance of distinguishing between disciplinary attitudes and behaviours. Caregivers, for instance, emphasized the importance of learning the proper disciplining attitudes and behaviours at the Parent School. In the survey instrument, we included questions designed to measure both these dimensions.

First, we examine attitudes. Respondents were asked a general question designed to measure their overall attitude toward child discipline: "Do you believe that in order to raise a child properly you need to physically discipline the child? By this, I mean do you believe that you need to spank or hit the child, or take any other physical measures to discipline the child?" Caregivers were also asked a series of specific questions about their attitude towards using physical discipline: "I am going to read to you accounts of a few different situations, and I would like you to tell me if you think that a caregiver would be justified in using physical discipline in a particular situation." Some of the particular situations mentioned were "if the child does something without parental permission," "if the child disobeys an adult," and "if the child steals something." 
Evaluation of Centres for the Integral Attention of Children in Dominican Republic (CIANIs) and Local Community Organizations for Child Protection (LCOCP)

\section{Figure 6.4: Selected Attitudes towards Physical Discipline by Group Percent saying "yes," it is justifiable to use physical discipline in various situations \\ All Three Groups $(\mathrm{N}=1,685)$}

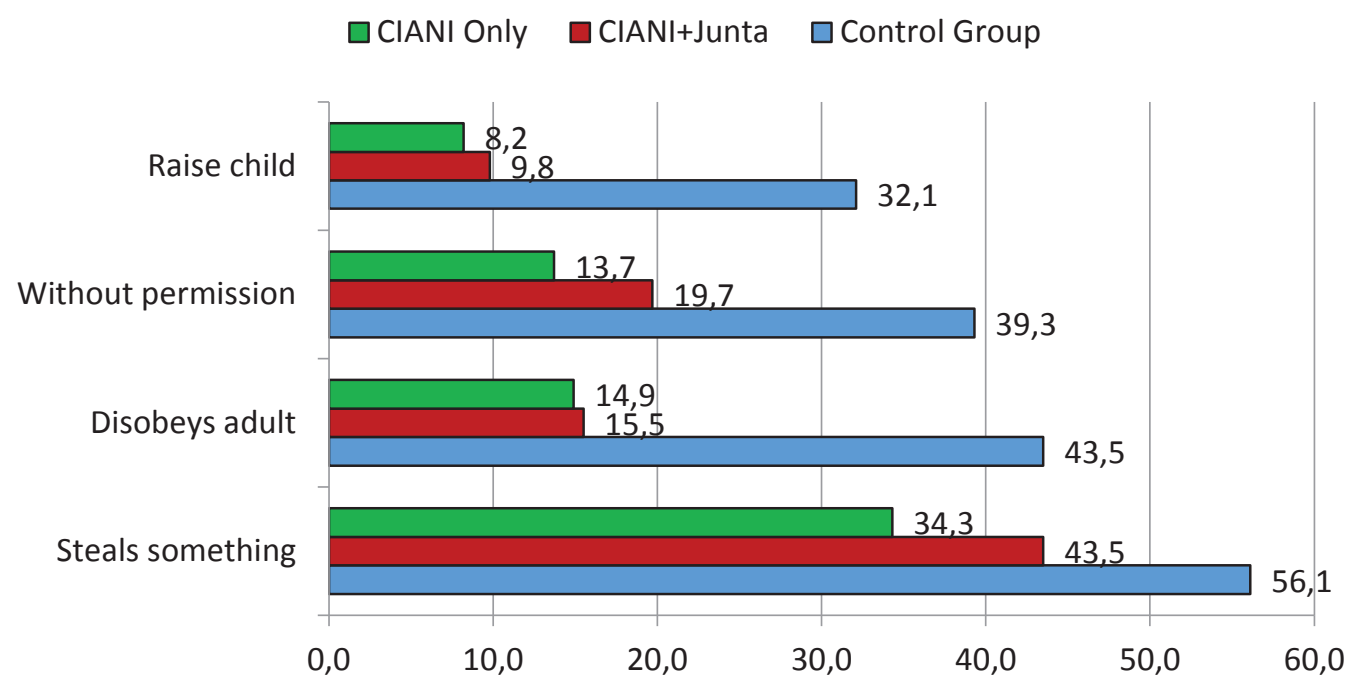

Figure 6.4 compares respondents in the three groups according to their general attitudes about using physical discipline in the process of raising a child. The figure also compares them according to their specific attitudes about use of discipline in selected situations. The figure demonstrates that there are large and significant differences in attitudes among the three Groups. ${ }^{10}$ Especially evident is the difference between the two Intervention Groups and the Control Group, as indicated by the different lengths of the coloured bars. On three of the four variables shown in the figure, the percentage of respondents saying that they would use physical discipline is two to four times higher in the Control Group than it is in the Intervention

\footnotetext{
10 The methodological literature is split on whether it is appropriate to use tests of statistical significance on the whole population. As the section on methodology discussed, we surveyed the population (or as close to the population as one can reasonably come) of caregivers in each of the three groups. We conducted tests of statistical significance on all the relationships examined in this report. All those relationships are significant at .05 or beyond, unless otherwise indicated. For a classic statement and some responses on the use of statistical tests with populations, see Blalock, H. (1972). Social statistics (2d Ed.). New York: McGraw-Hill; Rubin, A. (1985). Significance testing with population data. The Social Service Review, 59(3), 518-520; and Cowger, C. D. (1985). Author's Reply. The Social Service Review, 59(3) 520-522.
} 
Evaluation of Centres for the Integral Attention of Children in Dominican Republic (CIANIs) and Local Community Organizations for Child Protection (LCOCP)

Groups. As an example, a total of 32.1 percent of caregivers in the Control Group believe it is necessary to use physical discipline to raise a child properly. The corresponding figures for the CIANI Only and CIANI + LCOCP Groups are markedly lower: just 8.2 percent and 9.8 percent, respectively. Similarly, 43 percent of those in the Control Group believe physical discipline is appropriate if a child disobeys an adult, but only about 15 percent of those in the Intervention Groups believe so. The smallest group difference is on the variable Steals Something, but, even here, the difference is considerable: 56 percent in the Control Group, as compared to 34 percent and 44 percent in the two Intervention Groups.

We also included in the survey a battery of questions to measure the disciplinary behaviours of caregivers in the three groups. Once again, we asked a general question: "In the past year, have you used physical discipline to correct your child's behaviour?" We also asked a series of questions about specific forms of discipline: "I am going to ask you about certain ways of teaching children the right behaviour or correcting behaviour problems. I am going to read various methods used by caregivers and I want you to tell me if you have used this method during the last year." Respondents were asked, among other things, if they had "shouted, yelled or screamed at the child," "shaken the child," or hit the child "on the bottom with something like a belt, hairbrush, stick or hard object."

Figure 6.5: Selected Physical Discipline Behaviours by Group Percent saying "yes" that they used physical discipline and various forms of discipline in the past year All Three Groups $(\mathrm{N}=1,685)$

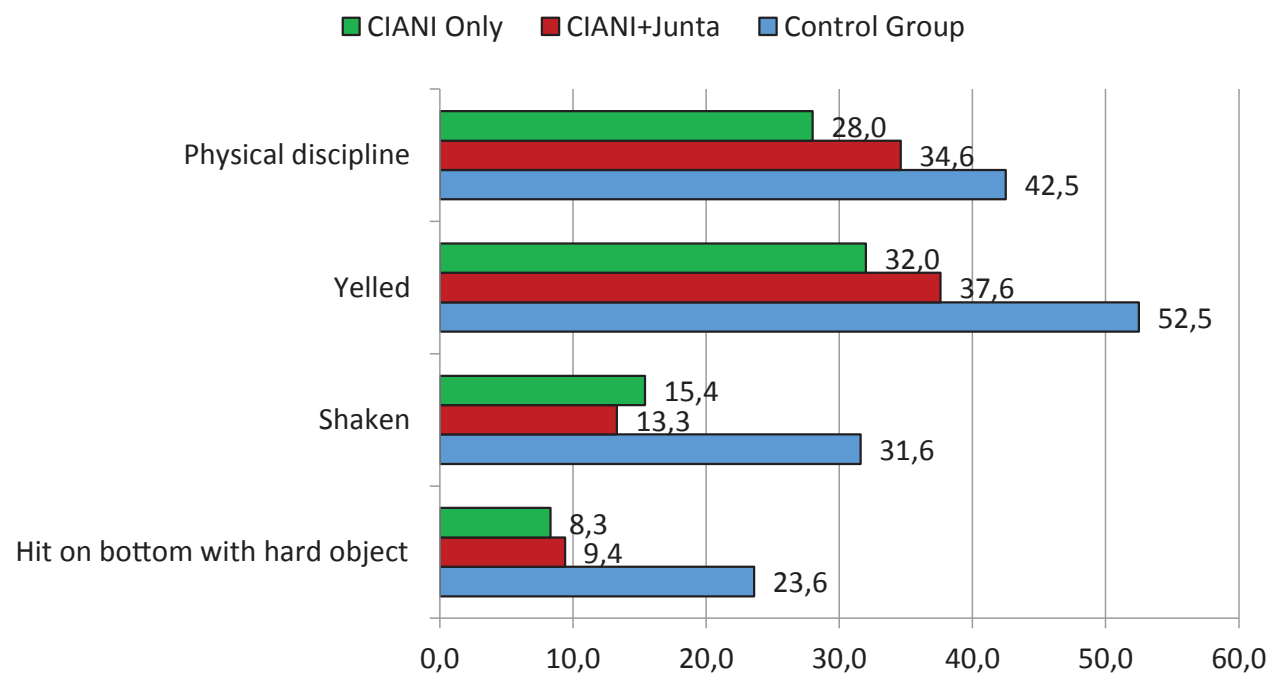


Evaluation of Centres for the Integral Attention of Children in Dominican Republic (CIANIs) and Local Community Organizations for Child Protection (LCOCP)

Figure 6.5 compares caregivers in the three groups according to these disciplinary behaviours. We see a similar pattern to that displayed in the previous figure on attitudes; more respondents in the Control Group report using physical discipline than do those in the two Intervention Groups. The gap between the two sets of groups is largest for more extreme forms of discipline. Over 23 percent of Control Group respondents said that they had hit their children on the bottom with a hard object; only 8.3 percent of those in the CIANI Only Group and 9.4 percent in the CIANI + LCOCP Group reported doing so. The same pattern holds for respondents who report that they have shaken their child.

Comparing Figure 6.4 on disciplinary attitudes and Figure 6.5 on disciplinary behaviours highlights an attitude-behaviour discrepancy. In all three groups, many more respondents actually use physical discipline than the number of respondents who believe that such discipline is necessary. Some 28 percent of respondents in the CIANI Only Group said that they had used physical discipline during the past year (Figure 6.5), but only 8.2 percent of them said that they believe physical discipline is needed to raise a child (Figure 6.4). This attitude-behaviour gap also appears for respondents in the CIANI + LCOCP and Control Groups, with higher numbers of caregivers using physical discipline than the numbers of caregivers who believed it was necessary.

Part of the reason for this gap may be the survey instrument itself. It is not uncommon in surveys to find a discrepancy between abstract and concrete measures of similar phenomena. ${ }^{11}$ To the extent that the difference between disciplinary attitudes and behaviours is situated along this abstract-concrete continuum, we would expect discrepancies to arise. Another aspect of the reason might be the imperfect relationship between attitudes and behaviour. There is often a strong relationship between the two, but there is no one-to-one correspondence. The same attitude can lead to different behaviours, and different attitudes can lead to the same behaviour. We see this strong but imperfect relationship in our data when we correlate the measures of disciplinary attitude and behaviour.

11 This discrepancy is well established in survey research. See, for example, Roberts, M. L., Hite, P. A., \& Bradley, C. F. (1994). Understanding attitudes toward progressive taxation. Public Opinion Quarterly, 58(2), 165-190. For a general discussion of the difference between abstract and concrete attitudes, see Mickelson, R.A. (2002). Educational Attitudes: Abstract and Concrete. In D. Levinson, P. Cookson, \& A. Sadovnik (Eds.), Education and sociology: An encyclopedia (pp. 199-202). New York and London: RoutledgeFalmer. 
Evaluation of Centres for the Integral Attention of Children in Dominican Republic (CIANIs) and Local Community Organizations for Child Protection (LCOCP)

Across all three of our groups, 72 percent of the respondents who said physical punishment is not necessary to raise a child reported that they had not used such discipline in the past year; that is, the relationship is strong. Still, it is not perfect: 28 percent who believed that physical discipline is unnecessary had actually used it during the past year. A final, related part of the reason for the attitude-behaviour discrepancy is that there is often a time lag between attitude change and behaviour change. Attitudes might change at a given time, but the change may be manifested in behaviour change only at some later time. This lag effect, of course, is one explanation for the imperfect relationship between attitudes and behaviour.

To summarize our analysis so far, there are significant group differences in disciplinary patterns. Respondents in the two Intervention Groups are much less likely to have favourable attitudes towards physical discipline and much less likely to report using such discipline than are respondents in the Control Group. Still, to this point, we have examined only a few examples of disciplinary attitudes and behaviours. One possible explanation for our results is that the group differences we find are just a function of the particular examples we have selected for analysis. We can test this explanation. Our survey included many more items measuring attitudes and behaviours than the items displayed in Figures 4.4 and 4.5. The next step in the analysis, then, is to build more comprehensive measures of disciplinary attitudes and behaviours and to see if significant group differences persist. These comprehensive measures are, in a sense, more robust tests of the extent to which the group variable has an impact on disciplinary patterns.

\section{ii. Building Comprehensive Measures of Discipline}

In this section, we construct one comprehensive index of disciplinary attitudes and three multiple-item indices of disciplinary behaviours, and we examine group differences across these comprehensive measures of discipline.

Figure 6.6 shows the distribution of all nine of our measures of attitudes towards physical discipline. The percentages in the figure are for all three groups combined. There is quite a range in the number of caregivers who believe physical discipline is justified under different conditions. Over 44 percent believe such discipline is justified if a child steals something. Only 11.4 percent believe it is justified if a child does poorly at school. Some 20 to 25 percent of caregivers hold favourable attitudes towards many of the forms of discipline displayed in the figure. 
Evaluation of Centres for the Integral Attention of Children in Dominican Republic (CIANIs) and Local Community Organizations for Child Protection (LCOCP)

Figure 6.6: Attitudes towards Physical Discipline Percent saying "yes," it is justifiable to use physical discipline in various situations

All Three Groups $(\mathrm{N}=1,690)$

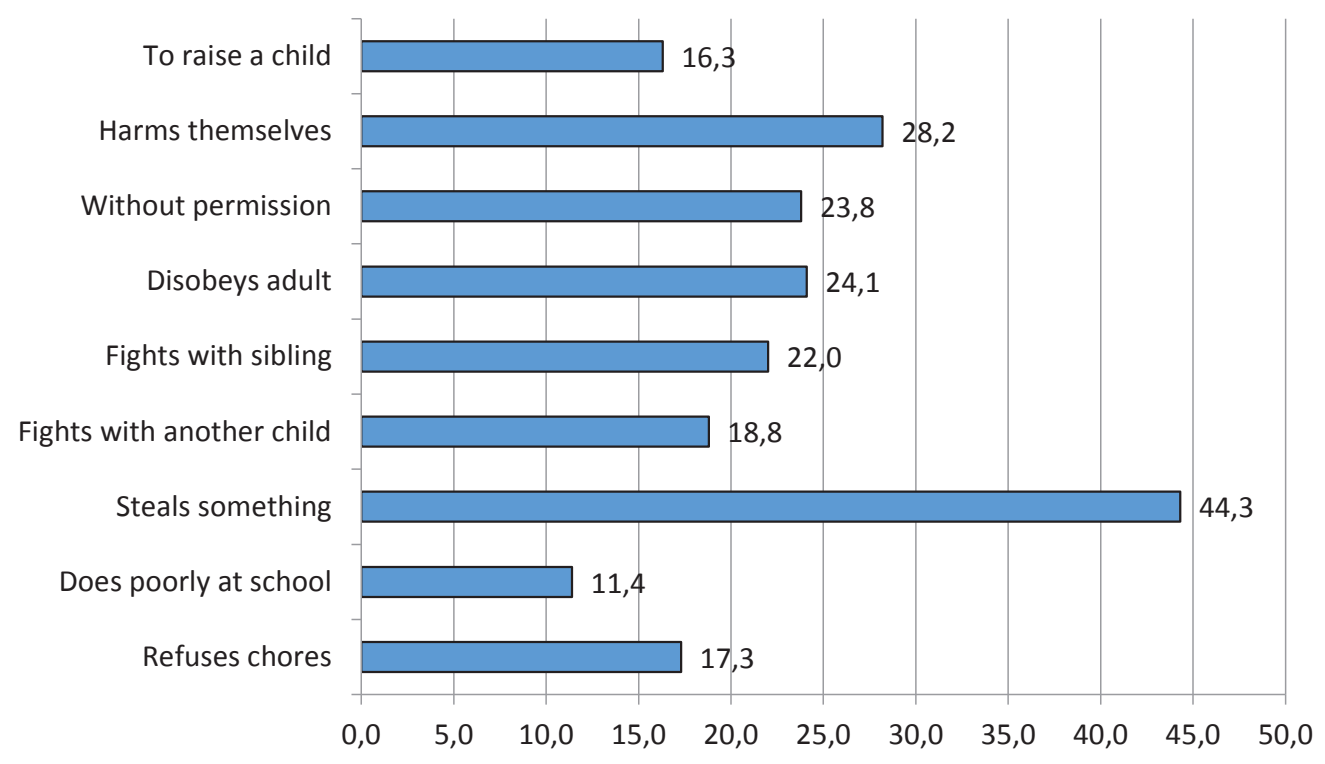

Table 6.7: Index of Attitudes towards Physical Discipline

\begin{tabular}{|c|c|c|}
\hline Attitude towards Discipline & Index Score & Percent \\
\hline Most Unfavourable & 0 & 37.6 \\
\hline \multirow{4}{*}{$\downarrow$} & 1 & 18.3 \\
\hline & 2 & 12.8 \\
\hline & 3 & 8.9 \\
\hline & 4 & 8.1 \\
\hline Most Favourable & 5 & 2.3 \\
& 6 & 3.2 \\
& 7 & 2.5 \\
& 8 & 2.2 \\
& 9 & 4.0 \\
\hline
\end{tabular}


Evaluation of Centres for the Integral Attention of Children in Dominican Republic (CIANIs) and Local Community Organizations for Child Protection (LCOCP)

To construct a comprehensive Index of Attitudes towards Physical Discipline, we added how many times each respondent said "yes" to the nine situations displayed in Figure 6.6. The distribution of the index is shown in Table 6.7. Over 37 percent of respondents scored zero on the index, indicating that they always said "no": they found all nine forms of discipline unjustifiable. A total of 4 percent, or 68 respondents, always said "yes," that physical discipline was appropriate in each of the nine situations. Over two thirds of respondents had index scores less than or equal to two. In the tabular analysis presented below, we use a recoded version of the Physical Discipline Attitudes Index to ensure a sufficient number of cases in different categories of the index:

Very Unfavourable (score of 0 )

Favourable and Very Favourable (scores of 3 through 9) $\quad 31.2 \%$

We also wanted to construct comprehensive measures of the kinds of disciplinary behaviours respondents use. Here we relied on what we had learned from our qualitative interviews with caregivers and CIANI staff about the battery of disciplinary measures used in the Multiple Indicator Cluster Survey (MICS) questionnaire, and on the work of Straus, Hamby, Finkelhor, Moore, \& Runyan (1998). ${ }^{12}$ Among the disciplinary techniques mentioned by primary caregivers, for instance, were swearing, pulling hair, smacking on the bum, shaking, and hitting with a stick. We built three behavioural indices: an Index of Psychologically Aggressive Discipline, an Index of Physical Discipline Behaviours, and an Overall Discipline Index.

\footnotetext{
12 MICS Household Questionnaire, version 3.0, 16 January 2012, available online at http://www.childinfo.org/mics4_questionnaire.html
} 
Evaluation of Centres for the Integral Attention of Children in Dominican Republic (CIANIs) and Local Community Organizations for Child Protection (LCOCP)

Figure 6.7: Psychologically Aggressive Discipline Percent saying "yes," they have used various forms of discipline in the past year

All Three Groups $(\mathrm{N}=1,690)$

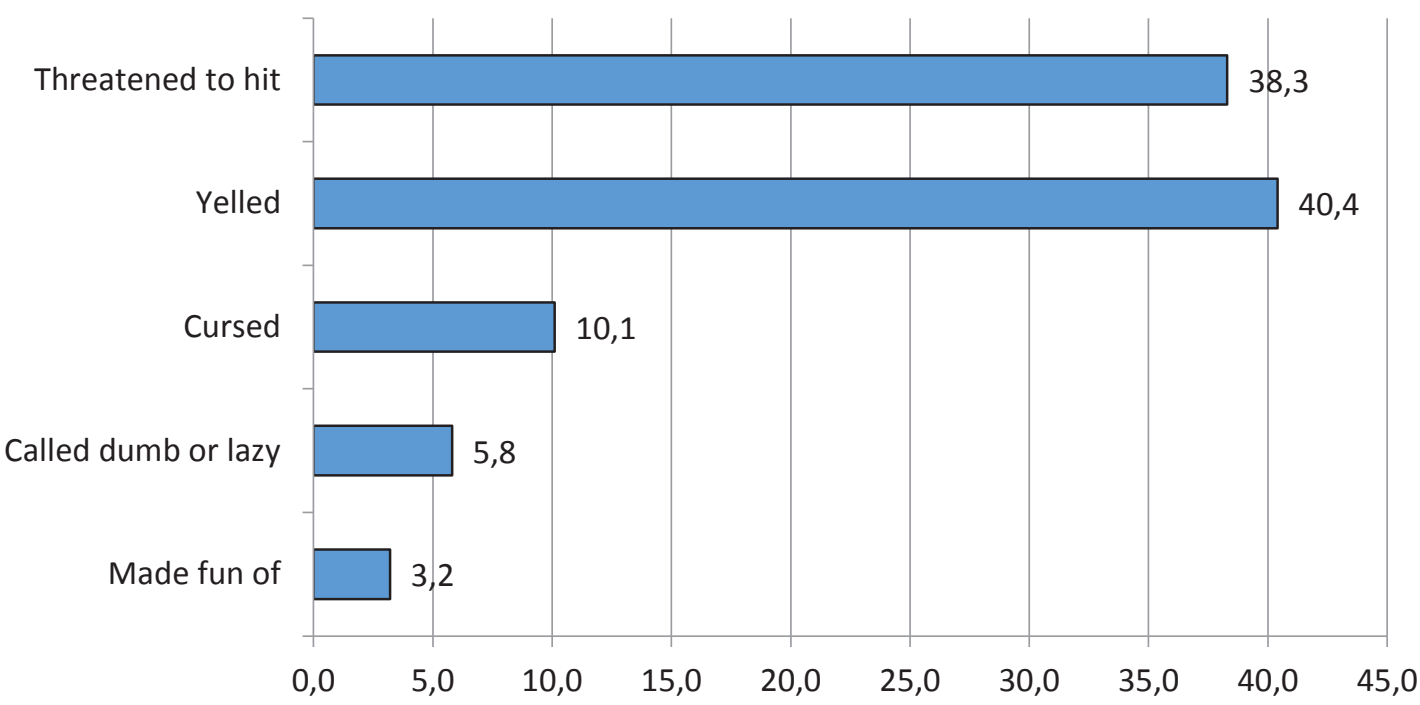

Table 6.8: Index of Psychologically Aggressive Discipline

\begin{tabular}{|c|c|c|}
\hline Level of Aggression & Index Score & Percent \\
\hline Lowest & 0 & 44.3 \\
\hline & 1 & 25.9 \\
\hline Highest & 2 & 20.7 \\
& 3 & 6.6 \\
\hline & 4 & 1.8 \\
\hline & Total Percent & 0.7 \\
\hline & $\mathbf{N}=$ & $\mathbf{1 0 0 . 0}$ \\
\hline
\end{tabular}


Evaluation of Centres for the Integral Attention of Children in Dominican Republic (CIANIs) and Local Community Organizations for Child Protection (LCOCP)

Figure 6.7 gives the distribution of individual items that measure psychologically aggressive discipline. In this form of discipline, children suffer no physical punishment, but are the object of verbal aggression, including threats, shouts, insults, and ridicule. Some 40 percent of respondents threatened to hit the child and yelled at the child. A smaller number cursed at the child $(10.1 \%)$, called the child dumb or lazy $(5.8 \%)$, or made fun of the child (3.2\%). Counting the number of times respondents engaged in the five kinds of verbal aggression yields the Index of Psychologically Aggressive Discipline (see Table 6.8). Some 44 percent of respondents with a score of zero have not used any form of psychological aggression against their children during the past year. In fact, the index is weighted towards the low end of the index, with over 70 percent of caregivers having scores of zero or one. Just 12 caregivers $(0.7 \%)$ reported using all five kinds of psychological aggression. The recoded version of this index is:

$\begin{array}{ll}\text { No Aggression (score of 0) } & 44.3 \% \\ \text { Low Aggression (score of 1) } & 25.9 \% \\ \text { Moderate and High Aggression (scores of 2 through 5) } & 29.8 \%\end{array}$

Verbal aggression towards children is one kind of discipline. Another is the actual use of some form of physical discipline that the child experiences as corporal punishment. Figure 6.8 shows the distribution of various physical discipline behaviours. The first item is the general one we discussed earlier, which asks caregivers if they have used physical discipline during the past year. This item is followed by 11 others that measure specific kinds of physical discipline the caregiver may have used during the past year. These 11 items are arranged very generally in order of the severity of the discipline, with minor forms of physical discipline near the top of the figure and more severe forms near the bottom. ${ }^{13}$ Overall, 35 percent of respondents report having used physical discipline in the past year. Very few respondents have slapped the child in the area of the face $(3.0 \%)$, pushed or knocked down the child (1.5\%), or hit the child with a fist (1.4\%). More caregivers used the other specific kinds of corporal punishment, ranging from the 7.4 percent who report beating up the child and the 8.3 percent who have hit the child on the body with a hard object, to the 22 percent who have hit the child on the bottom with their hand and the 31 percent who have hit the child's leg with their hand. Almost 20 percent of caregivers report shaking their child, which is considered a very severe form of punishment for children under the age of two.

\footnotetext{
13 The severity of punishment is based on Straus et al.'s (1998) classification of minor, severe, and very severe assault.
} 
Evaluation of Centres for the Integral Attention of Children in Dominican Republic (CIANIs) and Local Community Organizations for Child Protection (LCOCP)

Figure 6.8: Physical Discipline Behaviours Percent saying "yes," they have used physical discipline and various forms of discipline in the past year

All Three Groups $(\mathrm{N}=1,690)$

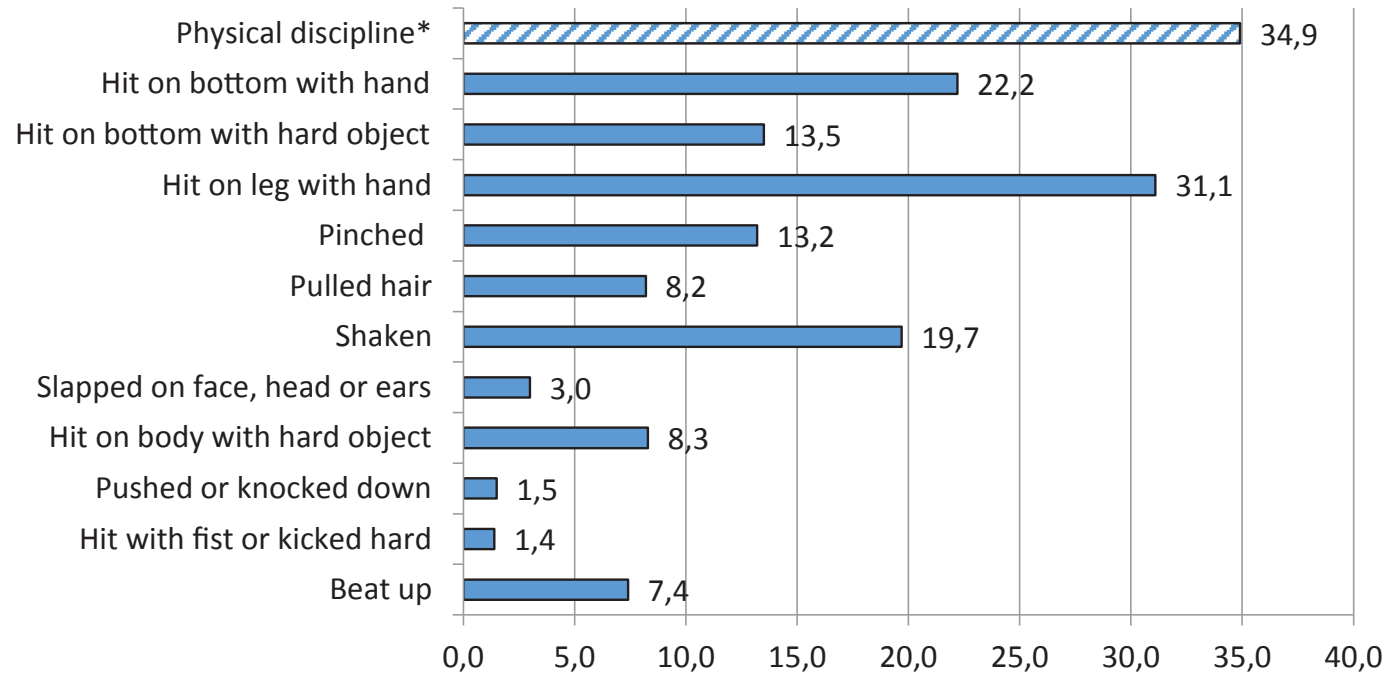

*Item not used in the Index of Physical Discipline Behaviours. See the discussion in the text.

Table 6.9 displays the Index of Physical Discipline Behaviours, which was constructed in the usual way by adding the number of times each respondent reported "yes," they had used a particular form of physical punishment. In this index, we added across only the 11 specific kinds of physical discipline in Figure 6.8. The general item on use of physical discipline during the past year, without specification of the form of discipline, is not part of index. In the figure, the bar for "physical discipline" is not solid, but instead filled with diagonal lines in order to underline that the item is not part of the index. There are two points to note immediately in the distribution of the index in Table 6.9. First, even though we add across 11 items, the highest score on the index is nine; that is, no respondents reported using 10 or all 11 of the modes of discipline. Second, no one scores seven on the index since no respondents reported using seven different forms of discipline. 
Evaluation of Centres for the Integral Attention of Children in Dominican Republic (CIANIs) and Local Community Organizations for Child Protection (LCOCP)

Table 6.9: Index of Physical Discipline Behaviours

\begin{tabular}{|c|c|c|}
\hline Level of Use & Index Score & Percent \\
\hline Lowest & 0 & 48.2 \\
\hline & 1 & 18.0 \\
\hline & 2 & 13.7 \\
\hline & 3 & 8.1 \\
\hline Highest & 4 & 5.7 \\
\hline & 5 & 3.4 \\
\hline & 6 & 1.9 \\
\hline & Total Percent & 0.7 \\
\hline & $\mathbf{N}=$ & 0.4 \\
\hline
\end{tabular}

We can see in Table 6.9 that almost one half of the respondents (48\%) have not used any one of the 11 kinds of physical discipline and therefore have an index score of zero. Just 20 percent of caregivers reported using three or more kinds of discipline. The recoded version of the index of Physical Discipline Behaviours has the following categories:

No Use (score of 0 ) $48.2 \%$ Low Use (scores of 1 and 2) $31.7 \%$ Moderate and High Use (scores of 3 through 9) $20.1 \%$ 
Table 6.10: Overall Discipline Index

\begin{tabular}{|c|c|c|}
\hline Level of Use & Index Score & Percent \\
\hline \multirow{13}{*}{ Lowest } & 0 & 36.0 \\
\hline & 1 & 13.4 \\
\hline & 2 & 11.9 \\
\hline & 3 & 12.5 \\
\hline & 4 & 8.2 \\
\hline & 5 & 6.7 \\
\hline & 6 & 3.9 \\
\hline & 7 & 3.0 \\
\hline & 8 & 1.5 \\
\hline & 9 & 0.9 \\
\hline & 10 & 0.7 \\
\hline & 11 & 0.5 \\
\hline & 12 & 0.2 \\
\hline \multirow[t]{3}{*}{ Highest } & 13 & 0.4 \\
\hline & Total Percent $=$ & 100.0 \\
\hline & $N=$ & 1,690 \\
\hline
\end{tabular}

The third and final comprehensive index of behaviour that we constructed is the Overall Discipline Index, which is simply a combination of the Index of Psychologically Aggressive Discipline and the Index of Physical Discipline Behaviours. We counted how many times each respondent mentioned using any of the five psychologically aggressive forms of discipline in Figure 6.7 and how many times they reported using any of the 11 modes of physical punishment in Figure 6.8. The result is displayed in Table 6.10. Few respondents have high scores on the Overall Discipline Index, with less than 1 percent recording scores greater than or equal to nine. There are a considerable number of caregivers at other points along the index. A total of 36 percent have a score of zero, and over 10 per percent ent have scores of one, two, and three. The recoded Overall Discipline Index has the following distribution:

No Use (score of 0 )

Low Use (scores of 1 through 3)

Moderate and High Use (scores of 4 through 13)
$36.0 \%$

$37.8 \%$

$26.2 \%$ 
Evaluation of Centres for the Integral Attention of Children in Dominican Republic (CIANIs) and Local Community Organizations for Child Protection (LCOCP)

\section{iii. Group Differences on the Comprehensive Measures of Discipline}

At this point, it is useful to recall that our purpose in building these comprehensive measures was to provide a robust test for the impact of the group variable on disciplinary attitudes and behaviours. Do caregivers in the two Intervention Groups still show lower disciplinary rates than do those in the Control Group across all our multiple-item indices?

The group differences on the Index of Attitudes towards Physical Discipline are shown in Figure 6.9. Once again, these differences are stark. The number in the Control Group with favourable or very favourable disciplinary attitudes $(47.6 \%)$ is two and one-half times higher than the number in the CIANI Only Group (18.2\%), and one and one-half times higher than that in the CIANI + LCOCP Group (29\%). Group differences persist, then, when we examine this comprehensive, multiple-item measure of discipline and seem not to be a function of just the individual disciplinary items we examined in the earlier section.

Figure 6.9: Index of Attitudes towards Physical Discipline by Group Percent with favourable or very favourable scores on the Index All Three Groups $(\mathrm{N}=1,690)$

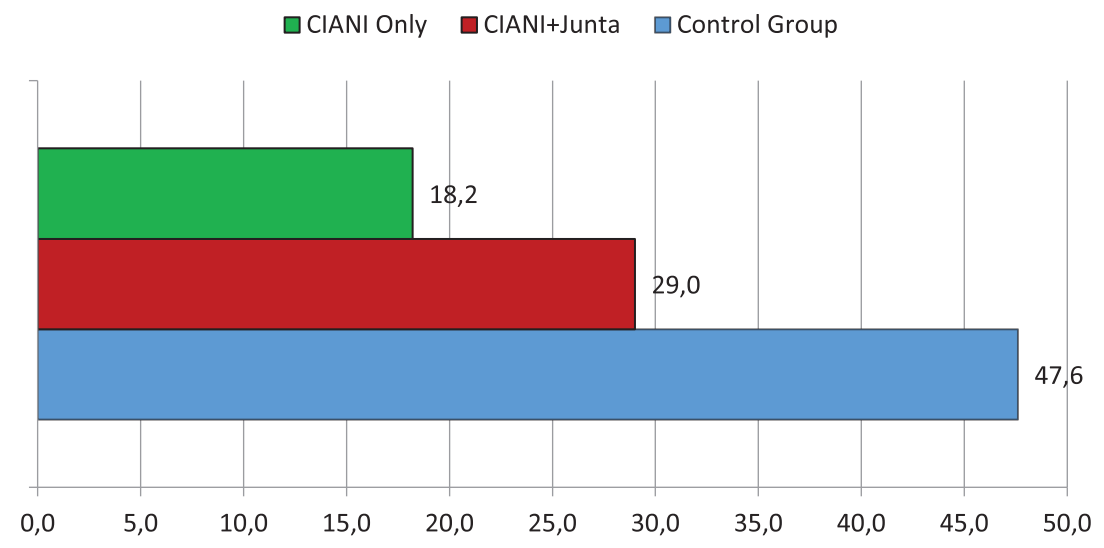


Evaluation of Centres for the Integral Attention of Children in Dominican Republic (CIANIs) and Local Community Organizations for Child Protection (LCOCP)

\section{Figure 6.10: Three Indices of Discipline Behaviour by Group Percent with moderate or high scores on the Index All Three Groups $(\mathrm{N}=1,690)$}

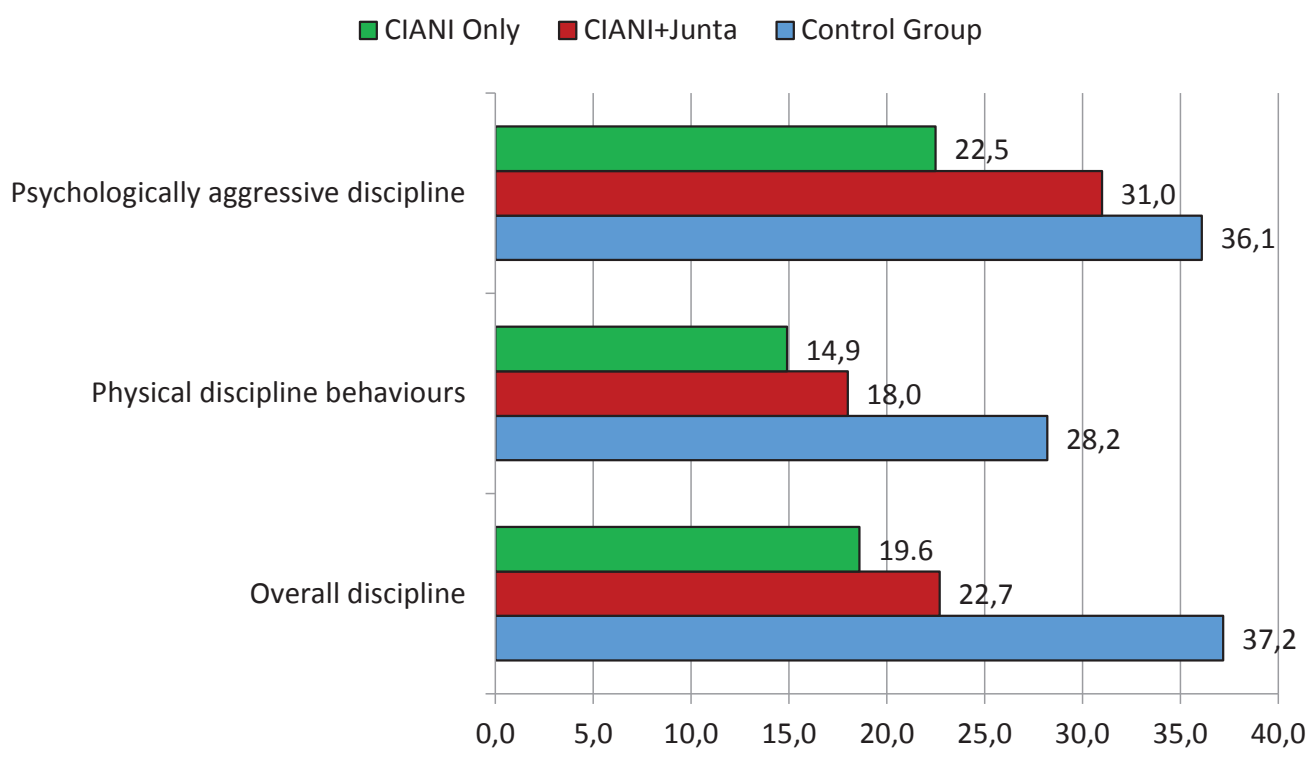

Figure 6.10 shows the group differences across the three indices of disciplinary behaviour that we constructed in the previous section. The familiar pattern emerges once again. There are large differences between the two Intervention Groups on one hand and the Control Group on the other hand; that is, caregivers in the CIANI Only Group and CIANI + LCOCP Group are less likely to threaten or yell at their children and less likely to use corporal punishment than are caregivers in the Control Group. On the Index of Psychologically Aggressive Discipline, only 22.5 percent of respondents in the CIANI Only Group have moderate or high scores. This figure rises to 36.1 percent for those in the Control Group. Group differences on the other two indices are even higher. Only 14.9 percent of respondents in the CIANI Only Group have moderate or high scores on the Index of Physical Discipline Behaviours, as compared to 28.2 percent in the Control Group. The corresponding difference on the Overall Discipline Index (Figure 6.10) is 18.6 percent versus 37.2 percent.

There is one further point to note about both Figures 6.9 and 6.10 . In their disciplinary attitudes and behaviours, caregivers in the CIANI + LCOCP Group regularly stand between caregivers in the CIANI Only Group and the Control Group. This pattern is 
Evaluation of Centres for the Integral Attention of Children in Dominican Republic (CIANIs) and Local Community Organizations for Child Protection (LCOCP)

revealed in the figures by the varying lengths of the bars: the green bar for the CIANI Only group is shortest, the blue bar for the Control Group is longest, and the red bar for the CIANI + LCOCP Group has a length between the two. These different bar lengths mean that respondents in the CIANI + LCOCP Group have more favourable attitudes towards discipline than do those in the CIANI Only Group, but they also have less favourable attitudes than do those in the Control Group (Figure 6.9). The same comparison holds for disciplinary behaviours (Figure 6.10). This in-between or intermediate status of the CIANI + LCOCP Group appears consistently in the data. The same finding emerged in our earlier discussion of group differences on individual items measuring disciplinary attitudes and behaviour (see Figures 6.4 and 6.5). This pattern is not what we expected. As discussed in the section on study design, we expected the CIANI + LCOCP Group to have the lowest inclination to physical punishment, since that group should demonstrate the combined effects of the CIANI and LCOCP interventions. Perhaps this anomalous finding for the CIANI + LCOCP Group is related to the nonequivalency of the three groups that we examined earlier. This anomaly appears again in slightly different form in the multivariate analysis we present later in the report. There we explore in more detail the intermediate status of the CIANI + LCOCP Group.

\section{iv. Social Characteristics and Discipline}

To assess the impact of belonging to one of these groups on disciplinary attitudes and behaviour, we need to take into account the impact that other factors might have. We begin this task here by examining the extent to which social characteristics are related to the measures of discipline.

We examined the relationship between our various measures discipline and all the social characteristics of caregivers listed in Table 6.3, which we discussed earlier in our social profile of survey respondents. There were inconsistent relationships between discipline and most social characteristics, including sex, marital status, number of children in the household, number of years in the neighbourhood, income, and level of community engagement. Sometimes these characteristics were significantly related to disciplinary attitudes and behaviour, sometimes not. Most of the time, their effects were weak.

Other characteristics of respondents had stronger and more significant effects on discipline: the average age of children in their household, their levels of education, 
Evaluation of Centres for the Integral Attention of Children in Dominican Republic (CIANIs) and Local Community Organizations for Child Protection (LCOCP)

and their degrees of family stress, and community trust. Below, we explore in more detail the impact of these social characteristics on discipline. As in the previous exploration, the analysis looks at both a selection of individual items measuring discipline and the various comprehensive discipline indices that we have constructed.

Figure 6.11 shows the extent to which disciplinary attitudes and behaviour vary by the average age of children in the household. In order to provide a general indication of the nature of the relationship, the figure shows only the end points of the variable Average Age of Children, and contrasts the lowest average age, "two or younger," to the highest average age, "five or older." Caregivers with older children have stricter attitudes to discipline than do those with younger children in the household. Some 19 percent of the former, but only 9 percent of the latter believe that the use of physical discipline to raise a child is justifiable. This pattern is repeated in the behavioural measure in the figure; 39.7 percent of caregivers with older children report having used physical discipline in the past year, compared to 24.9 percent of those with younger children in the household.

Figure 6.11: Selected Physical Discipline Items by Average Age of Children Percent saying "yes," it is justifiable to use physical discipline, or "yes," they used physical discipline

All Three Groups $(\mathrm{N}=1,690)$

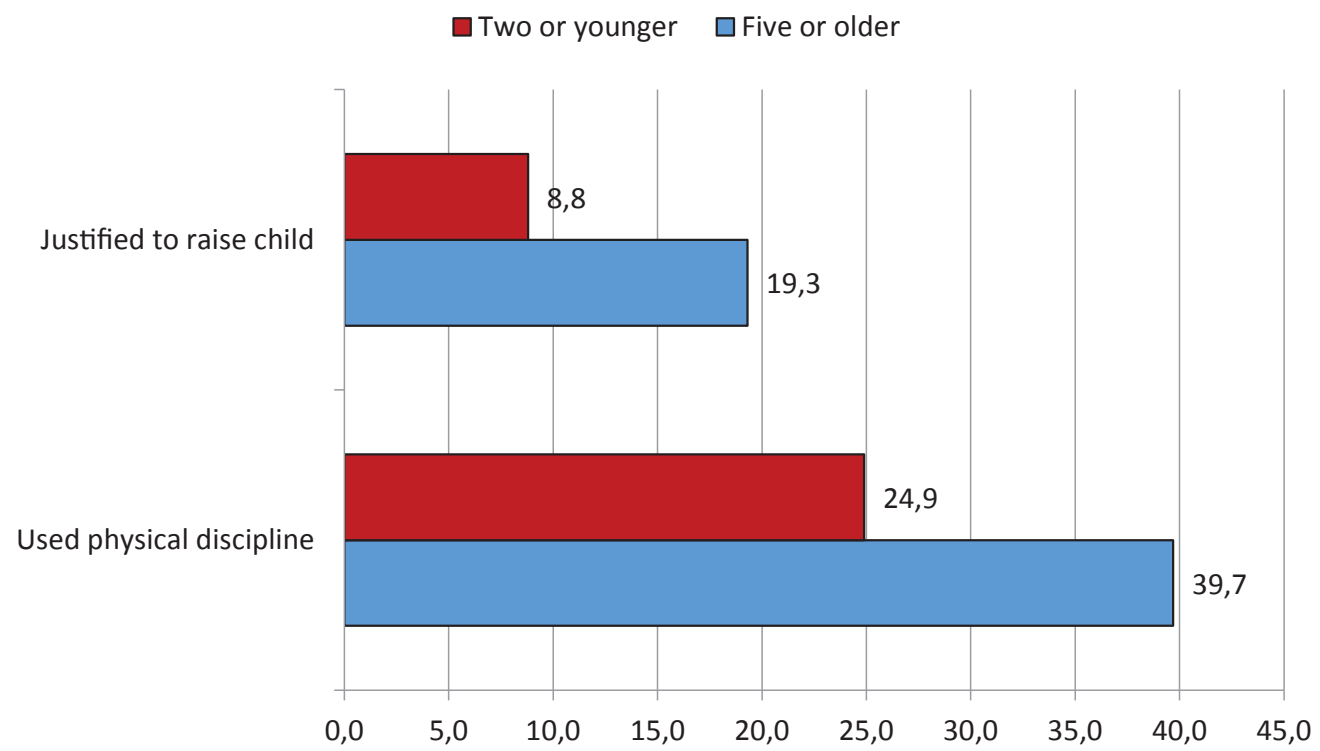


Evaluation of Centres for the Integral Attention of Children in Dominican Republic (CIANIs) and Local Community Organizations for Child Protection (LCOCP)

Figure 6.12 examines the relationship between the average age of children and the four disciplinary indices; attitudes towards discipline, psychologically aggressive discipline, physical discipline behaviours, and overall discipline. Generally, respondents with older children are more favourably disposed toward corporal punishment or use physical discipline more frequently than do caregivers with younger children. This kind of pattern is called a positive relationship, in which high values on one variable are paired with high values on another variable. In this case, the older the average age of children in the household is, the higher is the score on the disciplinary index. The difference in relation to age is especially large for the Index of Psychologically Aggressive Discipline, which measures the extent of verbal aggression towards children. Here, 22 percent of caregivers with younger children, but 34 percent of those with older children have high scores on the index. There is a similar gap in the Index of Overall Discipline, which is partly a function of the way this index was constructed. It is useful to recall that the Overall Index combines all the items used in both the Psychologically Aggressive Discipline Index and the Physical Discipline Behaviours Index.

Figure 6.12: Four Indices of Discipline by Average Age of Children Percent with moderate or high scores on the Discipline Indices* All Three Groups $(\mathrm{N}=1,690)$

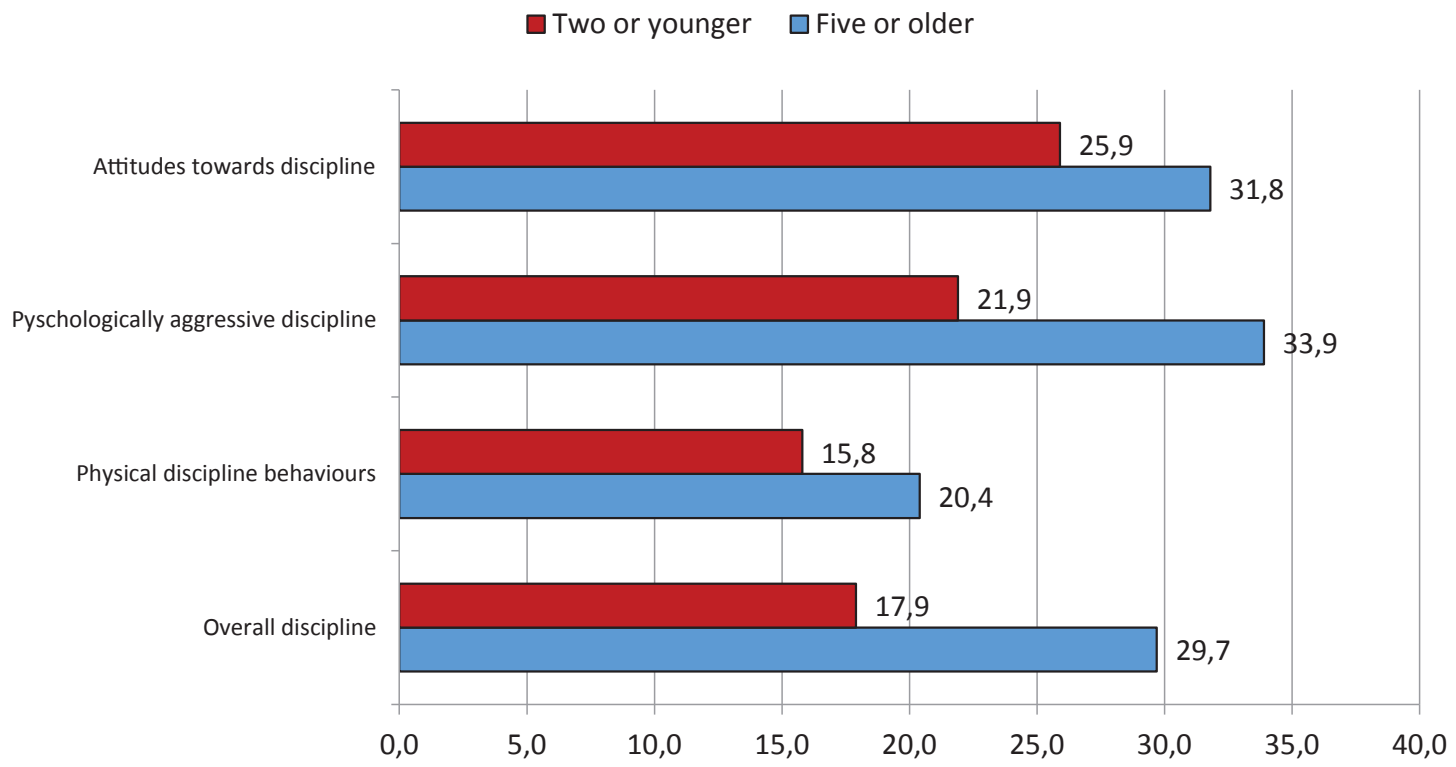


Evaluation of Centres for the Integral Attention of Children in Dominican Republic (CIANIs) and Local Community Organizations for Child Protection (LCOCP)

${ }^{*}$ On the Attitudes Index, the percent shows those with very favourable or favourable attitudes.

Next, we explore the relationship between discipline and the caregivers' levels of education, comparing once again the end points of, in this case, the education measure. The first item in Figure 6.13 demonstrates that, while 23.7 percent of respondents with the lowest level of education (completed grade school or less) feel it is justified to use physical discipline to raise a child, only 10.5 percent of those with the highest education (some university or more) feel the same way. The second item, on reports about using physical discipline during the past year, reveals a similar pattern.

Figure 6.13: Selected Physical Discipline Items by Level of Education Percent saying "yes," it is justifiable to use physical discipline, or "yes," they used physical discipline

All Three Groups $(\mathrm{N}=1,690)$

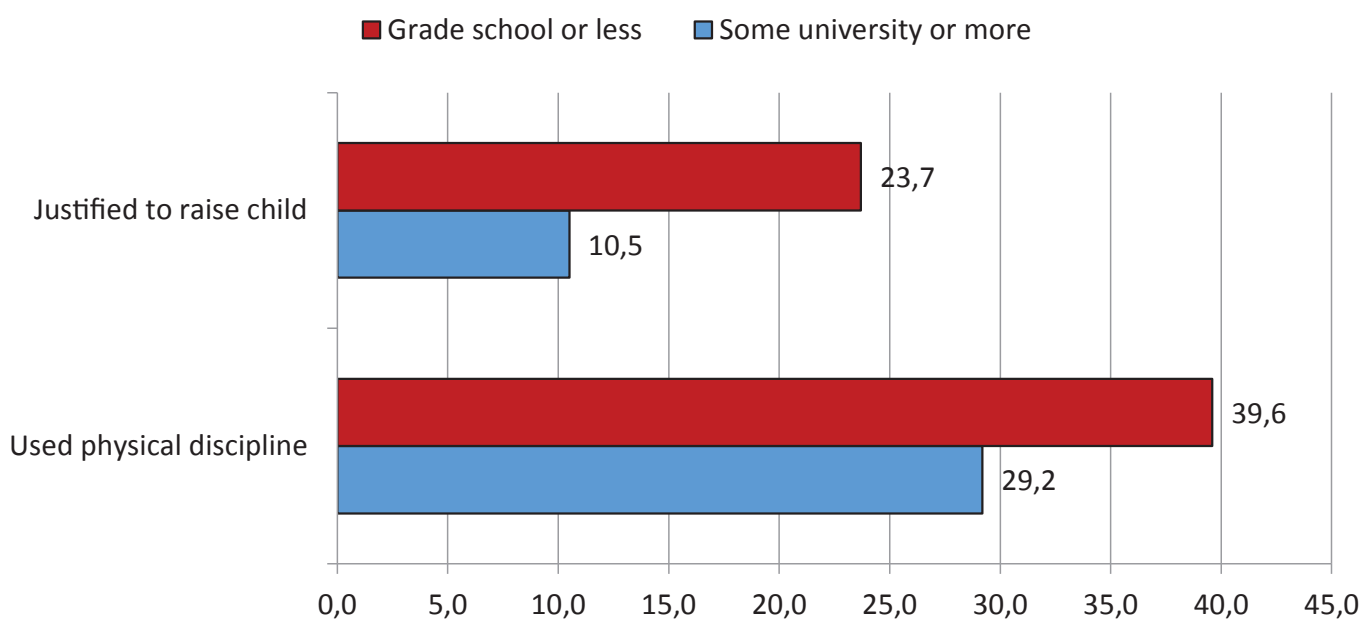


Evaluation of Centres for the Integral Attention of Children in Dominican Republic (CIANIs) and Local Community Organizations for Child Protection (LCOCP)

Figure 6.14: Four Indices of Discipline by Level of Education Percent with moderate or high scores on the Discipline Indices* All Three Groups $(\mathrm{N}=1,690)$

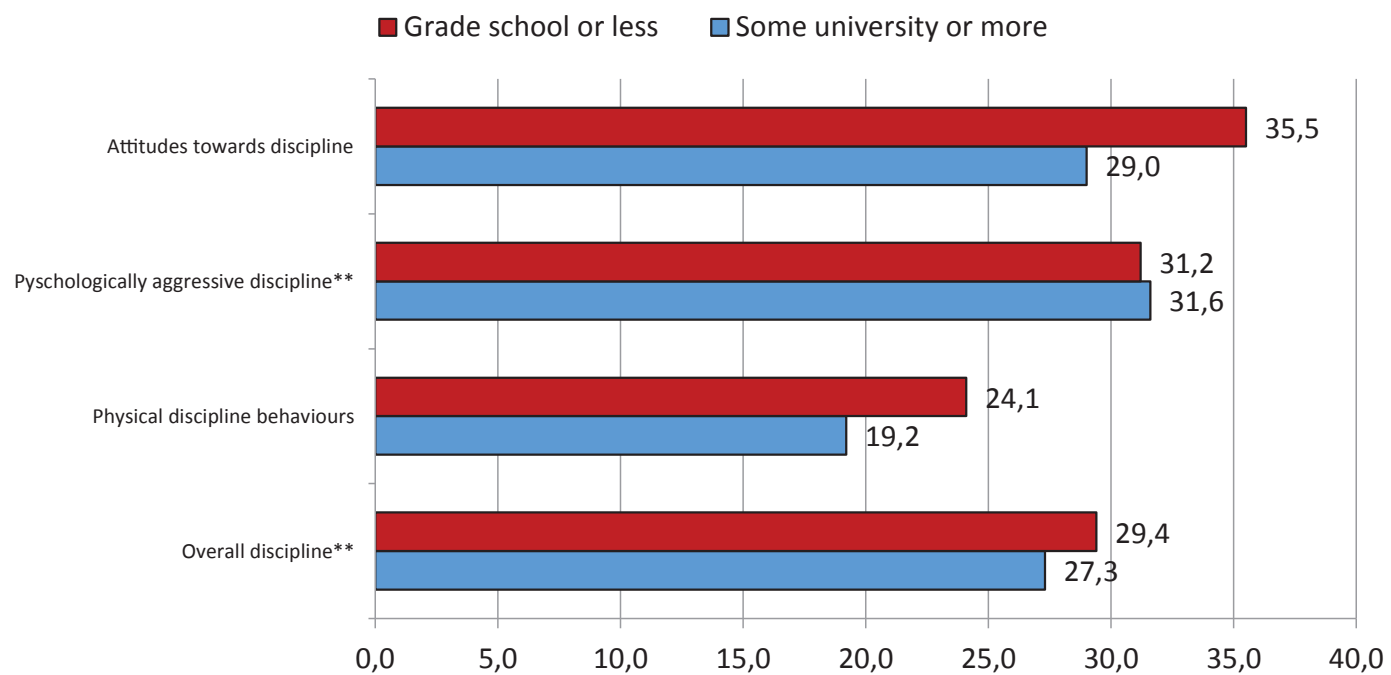

*On the Attitudes Index, the percent shows those with very favourable or favourable attitudes.

${ }^{* *}$ Relationship with the Level of Education is not significant.

Figure 6.14 presents the results for the four discipline indices. Here the relationship with level of education is not consistent. On two of the four indices, Psychological Aggression and Overall Discipline, the disciplinary differences between respondents with low and high education are not significant. On the other two indices, Attitudes towards Discipline and Physical Discipline Behaviours, the differences are a little larger and significant. On the Attitudes Index, for example, 35.5 percent of respondents with low levels of education have high scores on the index, compared to 29 percent of those with high levels of education. This kind of pattern indicates a negative relationship, in which low values on one variable "go together" with high values on another variable. Here, respondents with low values on the education variable tend to have higher values on the discipline index. In a corresponding way, those with high values on the education variable tend to have lower values on the discipline index. 
Evaluation of Centres for the Integral Attention of Children in Dominican Republic (CIANIs) and Local Community Organizations for Child Protection (LCOCP)

Figure 6.15: Selected Physical Discipline Items by Family Stress Index Percent saying "yes," it is justifiable to use physical discipline, or "yes," they used physical discipline

All Three Groups $(\mathrm{N}=1,690)$

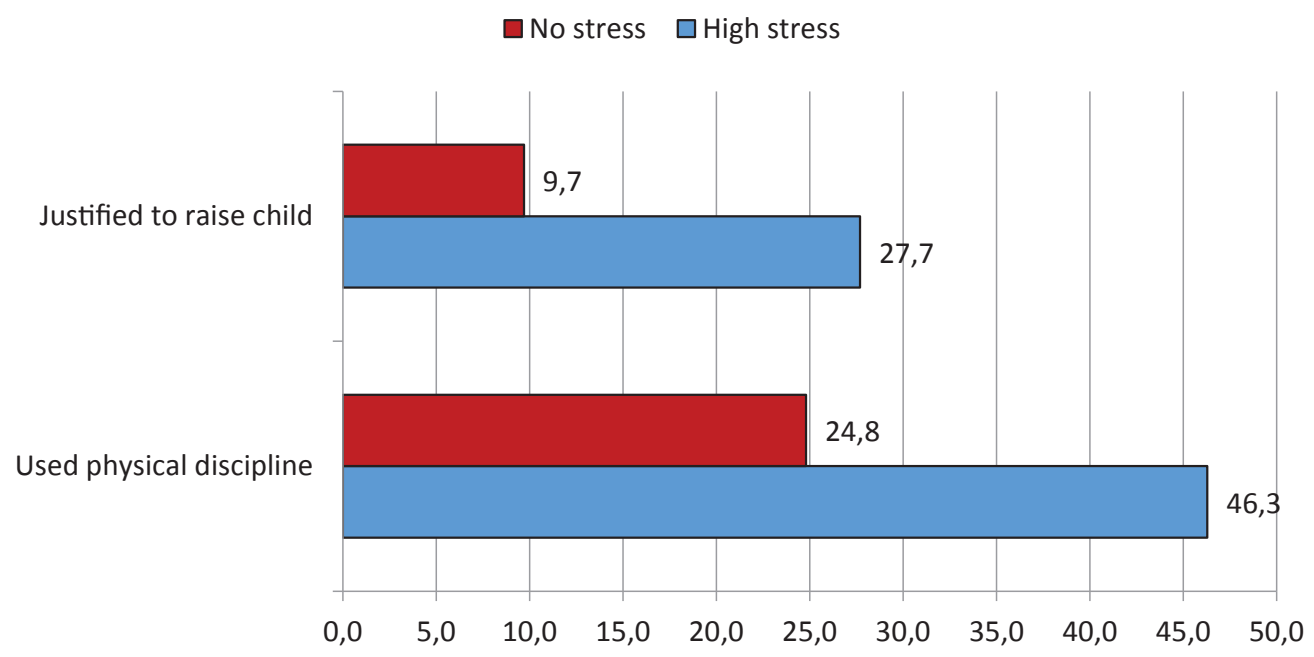

Figure 6.16: Four Indices of Discipline by Family Stress Index Percent with moderate or high scores on the Discipline Indices* All Three Groups $(\mathrm{N}=1,690)$

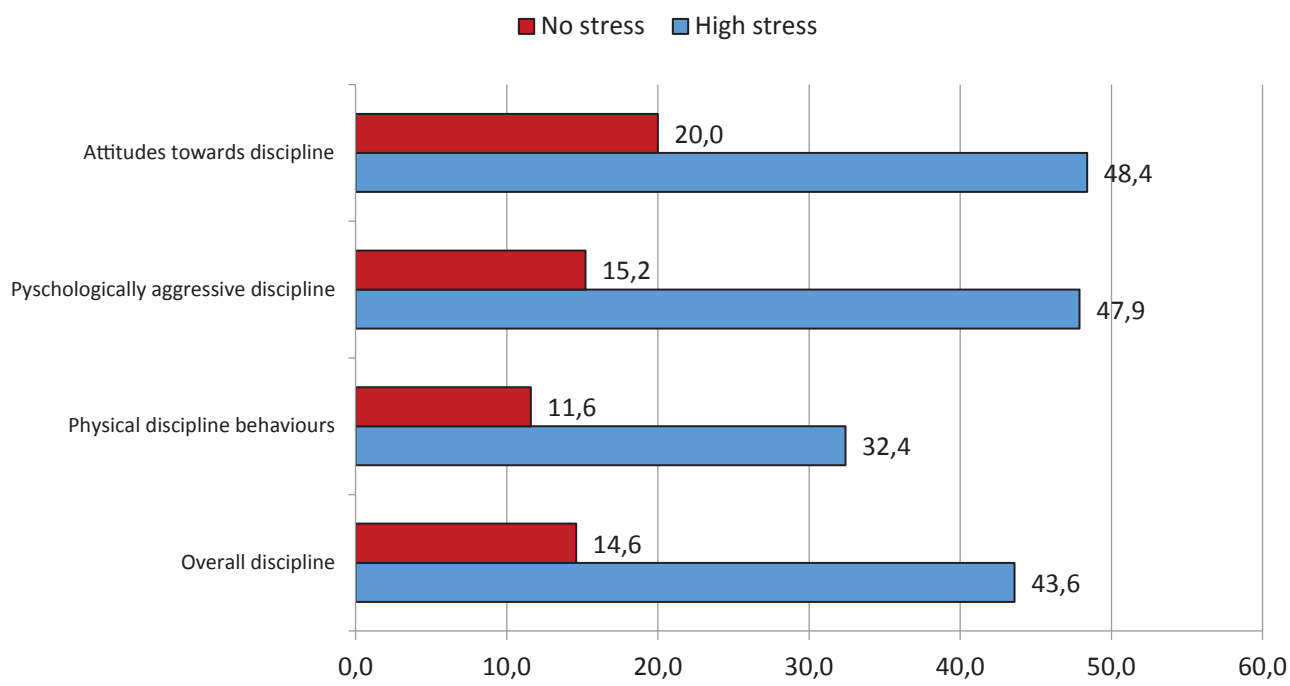

*On the Attitudes Index, the percent shows those with very favourable or favourable attitudes. 
Evaluation of Centres for the Integral Attention of Children in Dominican Republic (CIANIs) and Local Community Organizations for Child Protection (LCOCP)

Figures 6.15 and 6.16 relate family stress to discipline. Here, one needs to recall that the Family Stress Index measures how many different kinds of stressful situations caregivers have experienced during the past year, including money problems, divorce or breakup, problems putting food on the table, and so on (see Figure 6.1 and Table 6.4). There are stark differences between the lengths of the paired bars for caregivers with no family stress and those with high family stress. ${ }^{14}$ In Figure 6.16, respondents with high family stress are much more likely to have high discipline index scores than are those with no family stress. On the Overall Discipline Index, for instance, 43.6 percent of caregivers with high stress also have high discipline scores, but only 14.6 percent of those with no stress have high discipline scores.

The pattern of differences here indicates a positive relationship between family stress and discipline; high scores on family stress tend to go with high scores on the discipline indices. In one sense, this relationship is similar to the one we found between discipline and the average age of children in the household, which was also positive. Yet, in another sense, the two sets of relationships are different. The relationship between family stress and discipline is stronger than is the relationship between average age of children and discipline. The varying strengths of relationship are indicated by the different lengths of the pairs of red and blue bars: the greater the difference in length, the greater the difference in percentage between high and low stress, and the stronger the relationship. A comparison of Figure 6.12 , on the average age of children, to Figure 6.16 , on family stress, is a useful way to visualize the difference between a weaker relationship and stronger positive relationship, respectively.

The final social characteristic of caregivers that we examine in this section is their level of community trust, which measures the extent to which they feel that they are part of a community, that they are among people who share their beliefs, that they can count on people's support, and that their neighbourhood is safe for them and their children (see Figure 6.2). In Figures 6.17 and 6.18, we examine the relationship between the various measures of discipline and the Community Trust Index. We can focus on the latter figure (Figure 6.18), which provides an accurate representation of the nature of the relationship. Those caregivers with low com-

\footnotetext{
14 Since our intention is to give a general indication of the nature of the relationship, in the figure, we focus on the end points of the recoded Index of Family Stress (no stress, high stress), just as we focused on the end points in the analysis of the age of children and education.
} 
Evaluation of Centres for the Integral Attention of Children in Dominican Republic (CIANIs) and Local Community Organizations for Child Protection (LCOCP)

munity trust are much more likely to have high scores on disciplinary attitudes, psychologically aggressive discipline, and physical discipline behaviours than are those with high community trust. As an example, almost 41 percent with low trust, as opposed to only 15 percent with high trust, have high scores on the Index of Attitudes towards Discipline. As the above comparison suggests and as each set of bars in Figure 6.17 shows, there is a negative relationship between community trust and discipline; low trust tends to go with high discipline, and high trust with low discipline. This negative relationship is much stronger than the one we found between levels of education and discipline (see Figure 6.14).

Figure 6.17: Selected Physical Discipline Items by Community Trust Index Percent saying "yes," it is justifiable to use physical discipline, or "yes," they used physical discipline All Three Groups $(\mathrm{N}=1,690)$

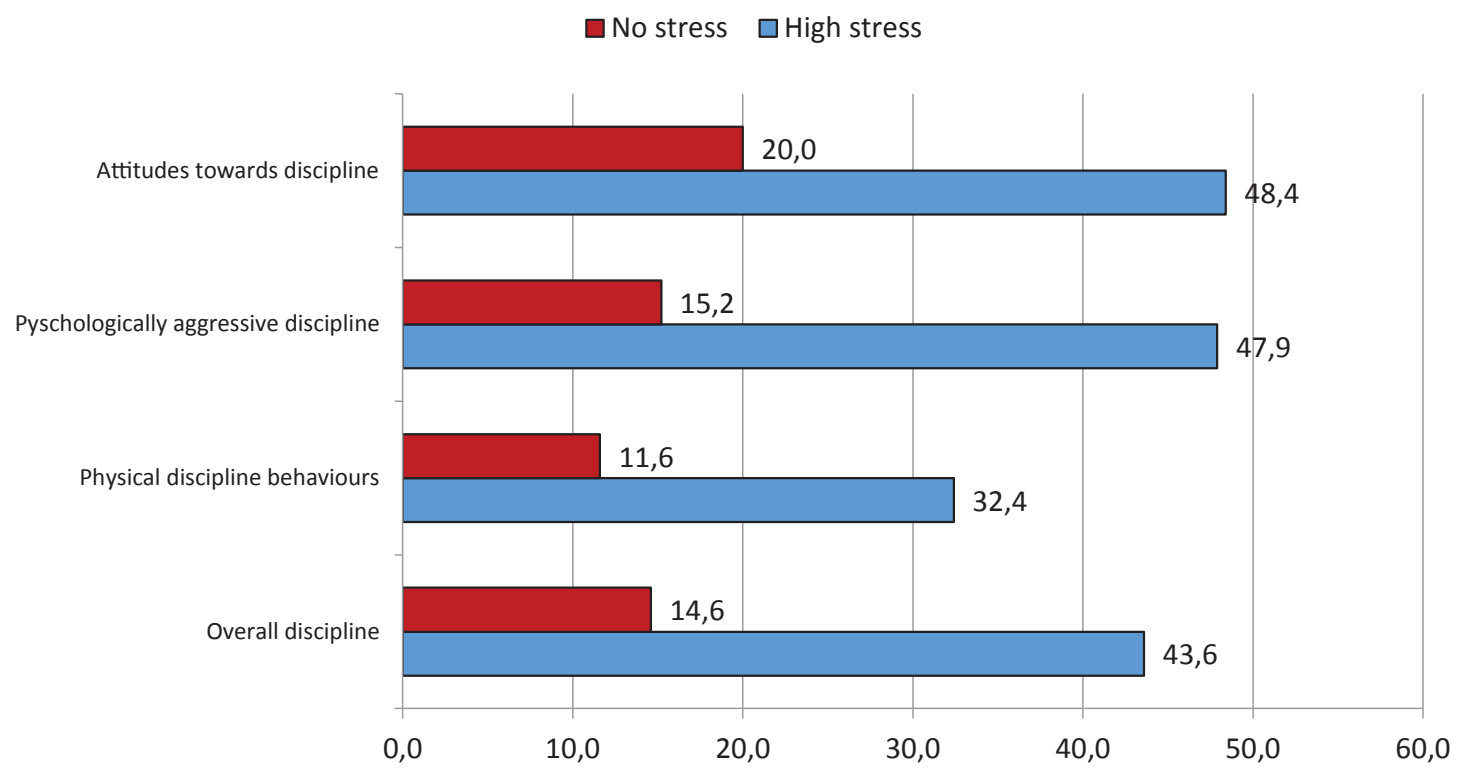


Evaluation of Centres for the Integral Attention of Children in Dominican Republic (CIANIs) and Local Community Organizations for Child Protection (LCOCP)

\section{Figure 6.18: Four Indices of Discipline by Community Trust Index Percent with moderate or high scores on the Discipline Indices* All Three Groups $(\mathrm{N}=1,690)$}

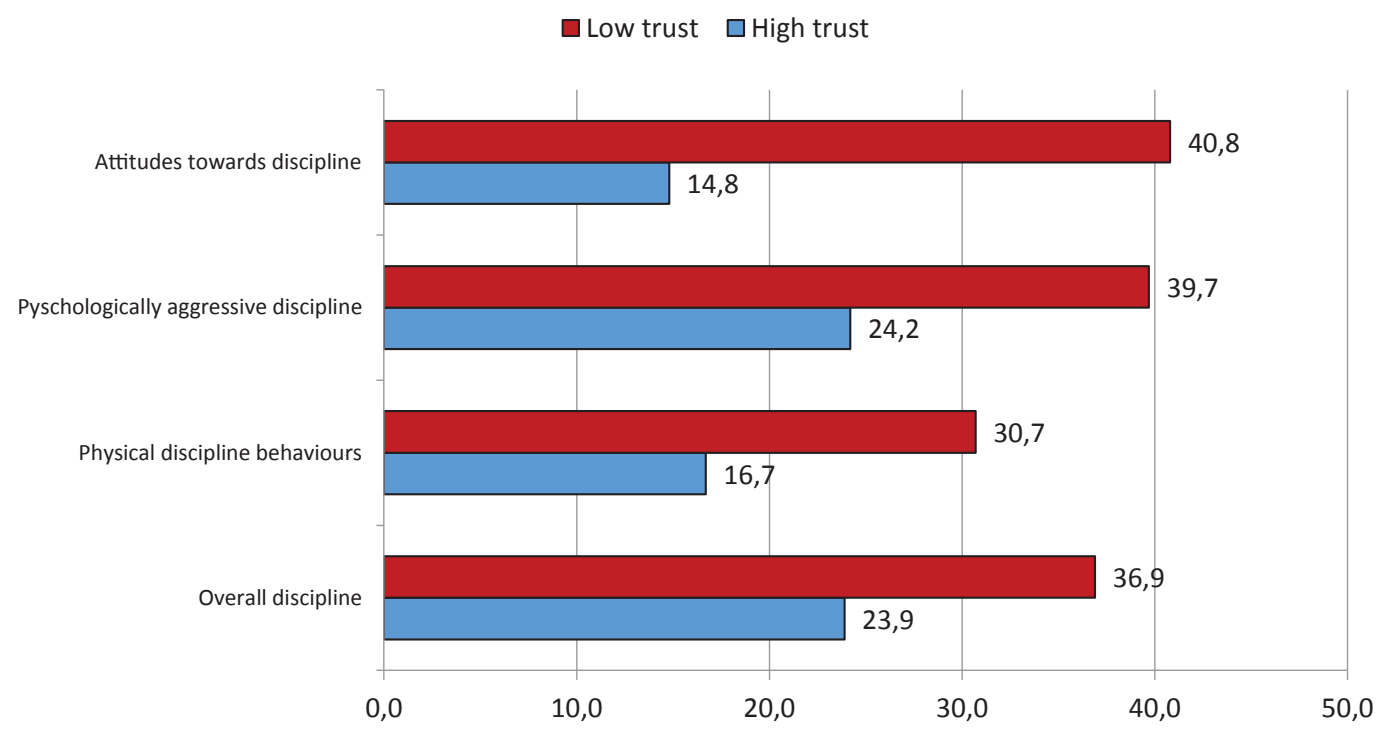

${ }^{*}$ On the Attitudes Index, the percent shows those with very favourable or favourable attitudes.

We began the section on "between-group analysis" by examining the impact of the group variable on the disciplinary attitudes and behaviours of the 1,690 caregivers in our study. We found that, generally, respondents in the two Intervention Groups (CIANI Only and CIANI + LCOCP) not only had less favourable attitudes towards the physical disciplining of children, but also used corporal punishment less often than did those in the Control Group. The final part of the analysis in this section showed that there are numerous correlates of discipline in addition to the group variable: the age of children in the household, the caregivers' education, their sense of community trust, and the level of family stress. If our purpose is to estimate the impact of group - that is, to assess the effectiveness of the CIANI and LCOCP programs in relation to disciplinary attitudes and behaviour-we need to be mindful of these other correlates. While the effect of some variables can be weak or inconsistent, for example, the age of children and the level of education, the effect of others, like family stress and community trust, is stronger. In fact, the strength of the bivariate relationships between stress and discipline and between trust and discipline is comparable to that of the bivariate relationship between group and discipline. The section on multivariate analysis addresses this question 
Evaluation of Centres for the Integral Attention of Children in Dominican Republic (CIANIs) and Local Community Organizations for Child Protection (LCOCP)

that is, estimating the independent impact of group on disciplinary attitudes and behaviours while controlling for the other correlates of discipline.

Before we turn to that multivariate analysis, we need to examine the caregivers in the two Intervention Groups and estimate how their involvement in the CIANI program may have affected their disciplinary attitudes and practices.

\section{c. Within-Group Analysis: Examining the Two Intervention Groups}

This section examines the experiences of caregivers within the two Intervention Groups, the CIANI Only Group and the CIANI + LCOCP Group; that is, it is concerned with caregivers who are registered in a CIANI. The section explores how satisfied caregivers are with the services provided by the CIANI and also examines the extent to which caregivers' experiences in the CIANI influence their disciplinary attitudes and behaviours.

The within-group analysis presented here complements the between-group analysis of the previous section. That section showed many significant differences in disciplinary patterns between caregivers in the two Intervention Groups and those in the Control Group. This section extends that analysis by beginning to address the question of why caregivers in the CIANI Only and CIANI + LCOCP Groups have a lower proclivity to physical discipline than do caregivers in the Control Group. What is it about their experiences in the CIANI that might lead to such a beneficent outcome?

\section{i. Satisfaction with CIANI Services}

In this report, the introductory section and the section on qualitative analysis outlined the many services the CIANI offers and the ways those services affect important connections between caregiver and child, among other outcomes. In fact, the many qualitative interviews we conducted with caregivers, professional CIANI staff, and key informants in the community led us to include in the survey questionnaire a battery of questions on satisfaction with CIANI services.

Respondents were asked how satisfied they are "with the different supports the CIANI provides for children and families." Figure 6.19 shows the distribution of the 
Evaluation of Centres for the Integral Attention of Children in Dominican Republic (CIANIs) and Local Community Organizations for Child Protection (LCOCP)

various levels of satisfaction with services. The most obvious point in the Figure is the very high level of satisfaction with the CIANI's services related to child care, education provided to the children, child social development, health care, and food and nutrition. For each of these five services, almost all respondents reported that they were either "very satisfied" or "satisfied." Adding the "very satisfied" responses to the "satisfied" responses brings the total very close to 100 percent across all five dimensions of satisfaction. When we examine caregivers' relative levels of satisfaction with CIANI services, it is important to remember that we are talking about the difference between very satisfied and satisfied. Only a handful of respondents reported that they were dissatisfied or very dissatisfied with any of the CIANI services. This result is not surprising, given what our semi-structured interviews revealed. While the interviewees in the qualitative research were not completely uncritical of the CIANI program, they were genuinely appreciative of the supports the CIANI provided to children and families.

\section{Figure 6.19: Satisfaction with CIANI Services Percent saying "Very Satisfied," "Satisfied," or Dissatisfied/Very Dissatisfied Two Intervention Groups (N=799)*}

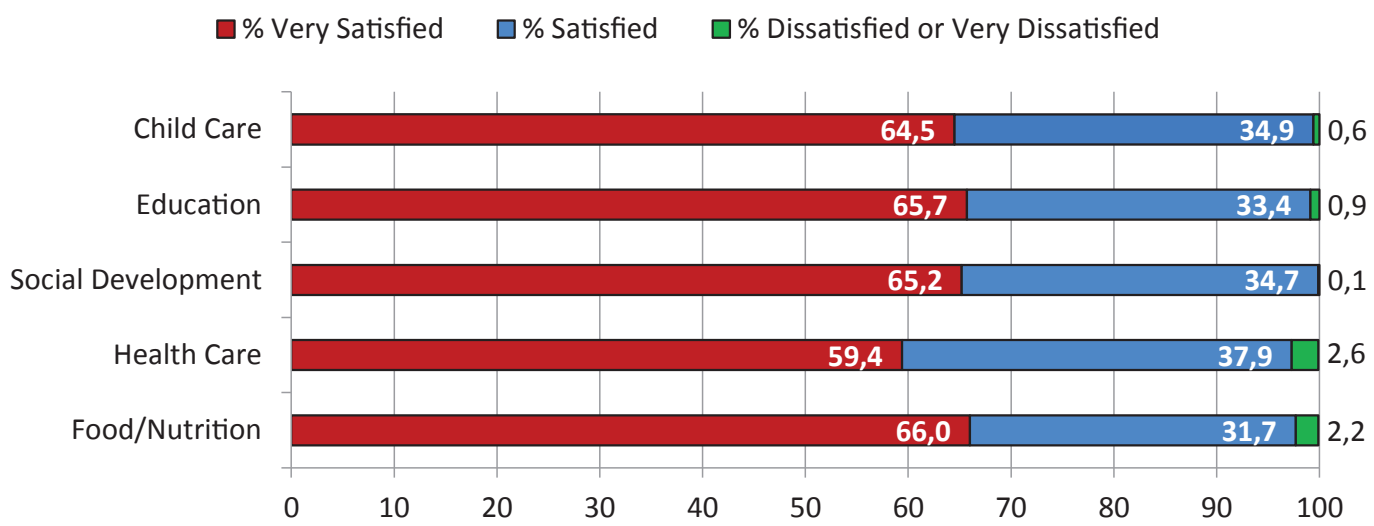

*There are 565 respondents in the CIANI Only Group and 596 in the CIANI + LCOCP Group, for a Total $N=1,161$. Of these, 362 are new registrants in the CIANI. Since the new registrants have no history with the CIANI, they were not asked questions about CIANI experiences. The overall $\mathrm{N}$ for this figure and subsequent figures in this section is therefore 799 (1,161-362). For Figure 6.19 and the remaining figures in this section, the $\mathrm{N}$ for each individual item in the figure will vary slightly because some respondents did not answer every question. 
Evaluation of Centres for the Integral Attention of Children in Dominican Republic (CIANIs) and Local Community Organizations for Child Protection (LCOCP)

\section{Table 6.11: Index of Satisfaction with CIANI Services}

\begin{tabular}{|c|c|c|}
\hline Level of Satisfaction & Index Score & Percent \\
\hline Satisfied & 0 & 24.8 \\
\hline & 1 & 3.9 \\
& 2 & 5.1 \\
\hline & 3 & 7.1 \\
\hline Always Very Satisfied & 4 & 10.9 \\
& 5 & 48.2 \\
\hline & Total Percent & $\mathbf{1 0 0 . 0}$ \\
\hline & $\mathbf{N}=$ & $\mathbf{7 9 9}$ \\
\hline
\end{tabular}

The Satisfaction Index constructed from these individual items is shown in Table 6.11. Since the overall level of satisfaction is so high, the index counts only the number of times caregivers said they were "very satisfied" with the CIANI services. It is necessary to be clear about what a score of zero on the index means. It does not mean that the 25 percent of respondents with this score are unsatisfied. Given the way the index was built, these respondents could have said "satisfied" to all five items and still received a score of zero, because they never said "very satisfied." The 48 percent of respondents with scores of five on the Satisfaction Index responded "very satisfied" to each of the five items. The index remains a relative measure of satisfaction, so we can say that those with high scores on the index are more satisfied than are those with low scores, remembering that the distinction is essentially between being "satisfied" and "very satisfied." The category labels of the recoded version of the Satisfaction Index reflect the high overall level of satisfaction:

Satisfied (score of 0)

Sometimes Very Satisfied (scores of 1 through 4)

Always Very Satisfied (score of 5)
$24.8 \%$

$27.0 \%$

$48.2 \%$

\section{ii. CIANI Engagement and Physical Discipline}

It is important to establish in itself the level of caregiver satisfaction with CIANI services. Yet satisfaction shows an erratic relationship to our measures of discipline, reminiscent of the inconsistencies we found in the previous section on respon- 
Evaluation of Centres for the Integral Attention of Children in Dominican Republic (CIANIs) and Local Community Organizations for Child Protection (LCOCP)

dents' social characteristics. For some disciplinary measures, caregivers who are very satisfied with CIANI services exhibit a lower proclivity for physical punishment than do those who are less satisfied. For other measures, there are no significant differences in discipline across the various categories of satisfaction.

This pattern of inconsistency is repeated for a second CIANI-specific variable we examine. The survey asked respondents in the two Intervention Groups how long their children had been registered in the CIANI. We expected that any effect membership in the CIANI would have on reduction of caregiver inclination for physical discipline might increase with the years spent in the CIANI. The findings in this regard are mixed. The variable "years spent in the CIANI," like the variable "satisfaction," shows an irregular relationship to disciplinary attitudes and behaviours. Sometimes the percent of caregivers holding favourable attitudes towards discipline or engaging in corporal punishment declines with years spent in the CIANI; sometimes it does not, and the relationship to discipline is weak and not significant. This inconsistent effect might be due to the variable's abbreviated range; 90 percent of caregivers have been registered in a CIANI for two years or less, with only a few registered for four or more years. The average (mean) length of time spent in a CIANI is 1.1 years. Perhaps this is just not enough "time" for any effect to materialize.

At first glance, then, neither satisfaction with CIANI services nor years spent in the CIANI help to explain why respondents in the CIANI Only and CIANI + LCOCP Groups have a lower proclivity for physical discipline than do those in the Control Group. The "CIANI effect" appears not to be mediated through caregiver satisfaction or time in the CIANI. We examined a third potential CIANI-specific factor that might be related to a lower proclivity for corporal punishment. There is a possibility that active engagement with the CIANI, rather than satisfaction or time spent, has a real impact on a caregiver's disposition toward corporal punishment.

We asked respondents in the two Intervention Groups how often they attended or helped out at the CIANI's Parent School. It is helpful to recall that the Parent School is a legally-mandated structural component of each CIANI. CIANIs are required by law to hold regular Parent School meetings to discuss various topics of interest to CIANI members. As we saw earlier, violence against children, responsible parenting, abuse prevention, and appropriate methods of child discipline are regular topics. Members of the larger community are often if not always invited to attend the school. 
The initial findings regarding Parent School engagement are promising. Figure 6.20 shows the relationship between frequency of attendance at the CIANI Parent School and two measures of discipline we have examined before, that is, caregivers' attitudes about the need for physical discipline to raise a child properly and caregivers' actual use of physical discipline during the past year. Caregivers who attend the Parent School "very often" or "often" are much less likely to have a favourable attitude towards the use of corporal punishment $(6.8 \%)$ than are those who "sometimes" or "hardly ever" attend (19.1\%). The corresponding difference for respondents who report using physical discipline in the past year is 30.1 percent for frequent attenders and 45.4 percent for infrequent attenders. Figure 6.21 shows the relationships with discipline, using a second measure of Parent School engagement, that is, how often caregivers "help out" at the Parent School. The pattern is the same, with caregivers who frequently help out showing a lower attitudinal and behavioural proclivity for physical discipline than do caregivers who only sometimes or hardly ever help out.

\section{Figure 6.20: Selected Physical Discipline Items by Attending Parent School Percent saying "yes," it is justifiable to use physical discipline, or "yes," they used physical discipline Two Intervention Groups ( $\mathbf{N}=\mathbf{7 9 5})$}

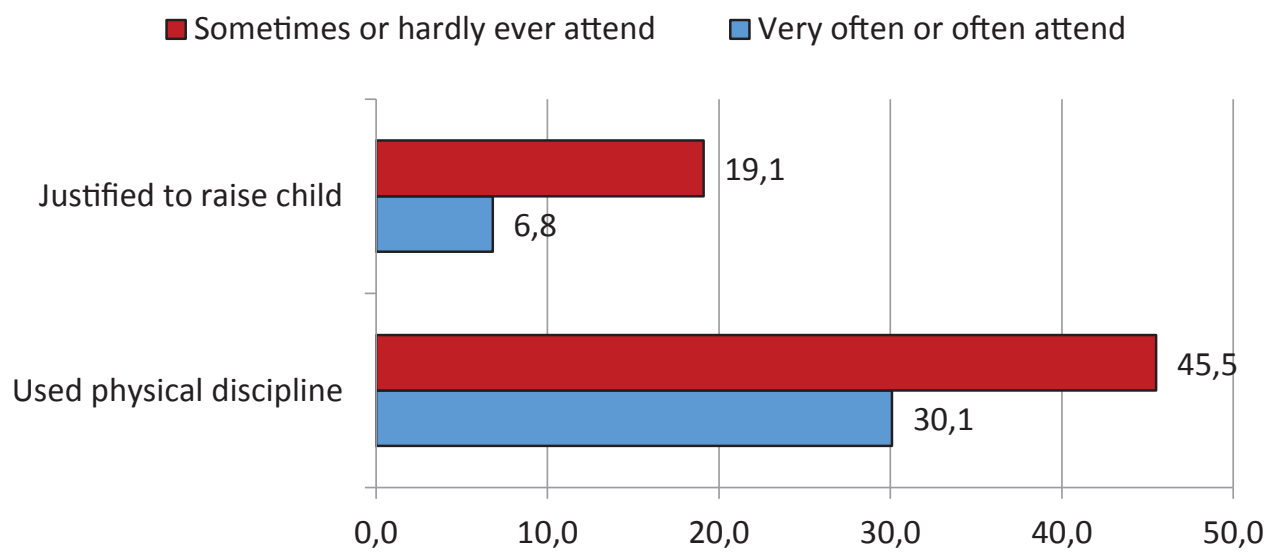


Evaluation of Centres for the Integral Attention of Children in Dominican Republic (CIANIs) and Local Community Organizations for Child Protection (LCOCP)

Figure 6.21: Selected Physical Discipline Items by Helping Out at Parent School

Percent saying "yes," it is justifiable to use physical discipline, or "yes," they used physical discipline

Two Intervention Groups ( $=797)$

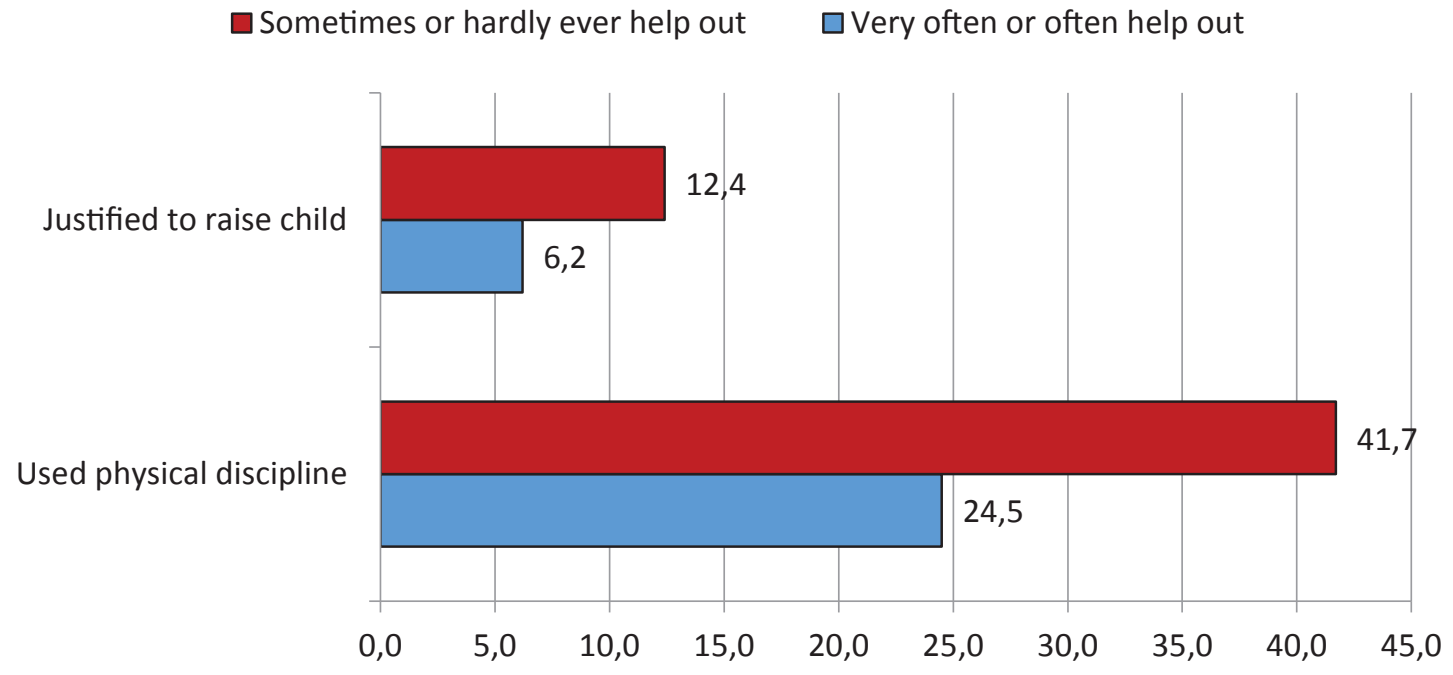

Attending or helping out at the parent school are important ways that caregivers engage in the CIANI, but they are not the only ways. The CIANI organizes many social events over the course of the year, for example, public meetings, holiday celebrations, and birthday parties. The survey asked respondents how often they attended or helped out at these other CIANI events. Figure 6.22 shows the distribution of the four measures designed to gauge participation in the CIANI. There is strong participation in the CIANI across all four modes. The percentages of caregivers who report having attended or helped out either "very often" or "often" are $76.2,46.5,82.5$ and 59.3, as we move from top to bottom in the figure. 
Evaluation of Centres for the Integral Attention of Children in Dominican Republic (CIANIs) and Local Community Organizations for Child Protection (LCOCP) Figure 6.22: Attending and Helping Out at Parent School and Other CIANI
Events

Percent saying "very often," "often," "sometimes," or "hardly ever" Two Intervention Groups ( $\mathbf{N}=\mathbf{7 9 9}$ )

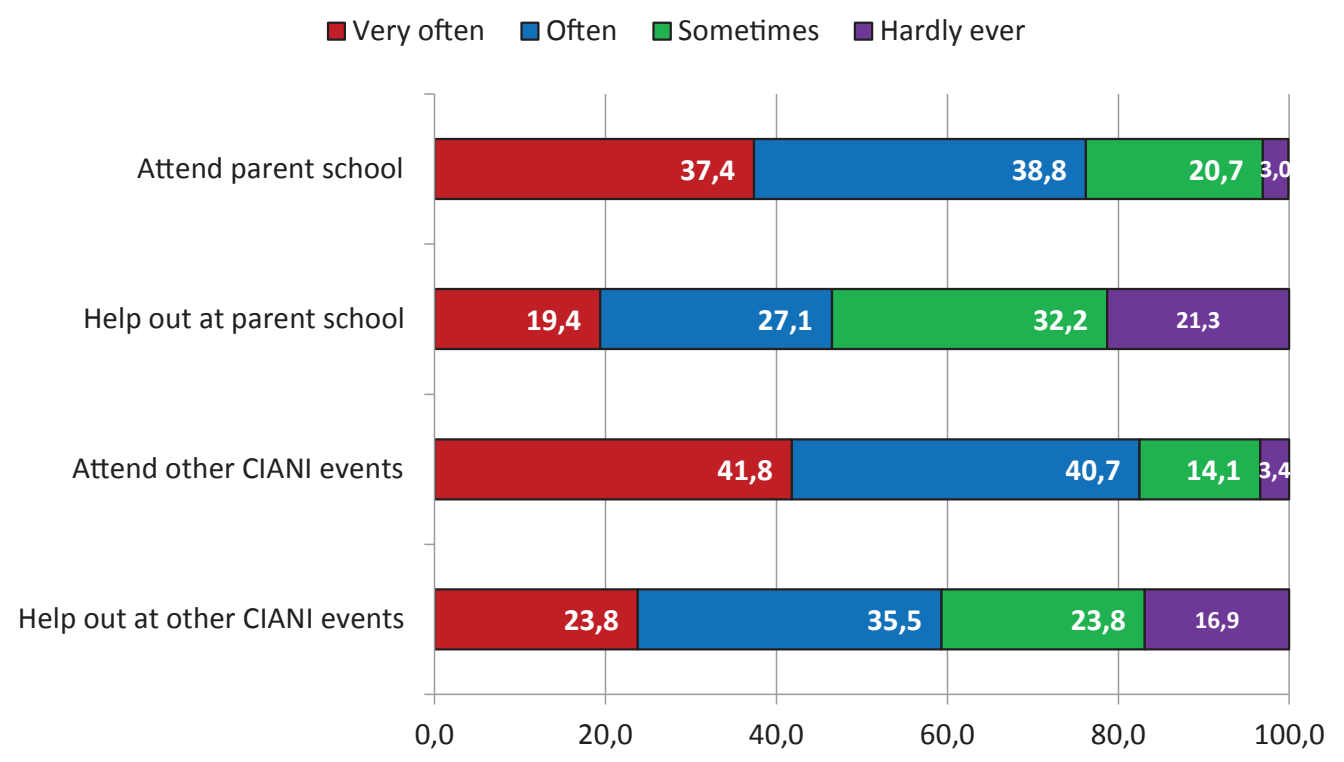

Table 6.12: Index of Engagement in the CIANI

\begin{tabular}{|c|c|c|}
\hline Level of Engagement & Index Score & Percent \\
\hline Lowest & 0 & 10.4 \\
\hline & 1 & 11.3 \\
\hline Higkest & 2 & 20.0 \\
\hline & 3 & 20.7 \\
& 4 & 37.7 \\
\hline & Total Percent & 100.0 \\
\hline & $\mathbf{N}=$ & $\mathbf{7 9 9}$ \\
\hline
\end{tabular}


Evaluation of Centres for the Integral Attention of Children in Dominican Republic (CIANIs) and Local Community Organizations for Child Protection (LCOCP)

We constructed an Index of Engagement in the CIANI from these four items by summing the number of time caregivers said "very often" or "often". Table 6.12 presents the distribution of the Index. At the low end of the Index with the score of zero are the least engaged: the 10.4 percent of caregivers who responded "sometimes" or "hardly ever" to each of the four items. The highly engaged at the other end of the Index with a score of four are the 37.7 percent of respondents who always said that they "very often" or "often" attended and helped out at the various CIANI functions. The recoded version of the Index of CIANI Engagement used in the tabular analysis and figures is:

Low CIANI Engagement (scores of 0 and 1)

Moderate CIANI Engagement (scores of 2 and 3)

High CIANI Engagement (score of 4)
$21.7 \%$

$40.7 \%$

$37.7 \%$

Figure 6.23 shows the relationship between the CIANI Engagement Index and the individual discipline items. Figure 6.24 relates the Engagement Index to the four discipline indices. Again, for purposes of illustration, we show the end points, the lowest and highest categories, of the recoded CIANI Engagement Index. Both Figure 6.23 and Figure 6.24 show a fairly strong negative relationship between engagement and discipline. Caregivers with low engagement tend to have higher scores on discipline, and those with high engagement tend to have lower discipline scores. To illustrate, Figure 6.24 shows that 43.4 percent of respondents with low engagement in the CIANI have moderate or high scores on the Index of Psychologically Aggressive Discipline; only 23.3 percent of those with high engagement are also moderate-to-high on the Index of Psychologically Aggressive Discipline. These large percentage differences and the associated disparities in the length of the pairs of bars in the figures, are similar to the differences we saw previously in relation to Family Stress and Community Trust. 
Evaluation of Centres for the Integral Attention of Children in Dominican Republic (CIANIs) and Local Community Organizations for Child Protection (LCOCP)

Figure 6.23: Selected Physical Discipline Items by Index of Engagement in the CIANI

Percent saying "yes," it is justifiable to use physical discipline, or "yes," they used physical discipline

Two Intervention Groups ( $\mathbf{N}=799$ )

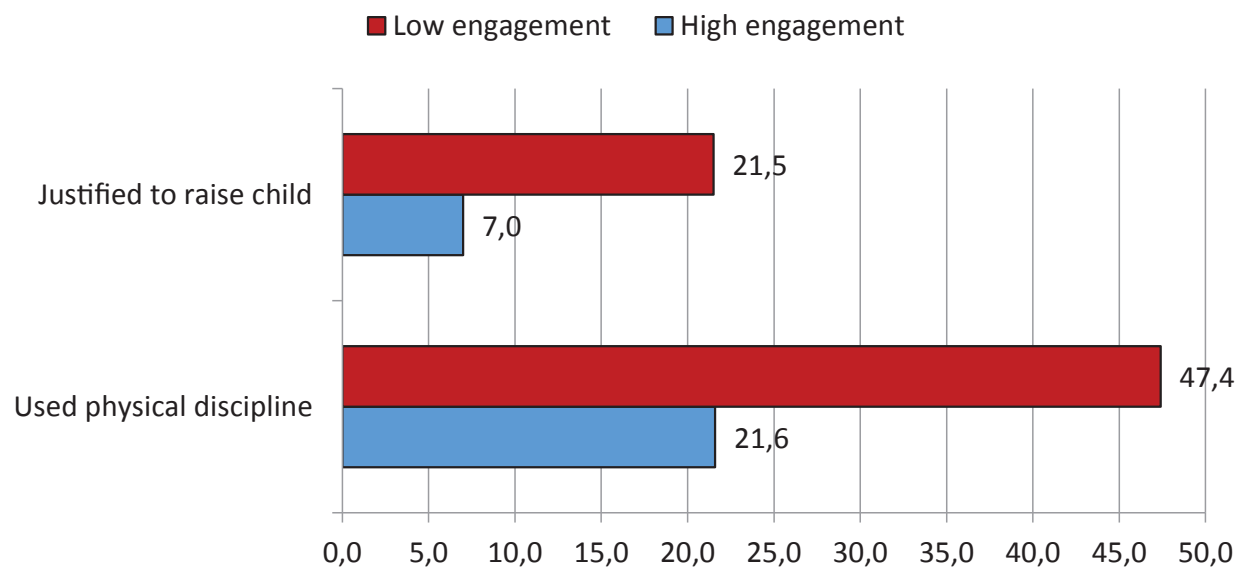

Figure 6.24: Four Indices of Discipline by Index of Engagement in the CIANI Percent with moderate or high scores on the Discipline Indices* Two Intervention Groups ( $\mathbf{N}=\mathbf{7 9 9}$ )

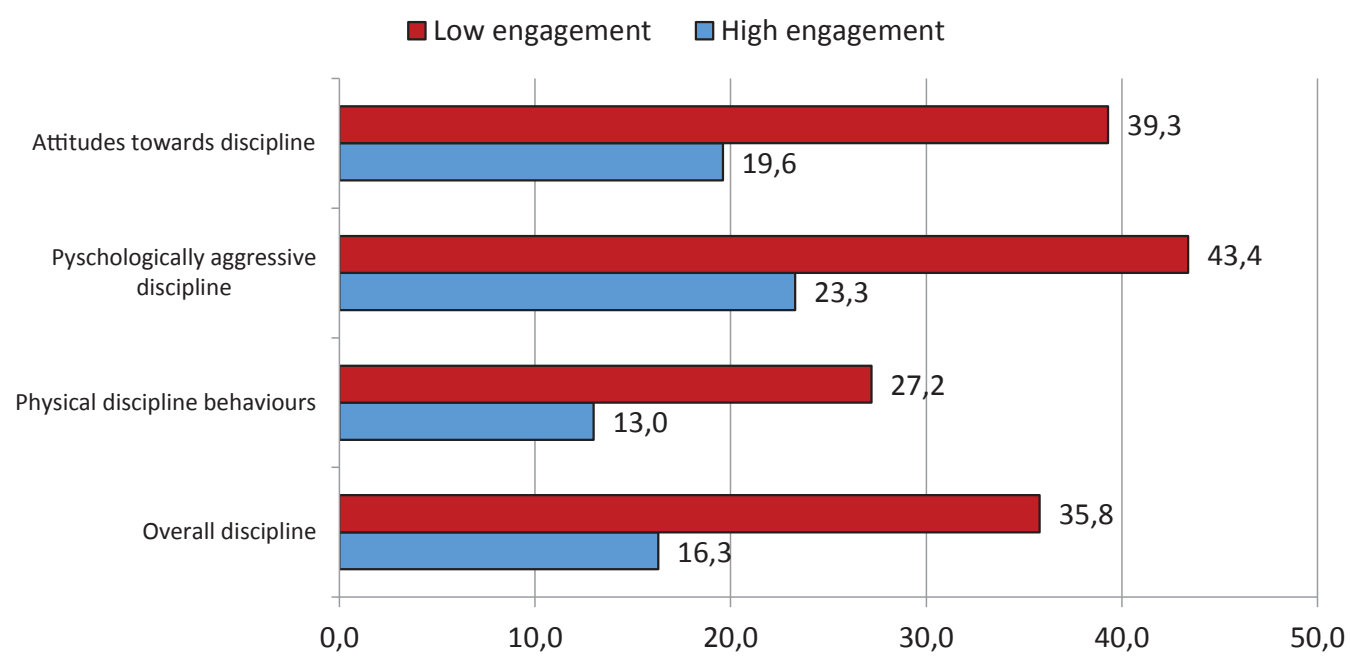

${ }^{*}$ On the Attitudes Index, the percent shows those with very favourable or favourable attitudes. 
Evaluation of Centres for the Integral Attention of Children in Dominican Republic (CIANIs) and Local Community Organizations for Child Protection (LCOCP)

The magnitude of the impact of CIANI engagement on disciplinary attitudes and behaviours may provide a clue as to why we consistently saw between-group differences in the previous section. The robust negative relationship of CIANI engagement to discipline may be one reason why the inclination to physical discipline is lower in the CIANI Only Group and the CIANI + LCOCP Group than it is in the Control Group. The "CIANI effect" may be partly the result of caregivers' engagement in the CIANI.

Just as with the group variable, the independent impact of the CIANI engagement variable on discipline must be assessed relative to the influence that other variables may have. Multiple regression analysis, to which we now turn, will allow the simultaneous estimation of the independent impact of multiple variables on the disciplinary attitudes and behaviours of the caregivers in our study.

\section{d. Multivariate Analysis}

This section will follow the same logic of analysis as earlier sections. It first examines between-group patterns to determine if the CIANI Only and CIANI + LCOCP Groups remain different from the Control Group. The section answers this basic question: does CIANI membership still reduce caregivers' disciplinary inclinations, after taking into account the effects on discipline of such factors as education, the age of children in the household, family stress, community trust, etc. Second, this section examines the within-group differences by focusing on only the two Intervention Groups (CIANI Only and CIANI + LCOCP) in order to assess the role that $\mathrm{CIANI}$-specific factors play in decreasing discipline, over and above the impact of other factors.

\section{i. Between-Group Multiple Regression Analyses}

Multiple regression is a statistical technique that estimates the independent impact of a series of shaping variables on some outcome variable, in this case the inclination towards physical disciplining of children. Generally speaking, multiple regression is a particularly appropriate technique for public policy analysis, for at least two reasons. First, it provides an estimate, in the form of the unstandardized (B) coefficients described below, of how a unit change in a shaping variable affects the outcome variable. With this measure, policy analysts can predict how a given 
change in some shaping variable--community engagement, for instance-will increase or decrease caregivers' propensity for using physical discipline. Second, regression analysis also yields a standard measure of effect size, the Beta or standardized coefficients discussed below. This coefficient allows analysts to compare the relative effect of different shaping variables on the outcome variable. That is, it will show if community engagement or family stress has the greater impact on the inclination towards physical punishment.

We performed four regression analyses, one for each of our four outcome variables: the Index of Physical Discipline Attitudes, the Index of Psychologically Aggressive Discipline, the Index of Physical Discipline Behaviours, and the Index of Overall Discipline.

Table 6.13 shows the results of the regression analysis for the Index of Physical Discipline Attitudes. As discussed earlier, this Index measures the extent to which caregivers generally believe that physical discipline is needed to raise a child properly, and specifically believe that it is justified under certain circumstances-if the child fights with another child, is disobedient, steals something, or engages in similar behaviour (see Figure 6.6). The discussion of the regression for this Index will be more detailed than the discussion for the three other indices because it will spend some time explaining the basic interpretation of regression results. 
Evaluation of Centres for the Integral Attention of Children in Dominican Republic (CIANIs) and Local Community Organizations for Child Protection (LCOCP)

Table 6.13: Multiple Regression: Index of Physical Discipline Attitudes (range: 0-9)

All Three Groups $(\mathrm{N}=1,568)$

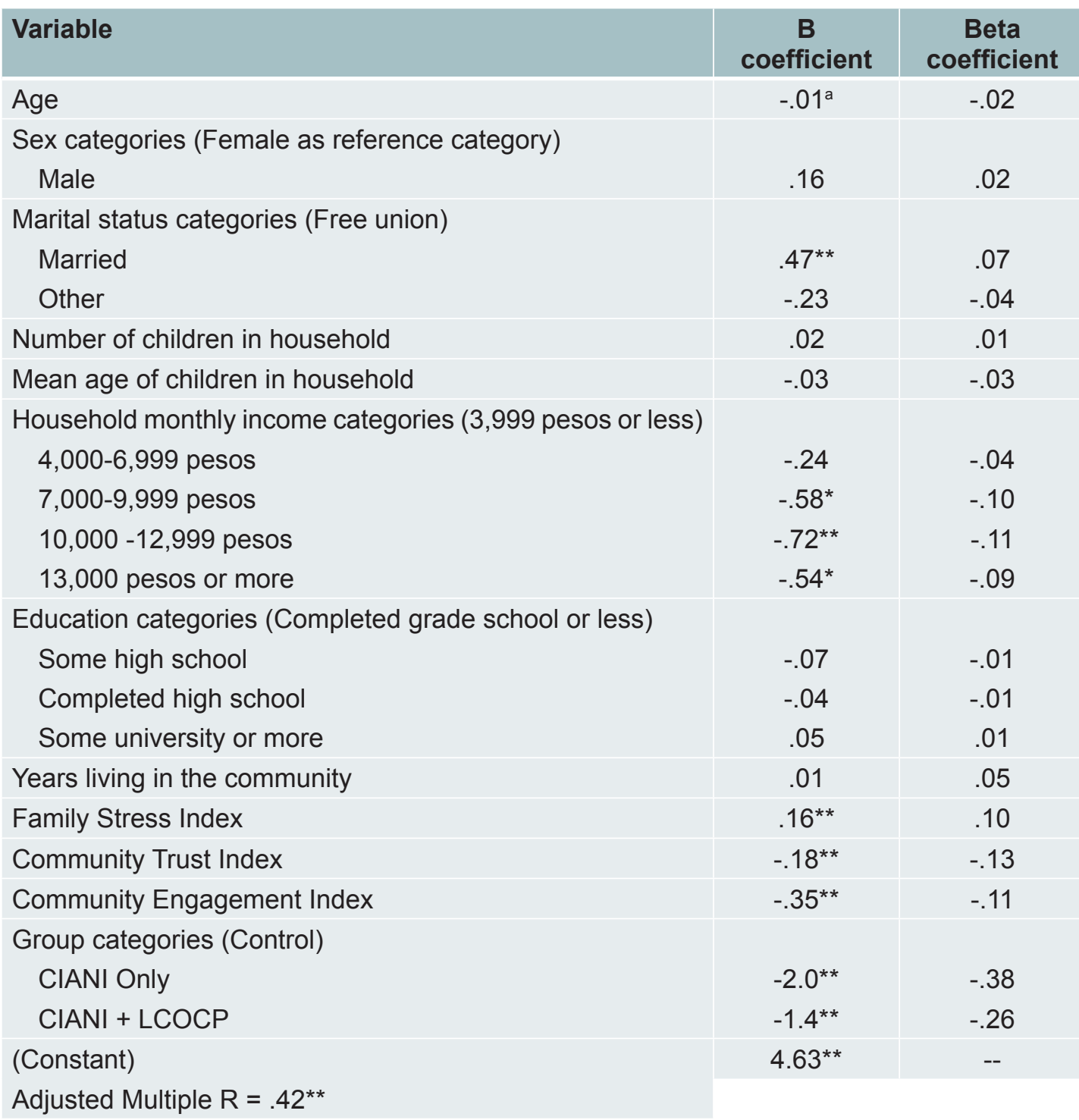

aln this and subsequent regression tables, \pm .01 indicates a non-zero coefficient less than or equal to \pm .01 .

*Significant at .05 (two-tailed)

**Significant at .01 (two-tailed 
Evaluation of Centres for the Integral Attention of Children in Dominican Republic (CIANIs) and Local Community Organizations for Child Protection (LCOCP)

The structure of Table 6.13 is the same as the structure for all the other regression analyses. The first column of the Table, labelled "Variable," lists the different factors whose effects on disciplinary attitudes are being estimated, including age, sex, and marital status. The second column lists the "B" or unstandardized regression coefficients, and the third lists the "Beta" or standardized coefficients. Each column will be discussed in turn.

There are a number of points to note about the variables listed in the first column of the Table. To give as rigorous a test as possible to our assessment of the impact of the group variable, we decided to include a number of social background variables that, in the literature review, were seen to have an impact on disciplinary attitudes and behaviours. In the earlier bivariate analysis, some of these variables were shown to have a strong and consistent impact on discipline, for instance, family stress and community trust. At the other end of the continuum of influence were a series of variables, including sex and income that had weak or insignificant effects on discipline. In between were variables, such as education and average age of children in the household that had some impact on discipline. We examine here the effect of all of them in order to assess the relative, independent impact of the group variable.

Regression analysis is a sophisticated statistical technique requiring that variables be measured at a high level of precision. In our analysis, these measurement requirements are met by the variables measuring caregiver age, number of children in the household, average (mean) age of children in the household, the number of years the caregiver has lived in the community, and the indices of family stress, community trust, and community engagement.

Many categorical variables do not meet the measurement precision requirements of regression analysis; that is, variables measured in discrete categories--sex, marital status, and group, but also income and education ${ }^{15}$--often need to be transformed for use in regression analysis. The first column of Table 6.13 notes the categorical variables by separately listing their "categories." The need for separate notation of categorical variables will become apparent in our discussion of how to interpret the regression coefficients in column two of the Table.

15 In the way we have measured education and income, in categories. 
Evaluation of Centres for the Integral Attention of Children in Dominican Republic (CIANIs) and Local Community Organizations for Child Protection (LCOCP)

The second column gives the unstandardized $(\mathrm{B})$ coefficients. For the non-categorical variables listed in the Table, the interpretation of the $\mathrm{B}$ coefficient is straightforward. Take as an example the coefficient of .16 for family stress; this means that the outcome variable, the Physical Discipline Attitudes Index, increases by .16 units for every one-unit increase in the Family Stress Index, once the impact of all other variables is taken into account. The coefficient of -.35 for community engagement means that the Physical Discipline Attitudes Index decreases by 35 units for every one-unit increase in the Community Engagement Index, after controlling for all the other variables. The sign of the coefficient indicates the direction of the relationship, either positive or negative, in the way we discussed earlier. On one hand, family stress is positively related to disciplinary attitudes; families with high stress tend to have favourable attitudes to discipline. On the other hand, community engagement is negatively related to attitudes; caregivers with high scores on the Community Engagement Index tend to have low scores on the Attitudes Index.

The interpretation of coefficients for categorical variables is also fairly straightforward, but different and a little more complicated. The complication comes in the way the categorical variable must be transformed for use in regression analysis. A common strategy for transformation is to construct "dummy" or "indicator" variables. For dichotomous or two-category variables like sex, one category is coded as " 1 " and the other as " 0. " In Table 6.13, male is scored as 1 and female as 0 , which becomes the reference category or reference group. For the variable "sex," the reference category is noted in parentheses, and likewise for all the other categorical variables. The function of the reference category is explained below.

For categorical variables with more than two categories, we use an equivalent approach to building dummy variables. Take the example of education in Table 6.13. Education has four categories: completed grade school or less, some high school, completed high school, and some university or more. We constructed three dummy variables for these four categories:

Some high school

- coded as 1 for those with this level of education and 0 otherwise Completed high school

- coded as 1 for those with this level of education and 0 otherwise Some university or more:

- coded as 1 for respondents with this level of education and 0 otherwise 
Evaluation of Centres for the Integral Attention of Children in Dominican Republic (CIANIs) and Local Community Organizations for Child Protection (LCOCP)

Note that we did not construct a separate dummy variable for the category "completed grade school or less. ${ }^{16}$ Respondents with this level of education are always coded as 0 , and these respondents become the reference group or category.

In regression analysis with dummy variables, the reference category is key to interpreting the impact of a given variable's other categories. Column two shows that the B coefficient for the "male" category of the variable "sex" is .16. We now focus on the simple interpretation of this coefficient, ignoring for the moment the question of statistical significance. ${ }^{17}$ This coefficient of .16 means that, on average, males score .16 units higher than females on the Physical Discipline Attitudes Index, once all the other variables have been taken into account. The meaning of the male coefficient is interpreted relative to that of female, the reference category.

The same interpretation applies to categorical variables with more than two categories. For the variable "household monthly income," the reference category is "3,999 pesos or less." The B coefficient of .58 on the category "7,000-9,999 pesos" means that respondents with this income have a Disciplinary Attitudes Index score that is, on average, .58 units lower than those with an income of " 3,999 pesos or less," once the other variables are controlled. Coefficients for the remaining categories of the income variable are interpreted similarly, relative to the reference category of "3,999 pesos or less." Respondents in the category "10,000-12,999 pesos", with a B coefficient of .72, have an Attitudes Index score that is, on average, .72 units lower than those in the reference category "3,999 pesos or less," after holding constant the effect of other variables.

16 Consider the case for the dichotomous variable "sex." We already have a dummy variable for males, coded as 1 for males and 0 for females. If we included in the regression analysis a second dummy variable for females, coded as 1 for female respondents and 0 for males, it would be perfectly correlated with our dummy variable for male respondents. Regression will "not work" for perfectly correlated predictor variables. The same logic applies to categorical variables with more than two categories. For education, if we included a fourth dummy variable for respondents with "completed grade school or less," the education categories would form a perfect linear combination and regression analysis will "not work." More generally, this problem of regression "not working" is referred to as multicollinearity. The rule for the construction of dummy variables is this: if the variable has $k$ categories, you construct $k-1$ dummy variables, with the omitted category serving as the reference category. According to this rule, the two-category variable of sex yields one dummy variable; the four-category variable of education yields three.

17 As the table notes, the B coefficient for "Male" is not statistically different from that for the reference category "Female." For the purposes of illustration, we ignore statistical significance in this preliminary explanation of how dichotomous dummy variable coefficients are interpreted relative to the reference category. 
Evaluation of Centres for the Integral Attention of Children in Dominican Republic (CIANIs) and Local Community Organizations for Child Protection (LCOCP)

The reference category for the group variable is the Control Group. The B coefficients show how the two Intervention Groups differ from the Control Group after the other variables are controlled. The CIANI Only Group, with a coefficient of 2.0, is 2.0 units lower on the Disciplinary Attitudes Index than is the Control Group. The CIANI + LCOCP Group, whose coefficient is .14, is similarly 1.4 units lower on the Disciplinary Attitudes Index than is the Control Group.

In summary, it may be said that the precise interpretation of B coefficients in column two of Table 6.13 depends on whether the variable is categorical or non-categorical, but the general meaning of the B coefficient is the same. It estimates the "direction," positive or negative, of the relationship between any given variable and the Disciplinary Attitudes Index. ${ }^{18}$ It also estimates the strength of that relationship, or the size of the effect of the variable on the Disciplinary Attitudes Index. It is important to remember that, for dummy categorical variables, both the "direction" and size of the effect are always assessed in relation to the reference category.

The B coefficients in column two cannot be used to assess the relative impact that different variables have on the Disciplinary Attitudes Index; that is, we cannot directly compare the magnitude of the $B$ coefficients in order to say that one variable has a larger or smaller effect than another. We cannot, for instance, say that the B coefficient of .35 on community engagement indicates a much stronger effect than does the corresponding coefficient of .18 on community trust. These comparisons are not valid because the magnitude of the $B$ coefficient is partly dependent on the variable's unit of measurement. To give a common example of this problem, a coefficient for a variable measured in metres will be 100 times larger than the coefficient for that same variable measured in centimetres.

The Beta or standardized coefficients in column three of Table 6.13 provide a way to circumvent this problem. Standardization removes the confounding effect of different units of measurement and allows for the direct comparison of Beta coefficients as an estimate of the relative impact of variables on the Disciplinary

18 Nominal variables like sex and group cannot have a positive or negative relationship with outcome variables like the Disciplinary Attitudes Index. There is no "direction" to this kind of relationship. In this case, the positive or negative sign of the coefficient indicates if the given category has a higher or lower index score than does the reference category. For ordinal variables like income and education, the direction of the relationship is relevant. 
Evaluation of Centres for the Integral Attention of Children in Dominican Republic (CIANIs) and Local Community Organizations for Child Protection (LCOCP)

Attitudes Index. ${ }^{19}$ The Beta coefficients show that the impacts of community engagement and community trust are actually very similar, with coefficients of .11 and .13 , respectively.

The final two introductory points to note about Table 6.13 are the constant and the statistic "Adjusted Multiple R." Statistically, the constant is the value of the outcome variable, that is, the value of the Index of Physical Discipline Attitudes, when the values of all other variables are zero. Multiple $\mathrm{R}$ or multiple correlation is a measure of the combined effects of all the variables on the Disciplinary Attitudes Index.

Since the structure of Table 6.13 and the interpretation of regression statistics have been addressed, we can now turn to the substantive results. The discussion of regression results will be guided by those variables found to be statistically significant, as indicated by the asterisks attached to the B coefficients in column two. ${ }^{20}$ On the group variable, caregivers in the CIANI Only and CIANI + LCOCP Groups have much less favourable attitudes toward physical discipline than do those in the Control Group. Their scores on the Disciplinary Attitudes Index are 2 and 1.4 units below those in the Control Group, after taking into account the effects of all the other variables. This is the kind of pattern we would expect to find if the CIANI program has been having an independent impact on attitudes towards physical discipline.

The added impact of the LCOCP, which we would expect to see in the CIANI + LCOCP Group, does not materialize. Even though the CIANI + LCOCP Group has a Disciplinary Attitudes Index score significantly lower than the score of the Control Group, its score is closer to the score of the Control Group than is the score of the CIANI Only Group. In the various figures in the previous section, we noted this intermediary position of the CIANI + LCOCP Group; it is much less different from the Control Group than is the CIANI Only Group. This pattern is repeated, in starker form, in the remaining regression analyses in this section. At the end of our

19 In essence, standardization involves converting the raw scores for each variable into corresponding $Z$ scores to ensure that each variable has a mean of 0 and a standard deviation of 1 . See Healy, J., \& Prus, S. (2015). Statistics: A Tool for Social Research (3rd Canadian Ed.). Toronto: Nelson Education., chap. 14.

20 See note 3 above. Statistical significance is a useful guide to our discussion, in the sense that variables with statistically significant coefficients tend to be those variables with the biggest impact on the outcome variable. 
Evaluation of Centres for the Integral Attention of Children in Dominican Republic (CIANIs) and Local Community Organizations for Child Protection (LCOCP)

discussion of the regression results, we shall return to the question of the CIANI + LCOCP Group.

Community engagement, community trust, and family stress are also significantly related to the Disciplinary Attitudes Index. On one hand, respondents who are very engaged with their community and trustful of that community tend to have low scores on the Disciplinary Attitudes Index. Family stress, on the other hand, is positively related to the outcome variable; caregivers in families with high stress have more favourable attitudes towards physical discipline than do those with low stress.

Background variables generally do not have a significant impact on attitudes towards physical discipline, with two exceptions. First, respondents who are married have higher Disciplinary Attitudes Index scores than do those in "free unions," and are therefore more favourably disposed to the use of corporal punishment. Second, caregivers with moderate-to-high monthly income (7,000-9,999 and 10,000$12,999)$ are less favourable to discipline than are caregivers in the reference group of lowest income earners. Here, income is negatively related to attitudes: moderate and high income earners tend to have low scores on the Disciplinary Attitudes Index; low income earners tend to have high scores.

The Beta coefficients in column three show that the variables with the strongest impact on reduction of favourable attitudes towards discipline are the CIANI Only and CIANI + LCOCP Groups, community trust, community engagement, and income. Family stress is the variable with the strongest positive impact, with higher stress leading to increases in the Disciplinary Attitudes Index.

Moving from disciplinary attitudes to behaviours, Table 6.14 presents the regression results for the Index of Psychologically Aggressive Discipline, a measure of verbal maltreatment of children; Table 6.15 presents the results for the Index of Physical Discipline Behaviours, a measure of caregivers' various disciplinary behaviours. Table 6.16 presents the results for the Overall Discipline Index, which is a combination of the Aggression and Behaviour Indices. There are common patterns in these three regression results that can perhaps best be summarized through an examination of how selected variables behave in the different regressions. Along the way, we shall also point out important differences in the regression findings. 
Evaluation of Centres for the Integral Attention of Children in Dominican Republic (CIANIs) and Local Community Organizations for Child Protection (LCOCP)

Table 6.14: Multiple Regression: Index of Psychologically Aggressive Discipline (range: $0-5)$

All Three Groups $(\mathrm{N}=1,568)$

\begin{tabular}{|c|c|c|}
\hline Variable & B coefficient & Beta coefficient \\
\hline Age & .01 & .03 \\
\hline $\begin{array}{l}\text { Sex categories (Female as reference category) } \\
\text { Male }\end{array}$ & $.15^{*}$ & .05 \\
\hline $\begin{array}{l}\text { Marital status categories (Free union) } \\
\text { Married } \\
\text { Other }\end{array}$ & $\begin{array}{l}.11 \\
.04\end{array}$ & $\begin{array}{l}.04 \\
.02\end{array}$ \\
\hline Number of children in household & .02 & .02 \\
\hline Mean age of children in household & $.04^{* *}$ & .08 \\
\hline $\begin{array}{l}\text { Household monthly income categories }(3,999 \text { pesos } \\
\text { or less) } \\
4,000-6,999 \text { pesos } \\
7,000-9,999 \text { pesos } \\
10,000-12,999 \text { pesos } \\
13,000 \text { pesos or more }\end{array}$ & $\begin{array}{l}.02 \\
.05 \\
.03 \\
.25^{*}\end{array}$ & $\begin{array}{l}.01 \\
.02 \\
.01 \\
.10\end{array}$ \\
\hline $\begin{array}{l}\text { Education categories (Completed grade school or } \\
\text { less) } \\
\text { Some high school } \\
\text { Completed high school } \\
\text { Some university or more }\end{array}$ & $\begin{array}{l}-.10 \\
-.05 \\
-.03\end{array}$ & $\begin{array}{l}-.04 \\
-.02 \\
-.01\end{array}$ \\
\hline Years living in the community & .01 & .01 \\
\hline Family Stress Index & $.21^{* *}$ & .30 \\
\hline Community Trust Index & $-.08^{* *}$ & -.14 \\
\hline Community Engagement Index & -.06 & -.04 \\
\hline $\begin{array}{l}\text { Group categories (Control) } \\
\text { CIANI Only } \\
\text { CIANI + LCOCP }\end{array}$ & $\begin{array}{c}-.17^{*} \\
.03\end{array}$ & $\begin{array}{r}-.08 \\
.01\end{array}$ \\
\hline $\begin{array}{l}\text { (Constant) } \\
\text { Adjusted Multiple } \mathrm{R}=.38^{* *}\end{array}$ & $.74^{* *}$ & -- \\
\hline
\end{tabular}


Evaluation of Centres for the Integral Attention of Children in Dominican Republic (CIANIs) and Local Community Organizations for Child Protection (LCOCP)

Table 6.15: Multiple Regression: Index of Physical Discipline Behaviours (range: 0-9)

All Three Groups $(\mathrm{N}=1,568)$

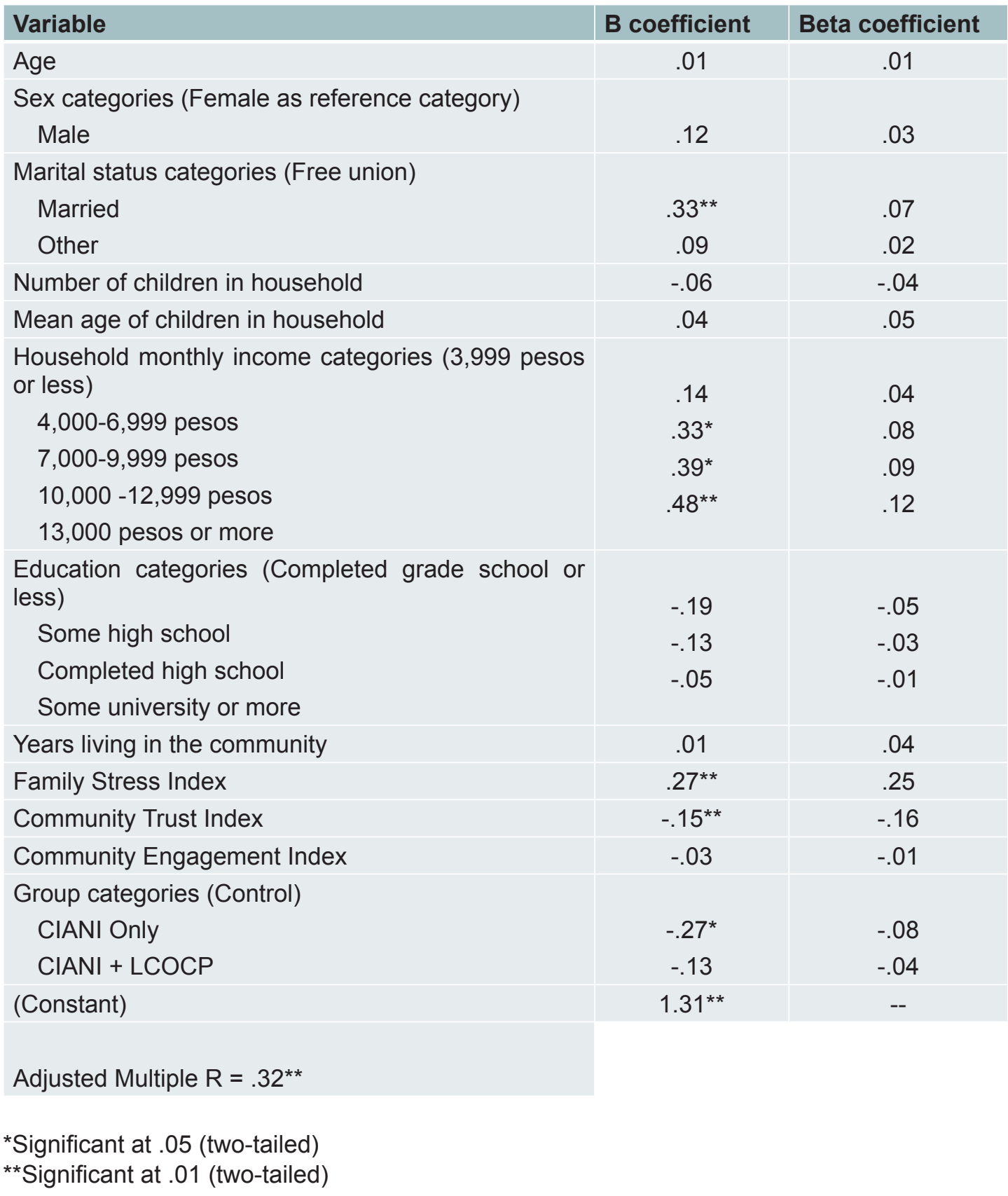


Evaluation of Centres for the Integral Attention of Children in Dominican Republic (CIANIs) and Local Community Organizations for Child Protection (LCOCP)

Table 6.16: Multiple Regression: Index of Overall Discipline (range: $0-13$ ) All Three Groups $(\mathrm{N}=1,568)$

\begin{tabular}{|c|c|c|}
\hline Variable & B coefficient & Beta coefficient \\
\hline Age & .01 & .02 \\
\hline $\begin{array}{l}\text { Sex categories (Female as reference category) } \\
\quad \text { Male }\end{array}$ & .27 & .04 \\
\hline $\begin{array}{l}\text { Marital status categories (Free union) } \\
\text { Married } \\
\text { Other }\end{array}$ & $\begin{array}{l}.43^{*} \\
.13\end{array}$ & $\begin{array}{l}.06 \\
.02\end{array}$ \\
\hline Number of children in household & -.04 & -.02 \\
\hline Mean age of children in household & $.08^{*}$ & .07 \\
\hline $\begin{array}{l}\text { Household monthly income categories }(3,999 \text { pesos } \\
\text { or less) } \\
\quad 4,000-6,999 \text { pesos } \\
7,000-9,999 \text { pesos } \\
10,000-12,999 \text { pesos } \\
13,000 \text { pesos or more }\end{array}$ & $\begin{array}{l}.16 \\
.38 \\
.43 \\
.73^{* *}\end{array}$ & $\begin{array}{l}.03 \\
.07 \\
.06 \\
.13\end{array}$ \\
\hline $\begin{array}{l}\text { Education categories (Completed grade school or } \\
\text { less) } \\
\text { Some high school } \\
\text { Completed high school } \\
\text { Some university or more }\end{array}$ & $\begin{array}{l}-.28 \\
-.17 \\
-.08\end{array}$ & $\begin{array}{l}-.05 \\
-.03 \\
-.01\end{array}$ \\
\hline Years living in the community & .01 & .03 \\
\hline Family Stress Index & $.47^{* *}$ & .29 \\
\hline Community Trust Index & $-.23^{\star *}$ & -.16 \\
\hline Community Engagement Index & -.08 & -.02 \\
\hline Group categories (Control) & & \\
\hline CIANI Only & $-.45^{\star *}$ & -.08 \\
\hline CIANI + LCOCP & -.10 & -.02 \\
\hline (Constant) & $2.05^{\star *}$ & -- \\
\hline Adjusted Multiple $\mathrm{R}=.38^{\star *}$ & & \\
\hline
\end{tabular}


Evaluation of Centres for the Integral Attention of Children in Dominican Republic (CIANIs) and Local Community Organizations for Child Protection (LCOCP)

Overall, only a few social background variables are significantly related to disciplinary behaviours. This finding is similar to that we saw in our discussion of disciplinary attitudes in Table 6.13. In many cases, disciplinary behaviours tend to cut across various social groups with little variation according to sex, education, or number of children in the household. Income, though, does tend to have a significant effect on discipline, as do the variables "age of children living in the household" and "marital status."

The effects of income are inconsistent. In the above discussion of Table 6.13, we pointed out that income is negatively associated with disciplinary attitudes, but the next three tables show that income is positively related to the other measures of discipline. Tables 6.14 and 6.16 demonstrate that the highest income earners are significantly more inclined to use physical discipline than are the lowest income earners. In Table 6.15, the tendency to use physical discipline rises with every increment in level of income.

There is no readily apparent explanation for this irregular impact of income on disciplinary attitudes and behaviours, but the irregular impact might have something to do with the nature of the respondents in our study. Recall that the caregivers in the two Intervention Groups qualified for registration in the CIANI program on the basis of need, and respondents in the Control Group have a similar economic profile. The range of monthly income in our study is therefore abbreviated at the moderate and high points of the income scale. Our study is not representative of middle-income and wealthier Dominicans. A representative sample of the Dominican population, with a much broader range on the income variable, might help to untangle questions about the influence of income on disciplinary attitudes and behaviours.

The mean or average age of children in the household is significantly related to the Psychologically Aggressive Discipline Index (Table 6.14) and the Overall Discipline Index (Table 6.16). In both cases, the positive direction of the relationship is as expected; the older are the children, the more likely the caregivers are to use physical discipline.

In Tables 6.15 and 6.16 (Multiple Regression: Index of Physical Discipline Behaviours and Multiple Regression: Index of Overall Discipline) the Index scores of married caregivers are higher than are the scores for respondents in a free union; that is, married respondents are especially inclined to engage in physical discipline behaviours. This is the same pattern found in Table 6.13 on disciplinary 
Evaluation of Centres for the Integral Attention of Children in Dominican Republic (CIANIs) and Local Community Organizations for Child Protection (LCOCP)

attitudes. Perhaps married respondents are more traditional than are those in a free union; they may hold more traditional disciplinary attitudes and use more traditional means to correct children's behaviour.

The regression results regarding disciplinary behaviours show that family stress has the strongest impact and community trust the second strongest impact (Tables $6.14,6.15$ and 6.16$)$. Stress is positively related to discipline; the higher the family stress, the more likely the caregiver is to engage in verbal or physical punishment. The effect of community trust is different and shows a negative relationship; the higher the level of trust, the less likely is the caregiver to use discipline.

The consistent effect of the group variable is also seen in the three tables. In each case, respondents in the CIANI Only Group have lower disciplinary scores than do those in the Control Group. This finding is impressive; the group has an independent impact after controlling for all the other variables in the analysis. The finding is remarkable, especially considering the strong impact exerted by family stress and community trust.

In a focus on the CIANI Only Group for the moment, it may be noted that part of its effect no doubt comes through the intervening factors of family stress and community trust. As we saw earlier in Table 6.3, the CIANI Only Group has low stress scores and high trust scores, and both of these patterns are in turn associated with a lower inclination to discipline. Yet the CIANI Only Group's impact on lowering discipline is also direct, and it remains even when the effects of family stress and community trust have been taken into account.

The role of the CIANI + LCOCP Group is again problematic. The CIANI + LCOCP Group is not significantly different from the Control Group in any of the three regressions on disciplinary behaviours; that is, the group has no effect on reducing discipline after controlling for all the other variables in the analysis. In the next section, we explore in more detail the pattern of relationships in both the CIANI + LCOCP Group and CIANI Only Group.

\section{ii. Within-Group Multiple Regression Analyses}

Tables 6.17 through 6.20 present the regression results for the two Intervention Groups. We examine the same set of social background variables as before-age, 
Evaluation of Centres for the Integral Attention of Children in Dominican Republic (CIANIs) and Local Community Organizations for Child Protection (LCOCP)

sex, marital status, number and age of children in household, education, income, and years living in the community. We also examine family stress and community trust and engagement, as was previously done.

Since we are examining just the CIANI Only and CIANI + LCOCP Groups, we include four CIANI-specific variables, which are listed at the bottom of the tables: a revised group dummy variable, the CIANI Engagement Index, years registered in the CIANI, and Index of Satisfaction with CIANI Services. Since the Control Group is omitted from this analysis, the revised group variable is dichotomous, with the CIANI + LCOCP Group serving as the reference category. 
Evaluation of Centres for the Integral Attention of Children in Dominican Republic (CIANIs) and Local Community Organizations for Child Protection (LCOCP)

Table 6.17: Multiple Regression: Index of Physical Discipline Attitudes (range: 0-9)

Two Intervention Groups ( $\mathrm{N}=767)$

\begin{tabular}{|c|c|c|}
\hline Variable & B coefficient & Beta coefficient \\
\hline Age & $-.02^{* *}$ & -.10 \\
\hline $\begin{array}{l}\text { Sex categories (Female as reference category) } \\
\text { Male }\end{array}$ & .33 & .06 \\
\hline $\begin{array}{l}\text { Marital status categories (Free union) } \\
\text { Married } \\
\text { Other }\end{array}$ & $\begin{array}{l}.26 \\
-.44^{* *}\end{array}$ & $\begin{array}{l}.05 \\
-.10\end{array}$ \\
\hline Number of children in household & .07 & .05 \\
\hline Mean age of children in household & .02 & .02 \\
\hline $\begin{array}{l}\text { Household monthly income categories }(3,999 \text { pesos or } \\
\text { less) } \\
\begin{array}{l}4,000-6,999 \text { pesos } \\
7,000-9,999 \text { pesos } \\
10,000-12,999 \text { pesos } \\
13,000 \text { pesos or more }\end{array}\end{array}$ & $\begin{array}{r}.23 \\
-.15 \\
-.12 \\
-.15\end{array}$ & $\begin{array}{l}.05 \\
-.03 \\
-.02 \\
-.03\end{array}$ \\
\hline $\begin{array}{l}\text { Education categories (Completed grade school or less) } \\
\text { Some high school } \\
\text { Completed high school } \\
\text { Some university or more }\end{array}$ & $\begin{array}{l}-.34 \\
-.49^{*} \\
.07\end{array}$ & $\begin{array}{r}-.07 \\
-.11 \\
.02\end{array}$ \\
\hline Years living in the community & -.01 & -.04 \\
\hline Family Stress Index & $.14^{* *}$ & .10 \\
\hline Community Trust Index & $-.25^{* *}$ & -.24 \\
\hline Community Engagement Index & .04 & .02 \\
\hline $\begin{array}{l}\text { Group categories (CIANI + LCOCP) } \\
\text { CIANI Only }\end{array}$ & $-.39^{* *}$ & -.10 \\
\hline CIANI Engagement Index & $-.20^{* *}$ & -.14 \\
\hline Years registered in a CIANI & -.02 & -.01 \\
\hline Satisfaction with CIANI Services Index & .01 & .01 \\
\hline (Constant) & $4.01^{* *}$ & -- \\
\hline Adjusted Multiple $\mathrm{R}=.41^{* *}$ & & \\
\hline
\end{tabular}


Evaluation of Centres for the Integral Attention of Children in Dominican Republic (CIANIs) and Local Community Organizations for Child Protection (LCOCP)

\section{Table 6.18: Multiple Regression: Index of Psychologically Aggressive Discipline (range: $0-5$ ) Two Intervention Groups ( $\mathbf{N = 7 6 7 )}$}

\begin{tabular}{|c|c|c|}
\hline Variable & B coefficient & Beta coefficient \\
\hline Age & .01 & .03 \\
\hline $\begin{array}{l}\text { Sex categories (Female as reference category) } \\
\text { Male }\end{array}$ & .17 & .06 \\
\hline $\begin{array}{l}\text { Marital status categories (Free union) } \\
\text { Married } \\
\text { Other }\end{array}$ & $\begin{array}{l}.13 \\
-.03\end{array}$ & $\begin{array}{l}.04 \\
-.01\end{array}$ \\
\hline Number of children in household & .05 & .06 \\
\hline Mean age of children in household & $.06^{* *}$ & .11 \\
\hline $\begin{array}{l}\text { Household monthly income categories }(3,999 \text { pesos } \\
\text { or less) } \\
\quad 4,000-6,999 \text { pesos } \\
7,000-9,999 \text { pesos } \\
10,000-12,999 \text { pesos } \\
13,000 \text { pesos or more }\end{array}$ & $\begin{array}{l}.11 \\
.32^{*} \\
.16 \\
.22\end{array}$ & $\begin{array}{l}.04 \\
.12 \\
.06 \\
.09\end{array}$ \\
\hline $\begin{array}{l}\text { Education categories (Completed grade school or } \\
\text { less) } \\
\text { Some high school } \\
\text { Completed high school } \\
\text { Some university or more }\end{array}$ & $\begin{array}{l}-.27^{*} \\
-.05 \\
-.08\end{array}$ & $\begin{array}{l}-.11 \\
-.02 \\
-.04\end{array}$ \\
\hline Years living in the community & $-.01^{*}$ & -.08 \\
\hline Family Stress Index & $.18^{* *}$ & .24 \\
\hline Community Trust Index & $-.09 * *$ & -.17 \\
\hline Community Engagement Index & .02 & .01 \\
\hline $\begin{array}{l}\text { Group categories (CIANI + LCOCP) } \\
\text { CIANI Only }\end{array}$ & $-.16^{*}$ & -.08 \\
\hline CIANI Engagement Index & $-.15^{\star *}$ & -.19 \\
\hline Years registered in a CIANI & $-.08^{*}$ & -.07 \\
\hline Satisfaction with CIANI Services Index & .01 & .02 \\
\hline (Constant) & $1.27^{* *}$ & -- \\
\hline Adjusted Multiple $\mathrm{R}=.44^{* *}$ & & \\
\hline
\end{tabular}


Evaluation of Centres for the Integral Attention of Children in Dominican Republic (CIANIs) and Local Community Organizations for Child Protection (LCOCP)

Table 6.19: Multiple Regression: Index of Physical Discipline Behaviours (range: 0-9)

Two Intervention Groups ( $\mathrm{N}=767)$

\begin{tabular}{|c|c|c|}
\hline Variable & B coefficient & Beta coefficient \\
\hline Age & .01 & .04 \\
\hline $\begin{array}{l}\text { Sex categories (Female as reference category) } \\
\text { Male }\end{array}$ & .03 & .01 \\
\hline $\begin{array}{l}\text { Marital status categories (Free union) } \\
\text { Married } \\
\text { Other }\end{array}$ & $\begin{array}{l}.24 \\
-.15\end{array}$ & $\begin{array}{l}.05 \\
-.04\end{array}$ \\
\hline Number of children in household & -.07 & -.05 \\
\hline Mean age of children in household & $.06^{*}$ & .07 \\
\hline $\begin{array}{l}\text { Household monthly income categories }(3,999 \text { pesos } \\
\text { or less) } \\
\quad 4,000-6,999 \text { pesos } \\
7,000-9,999 \text { pesos } \\
10,000-12,999 \text { pesos } \\
13,000 \text { pesos or more }\end{array}$ & $\begin{array}{l}.49^{*} \\
.45^{*} \\
.76^{* *} \\
.51^{*}\end{array}$ & $\begin{array}{l}.13 \\
.11 \\
.18 \\
.14\end{array}$ \\
\hline $\begin{array}{l}\text { Education categories (Completed grade school or } \\
\text { less) } \\
\text { Some high school } \\
\text { Completed high school } \\
\text { Some university or more }\end{array}$ & $\begin{array}{l}-.60^{* *} \\
-.41^{*} \\
-.26\end{array}$ & $\begin{array}{l}-.16 \\
-.11 \\
-.07\end{array}$ \\
\hline Years living in the community & -.01 & -.01 \\
\hline Family Stress Index & $.29^{* *}$ & .24 \\
\hline Community Trust Index & $-.18^{* *}$ & -.22 \\
\hline Community Engagement Index & .14 & .07 \\
\hline $\begin{array}{l}\text { Group categories (CIANI + LCOCP) } \\
\text { CIANI Only }\end{array}$ & -.07 & -.02 \\
\hline CIANI Engagement Index & $-.22^{* *}$ & -.18 \\
\hline Years registered in a CIANI & -.06 & -.03 \\
\hline Satisfaction with CIANI Services Index & .01 & .01 \\
\hline (Constant) & $1.84^{* *}$ & -- \\
\hline Adjusted Multiple $\mathrm{R}=.43^{* *}$ & & \\
\hline
\end{tabular}


Evaluation of Centres for the Integral Attention of Children in Dominican Republic (CIANIs) and Local Community Organizations for Child Protection (LCOCP)

Table 6.20: Multiple Regression: Index of Overall Discipline (range: $0-13$ ) Two Intervention Groups ( $\mathrm{N}=767$ )

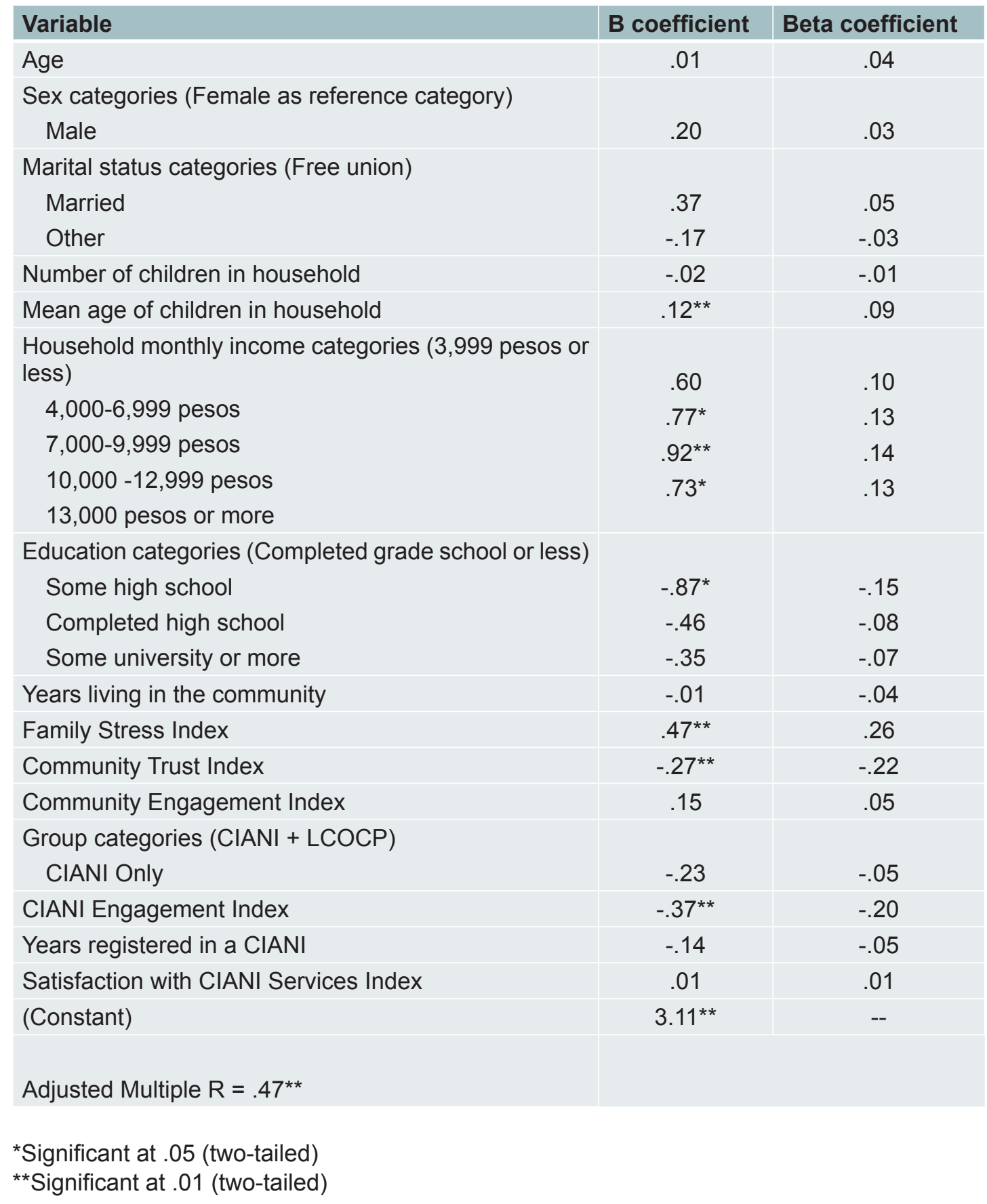


Evaluation of Centres for the Integral Attention of Children in Dominican Republic (CIANIs) and Local Community Organizations for Child Protection (LCOCP)

To summarize the four regression results, we can, as in the previous section, focus on the pattern of significant results for given variables. As was the case previously, there are not many significant coefficients for an array of social background variables. Generally speaking, the proclivity for discipline cuts across various social groups, with few differences according to age, sex, marital status, number of children in the household, and years living in the community. The variable "mean age of children in household" has the expected effect; in three of the four regressions, it is positively related to discipline. Caregivers with older children have a higher inclination to disciplinary attitudes and behaviours than to those with younger children. This variable's effect tends to be relatively weak, perhaps partly because the age of children has a restricted range. A total of 84 percent of the caregivers in the two Intervention Groups have children in the household whose average age is five years old or younger.

Income has a consistent and significant impact only in the last two tables, on the Index of Physical Discipline Behaviours (Table 6.19) and the related Overall Discipline Index (Table 6.20). ${ }^{21}$ Its effects are again counter-intuitive; after controlling for the influence of other variables, income tends to be positively related to discipline. Moderate and high income groups have higher discipline scores than does the lowest income group, that is, those who earn less than 4,000 pesos per month (the reference group).

The effects of education are uneven. Some dummy education variables are significant in some of the regressions. Recall that the reference category on the education dummy variables is the group of respondents with the lowest level of education that is, having "completed grade school or less." All the significant education coefficients are negative. To be more precise, the regression results show that caregivers with moderate levels of education have a lower inclination to discipline than do members of the least educated (reference) group. On the Attitudes Index, for instance, the B coefficient for respondents who have "completed high school" is .49 , a number that indicates that their score is well below that of the least educated group in the reference category (Table 6.17). On the Overall Discipline Index, the B coefficient for respondents with "some high school" is .87, which again indicates a score much lower than that for the least educated group in the reference category (Table 6.20).

21 Recall that the Overall Discipline Index is a combination of the Physical Discipline Behaviours Index and the Index of Psychologically Aggressive Discipline. 
Evaluation of Centres for the Integral Attention of Children in Dominican Republic (CIANIs) and Local Community Organizations for Child Protection (LCOCP)

It should be noted that this education effect is restricted to caregivers with moderate levels of education, that is, those who have a high school education and thus stand between the least educated group, with grade school, and the most educated group, with a university education. In none of the regressions does the most highly educated group — caregivers with at least some university education-differ significantly from the least educated group.

The effects on discipline of family stress and community trust can be summarized briefly. They are the same as we found in the previous discussion of between-group regression findings. Family stress has a consistently strong positive relationship to discipline. Caregivers with high stress scores also have high discipline scores; that is, caregivers in families experiencing many stressful situations are more likely to hold attitudes favourable to physical discipline and more likely to use corporal punishment than are those in families experiencing fewer stressors. Community trust is strongly and negatively related to discipline. The higher the level of caregivers' trust in the community, the less inclined are they to disciplinary attitudes and behaviours.

The last set of variables to discuss includes the four CIANI-specific measures. Two of these variables show no consistent pattern of influence on our disciplinary measures. Satisfaction with CIANI services is not related to discipline, a pattern reminiscent of the erratic relationship we found earlier in the bivariate analysis. Remember that the level of satisfaction among our respondents is extremely high. Substantively, then, there is not much variation in the Satisfaction Index, and the scores reflect the difference between caregivers who are "very satisfied" and caregivers who are "satisfied." Perhaps this kind of difference is too subtle to have an impact on discipline.

The second CIANI-specific variable, the number of years a caregiver has had children registered in a CIANI, is not significantly related to discipline across three of the four regressions. Table 6.18 shows that the variable has a relatively weak negative impact on psychologically aggressive discipline; for every year the caregiver has been enrolled in a CIANI, the Aggressive Discipline Index decreases by .08 units.

The CIANI Engagement Index, measuring how often caregivers attend or help out at the CIANI's Parent School and other social events, is one of the most powerful predictors of discipline. Engagement consistently has a strong and negative im- 
Evaluation of Centres for the Integral Attention of Children in Dominican Republic (CIANIs) and Local Community Organizations for Child Protection (LCOCP)

pact on disciplinary attitudes and behaviours. The variable's B coefficient in Table 6.20 , for instance, is .37, indicating that the Overall Discipline Index decreases by .37 units for every one-unit increase on the CIANI Engagement Index. We saw this kind of strong impact of caregiver engagement in the earlier bivariate analysis displayed in the figures. The CIANI engagement effect persists even after we control for the impact of other variables in the multivariate analysis. The Beta coefficients in Tables 6.17 through 6.20 show that CIANI engagement consistently ranks in the top three most powerful influences on discipline, along with family stress and community trust.

Recall that CIANI engagement is a behavioural variable that measures how often caregivers attend or help out at CIANI functions. It may be that engagement is related to caregiver motivation to the extent that highly motivated caregivers may be most likely to be engaged in the CIANI. If so, the effects of the CIANI Engagement Index may be confounded with the effects of caregiver motivation..$^{22}$ We think not. In our study, motivation was a constant, not a variable. Our qualitative interviews with both caregivers and professional staff revealed that caregiver motivation is uniformly high. Without exception, caregivers were keenly motivated to have their children enrolled in the CIANI. Some of them endured long lineups and time on waiting lists to become registered. Many advocated for additional CIANI spaces to expedite the process of enrollment and allow more families to register. All were extremely pleased to get a space. In sum, with motivation a virtual constant, we are confident that the regression results for the CIANI Engagement Index do measure the impact of engagement on the inclination towards physical discipline.

The revised group variable is the fourth and final CIANI-specific measure in the tables. This variable shows the extent to which the CIANI Only Group differs from the CIANI + LCOCP Group. In two of the four regressions, that difference is significant. With significant B coefficients of .39 and .16, the CIANI Only Group has lower scores than does the CIANI + LCOCP Group on the Discipline Attitudes Index and the Psychological Aggression Index, respectively (Tables 6.17 and 6.18). This pattern continues the uneven impact of the CIANI + LCOCP Group that we have seen throughout the analysis. The next section explores that unevenness in more detail.

22 Thanks to the anonymous reviewer who brought up this point, which allowed us to clarify our findings on caregiver motivation. 
Evaluation of Centres for the Integral Attention of Children in Dominican Republic (CIANIs) and Local Community Organizations for Child Protection (LCOCP)

\section{iii. The CIANI + LCOCP Group}

The section on quasi-experimental methodology explained the logic of including the two Intervention Groups in the research design. The CIANI Only Group would give a first approximation of the impact of the CIANI program on the reduction of the corporal punishment of children. The CIANI + LCOCP Group would give an initial estimate of the additional impact of the LCOCP program. In the light of this research logic, the empirical results leave two questions to address. First, why did the CIANI + LCOCP Group not show any additional impact of the LCOCP program? Second, why did the CIANI + LCOCP Group have a muted effect? This muted effect has, in turn, two dimensions; sometimes the CIANI + LCOCP Group was indistinguishable from the Control Group, and sometimes the impact of the CIANI + LCOCP Group was weaker than that of the CIANI Only Group.

As indicated, the empirical results reveal in a number of ways the problematic status of the CIANI + LCOCP Group. In the bivariate analysis, caregivers in the CIANI + LCOCP Group have an intermediate location, between those in the Control Group and those in the CIANI Only Group. Figure 6.9 provides a representative finding; whereas only $18.2 \%$ of caregivers in the CIANI Only Group have favourable or very favourable attitudes towards discipline, fully 47.6 percent of those in the Control Group do. Respondents in the CIANI + LCOCP Group are in the middle, with $29 \%$ having favourable or very favourable attitudes. In this case, there appears to be no additional impact of the CIANI + LCOCP Group. Indeed, the impact of membership in this group on disciplinary attitudes seems muted, in the sense that that the tendency to avoid discipline is weaker in the CIANI + LCOCP Group than it is in the CIANI Only Group.

The regression results confirm the bivariate findings. Three of the four regressions in the between-group analysis reveal that the level of discipline in the CIANI + LCOCP Group is not significantly different from that in the Control Group, after all the other variables are taken into account. ${ }^{23}$ The one significant regression result shows that the effect in relation to lowering discipline is weaker in the CIANI + LCOCP Group than it is in the CIANI Only Group. In summary, it may be said that the CIANI + LCOCP Group does not reveal any additional impact of the LCOCP

23 By controlling for the effects of all other variables, we have in a way corrected for the nonequivalency of groups that we saw earlier. Still, the anomalous status of the CIANI + LCOCP Group is evident. 
Evaluation of Centres for the Integral Attention of Children in Dominican Republic (CIANIs) and Local Community Organizations for Child Protection (LCOCP)

program, but that is not all. We should still see, in the CIANI + LCOCP Group, the effect of the CIANI program, but often we do not.

In the within-group regressions, which looked at only the two Intervention Groups, but added all the CIANI-specific variables to the analysis, we see the familiar pattern. In two of the four regressions, caregiver levels of disciplinary attitudes and behaviours in the CIANI + LCOCP Group are significantly higher than are the levels in the CIANI Only Group (Tables 6.17 and 6.18). ${ }^{24}$

Let us address the first question, which is about why the CIANI + LCOCP Group reveals no additional impact of the LCOCP program. Perhaps we were too optimistic when we expected an additional effect, for a number of reasons. CIANIs are much longer- and better-established programs than are the LCOCPs. This consideration was especially relevant at the time we conducted our survey. The LCOCPs may be too "new" to manifest the kind of effect that we were expecting.

The CIANIs and LCOCPs are also fundamentally different (though complementary) kinds of programs, in ways that go beyond the distinction between prevention and protection. Caregivers' experience with CIANIs is a daily affair, and the CIANI becomes a major and much-appreciated part of their lives. The children registered in the CIANI are in the centre all day long, each and every day during the week. Caregivers routinely drop off and pick up their children. ${ }^{25}$ The CIANI feeds the children and looks after their health and education. It provides a wide array of other services and social supports to the family. It regularly consults with caregivers and makes visits to the home. It holds frequent meetings and events that many caregivers attend. Caregivers and CIANI staff develop valued relationships with one another.

The LCOCP, on the other hand, is not as involved in the daily lives of caregivers, and it is not part of their "real, lived experiences" in the same way as the CIANI is. Unlike the CIANI, there is no registration process in the LCOCP. The LCOCP's primary mandate is the protection of children from abuse and maltreatment. One of its main orientations is responsive, in the sense that the specific work of the LCOCP is often activated as a response to allegations or suspicions of maltreatment. In

24 As revealed in the tables by the negative and significant B coefficients for the CIANI Only category.

25 Over $94 \%$ of caregivers dropped off children at the CIANI "every day" or "some days," and almost $90 \%$ picked up children "every day" or "some days." 
Evaluation of Centres for the Integral Attention of Children in Dominican Republic (CIANIs) and Local Community Organizations for Child Protection (LCOCP)

this responsive role, the LCOCP comes into firsthand and regular contact with only a small number of families. Just $7 \%$ of the caregivers in our study reported direct contact with a LCOCP. The LCOCP also has detection, investigative, monitoring, and reporting roles, and spends much time liaising with the legal system. Finally, it works with community organizations to increase awareness of the problems of child abuse and maltreatment. Even in all of these roles, the LCOCP's relationship with caregivers and their families is neither as wide-ranging nor as intimate as the relationship is in the case of the CIANI. For all these reasons, then, the general effect of the LCOCP on reduction of levels of violence will not approach that of the CIANI.

Certainly, the LCOCP also has an important preventive function as it works with specific families to ensure that steps are taken to reduce risks to children. As the LCOCP program develops, extends deeper roots into the community, and raises its public profile-as it is doing as we write-a more general effect may emerge.

If these reasons may partly explain why there is no additional impact associated with the CIANI + LCOCP Group, they do not explain why we see only a muted "CIANI effect" in this Group. Recall that, in the between-group regression analyses, the CIANI Engagement Index was one of the most powerful correlates of discipline, with effects that were strongly negative; that is, caregivers with high scores on engagement tended to have low scores on disciplinary attitudes and behaviours. One reason why we see a muted effect in the CIANI + LCOCP Group may be that there are fewer "high engagers" in this Group than in the CIANI Only Group. Figure 6.25 shows the relationship between the CIANI Engagement Index and the Intervention Groups. As we can see, the number of caregivers with high scores on the Engagement Index is actually much lower in the CIANI + LCOCP Group $(23.2 \%)$ than it is in the CIANI Only Group (54.6\%). ${ }^{26}$ To the extent that the CIANI effect on the reduction of the inclination to physical discipline "works through" CIANI Engagement, we would expect such an effect to be muted for the CIANI + LCOCP Group. We would also expect the levels of discipline in the CIANI + LCOCP Group to stand somewhere between the lower levels in the CIANI Only Group and the higher levels in the Control Group, which is what we have found.

\footnotetext{
26 This pattern holds, with some variation of course, across the three CIANIs in each of the two Intervention Groups; that is, engagement is much lower in each of the three CIANIs that compose the CIANI + LCOCP Group than it is in the three CIANIs that make up the CIANI Only Group.
} 


\section{Figure 6.25: CIANI Engagement Index by Group Percent with high scores on the CIANI Engagement Index Two Intervention Groups ( $\mathbf{N}=799)$}

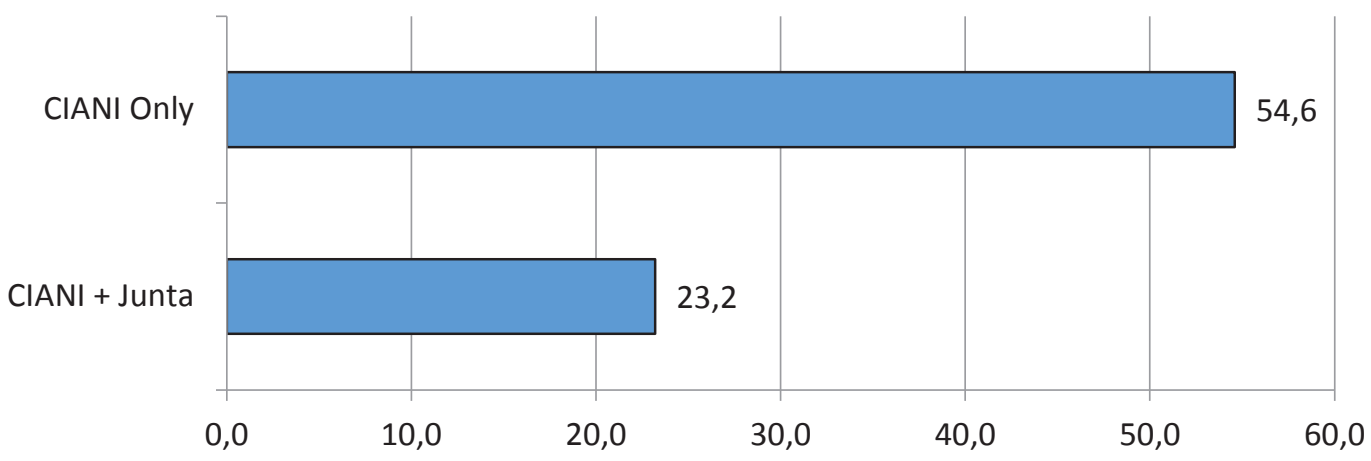

The point to note is not just that the CIANI + LCOCP Group has relatively fewer caregivers who are highly engaged in the CIANI; the differing impact of engagement is also significant. The relationship between the CIANI Engagement Index and discipline is weaker in the CIANI + LCOCP Group than it is in the CIANI Only Group. Compared to the CIANI Only Group, then, there are fewer "high engagers" in the CIANI + LCOCP Group, and the impact of engagement on the reduction of the proclivity to discipline is not as strong. ${ }^{27}$ The reasons for this pattern are not apparent, but they may be related to the particular structural and perhaps idiosyncratic characteristics of the three CIANIs that make up the CIANI + LCOCP Group ${ }^{28}$ The reasons may also have something to do with any contextual effects that result from the nonequivalency of the municipal-level environments.

27 We conducted the same kind of analysis for family stress and community trust, which, along with engagement in the CIANI, were the three strongest influences on discipline. The distribution of family stress and community trust is remarkably similar in the CIANI Only and CIANI + LCOCP Groups. The relationship between stress and trust, on one hand, and disciplinary attitudes and behaviours, on the other, is essentially the same in the two Intervention Groups. In contrast to the pattern we found for CIANI engagement, then, there are as many highly stressed caregivers in the CIANI Only Group as in the CIANI + LCOCP Group, and the impact of stress and trust on discipline is equivalent in both groups.

28 The structural characteristics of the CIANIs included in the CIANI + LCOCP Group may be important to understanding of another finding of the within-group regression analyses. In two of the four regressions, even when taking into account the effects of CIANI Engagement, the levels of discipline in the CIANI + LCOCP Group were higher than they were in the CIANI Only Group. 



\section{Stakeholder Consultation Summary}

$\mathrm{F}$ rom its onset, this evaluation set out to be a participatory and collaborative. It was expected that extensive and meaningful dialogue and knowledge exchange between all stakeholder groups would be carried out during the course of the evaluation. This included built-in engagement activities such as;

- Presenting preliminary findings to organization representatives (which has been a successful model with other DR research projects).

- Using the Dominican cultural practices of popular group consultations to share research findings and illicit recommendations; and

- Meeting with decision makers to review findings and recommendations regarding policies and institutional practices.

The evaluation tool was developed to provide a template for on-going program review and renewal. The initial qualitative interviews were used as a basis for which the survey was developed, and from the surveys, caregiver perspective was obtained. The survey was complex, and provided ample opportunity and breadth for caregivers to express themselves. Once this initial analysis was complete, the Canadian team developed a preliminary findings report which outlined the investigation; purpose, methodology, qualitative analysis, quantitative analysis and pre- 
Evaluation of Centres for the Integral Attention of Children in Dominican Republic (CIANIs) and Local Community Organizations for Child Protection (LCOCP)

liminary results and was presented at a conference held on December $4^{\text {th }}, 2014$ at the Great Hall of the Americas Hotel Crowne Plaza Santo Domingo. In attendance were various members from CONANI (including CONANI president), members from the National Protection System, leaders from non-governmental institutions, officials from DIGEPEP and CIANI directors from across the country.

Following this presentation, the Canadian team completed the analysis and began to work on the final report. Once the findings and analysis were complete, the Canadian team in collaboration with the Dominican team began to prepare and plan for consultation meetings to be held with front line workers to present the findings and receive feedback and validation.

\section{Group Consultations}

\begin{tabular}{|l|l|l|}
\multicolumn{1}{|c|}{ Date } & \multicolumn{1}{|c|}{ Location held } & \multicolumn{1}{c|}{ Centers } \\
\hline August 13,2015 & Santo Domingo & - Los Mina \\
\hline August 17,2015 & La Romana & Santo Domingo \\
\hline August 19,2015 & Santiago & - La Romana \\
\hline & & - El Seybo \\
\hline
\end{tabular}

Three group consultations involving 15 - 20 participants each were held across the country. Each consultation meeting brought together personnel from two different centers, and included different members from the center's interdisciplinary teams; social workers, educators, medical personnel, educational coordinators, directors, and psychologists. The consultations were structured in three parts; an information and review section, where participants were presented with the major findings; followed by a discussion section where participants were encouraged to ask questions and comment on the findings presented; ending with an open discussion for recommendations.

All three groups were very engaged with the presentation and findings. The qualitative findings in particular were extremely well received. Participants were appreciative that their work and dedication had been acknowledged and recognized. Particularly in the Relationships and Satisfaction sections, they commented on the care they take into developing those relationships with caregivers and com- 
Evaluation of Centres for the Integral Attention of Children in Dominican Republic (CIANIs) and Local Community Organizations for Child Protection (LCOCP)

munities; staying later and coming in early is a norm for most. Participants prided themselves on providing experiences marked with love and respect, commenting that graduates referred to themselves as "conanitos" (Little CONANI-ers)

The participants also commented that building those relationships involved mutual respect, pushing families, being constantly vigilant and engaging through conversations, phone calls and home visits. Home visits in particular were cited as crucial practices which facilitated better relationships between families and the center, serving as violence detection and protection measures. These visits and the follow-up provided by the centers was seen as "uno-a" (most important). By maintaining regular contact, participants felt they were able to help families feel supported. They stressed the importance of continuing the follow-up provided to graduates once they entered the school system stating that they regularly asked the teachers receiving them "what would you like from centers" to build a relationship with the new service providers.

When asked to discuss what they believed worked, much like in the findings the Parent School stood out. The way the school involved families was highlighted as a key aspect for prevention. The school was seen as being successful because it was welcoming, provided solutions for caregivers and allowed caregivers to share and be heard.

Although the Parent School was seen as successful, some areas for improvement identified included; developing a curriculum for all the parent schools as opposed to just guidelines and possibly holding more than one session a month to meet the demand and allow more caregivers to attend. Participants acknowledged that it will take generations to fully change attitudes and behaviours, but that they felt the parent school was a good place to start.

The general consensus was that these centers are absolutely necessary and that the benefits went beyond just the children but also families, communities and society as a whole. The centers did not just provide education and care, but also contributed to poverty reduction by allowing the opportunities for young mothers to work and go to school.

When asked for recommendations to make the centers better and more effective, participants listed the following: 
Evaluation of Centres for the Integral Attention of Children in Dominican Republic (CIANIs) and Local Community Organizations for Child Protection (LCOCP)

Need for professionalization: participants expressed the need to provide staff with training and workshops. Many personnel members although having the willingness to do the work have no training in ECD, and some concern was expressed over things being done "properly." Specifically with social workers in the centers, much like in the rest of the country there was a lack of qualified professionals. This is of particular concern since the social worker was identified as the go-to person for various referrals. Participants suggested more incentives to bring students to the centers outside of the capital for practicums was suggested.

Participants conveyed the willingness of personnel to learn and be taught, and an interest in an institutional relationship with the universities which currently does not exist. This relationship could facilitate personnel attaining their degrees and possibly providing more accessible options to studying (for the centers outside of the capital).

Center get-togethers: participants also expressed an interest in more regular meetings between members from different centers to discuss; work methodology, identifying different issues, and exchanging solutions and strategies to make for better service provision. *A practice that was put on hold during the transition from CIANIs to CAIPIs but is set to continue after the transition period.

Moderating risks: the centers were strategically placed in vulnerable communities, areas with high unemployment, drugs and delinquency, although the communities generally accept and welcome the centers and personnel - being grateful for the work being done and going so far as to protect and look out for personnel. Participants raised the need for establishing practices to moderate risks which included; workshops for personnel (especially those from outside community) to learn about gang identification and language and orientation of new staff to the neighbourhood to make the community aware of them. Working more closely with communities was highly recommended to be able to increase cooperation and reach. ${ }^{*}$ New administration has developed family centers which would serve children who do not get enrolled but still need support. These centers rely heavily on community support.

Junta integration: For the first two consultations, all but one participant was unaware of what a Junta was. In the final consultation there was knowledge of the Junta but the role in working with the centers was unclear. Upon discussing the Juntas (who they are, what they do) it was suggested that there should be a clos- 
Evaluation of Centres for the Integral Attention of Children in Dominican Republic (CIANIs) and Local Community Organizations for Child Protection (LCOCP)

er alignment between the two, having the centers provide more referrals to free up time to do other work, and not jeopardize relationships with caregivers (which could happen when centers tried to deal with abuse/neglect concerns).

Challenges: echoing the caregiver findings from the surveys the space did not meet demand. The number of children ultimately enrolled was always a fraction of those who applied. Sometimes 300 home visits are completed but only 50 children are being let in. The infrastructure was also deemed inadequate along with material and equipment. *Again these are concerns that are currently being addressed through the new administration. (Ex. Building new centers specifically as child care centers as opposed to repurposing existing buildings.)

The consultations validated the findings presented. Further, through these consultations recommendations and potential solutions were provided by the front line workers which were noted to be included in the report.

The change in administration was another important point. As the centers were in transition it was imperative to meet with the new administration.

\section{Think-Tank Consultation:}

A think-tank session was organized and the INAIPI director and assistant director were invited to Toronto on September $29^{\text {th }}-$ October $2^{\text {nd }}$ where they met with the Canadian team and reviewed the report, discussed findings and exchanged feedback. This meeting was of particular importance because through the inclusion of key decision-makers, it was anticipated that the findings would be utilized appropriately.

The meeting began with a review of the report - specifically the methodology and the qualitative and quantitative findings. The group was able to discuss and clarify questions and carefully examine the report. There was a consensus regarding the benefits of the centers and their importance to the children, families, and communities served. The effectiveness of the parent school and engagement initiatives were reverberated and the need to expand and increase outreach was also echoed. The Canadian team was introduced to the new administration, the changes being made and some of the initiatives that were either planned or in progress, many of which were in line with the recommendations proposed and developed from the findings. 
Evaluation of Centres for the Integral Attention of Children in Dominican Republic (CIANIs) and Local Community Organizations for Child Protection (LCOCP)

The INAIPI team expressed the need to elaborate on and include a more detailed overview of the development of early childcare development programs in the DR - how they have evolved, the policies and historical context that preceded and led to the present day. The historical portion was noted as being especially important when disseminating the findings to countries in Latin America, in order to provide political context.

In discussing steps for moving forward the focus was to where was there room for improvement? All parties acknowledged the importance of the centers and the good work and practices being done, and so based on the study findings and the first-hand knowledge and changes being implemented the discussion turned to how to build on success.

The Canadian team presented recommendations and implications and along with the INAIPI members who either explained how they were currently being implemented or discussed ways to elaborate on them and make them more realistic to the reality of the country and INAIPI structure. The most significant points of discussion were:

Strategies that standardize practices but also allow for local realities. Based on the findings and consultations guidelines exist for policies, practices and curriculums, however, there exists a need for these to be centralized. Centralization is part of the new initiatives currently being implemented. It is important to allow for centers to apply changes based on the local/geographical realities.

For the Parent School specifically, it was suggested that curriculum be divided into modules where caregivers would receive certificates of participation for completion.

Developing deeper community ties. The reach the centers have and the benefits they provide the community was a critical finding. The centers obviously provided various opportunities for engagement however, there is potential to amplify that, and in doing so amplifying the benefits. Under new INAIPI administration, initiatives were being implemented to do just that. CAIFls (family centers) which provide similar services to families who were not enrolled in the CAIPIs. These centers provide support through programs and services to ensure that "no child gets left behind." INAIPI is also working towards developing community networks between different organization in communities to strengthen community support and develop a community safety net. 
Evaluation of Centres for the Integral Attention of Children in Dominican Republic (CIANIs) and Local Community Organizations for Child Protection (LCOCP)

Increase communication. Creating a parent association for caregivers to develop leadership opportunities and enhance ownership and thus increase capacity and confidence that would improve not only their parenting but allow them to be role models for other caregivers in the community.

Increasing communication between centers to exchange knowledge and develop a feedback and planning mechanism was also noted as an important practice which new administration had planned to implement.

Periodic evaluation. The group discussed the importance of continued and regular evaluation - specifically the possibility of using the survey developed to continue evaluating and monitoring the program.

Research focus. The opportunity for continued partnership between Ryerson University and INAIPI was presented in the form of an initiative that would implement research into the day to day practices. Leveraging Ryerson's ties to the newly launched Masters of Social Work program a potential research opportunity would be with the student theses where in which they could research areas of child development and specific INAIPI practices. The centers themselves could also conduct small scale evaluations/research, looking at specific practices and policies as part daily activities. The potential to inform practice through evidence based research was seen as important to moving forward and continued improvement. As a next step developing this partnership and research program was set. 



\section{Implications and Recommendations}

* It is important to note that the centers are currently in transition and many of the implications and recommendations that are made in this report based on the findings made at the time of this study are part of the changes and improvements that are already being introduced and implemented under the new direction.

- A strong investment in ECD Research, practice, and the literature have demonstrated that ECD programs are sound investments in children's well-being, which provide a head start in life that offers long-term benefits (Executive Office of the President of the United States of America, 2014; UNICEF, 2013; 2014b). These interventions work to provide the foundations of learning and resilience for children. In so doing, they contribute to children's success as adults and to disruption of the inter-generational cycle of poverty.

- Taking a multidisciplinary approach to ECD interventions, which need to integrate education, health, nutrition, and protection. A holistic approach to care is not only a child's right, but also an effective way to help children thrive and to reduce the impact of negative early experiences (Tinajero \& Loizillon, 2012; UNICEF, 2006; 2014a; 2014b). 
Evaluation of Centres for the Integral Attention of Children in Dominican Republic (CIANIs) and Local Community Organizations for Child Protection (LCOCP)

- Clearly developed caregiver and family supports meant to improve family functioning, improve the way caregivers perform their role as parents, and increase knowledge and resources (Daly et al., 2015; UNESCO, 2014; UNICEF, 2006).

o Develop a standardized Parent School curriculum to be implemented in all the CIANIs,

o Develop clearly specified protocols for standardized interventions and practices,

o Promote efforts to discourage the social acceptance of the physical discipline of children and of any violence against children.

By strengthening knowledge and skills about child development and nonviolent positive discipline, these programs foster social safety nets and ultimately contribute to community well-being and violence prevention.

*One of the new initiatives being implemented currently includes family centers promoting community support.

- Continue to invest in the professionalization of those providing services in CIANIs to ensure the continuation of high-quality services, with age appropriate and child friendly curriculum, and teaching methods that incorporate both evidence-based approaches and traditional child-rearing practices and cultural beliefs (UNICEF, 2014a; Tinajero \& Loizillon, 2012). This could include

o Providing trainings and workshops on site for employees, or before starting as an employee as part of the orientation.

o Linkages with universities to promote and support CIANI staff who want to go back to school.

- Continue to strengthen the partnership between CIANIs and the community. Children's development depends on coordinated and collective efforts to providing ECD programs (UNESCO, 2014; Daly et al., 2015). These partnerships are particularly beneficial to children in communities disadvantaged by high rates of poverty and violence, who are at a higher risk of low educational attainment. 
Evaluation of Centres for the Integral Attention of Children in Dominican Republic (CIANIs) and Local Community Organizations for Child Protection (LCOCP)

- Establish strong and consistent monitoring and evaluation of programs, which should include periodic planned evaluations that collect and compile consistent data, that measure improvements, and that assess gaps and areas for improvement (Daly et al., 2015; Tinajero \& Loizillon, 2012; UNESCO, 2014; UNICEF, 2010; USAID, 2011). Building on this data, work to establish a national applied research agenda on the prevention and reduction of violence. Government organizations should develop and adequately resource research that will improve understanding of the issues and develop partnerships with universities and also other research organizations and institutions of higher education. 



\section{Reference List}

Abom, B. (2004). Social capital, NGOs, and development: A Guatemalan case study. Development in Practice, 14(3), 342-353.

Aracena, M., Krause, M., Pérez, C., Mendez, M. J., Salvatierra, L., Soto, M., Pantaja, T., Navarro, S., Salinas, A., Farah, C., \& Altimir, C. (2009). Cost-effectiveness evaluation of a home visit program for adolescent mothers. Journal of Health Psychology, 14, 878-87.

Araujo, M. C., López Bóo, F., \& Puyana, J. M. (2013). Overview of early childhood development services in Latin America and the Caribbean. Washington: Inter-American Development Bank.

Arteaga, T., Mendez, M., \& Munoz, V. (2011). Mapeo sobre la implementación de las recomendaciones del estudio mundial sobre la violencia contra niños, niñas y adolescentes. Sao Paulo, Brazil: Global Movement for Children.

Attanasio, O. P., Maro, V. D., \& Vera-Hernández, M. (2013). Community nurseries and the nutritional status of poor children. Evidence from Colombia. The Economic Journal, 123(571), 1025-1058. 
Evaluation of Centres for the Integral Attention of Children in Dominican Republic (CIANIs) and Local Community Organizations for Child Protection (LCOCP)

Banco Central de la República Dominicana. (2012). Banco Central - Mercado de Trabajo. Retrieved from: Banco Central de la República Dominicana: http:// www.bancentral.gov.do/estadisticas_economicas/mercado_trabajo/

Behrman, J. R., Cheng, Y., \& Todd, P. E. (2004). Evaluating preschool programs when length of exposure to the program varies: a nonparametric approach. Review of Economics and Statistics. 86(1), 108-132.

Belfer, M. L., \& Rohde, L. A. (2005). Child and adolescent mental health in Latin America and the Caribbean: problems, progress, and policy research. $R e-$ vista Panamericana de Salud Pública, 18(4-5), 359-365.

Bellei, C., \& Abarca, G., Sepúlveda, P., Orellana, V., Poblete, X. (2015). The State of Education in Latin America and the Caribbean: Towards a Quality Education for All - 2015. Santiago Chile: United Nations Educational, Scientific, and Cultural Organization.

Benfirrez, J. (June 2015). Personal interview.

Berlinski, S., Galiani, S., \& Gertler, P. J. (2009). The effect of pre-primary education on primary school performance. Journal of Public Economics, 93, 219-234.

Berlinski, S., Galiani, S., \& Manacorda, M. (2008). Giving children a better start: Preschool attendance and school-age profiles. Journal of Public Economics, 92(5-6), 1416-1440.

Berlinski, S., Galiani, S., \& Gertler, P. (2005). Public Pre-primary Schooling and Primary School Performance. Unpublished manuscript.

Bernard van Leer Foundation. (2009). Equity and quality? Challenges for early childhood and primary education in Ethiopia, India and Peru. The Hague, the Netherlands: Author.

Blanchet-Cohen, N. (2009). Children, agency and violence: In and beyond the United Nations study on violence against children. UNICEF (Ed.). Florence: UNICEF Innocenti Research Centre. 
Evaluation of Centres for the Integral Attention of Children in Dominican Republic (CIANIs) and Local Community Organizations for Child Protection (LCOCP)

Borht, T.A., Mendez, M.V., \& Villalobos, V.M. (2012). Violencia contra los niños, niñas y adolescentes: Estado de situación de los países de Centroamérica, México, Cuba, y República Dominicana en relación con la violencia contra los niños, niñas y adolescentes en seguimiento al estudio de Naciones Unidas sobre la violencia contra los niños. Costa Rica: Visión Mundial Internacional.

Bornstein, M., H., \& Cote, L., R. (2004). "Who Is Sitting Across From Me?" Immigrant Mothers' Knowledge of Parenting and Children's Development. Pediatrics, 114(5), e557-e564.

Bowen, L. K, Gwiasda, V., and Brown, M., M. (2004). Engaging community residents to prevent violence. Journal of Interpersonal Violence, 19(3), 356-367.

Brown, E. C., Hawkins, J. D., Arthur, M. W., Briney, J. S., \& Abbott, R. D. (2007). Effects of Communities That Care on prevention services systems: Findings from the Community Youth Development Study at 1.5 years. Prevention Science, 8(3), 180-191.

Brown, L. and Ashman, D. (1996). Participation, social capital, and intersectoral problem solving: African and Asian case studies. World Development, 24(9), 1467-1479.

Burt, R. S. (1987). Social contagion and innovation: Cohesion versus structural equivalence. American Journal of Sociology, 92, 1287-1335.

Carneiro, P., and Heckman, J. (2003). Human capital policy. In J. Heckman and A. Krueger (Eds.), Inequality in America: What role for human capital policy?. Cambridge, MA: MIT Press.

Center for Social and Demographic Studies (CESDEM) \& ICF International. (2014). Encuesta demográfica y de salud 2013. Santo Domingo, República Dominicana: CESDEM y ICF International.

Charmaz, C. (2006). Constructing grounded theory: A practical guide through qualitative analysis. London: Sage. 
Evaluation of Centres for the Integral Attention of Children in Dominican Republic (CIANIs) and Local Community Organizations for Child Protection (LCOCP)

Chaskin, R.J., Brown, P.,Venkatesh, S., \& Vidal, A. (2001). Building community capacity. New York: Aldine.

Chilenski, S. M., Ang, P. M., Greenberg, M. T., Feinberg, M. E., \& Spoth, R. (2014). The impact of a prevention delivery system on perceived social capital: The PROSPER project. Prevention Science, 15(2), 125-137.

Consultative Group on Early Childhood Care and Development. (2013). Early Childhood Development on the Post-2015 Development Agenda. Toronto, Canada: Author.

Contreras, J. M., Bott, S., Guedes, A., \& Dartnall, E. (2010). Sexual violence in Latin America and the Caribbean: A desk review. South Africa: Sexual Violence Research Initiative. Gender and Health Research Unit. Medical Research Council.

Coohey, C. (1996). Child maltreatment: Testing the social isolation hypothesis. Child Abuse \& Neglect, 20(3), 241-254.

Cousins, J. B., \& Whitmore, E. (1998). Framing participatory evaluation. New Directions for Evaluation, 80, 5-23.

Covell, K., \& Becker, J. (2011). Five years on: a global update on violence against children. Virgina, USA: NGO Advisory Council.

Cowan, C., Cowan, P., \& Barry, J. (2011). Couples' groups for parents of preschoolers: Ten-year outcomes of a randomized trial. Journal of Family Psychology, 25(2), 240-250.

Crowley, D. M., Greenberg, M. T., Feinberg, M. E., Spoth, R. L., \& Redmond, C. R. (2012). The effect of the PROSPER partnership model on cultivating local stakeholder knowledge of evidence-based programs: A five-year longitudinal study of 28 communities. Prevention Science, 13(1), 96-105.

Cunha, F., \& Heckman, J. (2007). The technology of skill formation. American Economic Review, 97(2), 31-47. 
Evaluation of Centres for the Integral Attention of Children in Dominican Republic (CIANIs) and Local Community Organizations for Child Protection (LCOCP)

Cunha, F., Heckman, J., Lochner, L., \& Masterov, D. (2005). Interpreting the Evidence on Life Cycle Skill Formation. NBER Working Paper 11331. Cambridge, MA: National Bureau of Economic Research.

Currie, J. (2001). Early childhood education programs. Journal of Economic Perspectives, 213-238.

Currie, V., \& Heykoop, C. (2012). Child and youth-centred accountability: A guide for involving young people in monitoring \& evaluating child protection systems. Victoria, BC: International Institute for Child Rights and Development.

Currie, M., King, G., Rosenbaum, P., Law, M., Kertoy, M., \& Specht, J. (2005). A model of impacts of research partnerships in health and social services. Evaluation and Program Planning, 28(4), 400-412.

Daly, M., Bray, R., Bruckauf, Z., Byrne, J., Margaria, A., Pec'nik, N., \& SammsVaughan, M. (2015). Family and parenting support: Policy and provision in a global context. Innocenti Insight. Florence: UNICEF Office of Research.

De Ferranti, D., Perry, G., Ferreira, F., Walton, M. (2003). Inequality in Latin America and the Caribbean: Breaking with history?. Mexico: World Bank Latina American and Caribbean Studies.

DiLorenzo, P., White, C. R., Morales, A., Paul, A., \& Shaw, S. (2013). Innovative cross-system and community approaches for the prevention of child maltreatment. Child welfare, 92(2), 161.

Dominguez, S., \& Watkins, C. (2003). Creating networks for survival and mobility: Social capital among African-American and Latin-American low-income mothers. Social Problems, 50(1), 111-135.

Drake, B., \& Pandey, S. (1996). Understanding the relationship between neighborhood poverty and specific types of child maltreatment. Child abuse \& neglect, 20(11), 1003-1018.

Dudley, J. R. (2014). Social work evaluation: Enhancing what we do (2 ${ }^{\text {nd }}$ Ed.). Chicago: Lyceum Books. 
Evaluation of Centres for the Integral Attention of Children in Dominican Republic (CIANIs) and Local Community Organizations for Child Protection (LCOCP)

Dudley, J.R. (2009). Social work evaluation: Enhancing what we do. Chicago: Lyceum Books.

Economic Commission for Latin America and the Caribbean (CEPAL) [Spanish acronym]. (2013). Proposed regional agenda on population and development for Latin American and the Caribbean beyond 2014 (LC/L.3641CRPD.1/4). Mexico: United Nations Publication.

Economic Commission for Latin America and the Caribbean - United Nations Children's Fund (ECLAC-UNICEF). (2011). Childcare and parental leave, Challenges, 2, Santiago, Chile: UNICEF.

Eriksson, U., Hochwälder, J., \& Sellström, E. (2011). Perceptions of community trust and safety-consequences for children's well $\square$ being in rural and urban contexts. Acta Paediatrica, 100(10), 1373-1378.

Executive Office of the President of the United States. (2014). Washington, D.C., U.S.: The economics of early childhood investments.

Fernald, L.C.H., Kariger, P., Engle, P. and Raikes, A. (2009). Examining early child development in low income countries. A toolkit for the assessment of children in the first five years of life. Washington, DC: The World Bank.

Fetterman, D. M. (2002). Empowerment evaluation: Building communities of practice and a culture of learning. American Journal of Community Psychology, 30(1), 89-102.

Fiedler, J. (2003). A cost analysis of the Honduras community-based integrated childcare program (Atención Integral a la Niñez Comunitaria, AIN-C). Health, Nutrition and Population Discussion Paper. Washington, D.C.: World Bank.

Fontes, L, A. (2002). Child discipline and physical abuse in immigrant Latino families: Reducing violence and misunderstandings. Journal of Counselling and Development, 80, 31-41.

Foxton, F., \& Jones, R. (2011). Social capital indicators review. Office for National Statistics, UK. 
Evaluation of Centres for the Integral Attention of Children in Dominican Republic (CIANIs) and Local Community Organizations for Child Protection (LCOCP)

Furstenberg, F. F. (2005). Banking on families: How families generate and distribute social capital. Journal of Marriage and Family, 67(4), 809-821.

Gallup. (2014). Child Abuse Underreported in Latin America. Retrieved from http:// http://www.gallup.com/poll/139376/child-abuse-underreported-latin-america.aspx

Garbarino, J., \& Sherman, D. (1980). High-risk neighborhoods and high-risk families: The human ecology of child maltreatment. Child development, 188-198.

Gardner, F., Montgomery, P., \& Knerr, W. (2015). Transporting evidence-based parenting programs for child problem behavior (age 3-10) between countries: Systematic review and meta-analysis. Journal of Clinical Child \& Adolescent Psychology, 1-14.

General Directorate of Special Programs (DIGEPEP) [Spanish acronym]. (2013a). Quisqueya empieza contigo: Lineamientos plan nacional de proteccion y atencion integral a la primera infancia. Santo Domingo, DR: Author.

General Directorate of Special Programs (DIGEPEP) [Spanish acronym]. (2013b). Quisqueya empieza contigo: Requerimientos tecnicos y administrativos para la cogestionde los centros comunitarios de atencion integral a la infancia y la familia. Santo Domingo, DR: Author.

General Directorate of Special Programs (DIGEPEP) [Spanish acronym] (n.d.). Quisqueya empieza contigo: Descripción del programa de atención integral de base familiar y comunitaria. Santo Domingo: DR: Author.

Gerring, J. (2005). Causation: a unified framework for the social sciences. Journal of Theoretical Politics, 17(2), 163-198.

Gertler, P., and Fernald, L. (2004). The Medium Term Impact of Opportunities on Child Development in Rural Areas. Available at: http://www.sarpn.org.za/ documents/d0001264/P1498-Child_dev_terminado_1dic04.pdf.

Given, L. M. (Ed.). (2008). The Sage encyclopedia of qualitative research methods. London: Sage Publications. 
Evaluation of Centres for the Integral Attention of Children in Dominican Republic (CIANIs) and Local Community Organizations for Child Protection (LCOCP)

Glasser, B., \& Strauss, A. (1967). The discovery of grounded theory: Strategies for qualitative research. Chicago: Aldine.

Glendford, H. (2012). Sexual violence against children in the Caribbean, progressive report. Barbados: UNICEF Office for the Eastern Caribbean Area.

Gonzalez, Z. (2002). Explotación comercial de niñas, niños y adolescentes: Una evaluación rápida. Switzerland: Organización Internacional del Trabajo.

Gracia, E., \& Herrero, J. (2004). Determinants of social integration in the community: An exploratory analysis of personal, interpersonal and situational variables. Journal of Community \& Applied Social Psychology, 14(1), 1-15.

Gracia, E., \& Musitu, G. (2003). Social isolation from communities and child maltreatment: A cross-cultural comparison. Child Abuse \& Neglect, 27(2), 153168.

Grantham-McGregor, S. M., Powell, C. A., Walker, S. P., \& Himes, J. H. (1991). Nutritional supplementation, psychosocial stimulation, and mental development of stunted children: the Jamaican study. The Lancet, 338(8758), 1-5.

Green, G. P., \& Haines, A. (2015). Asset building \& community development. London: Sage publications.

Green, G., Grimsley, M., Suokas, A., Prescott, M., Jowitt, T., \& Linacre, R. (2000). Social capital, health and economy in South Yorkshire coalfield communities. Sheffield: Centre for Regional Economic and Social Research, Sheffield Hallam University.

Gross, D., Fogg, L., Webster-Stratton, C., Garvey, C., Julion, W., \& Grady, J. (2003). Parent training of toddlers in day care in low-income urban communities. Journal of Consulting and Clinical Psychology, 71(2), 261-278.

Guba, E.G., \& Lincoln, Y.S. (1989). Fourth generation evaluation. Newbury Park, CA: Sage Publications.

Halpern, D. (2001). Moral values, social trust and inequality: can values explain crime?. British Journal of Criminology, 41(2), 236-251. 
Evaluation of Centres for the Integral Attention of Children in Dominican Republic (CIANIs) and Local Community Organizations for Child Protection (LCOCP)

Healy, K. (2001). Participatory action research and social work: A critical appraisal. International Social Work, 44(1), 93-105

Heckman, J. J. (2006). Skill formation and the economics of investing in disadvantaged children. Science, 312(5782), 1900-1902.

Hernandez, A. A., \& Grineski, S. E. (2012). Disrupted by violence: children's well-being and families' economic, social, and cultural capital in Ciudad Juarez, Mexico. Revista Panamericana de Salud Pública, 31(5), 373-379.

Hirsch, M. L., \& Quartaroli, T. A. (2009). Many hats: The methods and roles of the program evaluator. Journal of Applied Social Science, 3(2), 73-80.

Humanium. (2011). Children of the Dominican Republic: Realizing children's rights in the Dominican Republic. Retrieved from http://humanium.org/en/dominican-republic/

Inter-American Development Bank (IDB). (2013). Overview of early childhood development services in Latin America and the Caribbean. Washington, DC: Author.

International Collaboration for Participatory Health Research (ICPHR). (2013). Position Paper 1: What is Participatory Health Research? Version: Mai 2013. Berlin: Author.

International Labour Organization (ILO). (2011). Child abuse counselling manual: Combating child labour through education \& training. Switzerland: ILO.

Irwin, L. G., Siddiqi, A., \& Hertzman, C. (2007). Early child development: a powerful equalizer. Final report to the WHO Commission on social determinants of health. Geneva: World Health Organization.

Jones, E., Gutman, L., and Platt, L. (2013). Family stressors and children's outcomes. Kent: University of Kent, Childhood Wellbeing Research Center.

Kamerman, S. B. (2006). A global history of early childhood education and care. Background paper prepared for the Education for All Monitoring Report. Paris: UNESCO. 
Evaluation of Centres for the Integral Attention of Children in Dominican Republic (CIANIs) and Local Community Organizations for Child Protection (LCOCP)

Kimbrough-Melton, R. J., \& Melton, G. B. (2015). "Someone will notice, and someone will care": How to build strong communities for children. Child abuse \& neglect, 41, 67-78.

Knaul, F. M., \& Ramírez, M. Á. (2005). Family violence and child abuse in Latin America and the Caribbean: the cases of Colombia and Mexico. Washington, D.C: IDB, Sustainable Development Department Technical Papers Series, SOC-137.

Kotchick, B. A., \& Grover, R.L. (2008). Implementing evidence based treatments with ethnically diverse clients. In R. G. Steele, T. D. Elkin, M. C. Roberts (Eds.), Handbook of evidence-based therapies for children and adolescents. USA: Springer. pp. 487-504-504.

Lenzi, M., Vieno, A., Pastore, M., \& Santinello, M. (2013). Neighborhood social connectedness and adolescent civic engagement: An integrative model. Journal of Environmental Psychology, 34, 45-54.

Levy, S., \& Schady, N. (2013). Latin America's social policy challenge: education, social insurance, redistribution. The Journal of Economic Perspectives, 27(2), 193-218.

Loeber, R., \& Farrington, D. (2000). Young children who commit crime. Development and Psychopathology, 12, 737-762.

Longman-Mills, S., González, Y. W., Meléndez, M. O., García, M. R., Gómez, J. D., Juárez, C. G., \& Mann, R. E. (2011). Child maltreatment and its relationship to drug use in Latin America and the Caribbean: An overview and multinational research partnership. International Journal of Mental Health and Addiction, 9(4), 347-364.

López Stewart, C., George Lara, M., Herrera Amighetti, L. D., Wissow, L. S., Gutierrez, M. I., Levav, I., \& Maddaleno, M. (2000). Parenting and physical punishment: primary care interventions in Latin America. Revista Panamericana de Salud Pública, 8(4), 257-267.

Malik, K. (2014). Human development report 2014 - Sustaining human progress: Reducing vulnerabilities and building resilience. New York: UNDP. 
Evaluation of Centres for the Integral Attention of Children in Dominican Republic (CIANIs) and Local Community Organizations for Child Protection (LCOCP)

Mahoney, J., \& Goertz, G. (2006). A tale of two cultures: Contrasting quantitative and qualitative research. Political Analysis, 14(3), 227-249.

Mahoney, J. (2001). Strategies of causal inference in small-N analysis. Sociological Methods \& Research, 28(4), 387-424.

Maxwell, J. A. (2004). Using qualitative methods for causal explanation. Field methods, 16(3), 243-264.

Mejia, A., Calam, R., \& Sanders, M. R. (2012). A review of parenting programs in developing countries: opportunities and challenges for preventing emotional and behavioral difficulties in children. Clinical child and family psychology review, 15(2), 163-175.

Ministerio de Educacion Nacional. (2009). Guia operativa para la presentación del servicio de atención integral a la primera infancia. Comombia: Nomos Impresores.

Ministry of Economics, Planning and Development (MEPyD) [Spanish acronym]. (2014a). Unidad Asesora de Análisis Economía y Social - Informe General. Santo Domingo, República Dominicana: Author.

Ministry of Economics, Planning and Development (MEPyD) [Spanish acronym]. (2014B). Sistema de indicadores sociales de la República Dominicana (SISDOM). (Volumen II: serie de datos por áreas temáticas versión 2014). Distrito Nacional, República Dominicana: Author.

Moestue, H. \& Muggah, R. (2012). Preventing violence against children in fragile and conflict-affected settings: a child security index. Early Childhood Matters. Retrieved from «http://igarape.org.br/preventing-violence-against-children-in-fragile-and-conflict-affected-settings-a-childsecurity-index/s

Moliné, A. \& Rathe, M. (2011). Sistema de salud de República Dominicana. Salud Pública de México, 53, 255-264.

National Council for the Protection of Children (CONANI) [Spanish acronym]. (2014) Informe estadístico anual (enero-diciembre 2013). República Dominicana: Author. 
Evaluation of Centres for the Integral Attention of Children in Dominican Republic (CIANIs) and Local Community Organizations for Child Protection (LCOCP)

National Council for the Protection of Children (CONANI) [Spanish acronym]. (2012a). Diagnóstico sobre la situación de la atención a la primera infancia en la república dominicana. República Dominicana: Author.

National Council for the Protection of Children (CONANI) [Spanish acronym]. (2012b). Memoria de gestión de ocho (8) anos de gobierno 2004-2012. República Dominicana: Author.

National Council for the Protection of Children (CONANI) [Spanish acronym]. (2011). Lineamientos de política pública a favor de la primera infancia, enmarcadas en el cumplimiento de la estrategia nacional de desarrollo. Santo Domingo, DR: Author

National Council for the Protection of Children (CONANI) [Spanish acronym]. (n.d). Historia CIANI. Santo Domingo, DR: Author.

Nixon, R. D. V., Sweeney, L., Erickson, D. B., \& Touyz, S. W. (2003). Parent-child interaction therapy: A comparison of standard and abbreviated treatments for oppositional defiant preschoolers. Journal of Consulting and Clinical Psychology, 71(2), 251-260.

Nonoyama-Tarumi, Y., \& Ota, Y. (2009). Early childhood development in developing countries: Pre-primary education, parenting, and health care.Background Paper Education for all. Global Monitoring Report.

Oficina de Desarrollo Humano. (2010). Política social: Capacidades y derechos. Análisis y propuestas de políticas sociales en República Dominicana (Volumen I). Santo Domingo: República Dominicana: PNUD.

Oficina Nacional de Estadistica. (2015). Estadísticas provinciales y municipales. Retrieved from http://www.one.gob.do/Estadisticas/271/perfiles-provinciales

Oficina Nacional de Estadistica. (2011). Documentos. Retrieved from http://censo2010.one.gob.do/index.php?module=articles\&func $=$ view $\&$ ptid $=2 \& p=6$

Ohmer, M. L. (2007). Citizen participation in neighborhood organizations and its relationship to volunteers' self-and collective efficacy and sense of community. Social Work Research, 31(2), 109-120. 
Evaluation of Centres for the Integral Attention of Children in Dominican Republic (CIANIs) and Local Community Organizations for Child Protection (LCOCP)

OXFAM. (2014). Fiscal justice to reduce inequality in Latin America and the Caribbean. Oxford, UK: Author.

Papineau, D., \&. Kiely, M. C. (1996). Participatory evaluation in a community organization: Fostering stakeholder empowerment and utilization. Evaluation and Program Planning, 19, 79-93.

Parada, H. (2011). Prácticas Institucionales en el sistema de protección de niños, niñas y adolescentes: Etnografía institucional. Dominican Republic: UNICEF.

Patton, M. Q. (1998). Discovering process use. Evaluation, 4(2), 225-233.

Paxson, C., \& Schady, N. (2005). Child health and economic crisis in Peru. The World Bank Economic Review, 19(2), 203-223.

Pereznieto, P., Montes, A., Routier, S., \& Langston, L. (2014). The costs and economic impact of violence against children. Report for ChildFund Alliance. London: ODI.

Petersen, D. M. (2002). The potential of social capital measures in the evaluation of comprehensive community-based health initiatives. American Journal of Evaluation, 23(1), 55-64.

Pinhero, P.S. (2006). World report on violence against children. Geneva, Switzerland: United Nations Secretary-General's Study on Violence against Children.

Portes, A. (1998). Social capital: Its origins and applications in modern sociology. Annual Review of Sociology, 24, 1-24.

Portes, A., \& Landolt, P. (2002). Social Capital: Promises and Pitfalls of its Role in Development. Journal of Latin American Studies, 32, 529-547.

Putnam, R. D. (1993). The prosperous community: social capital and public life. The American Prospect, 13, 35-42.

Reid, M., Webster-Stratton, C., \& Baydar, N. (2004). Halting the development of externalizing behaviors in Head Start children. Journal of Clinical Child and Adolescent Psychology, 33, 279-291. 
Evaluation of Centres for the Integral Attention of Children in Dominican Republic (CIANIs) and Local Community Organizations for Child Protection (LCOCP)

Reimers, F. (1993). The challenges for early childhood education policy in Latin America and the Caribbean. International Journal of Educational Development, 13(4), 303-314.

Rossi, P., \& Freeman, H. (2004). Evaluation: A systematic approach (7th ed.). Newbury Park, CA: Sage.

Ruiz-Casares, M. (2010). The United Nations convention on the rights of the child: What is in there for us?. OYO, 9(1), 2. Windhoek, Namibia: Ombetja Yehinga.

Runyan, D. K., Hunter, W. M., Socolar, R. R., Amaya-Jackson, L., English, D., Landsverk, J., \& Mathew, R. M. (1998). Children who prosper in unfavorable environments: the relationship to social capital. Pediatrics, 101(1), 12-18.

Sabol, W. J., Coulton, C. J., \& Korbin, J. E. (2004). Building community capacity for violence prevention. Journal of Interpersonal Violence, 19(3), 322-340.

Sampson, R., Raudenbush, S., \& Earls, F. (1997). Neighbourhoods and violent crime: a multilevel study of collective efficacy, quoted in Halpern, D. (1999). Social capital: the new golden goose. London: Faculty of Social and Political sciences, Cambridge University.

Sanders, M. R., \& McFarland, M. (2000). The treatment of depressed mothers with disruptive children: A controlled evaluation of cognitive behavioral family intervention. Behavior Therapy, 31(1), 89-112.

Santos Pais, M. (1997). The Convention on the Rights of the Child. Manual on Human Rights Reporting under Six Major International Human Rights Instruments, 427. United Nations, Geneva: Office of the High Commissioner for Human Rights, United Nations Institute for Training and Research, and United Nations Staff College Project.

Save the Children. (2015). State of the world's mothers report. U.S.: Author.

Save the Children. (2012). Laying the Foundations: Early Childhood Care and Development. London, UK: Author. 
Evaluation of Centres for the Integral Attention of Children in Dominican Republic (CIANIs) and Local Community Organizations for Child Protection (LCOCP)

Schady, N. (2006). Early childhood development in Latin America and the Caribbean. Economía, 185-225.

Scott, S., O'Connor, T. G., Futh, A., Matias, C., Price, J., \& Doolan, M. (2010). Impact of a parenting program in a high-risk, multi-ethnic community: the PALS trial. Journal of Child Psychology and Psychiatry, 51(12), 1331-1341.

Shier, H. (2001). Pathways to participation: openings, opportunities and obligations. Children \& society, 15(2), 107-117.

Silva, A., Espíndola, E., \& Jiménez, M. (2010). Pobreza infantil en América Latina y el Caribe. Santiago, Chile: CEPAL-UNICEF.

Skelton, T. (2007). Children, young people, UNICEF and participation. Children's Geographies, 5(1-2), 165-181.

Social Watch. (2012). Inequality is the Biggest Obstacle. Retrieved from http:// www.socialwatch.org/sites/default/files/dominicanRepublic2012_eng.pdf

Special Representative of the Secretary General (SRSG). (2014). Violence against children Latin America. Advances on efforts to reduce violence against children: Launch of MMI-LAC report with the participation of SRSG Santos Pais in Panama. Retrieved from https://srsg.violenceagainstchildren.org/story/2014-05-08_996

Special Representative of the Secretary General (SRSG). (2013). Toward a world free from violence: Global survey on violence against children. New York: Author.

Speizer, I.S., Goodwin, M., Whittle, L., Clyde, M., \& Rogers, J. (2008). Dimensions of child sexual abuse before age 15 in 3 Central American countries: Honduras, El Salvador and Guatemala. Sexual Abuse and Neglect, 32, 455-462.

Strauss, A. \& Corbin, J. (1994). Grounded Theory Methodology. In N.K. Denzin \& Y.S. Lincoln (Eds.). Handbook of Qualitative Research (pp. 217-285). Thousand Oaks: Sage Publications. 
Evaluation of Centres for the Integral Attention of Children in Dominican Republic (CIANIs) and Local Community Organizations for Child Protection (LCOCP)

Steinberg, L. (2001). Parent-adolescent relationships in retrospect and prospect. Journal of Research on Adolescence, 11, 1-19.

Sullivan, M. P. (2014). Latin America and the Caribbean: Key issues for the 113th congress. Current Politics and Economics of South and Central America, 7(2), 245.

Tinajero, A.R, \& Loizillon, A. (2012). The review of care, education and child development indicators in early childhood. Paris: UNESCO.

Tinajero, A., \& Mustard, F. (2011). Cuba and Early Human Development The Brain \& Human Development. Report prepared for the Bernard van Leer Foundation.

United Nations Children's Fund (UNICEF). (2014a). Early childhood development in emergencies: Integrated programme guide. New York: Author.

United Nations Children's Fund (UNICEF). (2014b). Early childhood development: A statistical snapshot - building better brains and sustainable outcomes for children [Brochure]. New York: Author.

United Nations Children's Fund (UNICEF). (2014c). Ending violence against children: Six strategies for action. New York: Author.

United Nations Children's Fund (UNICEF). (2014d). Hidden in plain sight: A statistical analysis of violence against children. New York: Author.

United Nations Children's Fund (UNICEF). (2013). The formative years: UNICEF's work on measuring early childhood development. New York: Author.

United Nations Children's Fund (UNICEF). (2012). Inequities in early childhood development: What the data say - Evidence from the multiple indicator cluster surveys. New York: Author.

United Nations Children's Fund (UNICEF). (2011a) Caracterizacion de la primera infanciaL Cuidados, infantiles y servicios que se le ofrecen en comunidades selecionadas de la republica dominicana. Santo Domingo, Republica Dominicana: CENSIMI 
Evaluation of Centres for the Integral Attention of Children in Dominican Republic (CIANIs) and Local Community Organizations for Child Protection (LCOCP)

United Nations Children's Fund (UNICEF). (2011b). Childcare and parental leave. Challenges. Santiago, Chile: Author

United Nations Children's Fund (UNICEF). (2009a). Machel Study. 10-year Strategic Review: Children and Conflict in a Changing World. New York, NY: Author.

United Nations Children's Fund (UNICEF). (2009b). Maltrato infantil: Una dolorosa realidad puertas adentro. Desafíos. Santiago, Chile: Author.

United Nations Children's Fund (UNICEF). (2006). Programming experiences in early child development. New York, NY: Early Child Development Unit.

UN Committee on the Rights of the Child (CRC), General comment No. 12 (2009): The right of the child to be heard, 20 July 2009, CRC/C/GC/12, available at: http://www.refworld.org/docid/4ae562c52.html

United Nations Development Programme (UNDP). (2015). Millennium development goals report 2015. New York: UNDP.

United Nations Development Programme (UNDP). (2013). Regional human development report 2013 - 2014. Citizen security with a human face: Evidence and proposals for Latin America. New York: Author.

United Nations Educational, Scientific and Cultural Organization (UNESCO). (2014). Holistic early childhood development index (HECDI) framework: A technical guide. Paris, France: Author.

United Nations Educational, Scientific and Cultural Organization (UNESCO). (2010). Early Childhood care and education - Regional report Latin America and the Caribbean. Report prepared for the World Conference on Early Childhood Care and Education Moscow, September 2010. Caribbean. (AEPI). Moscow: Author.

United Nations Educational, Scientific and Cultural Organization (UNESCO). (2006). Strong foundations: early childhood care and education (Vol. 2007). France: Author. 
Evaluation of Centres for the Integral Attention of Children in Dominican Republic (CIANIs) and Local Community Organizations for Child Protection (LCOCP)

United Nations Office on Drugs and Crime (UNODC). (2009). Guide to implementing family skills training programmes for drug abuse prevention. New York, NY: United Nations.

USAID. (2013). Dominica Republic Country Development Cooperation Strategy. Retrieved from http://www.usaid.gov/sites/default/files/documents/1862/Dominican

USAID. (2011). 2011 USAID education strategy implementation guidance. Washington, D.C.: Author.

USAID. (2005). Education strategy: Improving lives through learning. Washington, D.C.: Author.

U.S. Global Health Programs. (2014). Dominican Republic Global Health Initiative Strategy. Retrieved from http://www.ghi.gov/wherewework/docs/dominicanrepublicstrategy.pdf

Van Der Land, M., \& Doff, W. (2010). Voice, exit and efficacy: dealing with perceived neighbourhood decline without moving out. Journal of Housing and the Built Environment, 25(4), 429-445.

Vegas, E., Santibáñez, L. (2011). Promises of Early Childhood Development in Latin America. Washington, D.C.: World Bank.

Walker, S. P., Chang, S. M., Vera-Hernández, M., \& Grantham-McGregor, S. (2011). Early childhood stimulation benefits adult competence and reduces violent behavior. Pediatrics, 127(5), 849-857.

Weaver, K., \& Maddaleno, M. (1999). Youth violence in Latin America: current situation and violence prevention strategies. Revista Panamericana de Salud Pública, 5(4-5), 338-343.

Webster-Stratton, C. (2009). Affirming diversity: Multicultural collaboration to deliver the Incredible Years parent programs. International Journal of Child Health and Human Development, 2, pp. 17-32. 
Evaluation of Centres for the Integral Attention of Children in Dominican Republic (CIANIs) and Local Community Organizations for Child Protection (LCOCP)

Weiss, C. (1998). Evaluation: Methods for studying programs and policies (2nd ed.). Upper Saddle River, N.J.: Prentice Hall.

Wessells, M. (2009). What are we learning about protecting children in the community? An inter-agency review of evidence on community based child protection mechanisms. London: Save the Children.

Whipple, E. E., \& Webster-Stratton, C. (1991). The role of parental stress in physically abusive families. Child abuse \& neglect, 15(3), 279-291.

World Bank. (2015). Dominican Republic: Overview. Retrieved from http://www. worldbank.org/en/country/dominicanrepublic/overview

World Bank (2013). World development indicators 2013. Washington, D.C.: Author.

World Bank. (2006). Early childhood development in Latin America and the Caribbean. Washington, D.C.: Author.

World Bank. (2001). Dominican Republic poverty assessment (Report No. 21306DR). Washington, D.C.: Author.

World Economic Forum. (2014). The Global Competitiveness Report 2014: Full Data Edition. Geneva: World Economic Forum.

World Health Organization (WHO). (2015). State of inequality: Reproductive, maternal and child health. Luxemborg: Author.

World Health Organization (WHO). (2012). Integrating early childhood development (ECD) activities into nutrition programmes in emergencies. UNICEF and $\mathrm{WHO}$.

World Health Organization (WHO). (2010). Violence prevention: the evidence. Geneva, Switzerland: WHO.

World Health Organization (WHO). (2008). Preventing violence through the development of safe, stable and nurturing relationships between children and their parents and caregivers. Series of briefings on violence prevention: The evidence. Geneva, Switzerland: World Health Organization. 
Evaluation of Centres for the Integral Attention of Children in Dominican Republic (CIANIs) and Local Community Organizations for Child Protection (LCOCP)

World Health Organization (WHO). (2004). The importance of caregiver child interactions for the survival and healthy development of young children: A review. Department of Child and Adolescent Health and Development.

World Vision. (2014). Child protection systems in Latin America and the Caribbean: A national and community level study across 10 countries. San Jose, Costa Rica: Latin American and the Caribbean Office.

Young-Wolff, K. C., Kendler, K. S., \& Prescott, C. A. (2012). Interactive effects of childhood maltreatment and recent stressful life events on alcohol consumption in adulthood. Journal of studies on alcohol and drugs, 73(4), 559. 


\section{Appendix A Interview Guides}

\section{A - 1: Interview Guide for Parents (Individual Interviews)}

\section{Demographic Information}

We would like to start by asking about you and your family.

1. How many children do you have and what are their ages?

2. Who lives with you?

3. Where is your income coming from? Is your monthly income more or less than $\$ 6,000$ Dominican pesos per month?

4. Can you describe your neighbourhood? Do you and your family feel safe in your neighbourhood? Explain

\section{Experience with CIANI}

Next we would like to ask about your relationship with the CIANI.

1. How did you find out about the CIANI?

2. How many children do you have in the CIANI? What are their ages? 
Evaluation of Centres for the Integral Attention of Children in Dominican Republic (CIANIs) and Local Community Organizations for Child Protection (LCOCP)

3. How long have they been in the CIANI? Have any of your children completed the program?

4. Can you tell me about the very first time that you came to the CIANI? What was the experience like for you and your children?

5. How often does your child attend the CIANI? Can you describe a typical day at the CIANI for your child?

6. Since your child has been attending the CIANI what has changed for the child? Can you provide examples?

7. What benefits or good things do you see in the CIANI? How has it benefitted your child/children? Give examples. How has it beneffited you? Give examples.

8. Let's talk about the staff. Can you describe your child's relationship with the staff? Examples?

a) Are there opportunities for you to observe your child while they are at the CIANI? Can you describe these?

b) What are some of your observations? What do you like most? What concerns do you have?

9. How do you get along with the staff at the CIANI? Do you feel respected by the staff?

10. Do you feel that you can trust the staff? Has any of the staff visited your home? What was the purpose of the visit?

11. What negative aspects do you see in the CIANI? Give examples.

12. What aspects do you believe would need improvement in the CIANI? Why?

\section{Opportunities for Engagement and Participation}

1. Are there opportunities/activities for you to participate at the CIANI? Can you list them? Which ones are you involved in?

2. Does your CIANI have a Parent School?
a) Have you or do you participate in the school? If no, why?
b) Do your friends participate?
c) Can you tell us about your experiences with the School?
d) What do you find useful about the parents school? Give examples
e) What do you think is not useful about the parents school? Give examples
f) Is there anything you would change about the Parent's School 
Evaluation of Centres for the Integral Attention of Children in Dominican Republic (CIANIs) and Local Community Organizations for Child Protection (LCOCP)

\section{Family Dynamics}

1. Do you feel that the CIANI has helped you as a parent? If so, how? Example? If not, what could the CIANl's do differently to meet your needs?

2. Does the CIANI provide you with information/ resources on parenting skills, behavoirs and attitudes, and around the use of appropriate discipline with your child? Please explain?

a) How do they do this? Examples?

b) How well informed do you feel you are about the appropriate ways in which parents should respond when their child is not behaving properly?

c) From your expereince, what is the best way to teach right behaviours to children?

d) Do you think that the CIANI's have influenced how you treat your child? Please explain with an example

e) Have the ways in which you discipline your children changed since your involvement with the CIANI?

3. What do you do when your children misbehave? Can you give some exapmles of what you did the last time your child misbehave?

4. What do other parents do when their children misbehave? Can you provide some examples?

5. Are there any other ways in which your participation at the CIANI has helped your family? Would you encourage other families to attend the CIANIs?

\section{Final Questions}

1. Do you think the CIANI has made a contribution/difference in your community? Please explain.

2. Can you think of ways in which the work of the CIANI could be improved? Please explain?

a) If there was one important thing you would change, what would it be?

b) What is the most important thing that you would NOT change? What would it be?

3. Would you encourage other families to attend the CIANI? Please explain?

Thank you!

Is there any other information you would like to share with us so that we will better understand the CIANI and your experiences and your child's experiences with it. 
Evaluation of Centres for the Integral Attention of Children in Dominican Republic (CIANIs) and Local Community Organizations for Child Protection (LCOCP)

\section{A - 2: Interview Guide for Professional Personnel (Individual Interviews)}

\section{Introduction Questions}

1. How long have you been working with the CIANI?

2. In what area(s) do you have formal training? Please describe with reference to degree/diploma?

3. What are your responsibilities in the CIANI? Can you describe a typical day?

4. Can you describe your work relationship with the other professional staff? What is your role on the team?

5. Did you have any on-the-job training to prepare you for your work at the CIANI?

6. Are there policies and procedures in place to guide your work? Please explain

7. What informal supports are in place to help you with your work? Please explain

\section{Role of the CIANI}

1. What would you say are the main objectives/goals of the CIANI when it comes to the children?

a) What are the main program strategies that are used to accomplish these objectives with the children? Can you describe these? What is your role?

b) How do you determine if you are successful? What do you look for?

2. What are some of the challenges that you face in achieving these objecitves? Please explain

a) Are the CIANIs more succesful with certain kind of children/families (as compared to others)? If so, why do you think this is the case?

3. Are there protocols for identifying at-risk families? Please explain and in relation to any measurement instruments that they use

a) Are there additional supports that you can use in these situations?

b) Do you work with other services in the community? Please descibe

4. Are children who do not have a birth certificate able to access the CIANI? In what proportion does this take place? What are the restrictions?

5. How do you keep track of a child's progress? Are there specific goals for each child?

a) Are there child development instruments that you se to track the kids' progress? 
Evaluation of Centres for the Integral Attention of Children in Dominican Republic (CIANIs) and Local Community Organizations for Child Protection (LCOCP)

b) Are reports prepared? Are these shared with parents?

c) Do you keep track of children once they leave the CIANI and go to regular school? Explain

\section{Relationship to Parents}

1. Can you descibe your relationship with the parents?

a) What are the ways in which you connect with parents?

b) How often do you meet with them?

c) What are some of the resources, supports that you provide?

2. Does your CIANI have a Parent School?

a) If yes, can you describe what it's purpose and what it does?

b) Can you share with us some lessons learned from parent school?

3. Do you/ the CIANI provide parents with information/ resources on parenting skills, behavoirs and attitudes, especially around the use of appropriate discipline with the child Please explain? How is this done?

a) what degree is child abuse and neglect a problem? For what precentage of families is this a problem?

b) How much of your time is spent on providing information and skills on appropriate discipline with the parents? Please describe?

c) What is the protocol that you have in place if you suspect abuse? What is your typical/required response? Please describe. Do you work with other services in the community in these situations, including the LCOCPs?

d) In these situations, do you feel that you have been successful at preventing further abuse or neglect? How would you know/what would be the signs that you have been effective?

\section{Relationship to Community}

1. In what ways do you think CIANIs make a contribution to their communities?

2. Do you think that the CIANI responds to the needs of the familites? Expand

a) Do you believe that the CIANI has been able to identify children who most need the services? (children at risk) Is this a priotiry for CIANIs?

b) How do you think is the reputation of CIANIs in the community?

3. Are there any other ways you think CIAN are effective or inefective? Please explain.

a) Could you share a lesson learned in general, about the kinds of effectiveness of the CIANI? 
Evaluation of Centres for the Integral Attention of Children in Dominican Republic (CIANIs) and Local Community Organizations for Child Protection (LCOCP)

4. Overall, how satisfied are you with your work at the CIANI? What do you enjoy most? What do you enjoy the least?

a) If there was one important thing you would change, what would it be?

b) What is the most important thing that you would NOT change?

5. Thank you ... Is there any other information you would like to share with us so that we might better understand the CIANI?

\section{A - 3: Interview Guide for Non-professional personnel (Individual Interviews)}

1. What are your responsibilities in the CIANI? Time working at the CIANI.

2. In addition to these responsibilities, do you have any other, even if it does not correspond to you?

3. How did you get the job?
a) What did they require from you to get the job?
b) Did they require you to have any formal training?
c) Did you receive on-the-job training?

4. Can you describe a typical day?

a) What aspects of your job do you find most enjoyable? Please explain

b) What aspects of your job do you find the least enjoyable? Please explain

c) If you could change one thing about your job what would it be?

d) What is the most important thing that you would NOT change?

5. Can you describe your relationship with the other staff? Pease explain

6. Do you have any involvment with the children? If yes, please exlain

7. Do you have any involvment with the parents? If yes, please explain

8. What do understand the goals of the CIANI to be?

a) To what degree do you feel the CIANI is achieving its goals?

b) Are there specific areas that they are more successful than others?

9. Just for kitchen staff, How is planned the food that you prepare? Fully description of menus and freshness of products. How you get all the products that you need?

10. Just for kitchen staff, Would you like to introduce in the menu some kind of new food? Have you tried? Explain the experience, obstacles, facilatators.

11. Just for cleaning staff, How many times per day you clean: bathrooms, classrooms, other places? 
Evaluation of Centres for the Integral Attention of Children in Dominican Republic (CIANIs) and Local Community Organizations for Child Protection (LCOCP)

12. Just for security staff, Whata re the security challenges at the CIANI?

13. For all. Do you think that your salary is fair? Why?

Thank you ... Is there any other information you would like to share with us so that we might better understand the CIANI?

\section{A - 4: Interview Guide for Key informants \& Community Leaders (Individual Interviews)}

1. Are you familiar eith the CINAI operating in your community?

a) Can you describe your relationship with the CIANI?

b) Have you had any opportunity to visit the CIANI or work with the CIANI? Please explain

2. Do you have a son or daughter who is beneficiary of the CIANI? If yes, stop the interview.

3. Can you tell me about your job and how you are involved in this community?

4. Do you have any expereince in the field of early child development and child protection? Please explain

5. Can you tell me what you know of the CIANI? Are you familiar with it's goals? Its activities?

6. Please tell me about the reputation that the CIANI has in the community. Provide examples.

a) Do you think that the CIANI is well known in the community?

b) Is it considered a desireable place for your children? Please explain

c) If you had the opportunity would you have sent your children to the CIANI?

7. Are the CIANIs more appropriate for certain groups of children (as compared to others)?

8. Are there other similar services/programs for children that you are aware of? If yes, what are they and how would they compare with the CIANI?

a) Do you think the CIANI is well connected to other programs and services for children in the community?

9. One of the important areas of healthy early child development is the prevention of child abuse and neglect.

a) Is child abuse and neglect a problem in this community? Please explain

b) Do you think that CIANIs address this issue? Please explain 
Evaluation of Centres for the Integral Attention of Children in Dominican Republic (CIANIs) and Local Community Organizations for Child Protection (LCOCP)

c) Do you think this is an important issue that they should address?

d) Do you think programs such as the CIANI should specifically develop programs that address the prevention of child abuse and neglect? Please explain

10. Are you familiar with the parent school at the CIANI?

a) What do you think about parents school? Why?

b) Have you heard any feedback about the parent school?

c) Do you think the CIANIs should provide additional programs for the parents?

11. How effective is the CIANI in responding to the needs of the children in the community?

a) What benefits or good things do you see in the CIANI? How has it benefits the parents and children? Give examples.

b) What negative aspects you see in the CIANI? Give examples.

12. Would you recommend CONANI to open more CIANIS at your community? Why? And in other communities?

\section{Key informants in schools}

1. Does the CIANI have a relationship with your school? Expand

2. What is your experience with children that come from the CIANI to this shool?

a) How do they compare to toher children? Socially, behariourally, academically

3. Please describe what you have been able to observe regarding how children from CIANIs perform at school. Provide examples.

Thank you ... Is there any other information you would like to share with us?

\section{A - 5: Interview Guide for Parents (Focus Group)}

\section{Introduction Questions}

1. Do you have a son or daughter that is currently enrolled in the CIANI?

a) If yes, how old and how many years has your son/daughter been in the CIANI?

b) Do you have a child that was at the CIANI and is now in the regular school? 
Evaluation of Centres for the Integral Attention of Children in Dominican Republic (CIANIs) and Local Community Organizations for Child Protection (LCOCP)

2. Before enrolling in the CIANI, who took care of your sons/dauhgters? Expand. Describe the situation before CIANI.

3. Please tell me how it was that your sons/daughters joined/was selected for the CIANI?

4. How oftern does your child attend? Can you describe a typical day for your child at the CIANI?

\section{Experience with CIANI}

1. Since you child has been attending, have you seen any changes? Can you give us some examples?
a) Developmental changes
b) Social changes
c) Behavioural changes

2. If you have children that are no longer at the CIANI, how have their experiences with the CIANI influenced their next steps/ transition to regular school?
a) Socially
b) Developmentally

3. Can you describe your relationship with the staff? Examples.

a) Are you in contact with the staff? How often? For what purposes? Please give examples?

b) When are home visits done? Are these useful? Please explain?

c) If you have any concern, do you feel that you can get help from the staff at the CIANI?

d) Do you feel respected by the staff? Do you feel you can trust the staff?

4. Can you describe your child's relationship with the staff? Examples?

a) Are there opportunities for you to observe your child while they are at the CIANI? Can you describe these?

b) What are some of your observations? What do you like most? What concerns do you have?

\section{Opportunities for Engagement and Participation}

1. Are there opportunities/activities for you to participate in the CIANI? What are they? Which ones do you participate in and why?

2. Does your CIANI have a Parent School?

a) Have you or do you participate in the school? If no, why? 
Evaluation of Centres for the Integral Attention of Children in Dominican Republic (CIANIs) and Local Community Organizations for Child Protection (LCOCP)

b) Do your friends participate?

c) Can you tell us about your experiences with the School?

d) What do you find useful about the parents school? Give examples

e) What do you think is not useful about the parents school? Give examples

f) Is there anything you would change about the Parent's School?

\section{Family Dynamics}

1. Do you feel that the CIANI has helped you as a parent? If so, how? Example? If not, what could the CIANI's do differently to meet your needs?

2. Does the CIANI provide you with information/ resources on parenting skills, behavoirs and attitudes, and the use of appropriate discipline with your child? Please explain?

a) How do they do this? Examples?

b) How well informed do you feel you are about the appropriate ways in which parents should respond when their child is not behaving properly?

c) Do you think that the CIANI's have influenced how you treat your child?

d) Please explain with an example

3. Can you tell me how your relationship with other members of your family might have been influenced by your participation in CIANI?

a) Can you tell me about a particular family experience that was made possible by your participation in the CIANI?

\section{Final Questions}

1. Do you think the CIANI has made a contribution/difference in your community? Please explain

2. Can you think of ways in which the work of the CIANI could be improved? Please explain?

a) a)If there was one important thing you would change, what would it be?

b) What is the most important thing that you would NOT change? What would it be?

3. Would you encourage other families to attend the CIANI? Please explain?

Thank you!

Is there any other information you would like to share with us so that we will better understand the CIANI and your experiences and your child's experiences with it. 
Evaluation of Centres for the Integral Attention of Children in Dominican Republic (CIANIs) and Local Community Organizations for Child Protection (LCOCP)

\section{A - 6: Interview Guide for Staff (Focus Group)}

1. Can you tell me how the organization reaches out and connects with the community?

2. How do you "typically" respond to a case of abuse, neglect or exploitation?

3. What policies and procedures are in place to guide your work?

4. What informal supports are in place to help you with your work?

5. What are your agency's strengths and weaknesses?

6. Can you tell me about a time when a client first approached you regarding abuse, neglect and/or exploitation? What things were in place to help him/ her and his/her family?

7. Can you tell me about a time when you were providing on-going services to a client?

a) What type of formal resources, training or policies and practices helped you?

b) Were there informal procedures, practices or attitudes that helped?

c) What made you feel comfortable working with the client?

8. Can you tell me about a time when things did not go well when you were providing on-going services to a client who disclosed abuse, neglect or exploitation?

a) Were there things that should have been in place to help you support them?

b) What type of formal resources, training or policies and practices would have helped you?

c) Are there things you can suggest that might have been done to improve the situation?

d) Did you feel uncomfortable? If yes, what made you feel that way?

9. How do CIANI's written policies and procedures guide staff who are working with child and family violence?

a) What are the daily practices in comparison to written policies and procedures?

b) What are the strengths of the policies, procedures and practices?

c) What are the barriers or challenges to the policies, procedures and practices?

d) How do you create sustainable policies, procedures and practices?

e) How do policies and procedures lead to good practices?

f) How do policies and procedures support the staff? 
Evaluation of Centres for the Integral Attention of Children in Dominican Republic (CIANIs) and Local Community Organizations for Child Protection (LCOCP)

10. How does change happen at CIANI/LCOCP?
a) What is the decision making process?
b) How are policies and procedures created or changed?
c) How is resource allocation made?

11. What challenges, if any, are there when attempting to make changes in your organization?

a) Are there particular areas in your organizations that are easier/harder to change than others? If so, what are they and why?

12. What about your organization needs to change or improve to be better equipped to provide services to clients that experience abuse, neglect and/ or exploitation?

13. Can you tell me how the organization has influenced your involvement in the community?

14. Can you tell me about an experience you have had in the community that resulted from your involvement in the organization? 


\section{Appendix B Surveys}


Evaluation of Centres for the Integral Attention of Children in Dominican Republic (CIANIs) and Local Community Organizations for Child Protection (LCOCP)

B - 1: Survey Questionnaire for the Two Experimental Groups: CIANI Only and CIANI + Junta

\author{
Respondent identification number \\ Name of interviewer \\ Interviewer identification number \\ Date of interview \\ Time interview started \\ Time interview ended
}

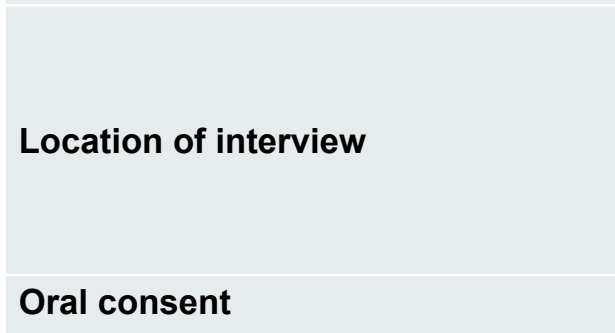

City in which interview was conducted

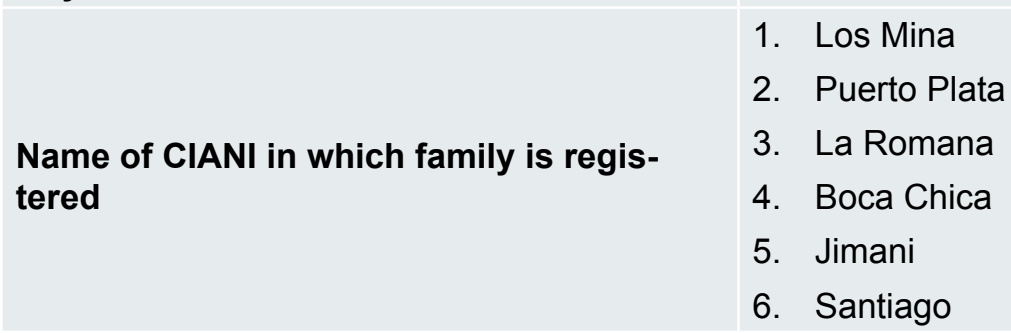

Hello. I'm an interviewer employed by Ryerson University in Toronto, Canada. I'm working on a survey that asks people what they think about the supports and programs provided by the CIANI. We are asking everyone with children in the CIANI to participate in our survey.

It's important that you know that I do not work for the CIANI or CONANI, but for Ryerson University in Toronto. All the information you give in the survey will remain strictly confidential. It will be analyzed by the team of academic researchers at Ryerson University. Only general reports will be prepared from the information in this survey, without any individual names attached. 
The information you give will be added to information given by other participants in the survey, and the combined results examined.

The survey should take about a half-hour or so to complete. Your participation is completely voluntary. If you choose not to participate, no one will be informed, and there will be no consequences. If there are any questions that make you uncomfortable, you do not have to answer them.

Do you have a few minutes to talk to us about the CIANI and related issues in your neighbourhood?

P_Q01 Confirm interviewee is the primary caregiver

1. Yes (continue with interview)

2. No (end the interview but ask who the primary caregiver is so you can try to contact her/him for an interview)

P_Q02 Have you or any other member of your family or household already completed this survey?

1. Yes (end interview)

2. No (continue with interview)

3. Don't know (continue with the interview)

\section{DEMOGRAPHICS:}

First we will ask some questions about your child. 
Evaluation of Centres for the Integral Attention of Children in Dominican Republic (CIANIs) and Local Community Organizations for Child Protection (LCOCP)

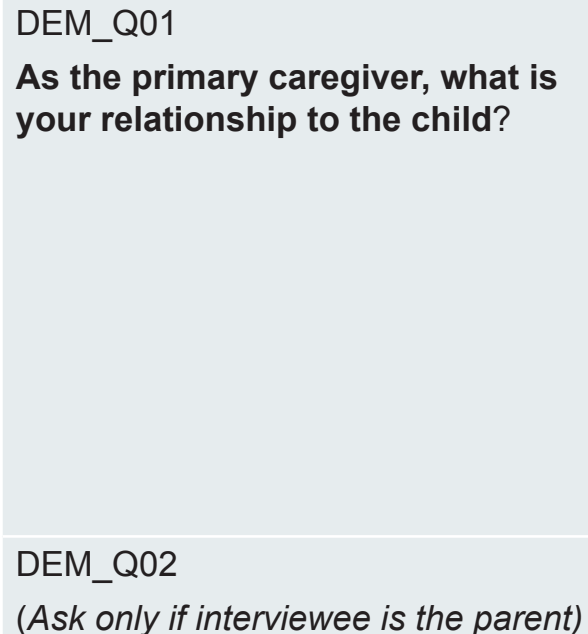

How many children do you have?
1. Mother

2. Father

3. Sister/brother

4. In-law of any type

5. Aunt/uncle

6. Grandparent

7. Other family member

8. Other non-relative

88. Don't know

99. Refuse to answer

(From this point on ask everyone parents, and primary caregivers like grandparents - unless it is otherwise specified.)

DEM_Q03

How many children are currently living with you in the household?

DEM_Q04

How many of the children in the household are currently registered in the CIANI?

DEM_Q05

(Please complete the following charts for all the children (if the interviewee is the parent) or children in the household (if non-parent))

CHART $A$ is specifically for children currently registered in the CIANI

CHART B is specifically for children who were previously registered in or completed a CIANI program, but are not currently registered in a CIANI

CHART $\mathrm{C}$ is for any of your other children (for parent) or any other children currently living in the household who have never been registered in a CIANI. 
Evaluation of Centres for the Integral Attention of Children in Dominican Republic (CIANIs) and Local Community Organizations for Child Protection (LCOCP)

\section{a) I am first going to ask you some questions about the child/children cur- rently registered in the CIANI.}

Children currently registered at a CIANI.

\begin{tabular}{|c|c|c|c|c|}
\hline $\begin{array}{c}\text { (i) } \\
\text { Name }\end{array}$ & $\begin{array}{l}\text { (ii) } \\
\text { Age }\end{array}$ & $\begin{array}{l}\text { (iii) } \\
\text { Sex }\end{array}$ & $\begin{array}{l}\text { (iv) } \\
\text { How many } \\
\text { years has } \\
\text { [name of child] } \\
\text { been regis- } \\
\text { tered at the } \\
\text { CIANI? }\end{array}$ & $\begin{array}{l}\text { **Skip this question and come back } \\
\text { during health section. } \\
\text { H_Q01 } \\
\text { In general how would you describe } \\
\text { (name of child)'s health? (Read } \\
\text { response categories out except for } \\
\text { options 8 \& 9) }\end{array}$ \\
\hline A1 & $\begin{array}{l}\overline{\text { year(s) }} \\
\overline{\text { month(s) }}\end{array}$ & $\begin{array}{l}\text { 1. Male } \\
\text { 2. Female }\end{array}$ & & $\begin{array}{l}\text { 1. Excellent } \\
\text { 2. Very good } \\
\text { 3. Good } \\
\text { 4. Fair } \\
\text { 5. Poor } \\
\text { 8. Don't know } \\
\text { 9. Refuse to answer }\end{array}$ \\
\hline A2 & $\begin{array}{l}\overline{\text { year(s) }} \\
\overline{\text { month(s) }}\end{array}$ & $\begin{array}{l}\text { 1. Male } \\
\text { 2. Female }\end{array}$ & & $\begin{array}{l}\text { 1. Excellent } \\
\text { 2. Very good } \\
\text { 3. Good } \\
\text { 4. Fair } \\
\text { 5. Poor } \\
\text { 8. Don't know } \\
\text { 9. Refuse to answer }\end{array}$ \\
\hline A3 & $\begin{array}{l}\overline{\text { year(s) }} \\
\overline{\text { month(s) }}\end{array}$ & $\begin{array}{l}\text { 1. Male } \\
\text { 2. Female }\end{array}$ & & $\begin{array}{l}\text { 1. Excellent } \\
\text { 2. Very good } \\
\text { 3. Good } \\
\text { 4. Fair } \\
\text { 5. Poor } \\
\text { 8. Don't know } \\
\text { 9. Refuse to answer }\end{array}$ \\
\hline A4 & $\begin{array}{l}\overline{\text { year(s) }} \\
\overline{\text { month(s) }}\end{array}$ & $\begin{array}{l}\text { 1. Male } \\
\text { 2. Female }\end{array}$ & & $\begin{array}{l}\text { 1. Excellent } \\
\text { 2. Very good } \\
\text { 3. Good } \\
\text { 4. Fair } \\
\text { 5. Poor } \\
\text { 8. Don't know } \\
\text { 9. Refuse to answer }\end{array}$ \\
\hline
\end{tabular}


Evaluation of Centres for the Integral Attention of Children in Dominican Republic (CIANIs) and Local Community Organizations for Child Protection (LCOCP)

b) Do you have any children who attended or completed the CIANI but are no longer registered in the CIANI?

1. Yes (If Yes, complete the chart below)

2. No *skip to $\mathrm{C}$

Children who have completed the CIANI program or were previously registered in a CIANI, but are not currently registered in a CIANI.

\begin{tabular}{|c|c|c|c|c|c|c|}
\hline $\begin{array}{c}\text { (i) } \\
\text { Name }\end{array}$ & $\begin{array}{l}\text { (ii) } \\
\text { Age }\end{array}$ & $\begin{array}{l}\text { (iii) } \\
\text { Sex }\end{array}$ & $\begin{array}{l}\text { (iv) } \\
\text { How many } \\
\text { years ago } \\
\text { was [name } \\
\text { of child] first } \\
\text { registered in } \\
\text { the CIANI? }\end{array}$ & $\begin{array}{l}(\mathrm{v}) \\
\text { How long did they } \\
\text { attend the CIANI? }\end{array}$ & $\begin{array}{c}\text { (vi) } \\
\text { Current } \\
\text { grade in } \\
\text { school }\end{array}$ & $\begin{array}{l}{ }^{* *} \text { Skip this ques- } \\
\text { tion and come } \\
\text { back during } \\
\text { health section. } \\
\quad \text { H_Q01 } \\
\text { In general how } \\
\text { would you de- } \\
\text { scribe (Insert } \\
\text { child's name) } \\
\text { Read response } \\
\text { categories out } \\
\text { except for options } \\
8 \text { \& } 9\end{array}$ \\
\hline B1 & $\begin{array}{l}\overline{\text { year(s) }} \\
\overline{\text { month(s) }}\end{array}$ & $\begin{array}{l}\text { 1. Male } \\
\text { 2. Female }\end{array}$ & & $\begin{array}{l}\text { 1. Less than } 1 \text { year } \\
\text { 2. } 1 \text { year } \\
\text { 3. } 2 \text { years } \\
\text { 4. } 3 \text { years } \\
\text { 5. } 4 \text { years } \\
\text { 6. } 5 \text { years } \\
\text { 8. Don't know } \\
\text { 9. Refuse to answer }\end{array}$ & & $\begin{array}{l}\text { 1. Excellent } \\
\text { 2. Very good } \\
\text { 3. Good } \\
\text { 4. Fair } \\
\text { 5. Poor } \\
\text { 8. Don't know } \\
\text { 9. Refuse to } \\
\text { answer }\end{array}$ \\
\hline B2 & $\begin{array}{l}\overline{\text { year(s) }} \\
\overline{\text { month(s) }}\end{array}$ & $\begin{array}{l}\text { 1. Male } \\
\text { 2. Female }\end{array}$ & & $\begin{array}{l}\text { 1. Less than } 1 \text { year } \\
\text { 2. } 1 \text { year } \\
\text { 3. } 2 \text { years } \\
\text { 4. } 3 \text { years } \\
\text { 5. } 4 \text { years } \\
\text { 6. } 5 \text { years } \\
\text { 8. Don't know } \\
\text { 9. Refuse to answer }\end{array}$ & & $\begin{array}{l}\text { 1. Excellent } \\
\text { 2. Very good } \\
\text { 3. Good } \\
\text { 4. Fair } \\
\text { 5. Poor } \\
\text { 8. Don't know } \\
\text { 9. Refuse to } \\
\text { answer }\end{array}$ \\
\hline B3 & $\begin{array}{l}\overline{\text { year(s) }} \\
\overline{\text { month(s) }}\end{array}$ & $\begin{array}{l}\text { 1. Male } \\
\text { 2. Female }\end{array}$ & & $\begin{array}{l}\text { 1. Less than } 1 \text { year } \\
\text { 2. } 1 \text { year } \\
\text { 3. } 2 \text { years } \\
\text { 4. } 3 \text { years } \\
\text { 5. } 4 \text { years } \\
\text { 6. } 5 \text { years } \\
\text { 8. Don't know } \\
\text { 9. Refuse to answer }\end{array}$ & 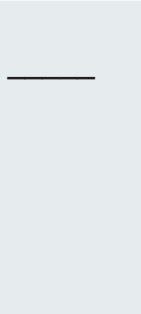 & $\begin{array}{l}\text { 1. Excellent } \\
\text { 2. Very good } \\
\text { 3. Good } \\
\text { 4. Fair } \\
\text { 5. Poor } \\
\text { 8. Don't know } \\
\text { 9. Refuse to An- } \\
\text { swer }\end{array}$ \\
\hline
\end{tabular}


Evaluation of Centres for the Integral Attention of Children in Dominican Republic (CIANIs) and Local Community Organizations for Child Protection (LCOCP)

\section{c) Do you have any other children living in the household who have never been registered in the CIANI}

1. Yes (If Yes, complete the chart below)

2. No ${ }^{* *}$ skip to next question

Children never registered in CIANI.

\begin{tabular}{|c|c|c|c|c|}
\hline $\begin{array}{c}\text { (i) } \\
\text { Name }\end{array}$ & $\begin{array}{c}\text { (ii) } \\
\text { Age }\end{array}$ & $\begin{array}{l}\text { (iii) } \\
\text { Sex }\end{array}$ & $\begin{array}{c}\text { (iv) } \\
\text { Current grade } \\
\text { in school }\end{array}$ & $\begin{array}{c}{ }^{* *} \text { Skip this question and come back during } \\
\text { health section. } \\
\text { H_Q01 } \\
\text { In general how would you de- } \\
\text { scribe the health of the child? } \\
\text { Read response categories out } \\
\text { except for options } 8 \text { \& } 9\end{array}$ \\
\hline C1 & $\begin{array}{l}\overline{\text { year(s) }} \\
\overline{\text { month(s) }}\end{array}$ & $\begin{array}{l}\text { 1. Male } \\
\text { 2. Female }\end{array}$ & 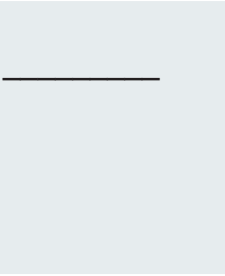 & $\begin{array}{l}\text { 1. Excellent } \\
\text { 2. Very good } \\
\text { 3. Good } \\
\text { 4. Fair } \\
\text { 5. Poor } \\
\text { 8. Don't know } \\
\text { 9. Refuse to answer }\end{array}$ \\
\hline C2 & $\begin{array}{l}\overline{\text { year(s) }} \\
\overline{\text { month(s) }}\end{array}$ & $\begin{array}{l}\text { 1. Male } \\
\text { 2. Female }\end{array}$ & - & $\begin{array}{l}\text { 1. Excellent } \\
\text { 2. Very good } \\
\text { 3. Good } \\
\text { 4. Fair } \\
\text { 5. Poor } \\
\text { 8. Don't know } \\
\text { 9. Refuse to answer }\end{array}$ \\
\hline C3 & $\begin{array}{l}\overline{\text { year(s) }} \\
\overline{\text { month(s) }}\end{array}$ & $\begin{array}{l}\text { 1. Male } \\
\text { 2. Female }\end{array}$ & & $\begin{array}{l}\text { 1. Excellent } \\
\text { 2. Very good } \\
\text { 3. Good } \\
\text { 4. Fair } \\
\text { 5. Poor } \\
\text { 8. Don't know } \\
\text { 9. Refuse to answer }\end{array}$ \\
\hline C4 & $\begin{array}{l}\overline{\text { year(s) }} \\
\overline{\text { month(s) }}\end{array}$ & $\begin{array}{l}\text { 1. Male } \\
\text { 2. Female }\end{array}$ & - & $\begin{array}{l}\text { 1. Excellent } \\
\text { 2. Very good } \\
\text { 3. Good } \\
\text { 4. Fair } \\
\text { 5. Poor } \\
\text { 8. Don't know } \\
\text { 9. Refuse to answer }\end{array}$ \\
\hline
\end{tabular}


Evaluation of Centres for the Integral Attention of Children in Dominican Republic (CIANIs) and Local Community Organizations for Child Protection (LCOCP)

Now we will ask you some questions about you and your household.

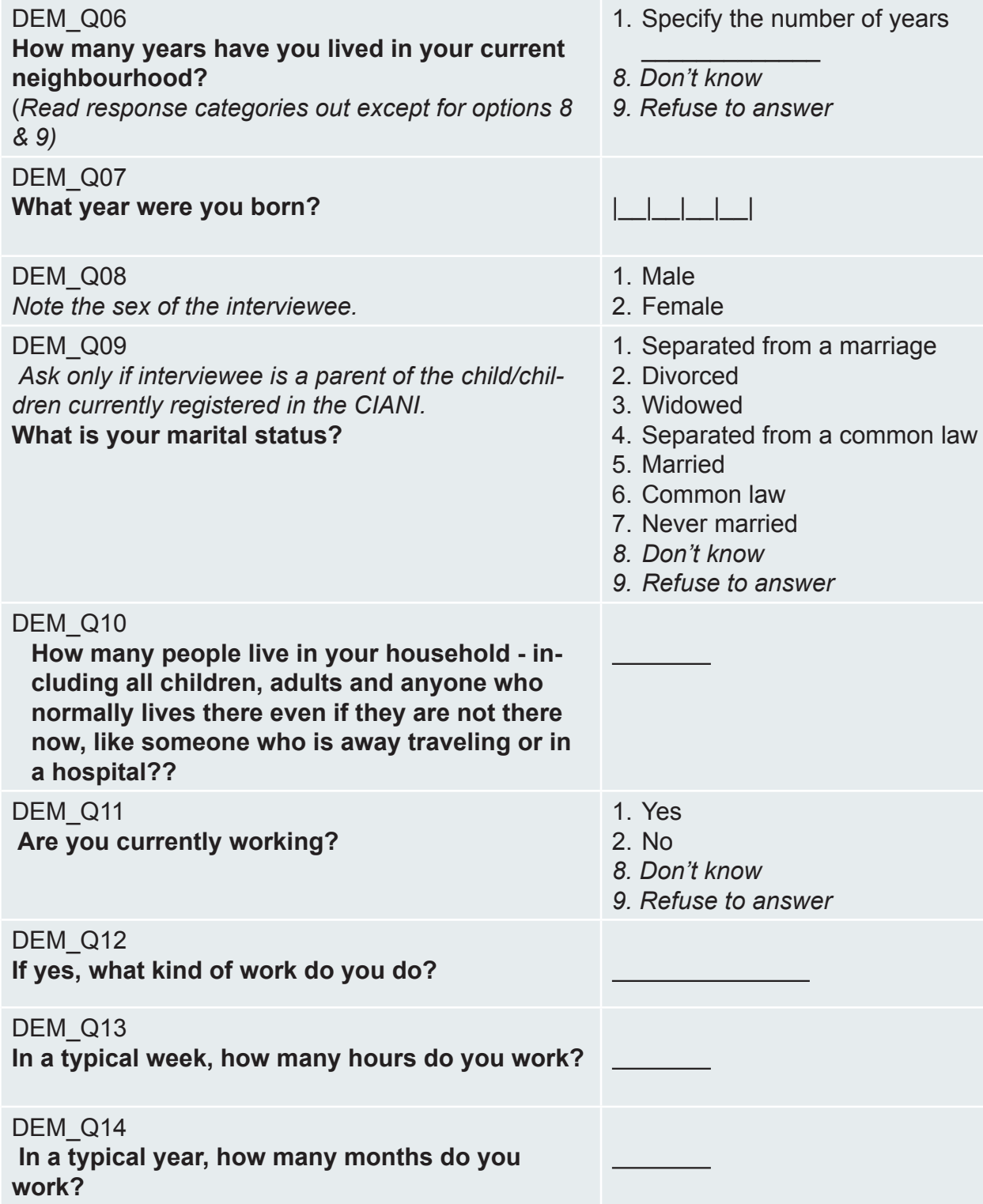

1. Yes

2. No

8. Don't know

9. Refuse to answer

1. Male

2. Female

1. Separated from a marriage

2. Divorced

3. Widowed

4. Separated from a common law

5. Married

6. Common law

7. Never married

8. Don't know

9. Refuse to answer

DEM_Q12

If yes, what kind of work do you do?

DEM_Q13

In a typical week, how many hours do you work?

DEM_Q14

In a typical year, how many months do you work?

People earn income from many different sources, for example: informal work, formal work, government assistance and other sources. 


DEM_Q15
Thinking of everyone who brings
income into your household, what
are the sources of income for your
household? (Check all that apply - let
interviewee respond and check the ones
mentioned)
DEMQ_15B

DEM_Q16

What is your best estimate of your total monthly income from all sources of income? Is your total monthly income ... (Read response categories to interviewee).

DEM_Q17

What is your best estimate of the total monthly income of ALL household members, including yourself, from all sources of income? Is the total monthly income of everyone ... (Read response categories to interviewee).

DEM_Q18

What is your highest level of education completed? (Read response categories to interviewee except for categories 8 and 9.)
1. Informal work

2. Formal work

3. Government assistance

4. Spouse/partners work

5. Remittance from other family member

6. Other (Go to DEM_Q15B)

8. Don't know

9. Refuse to answer

If "Other," Please specify

1. Less than 1000 pesos

2. $1000-3999$ pesos

3. $4000-6999$ pesos

4. $7000-9999$ pesos

5. $10000-12999$ pesos

6. $13000-15999 \mathrm{e}$

7. $16000-18999$

8. $19000-21999$

9. 22000 pesos or more

88. Don't know

99. Refuse to answer

1. Less than 1000 pesos

2. $1000-3999$ pesos

3. $4000-6999$ pesos

4. $7000-9999$ pesos

5. $10000-12999$ pesos

6. $13000-15999$ pesos

7. $16000-18999$ pesos

8. $19000-21999$ pesos

9. 22000 pesos or more

88. Don't know

99. Refuse to answer

1. No schooling

2. Some primary

3. Completed primary

4. Some secondary

5. Completed secondary

6. Some university

7. Completed university

8. Don't know

9. Refuse to answer 
Evaluation of Centres for the Integral Attention of Children in Dominican Republic (CIANIs) and Local Community Organizations for Child Protection (LCOCP)

\section{CIANI INFORMATION}

Now we are going to ask some questions about your experience with the CIANI

\begin{tabular}{|c|c|}
\hline $\begin{array}{l}\text { Cl_Q01 } \\
\text { How often do you drop the child off at the } \\
\text { CIANI? (Read response categories out except } \\
\text { for options } 8 \text { \& 9) }\end{array}$ & $\begin{array}{ll}\text { 1. } & \text { Every day } \\
\text { 2. Some days } \\
\text { 3. Not very often } \\
\text { 4. Do not drop them off } \\
8 \text { Don't know } \\
9 & \text { Refuse to answer }\end{array}$ \\
\hline $\begin{array}{l}\text { Cl_Q02 } \\
\text { How often do you pick up the child from the } \\
\text { CIANI? (Read response categories out except } \\
\text { for options } 8 \text { \& 9) }\end{array}$ & $\begin{array}{ll}\text { 1. } & \text { Every day } \\
\text { 2. } & \text { Some days } \\
\text { 3. Not very often } \\
\text { 4. Do not pick them up } \\
8 \text { Don't know } \\
9 & \text { Refuse to answer }\end{array}$ \\
\hline
\end{tabular}

The CIANI provides a number of supports for children and families, such as child care, child education, child social development, health care, food and nutrition, parent school/parent meetings, and general parent support. Thinking of all the different supports CIANI provides you and your family which three do you think are most important.

\begin{tabular}{|c|c|c|}
\hline $\begin{array}{l}\mathrm{Cl} \text { Q03 } \\
\text { Thinking of all the different supports CIANI } \\
\text { provides you and your family which three ser- } \\
\text { vices do you think are most important? (Do } \\
\text { not read responses, mark the ones mentioned.) }\end{array}$ & $\begin{array}{l}\text { 1. Child care } \\
\text { 2. Child education } \\
\text { 3. Child social development } \\
\text { 4. Health care } \\
\text { 5. Food and nutrition } \\
\text { 6. Parent school/parent meeting } \\
\text { 7. General parent support } \\
\text { 8. Other (Go to Cl_Q03B) } \\
\text { 88. Don't know } \\
\text { 99. Refuse to answer } \\
\text { If "other," please specify }\end{array}$ & $\begin{array}{l}\text { If any ser- } \\
\text { vices are list- } \\
\text { ed, use them } \\
\text { in Cl_Q09 }\end{array}$ \\
\hline
\end{tabular}

I am going to ask you about how satisfied you are with the different supports the CIANI provides for children and families. For each question, please tell me if you are very satisfied, satisfied, dissatisfied or very dissatisfied with the kind of support named 


CI_Q04
How satisfied are you with the child care
provided in the CIANI? (Read response cate-
gories out except for options 8 \& 9)
CI_Q05
How satisfied are you with the education
provided to the child/children in the CIANI?
(Read response categories out except for op-
tions 8 \& 9)
CI_Q06

How satisfied are you with the social development of the child/children in the CIANI? (for example playing with other children, talking and interacting) (Read response categories out except for options 8 \& 9)

Cl_Q07

How satisfied are you with the health care provided your child/children in the CIANI? (Read response categories out except for options 8 \& 9)

\section{Cl_Q08}

How satisfied are you with the food and nutrition at the CIANI? (Read response categories out except for options 8 \& 9)

\section{Cl_Q09}

How satisfied are you with insert other support listed in Cl_Q03?

(Read response categories out except for options 8 \& 9)
1. Very satisfied

2. Satisfied

3. Dissatisfied

4. Very dissatisfied

8. Don't know

9. Refuse to answer

1. Very satisfied

2. Satisfied

3. Dissatisfied

4. Very dissatisfied

8. Don't know

9. Refuse to answer

1. Very satisfied

2. Satisfied

3. Dissatisfied

4. Very dissatisfied

8. Don't know

9. Refuse to answer

1. Very satisfied

2. Satisfied

3. Dissatisfied

4. Very dissatisfied

8. Don't know

9. Refuse to answer

1. Very satisfied

2. Satisfied

3. Dissatisfied

4. Very dissatisfied

8. Don't know

9. Refuse to answer

1. Very satisfied

2. Satisfied

3. Dissatisfied

4. Very dissatisfied

8. Don't know

9. Refuse to answer 
Evaluation of Centres for the Integral Attention of Children in Dominican Republic (CIANIs) and Local Community Organizations for Child Protection (LCOCP)

The next few questions are going to deal with the parent school and related activities at the CIANI. The parent school refers to those meetings and presentations for parents that are organized by the CIANI.

\begin{tabular}{|c|c|c|}
\hline $\begin{array}{l}\text { CI_Q10 } \\
\text { How satisfied are you with the parent school - } \\
\text { those meetings and presentations for parents that } \\
\text { are organized by the CIANI? (Read response catego- } \\
\text { ries out except for options } 8 \& 9 \text { ) }\end{array}$ & $\begin{array}{l}\text { 1. Very satisfied } \\
\text { 2. Satisfied } \\
\text { 3. Dissatisfied } \\
\text { 4. Very dissatisfied } \\
\text { 8. Don't know } \\
\text { 9. Refuse to answer }\end{array}$ & \\
\hline $\begin{array}{l}\text { CI_Q11 } \\
\text { How often do you attend the parent school - those } \\
\text { meetings and presentations for parents that are } \\
\text { organized by the CIANI? (Read our each response } \\
\text { category except for } 8 \text { \&9) }\end{array}$ & $\begin{array}{l}\text { 1. Very often } \\
\text { 2. Often } \\
\text { 3. Sometimes } \\
\text { 4. Hardly ever } \\
\text { 8. Don't know } \\
\text { 9. Refuse to answer }\end{array}$ & \\
\hline $\begin{array}{l}\text { Cl_Q12 } \\
\text { Do you help out at the parent? For example arriv- } \\
\text { ing early to prepare, staying late for clean up or } \\
\text { other things like that. }\end{array}$ & $\begin{array}{l}\text { 1. Yes } \\
\text { 2. No } \\
8 \text { Don't know } \\
9 \text { Refuse to answer }\end{array}$ & $\begin{array}{l}\text { If they } \\
\text { respond } \\
\text { no jump to } \\
\text { Cl_Q14 }\end{array}$ \\
\hline $\begin{array}{l}\text { CI_Q13 } \\
\text { How often do you help out at the parent school - } \\
\text { those meetings and presentations for parents that } \\
\text { are organized by the CIANI? }\end{array}$ & $\begin{array}{l}\text { 1. Very often } \\
\text { 2. Often } \\
\text { 3. Sometimes } \\
\text { 4. Hardly ever } \\
\text { 8. Don't know } \\
\text { 9. Refuse to answer }\end{array}$ & \\
\hline $\begin{array}{l}\text { CI_Q14 } \\
\text { How satisfied are you with general parent supports } \\
\text { provided by the CIANI - other than the parent } \\
\text { school, such as help with birth certificates, medica- } \\
\text { tion and things like that. (Read response categories } \\
\text { out except for options } 8 \& 9 \text { ) }\end{array}$ & $\begin{array}{l}\text { 1. Very satisfied } \\
\text { 2. Satisfied } \\
\text { 3. Dissatisfied } \\
\text { 4. Very dissatisfied } \\
\text { 8. Don't know } \\
\text { 9. Refuse to answer }\end{array}$ & \\
\hline
\end{tabular}




\section{Cl_Q15}

The CIANI also organizes many social events, celebrations and parties outside the parent school. For example parties for mother's day, Christmas and birthdays. How often do you attend these kinds of events at the CIANI? (Read out each response category except for 8 \&9)

Cl_Q16

How often do you help out at these events? (Read out each response category except for 8 \&9)

\section{Cl_Q17}

How often do you interact with other parents at the CIANI? (Read out each response category except for 8 \&9)

Cl_Q18

Have you changed the way you parent and interact with the child since being involved at the CIANI?

Cl_Q18B

Cl_Q19

Do you think the CIANI makes an important contribution to the well-being of children in your neighborhood?

Cl_Q19B
1. Very often

2. Often

3. Sometimes

4. Hardly ever

8. Don't know

9. Refuse to answer

1. Very often

2. Often

3. Sometimes

4. Hardly ever

8. Don't know

9. Refuse to answer

1. Very often

2. Often

3. Sometimes

4. Hardly ever

8. Don't know

9. Refuse to answer

1. Yes (Go to Cl_Q18B)

2. NO

88. Don't know

99. Refuse to answer

If "yes," please specify

1. Yes (Go to Cl_Q19B)

2. NO

8. Don't know

9. Refuse to answer

If "yes," please specify 
Evaluation of Centres for the Integral Attention of Children in Dominican Republic (CIANIs) and Local Community Organizations for Child Protection (LCOCP)

\section{JUNTA}

The Local Community Organizations for Child Protection LCOCPs are the first non-governmental organizations authorized to detect and report any form of child mistreatment to the CONANI and Fiscalia municipal offices. They work with communities to ensure child protection. They train volunteers to conduct peer monitoring and reporting, also bringing awareness to children's rights, and parent responsibilities. They inform authorities of possibilities of child mistreatment and work with families to ensure protective legal mandates are properly followed by parents.

\begin{tabular}{|c|c|c|}
\hline $\begin{array}{l}\text { J_Q01 } \\
\text { Have you ever heard of the Protec- } \\
\text { tion Junta before? }\end{array}$ & $\begin{array}{l}\text { 1. Yes } \\
\text { 2. No } \\
\text { 3. Don't know } \\
\text { 4. Refuse to answer }\end{array}$ & $\begin{array}{l}\text { If no jump } \\
\text { to J_Q03 }\end{array}$ \\
\hline $\begin{array}{l}\text { J_Q02 } \\
\text { If yes how? } \\
\text { (Read responses, mark the ones } \\
\text { mentioned.) } \\
\text { J_Q02B }\end{array}$ & $\begin{array}{l}\text { 1. News or media } \\
\text { 2. Family/friend } \\
\text { 3. CIANI } \\
\text { 4. CONANI } \\
\text { 5. Fiscalia } \\
\text { 6. Other community organization/NGO } \\
\text { 7. Other (Go to J_Q02b) } \\
\text { 8. Don't know } \\
\text { 9. Refuse to answer } \\
\text { If "other," please specify }\end{array}$ & \\
\hline $\begin{array}{l}\text { J_Q03 } \\
\text { Do you know if there is a Protection } \\
\text { Junta working in your municipality? }\end{array}$ & $\begin{array}{l}\text { 1. Yes } \\
\text { 2. No } \\
\text { 8. Don't know } \\
\text { 9. Refuse to answer }\end{array}$ & $\begin{array}{l}\text { If no skip to } \\
\text { childcare } \\
\text { section. }\end{array}$ \\
\hline $\begin{array}{l}\text { J_Q04 } \\
\text { Have you had DIRECT contact with } \\
\text { any member of the Protection Junta } \\
\text { about your family situation? }\end{array}$ & $\begin{array}{l}\text { 1. Yes } \\
\text { 2. No } \\
\text { 8. Don't know } \\
\text { 9. Refuse to answer }\end{array}$ & $\begin{array}{l}\text { If no skip to } \\
\text { J_Q07 }\end{array}$ \\
\hline
\end{tabular}




\begin{tabular}{|c|c|c|}
\hline $\begin{array}{l}\text { J_Q05 } \\
\text { Are you still involved with the Pro- } \\
\text { tection Junta? }\end{array}$ & $\begin{array}{l}\text { 1. Yes } \\
\text { 2. No } \\
\text { 8. Don't know } \\
\text { 9. Refuse to answer }\end{array}$ & $\begin{array}{l}\text { If no skip to } \\
\text { J_Q07 }\end{array}$ \\
\hline $\begin{array}{l}\text { J_Q06 } \\
\text { Can you describe the outcome of the } \\
\text { contact with the Protection Junta? } \\
\text { (Read responses, mark the ones } \\
\text { mentioned.) } \\
\text { J_Q06B }\end{array}$ & $\begin{array}{l}\text { 1. The situation is ongoing } \\
\text { 2. The CIANI is now handling the situation } \\
\text { 3. The fiscalia is now handling the situation } \\
\text { 4. The situation was resolved } \\
\text { 5. Other (Go to J_Q06B) } \\
\text { 8. Don't know } \\
\text { 9. Refuse to answer } \\
\text { If "other" please specify }\end{array}$ & \\
\hline $\begin{array}{l}\text { J_Q07 } \\
\text { Do you think that the Junta makes an } \\
\text { important contribution to the protec- } \\
\text { tion of children in your municipality? } \\
\text { J_Q07B }\end{array}$ & $\begin{array}{l}\text { 1. Yes (Go to J_Q07B) } \\
\text { 2. No } \\
\text { 8. Don't know } \\
\text { 9. Refuse to answer } \\
\text { If "yes," please specify }\end{array}$ & \\
\hline
\end{tabular}


Evaluation of Centres for the Integral Attention of Children in Dominican Republic (CIANIs) and Local Community Organizations for Child Protection (LCOCP)

\section{CHILDCARE}

Now we would like to discuss you childcare arrangements outside of the CIANI.
CC_Q01
1. Very easy
Please tell me is it easy or difficult for you to find childcare in your neighbor- hood, outside of the CIANI? Is it (read out response category except for 8 and
9) (Read out each response category
2. Easy
3. Difficult
4. Very difficult except for 8 \&9)
8. Don't know
9. Refuse to answer
CC_Q02
1. Yes
Do you rely on others - family mem-
2. No
bers, friends and neighbours- to take care of children outside of the CIANI?
CC_Q03
8 Don't know
9 Refuse to answer
1. Very often
How often do you depend on others to take care of your children? (Read out each response category except for 8 \&9)
2. Often
3. Sometimes
4. Hardly ever
8. Don't know
9. Refuse to answer
CC_Q04
1. Very satisfied
How satisfied are you with your child- care arrangements outside of the CIANI? (Read out each response cate- gory except for 8 \&9)
2. Satisfied
3. Dissatisfied
4. Very dissatisfied
8. Don't know
9. Refuse to answer

Now I will ask some questions about how often you use childcare supports in your neighbourhood. 


\begin{tabular}{|c|c|c|}
\hline $\begin{array}{l}\text { CC_Q05 } \\
\text { How often do you use a daycare other } \\
\text { than the CIANI? (Read response catego- } \\
\text { ries out except for options } 8 \& 9 \text { ) }\end{array}$ & $\begin{array}{l}\text { 1. Very often } \\
\text { 2. Often } \\
\text { 3. Sometimes } \\
\text { 4. Hardly ever } \\
\text { 8. Don't know } \\
\text { 9. Refuse to answer }\end{array}$ & \\
\hline $\begin{array}{l}\text { CC_Q06 } \\
\text { Are there any other childcare services } \\
\text { that you use in your neighbourhood, } \\
\text { outside the CIANI? } \\
\text { CC_Q06B }\end{array}$ & $\begin{array}{l}\text { 1. Yes (Go to CC_Q06B) } \\
\text { 2. No } \\
\text { 8. Don't know } \\
\text { 9. Refuse to answer } \\
\text { If "yes," what are they? }\end{array}$ & $\begin{array}{l}\text { If none are listed, } \\
\text { move forward to } \\
\text { community. } \\
\text { If a service is list- } \\
\text { ed use it/them in } \\
\text { CC_Q07 }\end{array}$ \\
\hline $\begin{array}{l}\text { CC_Q07 } \\
\text { a) How often do you use } \\
\text { sert first service listed here) (Read } \\
\text { response categories out except for } \\
\text { options } 8 \text { \& 9) } \\
\text { b) How often do you use } \\
\text { second service listed here) (Read re- } \\
\text { sponse categories out except for op- } \\
\text { tions } 8 \text { \& 9) }\end{array}$ & $\begin{array}{l}\text { 1. Very often } \\
\text { 2. Often } \\
\text { 3. Sometimes } \\
\text { 4. Hardly ever } \\
\text { 8. Don't know } \\
\text { 9. Refuse to answer } \\
\text { 1. Very often } \\
\text { 2. Often } \\
\text { 3. Sometimes } \\
\text { 4. Hardly ever } \\
\text { 8. Don't know } \\
\text { 9. Refuse to answer }\end{array}$ & \\
\hline
\end{tabular}


Evaluation of Centres for the Integral Attention of Children in Dominican Republic (CIANIs) and Local Community Organizations for Child Protection (LCOCP)

\section{HEALTH}

\section{Now I am going to ask some questions about health.}

\begin{tabular}{|c|c|c|}
\hline $\begin{array}{l}\text { H_Q01 } \\
\text { How would you describe the health of the } \\
\text { children in the household - would you say } \\
\text { it is excellent, very good, good, fair poor? } \\
\text { Refer back to charts in DEM_Q05. Ask } \\
\text { question and mark on that chart. }\end{array}$ & & $\begin{array}{l}\text { Jump back to } \\
\text { Charts } A, B \text {, and } C \\
\text { in DEM_Q05 }\end{array}$ \\
\hline $\begin{array}{l}\text { H_Q02 } \\
\text { Would you say that in general your OWN } \\
\text { health is (Read response categories out } \\
\text { except for options } 8 \text { \& 9) }\end{array}$ & $\begin{array}{l}\text { 1. Excellent } \\
\text { 2. Very good } \\
\text { 3. Good } \\
\text { 4. Fair } \\
\text { 5. Poor } \\
\text { 8. Don't know } \\
\text { 9. Refuse to answer }\end{array}$ & \\
\hline $\begin{array}{l}\text { H_Q03 } \\
\text { In the past year have any of the children } \\
\text { been injured or ill? } \\
\text { H_Q03B }\end{array}$ & $\begin{array}{l}\text { 1. Yes (Go to H_Q03B) } \\
\text { 2. No } \\
\text { 8. Don't know } \\
\text { 9. Refuse to answer } \\
\text { If "yes," how many times? }\end{array}$ & \\
\hline $\begin{array}{l}\text { H_Q04 } \\
\text { In the past year was there a situation } \\
\text { where your child/children were ill or in- } \\
\text { jured and did not receive necessary med- } \\
\text { ical care? } \\
\text { H_Q04B }\end{array}$ & $\begin{array}{l}\text { 1. Yes (Go to H_Q03B) } \\
\text { 2. No } \\
\text { 8. Don't know } \\
\text { 9. Refuse to answer } \\
\text { If "yes," which child (use name } \\
\text { from tables from D Q05) }\end{array}$ & \\
\hline
\end{tabular}




\section{DISCIPLINE AND PARENTING ATTITUDE}

\section{All adults use different ways to teach their children the right behaviour or to} address behaviour problems.
DPA_Q01
1. Yes
Do you believe that in order to raise a child properly
2. No you need to physically discipline them? By this I mean do you believe that you need to spank or hit the child or take any other physical measures to discipline the
8. Don't know
9. Refuse to answer child?

I am going to read you a few different situations, and I would like you to tell me if you think that a parent would be justified in using physical discipline (hitting) in the particular situation. Do not read responses out.
DPA_Q02
1. Yes
If the child is at risk of harming themselves.
2. No
8. Don't know
9. Refuse to answer
DPA Q03
1. Yes
If the child does something without parent permission
DPA Q04
2. No
8. Don't know
9. Refuse to answer
If the child disobeys an adult
1. Yes
2. No
8. Don't know
9. Refuse to answer
DPA_Q05
1. Yes
If the child fights with a sibling
2. No
8. Don't know
9. Refuse to answer
DPA_Q06
1. Yes
If the child fights with another child
2. No
8. Don't know
9. Refuse to answer 
Evaluation of Centres for the Integral Attention of Children in Dominican Republic (CIANIs) and Local Community Organizations for Child Protection (LCOCP)
DPA_Q07
1. Yes
If the child robbed something
2. No
8. Don't know
9. Refuse to answer
DPA_Q08
1. Yes
If the child did poorly at school
2. No
8. Don't know
9. Refuse to answer
DPA_Q09.
1. Yes
If the child refuses to do chores?
2. No
8. Don't know
9. Refuse to answer

Let's talk about your experiences as a parent.

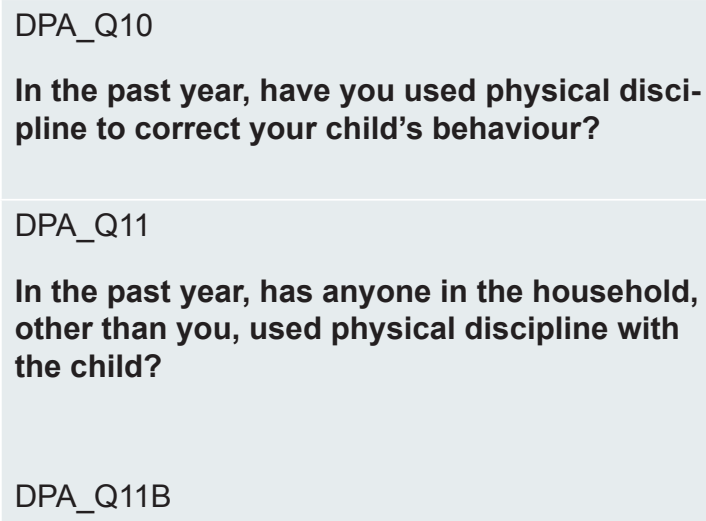

1. Yes

2. No

8. Don't know

9. Refuse to answer

1. Yes (Go to DPA_Q11B)

2. No

8. Don't know

9. Refuse to answer

If "yes" who in the household has used physical discipline with the child?

Once more I am going to ask you about certain ways of teaching children right behaviour or to correct behaviour problems.

I am going to read various methods used by parents and I want you to tell me if you have used this method in the last year. 


\begin{tabular}{|c|c|}
\hline $\begin{array}{l}\text { DPA_Q12 } \\
\text { Have you taken away privileges, forbade } \\
\text { something the child liked (for example; televi- } \\
\text { sion or toys) or not allowed them to leave the } \\
\text { house? }\end{array}$ & $\begin{array}{l}\text { 1. Yes } \\
\text { 2. No } \\
\text { 8. Don't know } \\
\text { 9. Refuse to answer }\end{array}$ \\
\hline $\begin{array}{l}\text { DPA_Q13 } \\
\text { Have you explained why something the child } \\
\text { did was wrong? }\end{array}$ & $\begin{array}{l}\text { 1. Yes } \\
\text { 2. No } \\
\text { 8. Don't know } \\
\text { 9. Refuse to answer }\end{array}$ \\
\hline $\begin{array}{l}\text { DPA_Q14 } \\
\text { Have you shaken the child? }\end{array}$ & $\begin{array}{l}\text { 1. Yes } \\
\text { 2. No } \\
\text { 8. Don't know } \\
\text { 9. Refuse to answer }\end{array}$ \\
\hline $\begin{array}{l}\text { DPA_Q15 } \\
\text { Have you shouted, yelled at or screamed at the } \\
\text { child? }\end{array}$ & $\begin{array}{l}\text { 1. Yes } \\
\text { 2. No } \\
\text { 8. Don't know } \\
\text { 9. Refuse to answer }\end{array}$ \\
\hline $\begin{array}{l}\text { DPA_Q16 } \\
\text { Have you hit the child on the leg with bare } \\
\text { hand? }\end{array}$ & $\begin{array}{l}\text { 1. Yes } \\
\text { 2. No } \\
\text { 8. Don't know } \\
\text { 9. Refuse to answer }\end{array}$ \\
\hline $\begin{array}{l}\text { DPA_Q17 } \\
\text { Have you hit the child on the leg with some- } \\
\text { thing like a belt, brush, stick or hard object? }\end{array}$ & $\begin{array}{l}\text { 1. Yes } \\
\text { 2. No } \\
\text { 8. Don't know } \\
\text { 9. Refuse to answer }\end{array}$ \\
\hline $\begin{array}{l}\text { DPA_Q18 } \\
\text { Have you spanked, hit or slap child on the bot- } \\
\text { tom with bare hand? }\end{array}$ & $\begin{array}{l}\text { 1. Yes } \\
\text { 2. No } \\
\text { 8. Don't know } \\
\text { 9. Refuse to answer }\end{array}$ \\
\hline $\begin{array}{l}\text { DPA_Q19 } \\
\text { Have you ever hit him/her on bottom with } \\
\text { something like a belt, hairbrush, stick or hard } \\
\text { object? }\end{array}$ & $\begin{array}{l}\text { 1. Yes } \\
\text { 2. No } \\
\text { 8. Don't know } \\
\text { 9. Refuse to answer }\end{array}$ \\
\hline
\end{tabular}


Evaluation of Centres for the Integral Attention of Children in Dominican Republic (CIANIs) and Local Community Organizations for Child Protection (LCOCP)

\begin{tabular}{|c|c|}
\hline $\begin{array}{l}\text { DPA_Q20 } \\
\text { Have you hit him/her on the body - not on the } \\
\text { bottom - with something like a belt, hairbrush, } \\
\text { stick or hard object? }\end{array}$ & $\begin{array}{l}\text { 1. Yes } \\
\text { 2. No } \\
\text { 8. Don't know } \\
\text { 9. Refuse to answer }\end{array}$ \\
\hline $\begin{array}{l}\text { DPA_Q21 } \\
\text { Have you called the child dumb, lazy or another } \\
\text { name like that? }\end{array}$ & $\begin{array}{l}\text { 1. Yes } \\
\text { 2. No } \\
\text { 8. Don't know } \\
\text { 9. Refuse to answer }\end{array}$ \\
\hline $\begin{array}{l}\text { DPA_Q22 } \\
\text { Have you hit or slapped the child on the face, } \\
\text { head or ears? }\end{array}$ & $\begin{array}{l}\text { 1. Yes } \\
\text { 2. No } \\
\text { 8. Don't know } \\
\text { 9. Refuse to answer }\end{array}$ \\
\hline $\begin{array}{l}\text { DPA_Q23 } \\
\text { Have you beat the child up - hit over and over } \\
\text { as hard as you could? }\end{array}$ & $\begin{array}{l}\text { 1. Yes } \\
\text { 2. No } \\
\text { 8. Don't know } \\
\text { 9. Refuse to answer }\end{array}$ \\
\hline $\begin{array}{l}\text { DPA_Q24 } \\
\text { Have you threatened the child? }\end{array}$ & $\begin{array}{l}\text { 1. Yes } \\
\text { 2. No } \\
\text { 8. Don't know } \\
\text { 9. Refuse to answer }\end{array}$ \\
\hline $\begin{array}{l}\text { DPA_Q25 } \\
\text { Have you made the child apologize? }\end{array}$ & $\begin{array}{l}\text { 1. Yes } \\
\text { 2. No } \\
\text { 8. Don't know } \\
\text { 9. Refuse to answer }\end{array}$ \\
\hline $\begin{array}{l}\text { DPA_Q26 } \\
\text { Have you hit the child with a fist, or kicked the } \\
\text { child hard? }\end{array}$ & $\begin{array}{l}\text { 1. Yes } \\
\text { 2. No } \\
\text { 8. Don't know } \\
\text { 9. Refuse to answer }\end{array}$ \\
\hline $\begin{array}{l}\text { DPA_Q27 } \\
\text { Have you threatened to hit or physically punish } \\
\text { the child? }\end{array}$ & $\begin{array}{l}\text { 1. Yes } \\
\text { 2. No } \\
\text { 8. Don't know } \\
\text { 9. Refuse to answer }\end{array}$ \\
\hline $\begin{array}{l}\text { DPA_Q28 } \\
\text { Have you sworn or cursed at the child? }\end{array}$ & $\begin{array}{l}\text { 1. Yes } \\
\text { 2. No } \\
\text { 8. Don't know } \\
\text { 9. Refuse to answer }\end{array}$ \\
\hline
\end{tabular}




\begin{tabular}{|c|c|}
\hline $\begin{array}{l}\text { DPA_Q29 } \\
\text { Have you told the child you would kick them } \\
\text { out of the house? }\end{array}$ & $\begin{array}{l}\text { 1. Yes } \\
\text { 2. No } \\
\text { 8. Don't know } \\
\text { 9. Refuse to answer }\end{array}$ \\
\hline $\begin{array}{l}\text { DPA_Q30 } \\
\text { Have you pulled the child's hair? }\end{array}$ & $\begin{array}{l}\text { 1. Yes } \\
\text { 2. No } \\
\text { 8. Don't know } \\
\text { 9. Refuse to answer }\end{array}$ \\
\hline $\begin{array}{l}\text { DPA_Q31 } \\
\text { Have you pinched the child? }\end{array}$ & $\begin{array}{l}\text { 1. Yes } \\
\text { 2. No } \\
\text { 8. Don't know } \\
\text { 9. Refuse to answer }\end{array}$ \\
\hline $\begin{array}{l}\text { DPA_Q32 } \\
\text { Have you given the child something else to do? } \\
\text { (As a distraction) }\end{array}$ & $\begin{array}{l}\text { 1. Yes } \\
\text { 2. No } \\
\text { 8. Don't know } \\
\text { 9. Refuse to answer }\end{array}$ \\
\hline $\begin{array}{l}\text { DPA_Q33 } \\
\text { Have you ignored the child? }\end{array}$ & $\begin{array}{l}\text { 1. Yes } \\
\text { 2. No } \\
\text { 8. Don't know } \\
\text { 9. Refuse to answer }\end{array}$ \\
\hline $\begin{array}{l}\text { DPA_Q34 } \\
\text { Have you pushed or knocked the child down? }\end{array}$ & $\begin{array}{l}\text { 1. Yes } \\
\text { 2. No } \\
\text { 8. Don't know } \\
\text { 9. Refuse to answer }\end{array}$ \\
\hline $\begin{array}{l}\text { DPA_Q35 } \\
\text { Have you made fun of the child? }\end{array}$ & $\begin{array}{l}\text { 1. Yes } \\
\text { 2. No } \\
\text { 8. Don't know } \\
\text { 9. Refuse to answer }\end{array}$ \\
\hline $\begin{array}{l}\text { DPA_Q36 } \\
\text { Has the way you discipline the child/children } \\
\text { changed since attending the CIANI? } \\
\text { DPA Q36B }\end{array}$ & $\begin{array}{l}\text { 1. Yes (Go to DPA_Q36B) } \\
\text { 2. No } \\
\text { 8. Don't know } \\
\text { 9. Refuse to answer } \\
\text { If "yes," please specify }\end{array}$ \\
\hline
\end{tabular}


Evaluation of Centres for the Integral Attention of Children in Dominican Republic (CIANIs) and Local Community Organizations for Child Protection (LCOCP)
DPA_Q37
Thinking of all the people living in your house- hold who might discipline the child/children, Has there been an overall change in the disci- pline in your household after being involved in the CIANI?
DPA_Q37B

1. Yes (Go to DPA_Q37B)

2. No

8. Don't know

9. Refuse to answer

If "yes," please specify

\section{PARENTING EXPERIENCES}

Many parents and families face different experiences in their everyday lives. I will read some statements of different experiences, and I would like you to tell me if you have faced this experience in the past year. Do not read out response categories.
PE_Q01
1. Yes
Have you had problems paying household ex- penses in the last year?
2. No
8. Don't know
9. Refuse to answer
PE_Q02.
1. Yes (Go to PE_Q02B)
Have you moved in the last year?
2. No
8. Don't know
PE_Q02B
9. Refuse to answer
If "yes" how many times?
PE_Q03
1. Yes
Have you had significant problems in your rela- tionship with your spouse or partner in the last year?
2. No
PE_Q04
8. Don't know
9. Refuse to answer
Have you experienced forms of violence in your household in the last year?
1. Yes
2. No
8. Don't know
9. Refuse to answer 


\begin{tabular}{|c|c|}
\hline $\begin{array}{l}\text { PE_Q05 } \\
\text { Have you experienced violence in your neigh- } \\
\text { bourhood in the last year? }\end{array}$ & $\begin{array}{l}\text { 1. Yes } \\
\text { 2. No } \\
\text { 8. Don't know } \\
\text { 9. Refuse to answer }\end{array}$ \\
\hline $\begin{array}{l}\text { PE_Q06 } \\
\text { Have you had a divorce, separation, or a break- } \\
\text { up from a partner or spouse? }\end{array}$ & $\begin{array}{l}\text { 1. Yes } \\
\text { 2. No } \\
\text { 8. Don't know } \\
\text { 9. Refuse to answer }\end{array}$ \\
\hline $\begin{array}{l}\text { PE_Q07 } \\
\text { Have you gone a significant period of time with- } \\
\text { out income in the last year? }\end{array}$ & $\begin{array}{l}\text { 1. Yes (Go to PE_Q07B) } \\
\text { 2. No } \\
\text { 8. Don't know } \\
\text { 9. Refuse to answer } \\
\text { If "yes" for how long a period } \\
\text { to time were you without } \\
\text { income in the last year? }\end{array}$ \\
\hline $\begin{array}{l}\text { PE_Q08 } \\
\text { Was there a time in the last year when your } \\
\text { child/children was/were unable to receive the } \\
\text { food they needed? }\end{array}$ & $\begin{array}{l}\text { 1. Yes } \\
\text { 2. No } \\
\text { 8. Don't know } \\
\text { 9. Refuse to answer }\end{array}$ \\
\hline $\begin{array}{l}\text { PE_Q09 } \\
\text { a) In the past year, have you left a child at } \\
\text { home without an adult there to look after } \\
\text { the child? }\end{array}$ & $\begin{array}{l}\text { 1. Yes (Go to b) } \\
\text { 2. No } \\
\text { 8. Don't know } \\
\text { 9. Refuse to answer }\end{array}$ \\
\hline $\begin{array}{l}\text { Was the child left at home alone or was a } \\
\text { non-adult looking after the child? }\end{array}$ & $\begin{array}{l}\text { 1. Alone } \\
\text { 2. Non-adult (Go to d) } \\
\text { 8. Don't know } \\
\text { 9. Refuse to answer }\end{array}$ \\
\hline $\begin{array}{l}\text { d) How old was the person looking after the } \\
\text { child? }\end{array}$ & \\
\hline
\end{tabular}


Evaluation of Centres for the Integral Attention of Children in Dominican Republic (CIANIs) and Local Community Organizations for Child Protection (LCOCP)

\section{COMMUNITY ENGAGEMENT}

Now I am going to read some statements about your neighbourhood. Please tell me if you strongly agree, agree, disagree or strongly disagree with each statement.

\begin{tabular}{|c|c|}
\hline $\begin{array}{l}\text { COM_Q01 } \\
\text { Children are safe in my neighbourhood. (Read } \\
\text { response categories out except for options } 8 \text { \& 9) }\end{array}$ & $\begin{array}{l}\text { 1. Strongly agree } \\
\text { 2. Agree } \\
\text { 3. Disagree } \\
\text { 4. Strongly disagree } \\
\text { 8. Don't know } \\
\text { 9. Refuse to answer }\end{array}$ \\
\hline $\begin{array}{l}\text { COM_Q02 } \\
\text { I feel unsafe in my neighbourhood. (Read re- } \\
\text { sponse categories out except for options } 8 \text { \& 9) }\end{array}$ & $\begin{array}{l}\text { 1. Strongly agree } \\
\text { 2. Agree } \\
\text { 3. Disagree } \\
\text { 4. Strongly disagree } \\
\text { 8. Don't know } \\
\text { 9. Refuse to answer }\end{array}$ \\
\hline $\begin{array}{l}\text { COM_Q03 } \\
\text { We take care of each other's children in my } \\
\text { neighbourhood? (Read response categories out } \\
\text { except for options } 8 \& 9 \text { ) }\end{array}$ & $\begin{array}{l}\text { 1. Strongly agree } \\
\text { 2. Agree } \\
\text { 3. Disagree } \\
\text { 4. Strongly disagree } \\
\text { 8. Don't know } \\
\text { 9. Refuse to answer }\end{array}$ \\
\hline $\begin{array}{l}\text { COM_Q04 } \\
\text { In my neighbourhood there are NO secure parks } \\
\text { or playgrounds for the children to play. (Read } \\
\text { response categories out except for options } 8 \& 9)\end{array}$ & $\begin{array}{l}\text { 1. Strongly agree } \\
\text { 2. Agree } \\
\text { 3. Disagree } \\
\text { 4. Strongly disagree } \\
\text { 8. Don't know } \\
\text { 9. Refuse to answer }\end{array}$ \\
\hline $\begin{array}{l}\text { COM_Q05 } \\
\text { It is easy for me to get help from organizations in } \\
\text { my neighbourhood. (Read response categories out } \\
\text { except for options } 8 \text { \& 9) }\end{array}$ & $\begin{array}{l}\text { 1. Strongly agree } \\
\text { 2. Agree } \\
\text { 3. Disagree } \\
\text { 4. Strongly disagree } \\
\text { 8. Don't know } \\
\text { 9. Refuse to answer }\end{array}$ \\
\hline
\end{tabular}




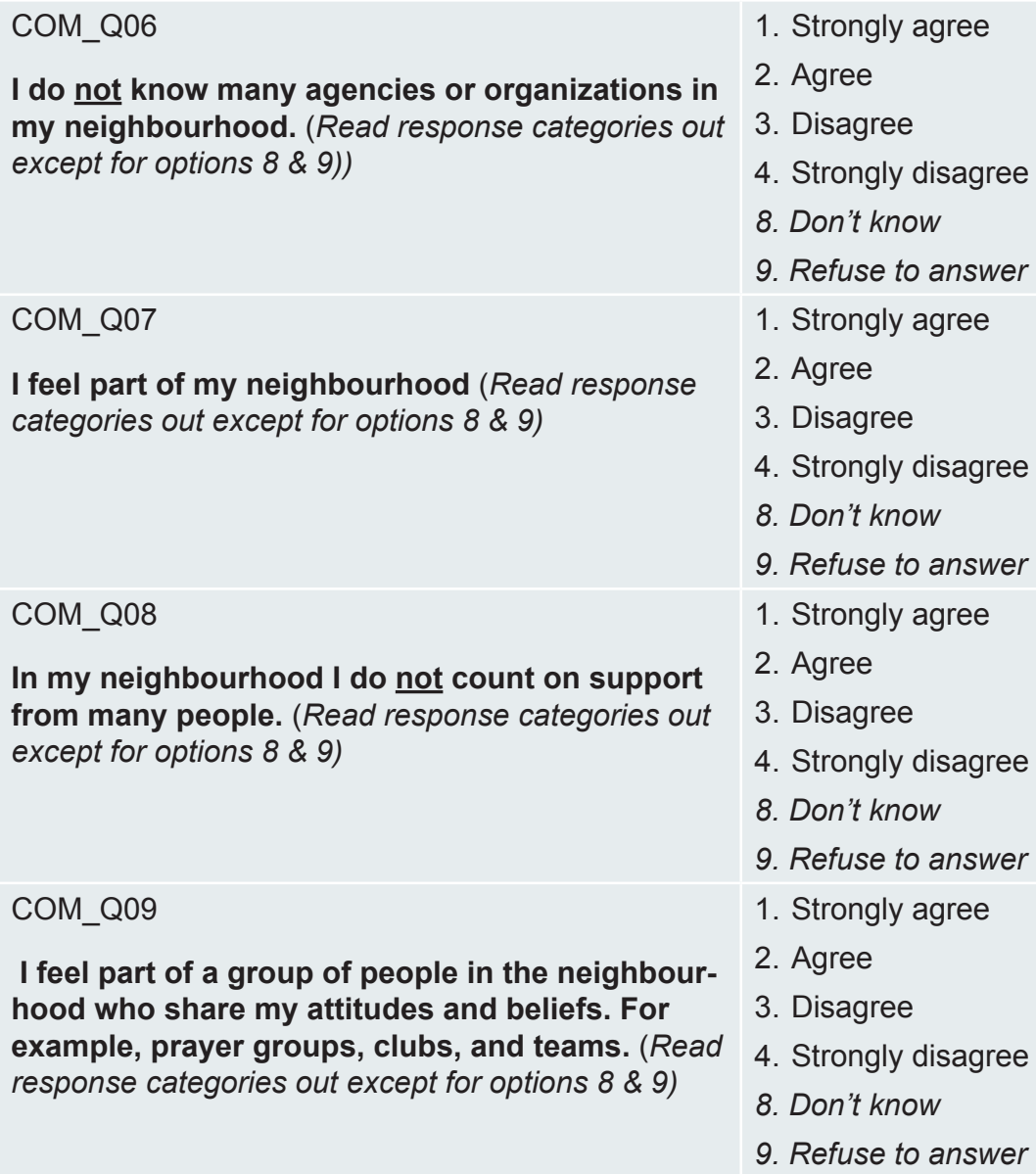

I do not know many agencies or organizations in my neighbourhood. (Read response categories out except for options 8 \& 9))

2. Agree

3. Disagree

4. Strongly disagree

8. Don't know

9. Refuse to answer

COM_Q07

1. Strongly agree

I feel part of my neighbourhood (Read response categories out except for options 8 \& 9)

2. Agree

3. Disagree

4. Strongly disagree

8. Don't know

9. Refuse to answer

COM_Q08

1. Strongly agree

In my neighbourhood I do not count on support from many people. (Read response categories out except for options 8 \& 9)

2. Agree

3. Disagree

4. Strongly disagree

8. Don't know

9. Refuse to answer

COM_Q09

1. Strongly agree

I feel part of a group of people in the neighbourhood who share my attitudes and beliefs. For example, prayer groups, clubs, and teams. (Read response categories out except for options 8 \& 9)

2. Agree

3. Disagree

4. Strongly disagree

8. Don't know

9. Refuse to answer

\section{There are many different neighbourhood events, some sponsored by church-} es, governments and other groups.

\begin{tabular}{l|l} 
COM_Q10 & $\begin{array}{l}\text { 1. Very often } \\
\text { 2. Often }\end{array}$ \\
$\begin{array}{l}\text { How often do you attend meetings and/or } \\
\text { events in the neighbourhood? }\end{array}$ & $\begin{array}{l}\text { 3. Sometimes } \\
\text { 4. Hardly ever }\end{array}$ \\
$\begin{array}{l}\text { (Read response categories out except for options } \\
8 \text { \& 9) }\end{array}$ & $\begin{array}{l}\text { 8. Don't know } \\
\text { 9. Refuse to answer }\end{array}$ \\
\hline COM_Q11 & 1. Very often \\
\hline How often do you work with others in your & 2. Often \\
neighbourhood to solve problems in the neigh- & 3. Sometimes \\
bourhood? & 4. Hardly ever \\
(Read response categories out except for options & 8. Don't know \\
8 \& 9) & 9. Refuse to answer
\end{tabular}


Evaluation of Centres for the Integral Attention of Children in Dominican Republic (CIANIs) and Local Community Organizations for Child Protection (LCOCP)

Thank you very much for taking the time to participate in the survey. Ryerson University appreciates your cooperation. Your information is very important to us. We value your support and your willingness to help us meet the goals of this project.

\section{B - 2: Survey Questionnaire for the Control Group}

\author{
Respondent identification number \\ Name of interviewer \\ Interviewer identification number \\ Date of interview \\ Time interview started \\ Time interview ended
}

Oral consent

Location of interview

City in which interview was conducted
1. At home

2. At CIANI

3. At work

4. Other

b) Please specify:

1. Given

2. Denied (end the interview)

Hello. I'm an interviewer employed by Ryerson University in Toronto, Canada. I am working on a survey that asks people what they think about the supports and programs available in your neighbourhood. We are asking everyone with children in Grade 1 (or 2 or 3 ) at the School to complete the survey.

It is important that you know that I do not work for the school, but for the University. All the information you give in the survey will remain strictly confidential. It will be analyzed by the team of academic researchers at Ryerson 
University. Only general reports will be prepared from the information in this survey, without any individual names attached. The information you give will be added to the information given by other participants in the survey, and the combined results examined.

The survey should take about a half-hour or so to complete. Your participation is completely voluntary. If you choose not to participate, no one will be informed, and there will be no consequences. If there are any questions that make you uncomfortable, you do not have to answer them.

Do you have a few minutes to talk to us about the issues in your neighbourhood?

P_Q01 Confirm interviewee is the primary caregiver

1. Yes

2. No (end the interview but ask who the primary caregiver is so you can try to contact her/him for an interview)

P_Q02 Have you or any other member of your family or household already completed this survey?

1. Yes (end interview)

2. No (continue with interview)

8. Don't know (continue with the interview) 
Evaluation of Centres for the Integral Attention of Children in Dominican Republic (CIANIs) and Local Community Organizations for Child Protection (LCOCP)

\section{DEMOGRAPHICS:}

First we will ask some questions about your child.
DEM_Q01
1. Mother
As the primary caregiver, what is your rela-
2. Father
tionship to the child?
3. Sister/Brother
4. In-law of any type
5. Aunt/uncle
6. Grandparent
7. Other family member
8. Other non-relative
88. Don't know
99. Refuse to answer

DEM_Q02

(Ask only if interviewee is the parent)

How many children do you have?

(From this point on ask everyone parents, and primary caregivers like grandparents - unless it is otherwise specified.)

\section{DEM_Q03}

How many children are currently living with you in the household?

DEM_Q04

Note to the interviewer: This question was not asked for this group of respondents.

\section{DEM_Q05}

(Please complete the following chart for all the children (if the interviewee is the parent) or children in the household (if non-parent)). 
Evaluation of Centres for the Integral Attention of Children in Dominican Republic (CIANIs) and Local Community Organizations for Child Protection (LCOCP)

d) I am going to ask you some questions about your children (if the interviewee is the parent) or children in the household (if non-parent)

*Note to the interviewer: parts a), b) c) of this question were not asked of this group of respondents.

\begin{tabular}{|c|c|c|c|c|}
\hline $\begin{array}{c}\text { (i) } \\
\text { Name }\end{array}$ & $\begin{array}{l}\text { (ii) } \\
\text { Age }\end{array}$ & $\begin{array}{l}\text { (iii) } \\
\text { Sex }\end{array}$ & $\begin{array}{c}\text { (iv) } \\
\text { Current } \\
\text { grade in } \\
\text { school }\end{array}$ & $\begin{array}{l}\text { **Skip this question and come back during health } \\
\qquad \text { section. } \\
\qquad \text { H_Q01 } \\
\text { In general how would you describe CHILD 1's } \\
\text { health? (Read response categories out except } \\
\text { for options } 8 \text { \& 9) }\end{array}$ \\
\hline D1 & $\begin{array}{c}\overline{\text { year(s) }} \\
\overline{\text { month(s) }}\end{array}$ & $\begin{array}{l}\text { 1. Male } \\
\text { 2. Female }\end{array}$ & & $\begin{array}{l}\text { 1. Excellent } \\
\text { 2. Very good } \\
\text { 3. Good } \\
\text { 4. Fair } \\
\text { 5. Poor } \\
\text { 8. Don't know } \\
\text { 9. Refuse to answer }\end{array}$ \\
\hline D2 & $\begin{array}{c}\overline{\text { year(s) }} \\
\overline{\text { month(s) }}\end{array}$ & $\begin{array}{l}\text { 1. Male } \\
\text { 2. Female }\end{array}$ & & $\begin{array}{l}\text { 1. Excellent } \\
\text { 2. Very good } \\
\text { 3. Good } \\
\text { 4. Fair } \\
\text { 5. Poor } \\
\text { 8. Don't know } \\
\text { 9. Refuse to answer }\end{array}$ \\
\hline D3 & $\begin{array}{c}\overline{\text { year(s) }} \\
\overline{\text { month(s) }}\end{array}$ & $\begin{array}{l}\text { 1. Male } \\
\text { 2. Female }\end{array}$ & & $\begin{array}{l}\text { 1. Excellent } \\
\text { 2. Very good } \\
\text { 3. Good } \\
\text { 4. Fair } \\
\text { 5. Poor } \\
\text { 8. Don't know } \\
\text { 9. Refuse to answer }\end{array}$ \\
\hline
\end{tabular}


Evaluation of Centres for the Integral Attention of Children in Dominican Republic (CIANIs) and Local Community Organizations for Child Protection (LCOCP)

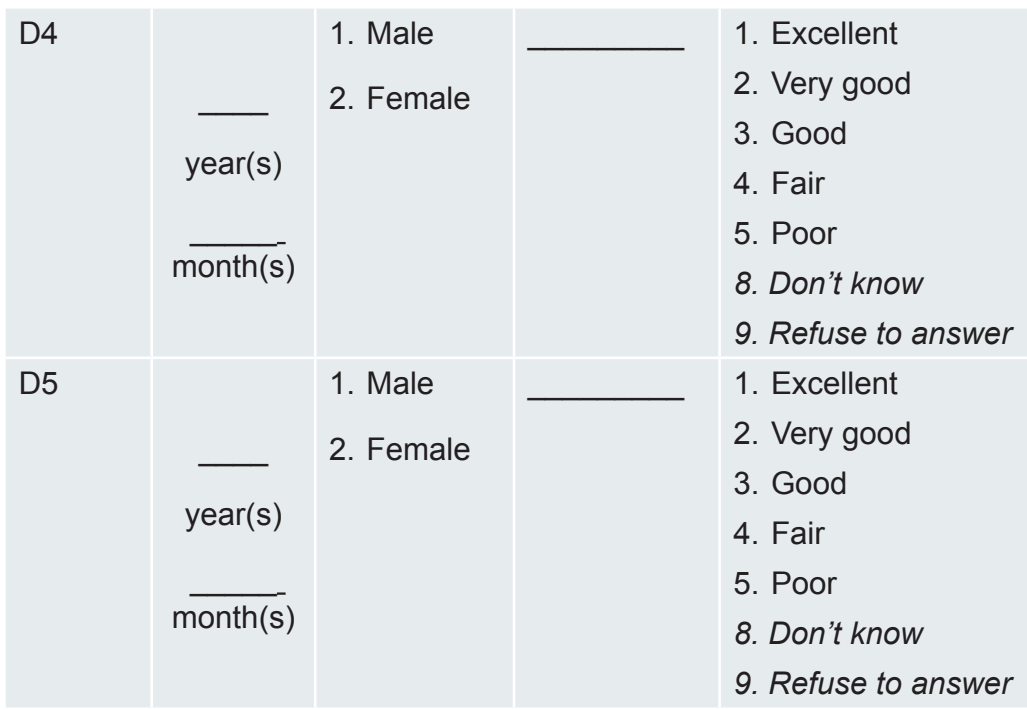

Now we will ask you some questions about you and your household.

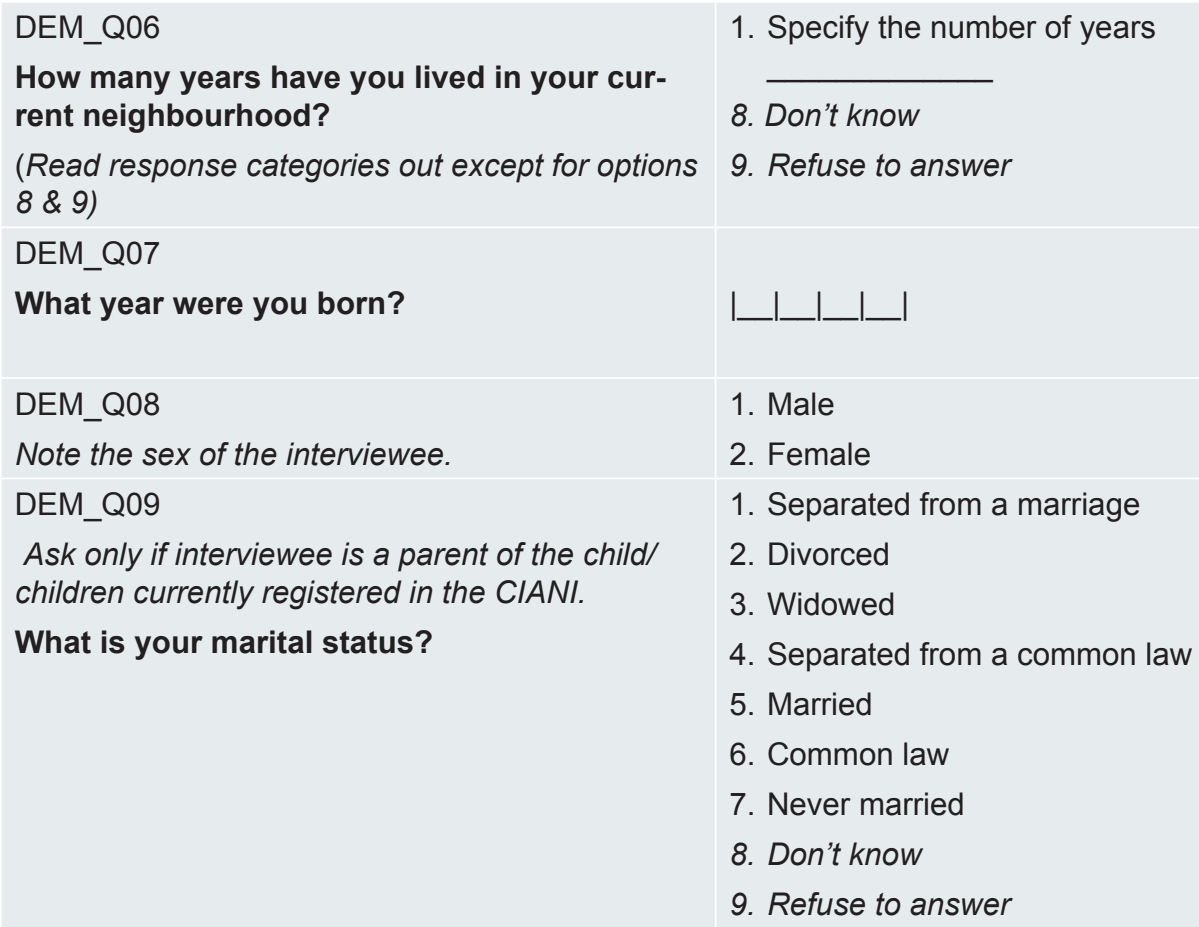




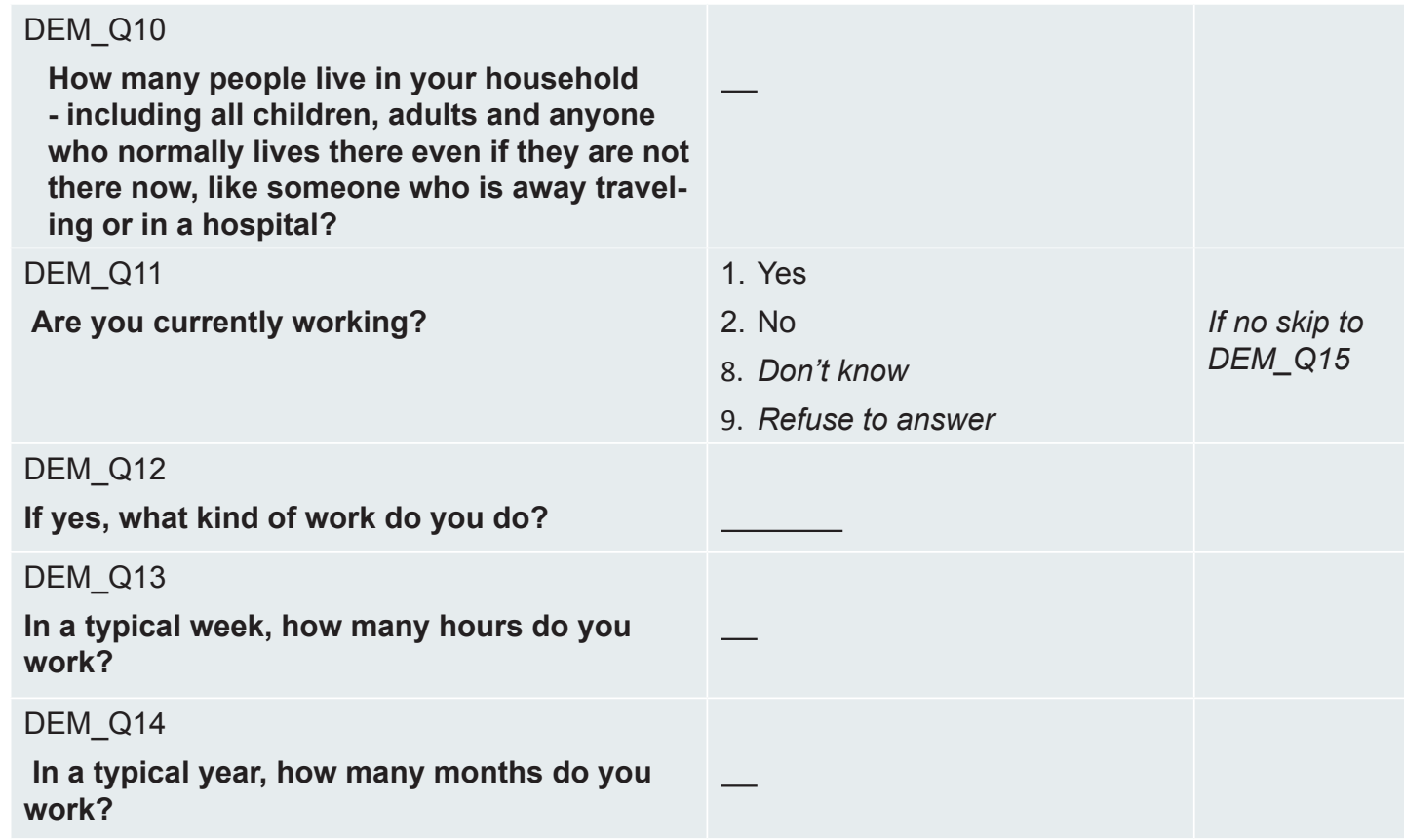

People earn income from many different sources, for example: informal work, formal work, government assistance and other sources.

\section{DEM_Q15}

Thinking of everyone who brings income into your household, what are the sources of income for your household? (Check all that apply - let interviewee respond and check the ones mentioned)

DEM_Q15B
1. Informal work

2. Formal work

3. Government assistance

4. Spouse/partners work

5. Remittance from other family member

6. Other (GO to DEM_Q15B)

8. Don't know

9. Refuse to answer

If "other," please specify 
Evaluation of Centres for the Integral Attention of Children in Dominican Republic (CIANIs) and Local Community Organizations for Child Protection (LCOCP)

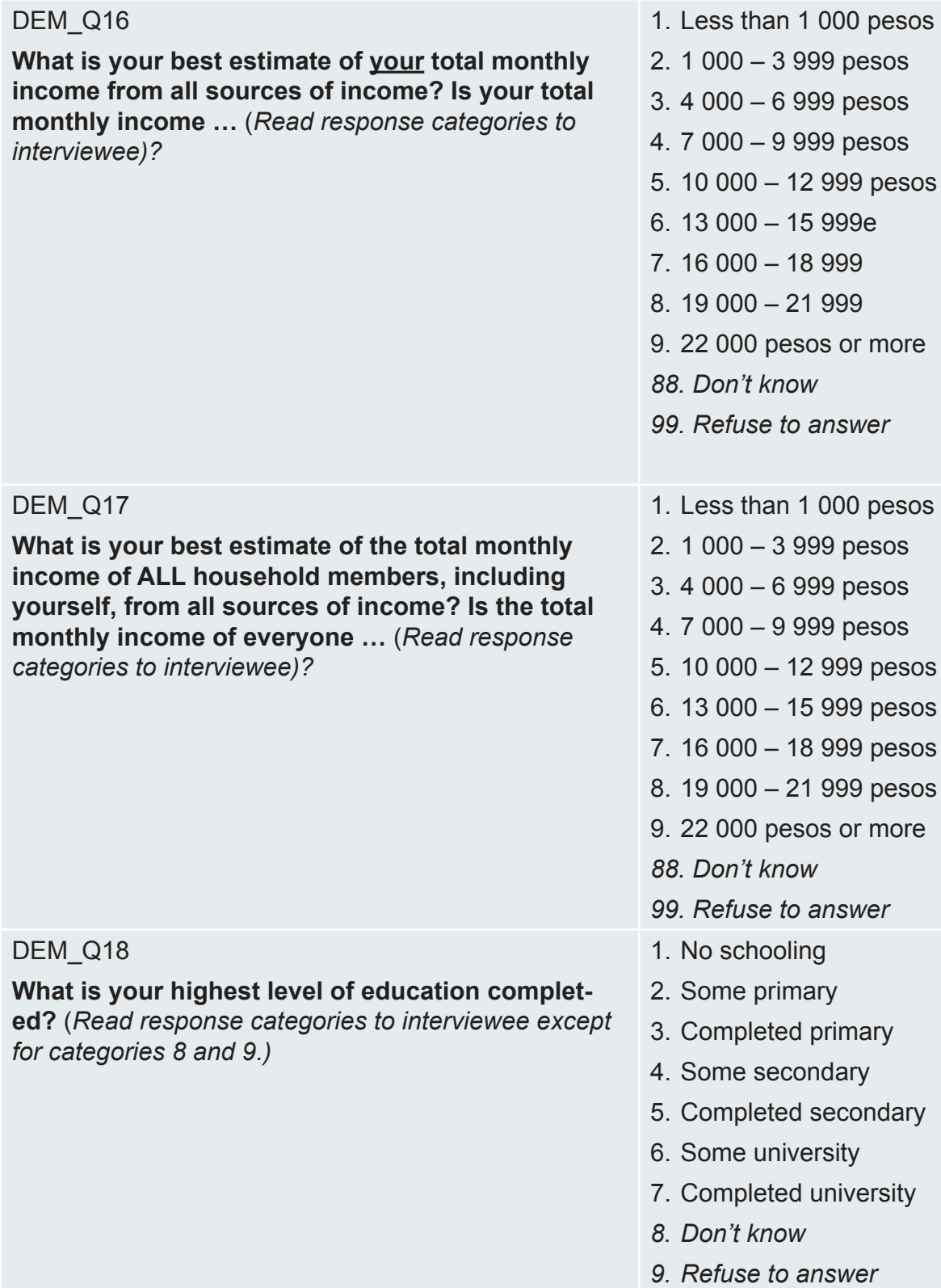

1. Less than 1000 pesos

2. $1000-3999$ pesos

3. $4000-6999$ pesos

4. $7000-9999$ pesos

5. $10000-12999$ pesos

6. $13000-15999$ pesos

7. $16000-18999$ pesos

8. $19000-21999$ pesos

9. 22000 pesos or more

88. Don't know

99. Refuse to answer

DEM_Q18

1. No schooling

What is your highest level of education completed? (Read response categories to interviewee except for categories 8 and 9.)

2. Some primary

3. Completed primary

4. Some secondary

5. Completed secondary

6. Some university

7. Completed university

8. Don't know

9. Refuse to answer 
Evaluation of Centres for the Integral Attention of Children in Dominican Republic (CIANIs) and Local Community Organizations for Child Protection (LCOCP)

\section{CIANI}

Centres for the Integral Attention of Children or CIANI's provide comprehensive early childhood care. The main objective is to develop, manage and expand services for the development of early childhood care to benefit low-income families in the country. They provide comprehensive, multidisciplinary services that include education, health, nutrition, psychology and social work.
C_Q01
1. Yes
Have you ever heard of CIANI?
2. No
8. Don't know
If no jump
9. Refuse to answer
to C_Q03
C_Q02
1. News or media
If yes how?
2. Family/friend
3. CONANI
(Read responses, mark the ones men- tioned.)
4. Fiscalia
5. Other community organization/NGO
6. Other (Go to C_002B)
8. Don't know
C_Q02B
9. Refuse to answer
If "other," please specify
C_Q03
1. Yes
If no skip to
2. No
Do you know if there is a CIANI work- ing in your municipality?
8. Don't know
childcare
9. Refuse to answer
C_Q04
1. Yes
If no skip to
Have you had direct contact with any member of a CIANI about your family situation?
2. No
C_Q07
section.
C_Q05
8. Don't know
9. Refuse to answer
1. Yes
Are you still involved with the CIANI?
2. No
8. Don't know
9. Refuse to answer 
Evaluation of Centres for the Integral Attention of Children in Dominican Republic (CIANIs) and Local Community Organizations for Child Protection (LCOCP)

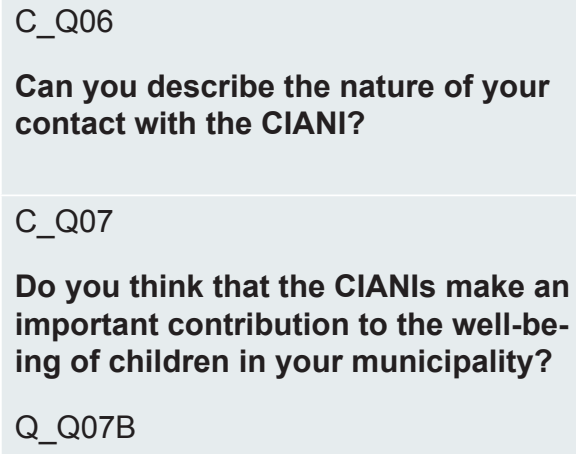

\section{JUNTA}

The Local Community Organizations for Child Protection LCOCPs are the first non-governmental organizations authorized to detect and report any form of child mistreatment to the CONANI and Fiscalia municipal offices. They work with communities to ensure child protection. They train volunteers to conduct peer monitoring and reporting, also bringing awareness to children's rights, and parent responsibilities. They inform authorities of possibilities of child mistreatment and work with families to ensure protective legal mandates are properly followed by parents.

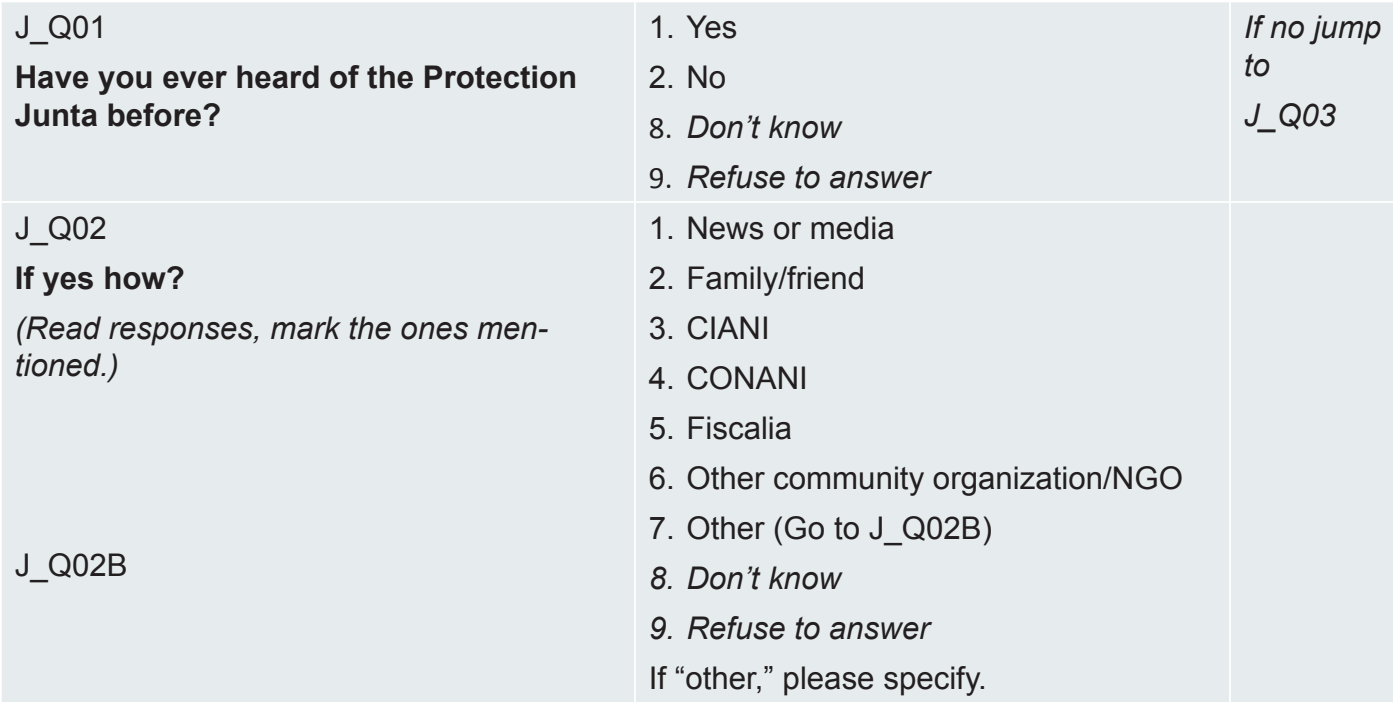

2. No

8. Don't know

Have you ever heard of the Protection Junta before?

9. Refuse to answer

J_Q02

1. News or media

If yes how?

2. Family/friend

(Read responses, mark the ones mentioned.)

3. CIANI

4. CONANI

5. Fiscalia

6. Other community organization/NGO

7. Other (Go to J_Q02B)

J_Q02B

8. Don't know

9. Refuse to answer

If "other," please specify.

If no jump

to

J_Q03 


\begin{tabular}{|c|c|c|}
\hline $\begin{array}{l}\text { J_Q03 } \\
\text { Do you know if there is a Protection Jun- } \\
\text { ta working in your municipality? }\end{array}$ & $\begin{array}{l}\text { 1. Yes } \\
\text { 2. No } \\
\text { 8. Don't know } \\
\text { 9. Refuse to answer }\end{array}$ & $\begin{array}{l}\text { If no skip to } \\
\text { CIANI sec- } \\
\text { tion. }\end{array}$ \\
\hline $\begin{array}{l}\text { J_Q04 } \\
\text { Have you had DIRECT contact with any } \\
\text { member of the Protection Junta about } \\
\text { your family situation? }\end{array}$ & $\begin{array}{l}\text { 1. Yes } \\
\text { 2. No } \\
\text { 8. Don't know } \\
\text { 9. Refuse to answer }\end{array}$ & $\begin{array}{l}\text { If no skip to } \\
J_{-} Q 07\end{array}$ \\
\hline $\begin{array}{l}\text { J_Q05 } \\
\text { Are you still involved with the Protection } \\
\text { Junta? }\end{array}$ & $\begin{array}{l}\text { 1. Yes } \\
\text { 2. No } \\
\text { 8. Don't know } \\
\text { 9. Refuse to answer }\end{array}$ & $\begin{array}{l}\text { If no skip to } \\
\text { J_Q07 }\end{array}$ \\
\hline $\begin{array}{l}\text { J_Q06 } \\
\text { Can you describe the outcome of the } \\
\text { contact with the Protection Junta? } \\
\text { (Read responses, mark the ones men- } \\
\text { tioned.) } \\
\text { J_Q06B }\end{array}$ & $\begin{array}{l}\text { 1. The situation is ongoing } \\
\text { 2. The CIANI is now handling the situ- } \\
\text { ation } \\
\text { 3. The fiscalia is now handling the situ- } \\
\text { ation } \\
\text { 4. The situation was resolved } \\
\text { 5. Other (Go to J_Q06B) } \\
\text { 8. Don't know } \\
\text { 9. Refuse to answer } \\
\text { If "other," please specify. }\end{array}$ & \\
\hline $\begin{array}{l}\text { J_Q07 } \\
\text { Do you think that the Junta makes an } \\
\text { important contribution to the protection } \\
\text { of children in your municipality? } \\
\text { J_Q07B }\end{array}$ & $\begin{array}{l}\text { 1. Yes (Go to J_Q07B) } \\
\text { 2. No } \\
\text { 8. Don't know } \\
\text { 9. Refuse to answer } \\
\text { If "other," please specify. }\end{array}$ & \\
\hline
\end{tabular}


Evaluation of Centres for the Integral Attention of Children in Dominican Republic (CIANIs) and Local Community Organizations for Child Protection (LCOCP)

\section{CHILDCARE}

\section{Now we would like to discuss your childcare arrangements.}

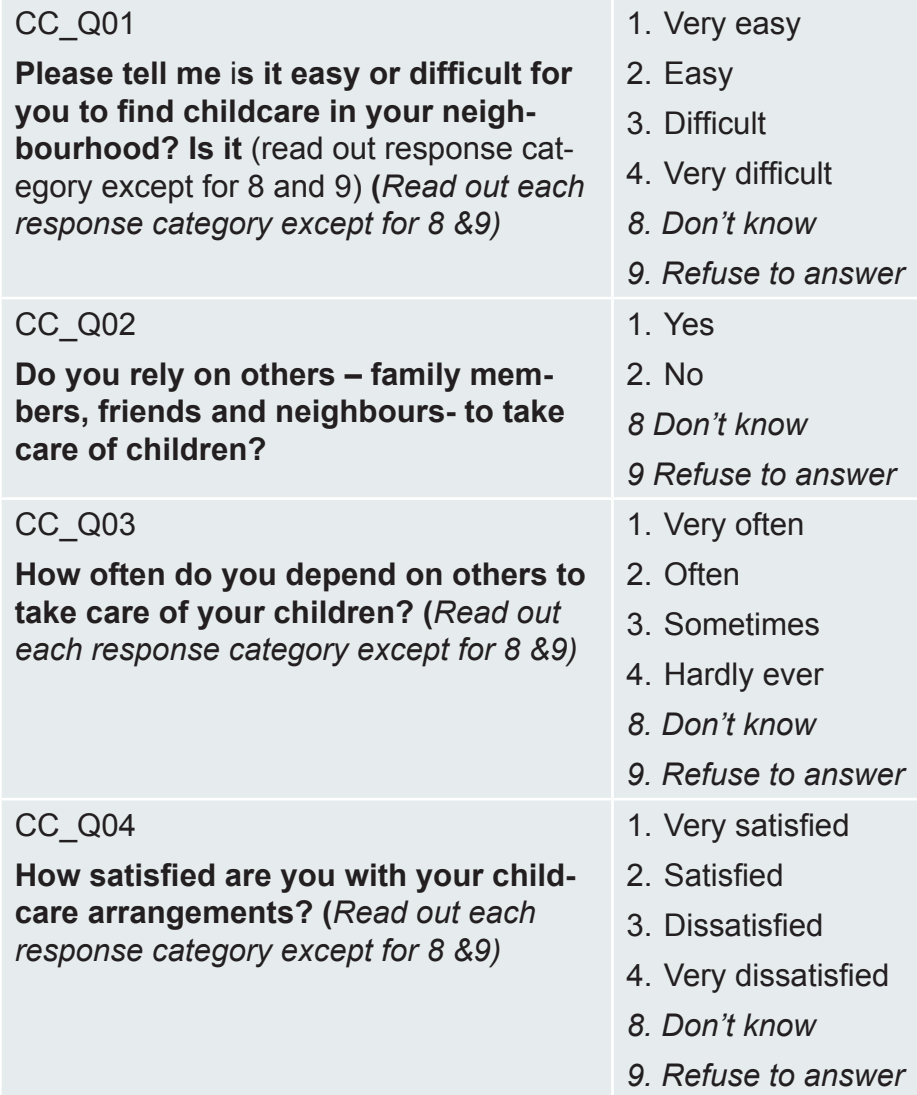

How satisfied are you with your childcare arrangements? (Read out each response category except for 8 \&9)

2. Satisfied

3. Dissatisfied

4. Very dissatisfied

8. Don't know

9. Refuse to answer

Now I will ask some questions about how often you use childcare supports in your neighbourhood.
CC_Q05
1. Very often
How often do you use a day- care? (Read response categories out except for options 8 \& 9)
2. Often
3. Sometimes
4. Hardly ever
8. Don't know
9. Refuse to answer 
Evaluation of Centres for the Integral Attention of Children in Dominican Republic (CIANIs) and Local Community Organizations for Child Protection (LCOCP)

\begin{tabular}{|c|c|c|}
\hline $\begin{array}{l}\text { CC_Q06 } \\
\text { Are there any other childcare } \\
\text { services that you use in your } \\
\text { neighbourhood? } \\
\text { CC_Q06B }\end{array}$ & $\begin{array}{l}\text { 1. Yes (Go to CC_Q06B) } \\
\text { 2. No } \\
\text { 8. Don't know } \\
\text { 9. Refuse to answer } \\
\text { If "yes," please specify. }\end{array}$ & $\begin{array}{l}\text { If none are listed, } \\
\text { move forward to } \\
\text { community. } \\
\text { If a service is list- } \\
\text { ed use it/them in } \\
\text { CC_Q07 }\end{array}$ \\
\hline $\begin{array}{l}\text { CC_Q07 } \\
\text { c) How often do you use } \\
\text { (Insert first service listed here) } \\
\text { (Read response categories } \\
\text { out except for options } 8 \text { \& 9) } \\
\text { d) How often do you use } \\
\text { (Insert second service } \\
\text { listed here) (Read response } \\
\text { categories out except for op- } \\
\text { tions } 8 \text { \& 9) }\end{array}$ & $\begin{array}{l}\text { 1. Very often } \\
\text { 2. Often } \\
\text { 3. Sometimes } \\
\text { 4. Hardly ever } \\
\text { 8. Don't know } \\
\text { 9. Refuse to answer } \\
\text { 1. Very often } \\
\text { 2. Often } \\
\text { 3. Sometimes } \\
\text { 4. Hardly ever } \\
\text { 8. Don't know } \\
\text { 9. Refuse to answer }\end{array}$ & \\
\hline
\end{tabular}

\section{HEALTH}

Now I am going to ask some questions about health.

$$
\text { H_Q01 }
$$

How would you describe the health of the children in the household - would you say it is excellent, very good, good, fair poor?

Refer back to charts in DEM_Q05.

Ask question and mark on that chart
Jump back to Charts $A, B$, and $C$ in DEM_Q05 
Evaluation of Centres for the Integral Attention of Children in Dominican Republic (CIANIs) and Local Community Organizations for Child Protection (LCOCP)

\begin{tabular}{|c|c|}
\hline $\begin{array}{l}\text { H_Q02 } \\
\text { Would you say that in general } \\
\text { your own health is (Read response } \\
\text { categories out except for options } 8 \\
\& 9 \text { ) }\end{array}$ & $\begin{array}{l}\text { 1. Excellent } \\
\text { 2. Very good } \\
\text { 3. Good } \\
\text { 4. Fair } \\
\text { 5. Poor } \\
\text { 8. Don't know } \\
\text { 9. Refuse to answer }\end{array}$ \\
\hline $\begin{array}{l}\text { H_Q03 } \\
\text { In the past year have any of the } \\
\text { children been injured or ill? } \\
\text { H_Q03B }\end{array}$ & $\begin{array}{l}\text { 1. Yes (Go to H_Q03B) } \\
\text { 2. No } \\
\text { 8. Don't know } \\
\text { 9. Refuse to answer } \\
\text { If "yes," go to H_Q03B. }\end{array}$ \\
\hline $\begin{array}{l}\text { H_Q04 } \\
\text { In the past year was there a sit- } \\
\text { uation where your child/children } \\
\text { were ill or injured and did not re- } \\
\text { ceive necessary medical care? } \\
\text { H_Q04B }\end{array}$ & $\begin{array}{l}\text { 1. Yes (Go to H_Q04B) } \\
\text { 2. No } \\
\text { 8. Don't know } \\
\text { 9. Refuse to answer } \\
\text { If "yes," which child (use name from ta- } \\
\text { bles from D Q05) }\end{array}$ \\
\hline
\end{tabular}

\section{DISCIPLINE AND PARENTING ATTITUDE}

All adults use different ways to teach their children the right behaviour or to address behaviour problems.
DPA_Q01
1. Yes
Do you believe that in order to raise a child properly you
2. No need to physically discipline them? By this I mean do you believe that you need to spank or hit the child or take any other physical measures to discipline the child?
8. Don't know
9. Refuse to answer

I am going to read you a few different situations, and I would like you to tell me if you think that a parent would be justified in using physical discipline (hitting) in the particular situation. Do not read responses out 


\begin{tabular}{|c|c|}
\hline $\begin{array}{l}\text { DPA_Q02 } \\
\text { If the child is at risk of harming themselves. }\end{array}$ & $\begin{array}{l}\text { 1. Yes } \\
\text { 2. No } \\
\text { 8. Don't know } \\
\text { 9. Refuse to answer }\end{array}$ \\
\hline $\begin{array}{l}\text { DPA_Q03 } \\
\text { If the child does something without parent } \\
\text { permission }\end{array}$ & $\begin{array}{l}\text { 1. Yes } \\
\text { 2. No } \\
\text { 8. Don't know } \\
\text { 9. Refuse to answer }\end{array}$ \\
\hline $\begin{array}{l}\text { DPA_Q04 } \\
\text { If the child disobeys an adult }\end{array}$ & $\begin{array}{l}\text { 1. Yes } \\
\text { 2. No } \\
\text { 8. Don't know } \\
\text { 9. Refuse to answer }\end{array}$ \\
\hline $\begin{array}{l}\text { DPA_Q05 } \\
\text { If the child fights with a sibling }\end{array}$ & $\begin{array}{l}\text { 1. Yes } \\
\text { 2. No } \\
\text { 8. Don't know } \\
\text { 9. Refuse to answer }\end{array}$ \\
\hline $\begin{array}{l}\text { DPA_Q06 } \\
\text { If the child fights with another child }\end{array}$ & $\begin{array}{l}\text { 1. Yes } \\
\text { 2. No } \\
\text { 8. Don't know } \\
\text { 9. Refuse to answer }\end{array}$ \\
\hline $\begin{array}{l}\text { DPA_Q07 } \\
\text { If the child robbed something }\end{array}$ & $\begin{array}{l}\text { 1. Yes } \\
\text { 2. No } \\
\text { 8. Don't know } \\
\text { 9. Refuse to answer }\end{array}$ \\
\hline $\begin{array}{l}\text { DPA_Q08 } \\
\text { If the child did poorly at school }\end{array}$ & $\begin{array}{l}\text { 1. Yes } \\
\text { 2. No } \\
\text { 8. Don't know } \\
\text { 9. Refuse to answer }\end{array}$ \\
\hline $\begin{array}{l}\text { DPA_Q09. } \\
\text { If the child refuses to do chores? }\end{array}$ & $\begin{array}{l}\text { 1. Yes } \\
\text { 2. No } \\
\text { 8. Don't know } \\
\text { 9. Refuse to answer }\end{array}$ \\
\hline
\end{tabular}


Evaluation of Centres for the Integral Attention of Children in Dominican Republic (CIANIs) and Local Community Organizations for Child Protection (LCOCP)

Let's talk about your experiences as a parent.
DPA_Q10
1. Yes
In the past year, have you used physical
2. No
discipline to correct your child's behaviour?
8. Don't know
9. Refuse to answer
DPA_Q11
In the past year, has anyone in the house-
1. Yes (Go to DPA_Q10B) hold, other than you, used physical disci-
2. No pline with the child?
8. Don't know
9. Refuse to answer
DPA_Q10B
If "yes," please specify who

Once more I am going to ask you about certain ways of teaching children right behaviour or to correct behaviour problems.

I am going to read various methods used by parents and I want you to tell me if you have used this method in the last year.
DPA_Q12
1. Yes
Have you taken away privileges, forbade some-
2. No
thing the child liked (for example; television or
8. Don't know
toys) or not allowed them to leave the house?
9. Refuse to answer
DPA_Q13
1. Yes
Have you explained why something the child did
2. No was wrong?
8. Don't know
9. Refuse to answer
DPA_Q14
1. Yes
Have you shaken the child?
2. No
8. Don't know
9. Refuse to answer 


\begin{tabular}{|c|c|}
\hline $\begin{array}{l}\text { DPA_Q15 } \\
\text { Have you shouted, yelled at or screamed at the } \\
\text { child? }\end{array}$ & $\begin{array}{l}\text { 1. Yes } \\
\text { 2. No } \\
\text { 8. Don't know } \\
\text { 9. Refuse to answer }\end{array}$ \\
\hline $\begin{array}{l}\text { DPA_Q16 } \\
\text { Have you hit the child on the leg with bare hand? }\end{array}$ & $\begin{array}{l}\text { 1. Yes } \\
\text { 2. No } \\
\text { 8. Don't know } \\
\text { 9. Refuse to answer }\end{array}$ \\
\hline $\begin{array}{l}\text { DPA_Q17 } \\
\text { Have you hit the child on the leg with something } \\
\text { like a belt, brush, stick or hard object? }\end{array}$ & $\begin{array}{l}\text { 1. Yes } \\
\text { 2. No } \\
\text { 8. Don't know } \\
\text { 9. Refuse to answer }\end{array}$ \\
\hline $\begin{array}{l}\text { DPA_Q18 } \\
\text { Have you spanked, hit or slap child on the bottom } \\
\text { with bare hand? }\end{array}$ & $\begin{array}{l}\text { 1. Yes } \\
\text { 2. No } \\
\text { 8. Don't know } \\
\text { 9. Refuse to answer }\end{array}$ \\
\hline $\begin{array}{l}\text { DPA_Q19 } \\
\text { Have you ever hit him/her on bottom with some- } \\
\text { thing like a belt, hairbrush, stick or hard object? }\end{array}$ & $\begin{array}{l}\text { 1. Yes } \\
\text { 2. No } \\
\text { 8. Don't know } \\
\text { 9. Refuse to answer }\end{array}$ \\
\hline $\begin{array}{l}\text { DPA_Q20 } \\
\text { Have you hit him/her on the body - not on the bot- } \\
\text { tom - with something like a belt, hairbrush, stick or } \\
\text { hard object? }\end{array}$ & $\begin{array}{l}\text { 1. Yes } \\
\text { 2. No } \\
\text { 8. Don't know } \\
\text { 9. Refuse to answer }\end{array}$ \\
\hline $\begin{array}{l}\text { DPA_Q21 } \\
\text { Have you called the child dumb, lazy or another } \\
\text { name like that? }\end{array}$ & $\begin{array}{l}\text { 1. Yes } \\
\text { 2. No } \\
\text { 8. Don't know } \\
\text { 9. Refuse to answer }\end{array}$ \\
\hline $\begin{array}{l}\text { DPA_Q22 } \\
\text { Have you hit or slapped the child on the face, head } \\
\text { or ears? }\end{array}$ & $\begin{array}{l}\text { 1. Yes } \\
\text { 2. No } \\
\text { 8. Don't know } \\
\text { 9. Refuse to answer }\end{array}$ \\
\hline $\begin{array}{l}\text { DPA_Q23 } \\
\text { Have you beat the child up - hit over and over as } \\
\text { hard as you could? }\end{array}$ & $\begin{array}{l}\text { 1. Yes } \\
\text { 2. No } \\
\text { 8. Don't know } \\
\text { 9. Refuse to answer }\end{array}$ \\
\hline
\end{tabular}


Evaluation of Centres for the Integral Attention of Children in Dominican Republic (CIANIs) and Local Community Organizations for Child Protection (LCOCP)

\begin{tabular}{|c|c|}
\hline $\begin{array}{l}\text { DPA_Q24 } \\
\text { Have you threatened the child? }\end{array}$ & $\begin{array}{l}\text { 1. Yes } \\
\text { 2. No } \\
\text { 8. Don't know } \\
\text { 9. Refuse to answer }\end{array}$ \\
\hline $\begin{array}{l}\text { DPA_Q25 } \\
\text { Have you made the child apologize? }\end{array}$ & $\begin{array}{l}\text { 1. Yes } \\
\text { 2. No } \\
\text { 8. Don't know } \\
\text { 9. Refuse to answer }\end{array}$ \\
\hline $\begin{array}{l}\text { DPA_Q26 } \\
\text { Have you hit the child with a fist, or kicked the } \\
\text { child hard? }\end{array}$ & $\begin{array}{l}\text { 1. Yes } \\
\text { 2. No } \\
\text { 8. Don't know } \\
\text { 9. Refuse to answer }\end{array}$ \\
\hline $\begin{array}{l}\text { DPA_Q27 } \\
\text { Have you threatened to hit or physically punish } \\
\text { the child? }\end{array}$ & $\begin{array}{l}\text { 1. Yes } \\
\text { 2. No } \\
\text { 8. Don't know } \\
\text { 9. Refuse to answer }\end{array}$ \\
\hline $\begin{array}{l}\text { DPA_Q28 } \\
\text { Have you sworn or cursed at the child? }\end{array}$ & $\begin{array}{l}\text { 1. Yes } \\
\text { 2. No } \\
\text { 8. Don't know } \\
\text { 9. Refuse to answer }\end{array}$ \\
\hline $\begin{array}{l}\text { DPA_Q29 } \\
\text { Have you told the child you would kick them out of } \\
\text { the house? }\end{array}$ & $\begin{array}{l}\text { 1. Yes } \\
\text { 2. No } \\
\text { 8. Don't know } \\
\text { 9. Refuse to answer }\end{array}$ \\
\hline $\begin{array}{l}\text { DPA_Q30 } \\
\text { Have you pulled the child's hair? }\end{array}$ & $\begin{array}{l}\text { 1. Yes } \\
\text { 2. No } \\
\text { 8. Don't know } \\
\text { 9. Refuse to answer }\end{array}$ \\
\hline $\begin{array}{l}\text { DPA_Q31 } \\
\text { Have you pinched the child? }\end{array}$ & $\begin{array}{l}\text { 1. Yes } \\
\text { 2. No } \\
\text { 8. Don't know } \\
\text { 9. Refuse to answer }\end{array}$ \\
\hline
\end{tabular}




\begin{tabular}{|c|c|}
\hline $\begin{array}{l}\text { DPA_Q32 } \\
\text { Have you given the child something else to do? } \\
\text { (As a distraction) }\end{array}$ & $\begin{array}{l}\text { 1. Yes } \\
\text { 2. No } \\
\text { 8. Don't know } \\
\text { 9. Refuse to answer }\end{array}$ \\
\hline $\begin{array}{l}\text { DPA_Q33 } \\
\text { Have you ignored the child? }\end{array}$ & $\begin{array}{l}\text { 1. Yes } \\
\text { 2. No } \\
\text { 8. Don't know } \\
\text { 9. Refuse to answer }\end{array}$ \\
\hline $\begin{array}{l}\text { DPA_Q34 } \\
\text { Have you pushed or knocked the child down? }\end{array}$ & $\begin{array}{l}\text { 1. Yes } \\
\text { 2. No } \\
\text { 8. Don't know } \\
\text { 9. Refuse to answer }\end{array}$ \\
\hline $\begin{array}{l}\text { DPA_Q35 } \\
\text { Have you made fun of the child? }\end{array}$ & $\begin{array}{l}\text { 1. Yes } \\
\text { 2. No } \\
\text { 8. Don't know } \\
\text { 9. Refuse to answer }\end{array}$ \\
\hline $\begin{array}{l}\text { DPA_Q36 } \\
\text { Has the way you discipline the child/children } \\
\text { changed since attending the CIANI? }\end{array}$ & $\begin{array}{l}\text { 1. Yes (Go to DPA_Q36B) } \\
\text { 2. No } \\
\text { 8. Don't know } \\
\text { 9. Refuse to answer } \\
\text { If "yes," please specify. }\end{array}$ \\
\hline $\begin{array}{l}\text { DPA_Q37 } \\
\text { Thinking of all the people living in your household } \\
\text { who might discipline the child/children, Has there } \\
\text { been an overall change in the discipline in your } \\
\text { household after being involved in the CIANI? } \\
\text { DPA_Q37B }\end{array}$ & $\begin{array}{l}\text { 1. Yes (Go to DPA_Q37B) } \\
\text { 2. No } \\
\text { 8. Don't know } \\
\text { 9. Refuse to answer } \\
\text { If "yes," please specify. }\end{array}$ \\
\hline
\end{tabular}

\section{PARENTING EXPERIENCES}

Many parents and families face different experiences in their everyday lives. I will read some statements of different experiences, and I would like you to tell me if you have faced this experience in the past year. Do not read out response categories. 
Evaluation of Centres for the Integral Attention of Children in Dominican Republic (CIANIs) and Local Community Organizations for Child Protection (LCOCP)

\begin{tabular}{|c|c|}
\hline $\begin{array}{l}\text { PE_Q01 } \\
\text { Have you had problems paying house- } \\
\text { hold expenses in the last year? }\end{array}$ & $\begin{array}{l}\text { 1. Yes } \\
\text { 2. No } \\
\text { 8. Don't know } \\
\text { 9. Refuse to answer }\end{array}$ \\
\hline $\begin{array}{l}\text { PE_Q02. } \\
\text { Have you moved in the last year? } \\
\text { PE_Q02B }\end{array}$ & $\begin{array}{l}\text { 1. Yes (Go to PE_Q02B) } \\
\text { 2. No } \\
\text { 8. Don't know } \\
\text { 9. Refuse to answer } \\
\text { If "yes," how many times have you } \\
\text { moved in the last year? }\end{array}$ \\
\hline $\begin{array}{l}\text { PE_Q03 } \\
\text { Have you had significant problems in } \\
\text { your relationship with your spouse or } \\
\text { partner in the last year? }\end{array}$ & $\begin{array}{l}\text { 1. Yes } \\
\text { 2. No } \\
\text { 8. Don't know } \\
\text { 9. Refuse to answer }\end{array}$ \\
\hline $\begin{array}{l}\text { PE_Q04 } \\
\text { Have you experienced forms of vio- } \\
\text { lence in your household in the last } \\
\text { year? }\end{array}$ & $\begin{array}{l}\text { 1. Yes } \\
\text { 2. No } \\
\text { 8. Don't know } \\
\text { 9. Refuse to answer }\end{array}$ \\
\hline $\begin{array}{l}\text { PE_Q05 } \\
\text { Have you experienced violence in your } \\
\text { neighbourhood in the last year? }\end{array}$ & $\begin{array}{l}\text { 1. Yes } \\
\text { 2. No } \\
\text { 8. Don't know } \\
\text { 9. Refuse to answer }\end{array}$ \\
\hline $\begin{array}{l}\text { PE_Q06 } \\
\text { Have you had a divorce, separation, or } \\
\text { a breakup from a partner or spouse? }\end{array}$ & $\begin{array}{l}\text { 1. Yes } \\
\text { 2. No } \\
\text { 8. Don't know } \\
\text { 9. Refuse to answer }\end{array}$ \\
\hline
\end{tabular}




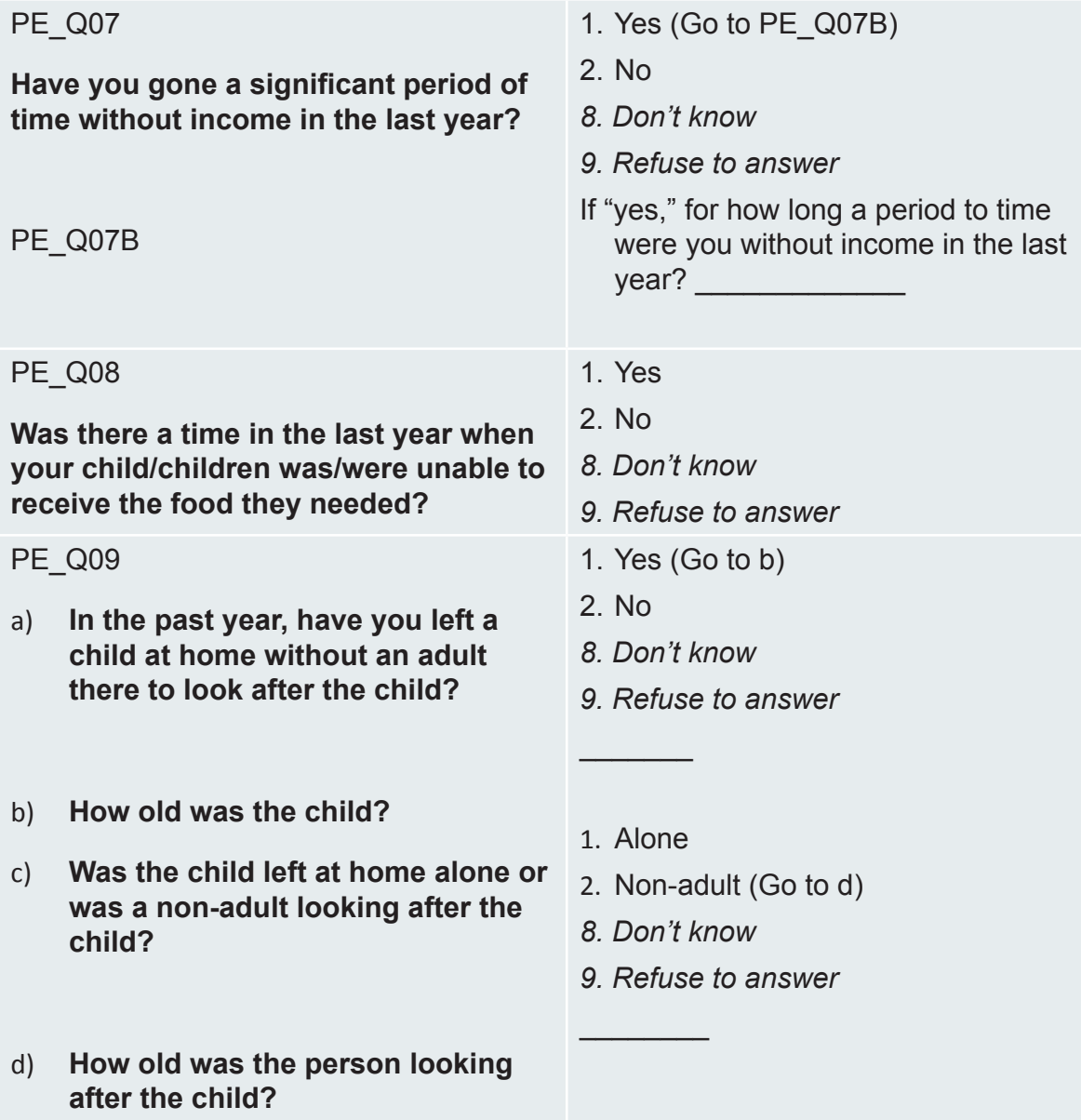

2. No

Was there a time in the last year when your child/children was/were unable to receive the food they needed?

8. Don't know

9. Refuse to answer

1. Yes (Go to b)

2. No

a) In the past year, have you left a child at home without an adult

8. Don't know there to look after the child?

9. Refuse to answer

b) How old was the child?

c) Was the child left at home alone or was a non-adult looking after the child?
1. Alone
2. Non-adult (Go to d)
8. Don't know

9. Refuse to answer

d) How old was the person looking after the child?

\section{COMMUNITY ENGAGEMENT}

Now I am going to read some statements about your neighbourhood. Please tell me if you strongly agree, agree, disagree or strongly disagree with each statement.

$$
\text { COM_Q01 }
$$

My child is safe in my neighbourhood. (Read response categories out except for options 8 \& 9)
1. Strongly agree

2. Agree

3. Disagree

4. Strongly disagree

8. Don't know

9. Refuse to answer 
Evaluation of Centres for the Integral Attention of Children in Dominican Republic (CIANIs) and Local Community Organizations for Child Protection (LCOCP)

\begin{tabular}{|c|c|}
\hline $\begin{array}{l}\text { COM_Q02 } \\
\text { I am safe in my neighbourhood. (Read re- } \\
\text { sponse categories out except for options } 8 \text { \& 9) }\end{array}$ & $\begin{array}{l}\text { 1. Strongly agree } \\
\text { 2. Agree } \\
\text { 3. Disagree } \\
\text { 4. Strongly disagree } \\
\text { 8. Don't know } \\
\text { 9. Refuse to answer }\end{array}$ \\
\hline $\begin{array}{l}\text { COM_Q03 } \\
\text { We take care of each other's children in my } \\
\text { neighbourhood? (Read response categories } \\
\text { out except for options } 8 \& 9 \text { ) }\end{array}$ & $\begin{array}{l}\text { 1. Strongly agree } \\
\text { 2. Agree } \\
\text { 3. Disagree } \\
\text { 4. Strongly disagree } \\
\text { 8. Don't know } \\
\text { 9. Refuse to answer }\end{array}$ \\
\hline $\begin{array}{l}\text { COM_Q04 } \\
\text { In my neighbourhood there are NO secure } \\
\text { parks or playgrounds for the children to } \\
\text { play. (Read response categories out except for } \\
\text { options } 8 \text { \& 9) }\end{array}$ & $\begin{array}{l}\text { 1. Strongly agree } \\
\text { 2. Agree } \\
\text { 3. Disagree } \\
\text { 4. Strongly disagree } \\
\text { 8. Don't know } \\
\text { 9. Refuse to answer }\end{array}$ \\
\hline $\begin{array}{l}\text { COM_Q05 } \\
\text { It is easy for me to get help from organiza- } \\
\text { tions in my neighbourhood. (Read response } \\
\text { categories out except for options } 8 \& 9 \text { ) }\end{array}$ & $\begin{array}{l}\text { 1. Strongly agree } \\
\text { 2. Agree } \\
\text { 3. Disagree } \\
\text { 4. Strongly disagree } \\
\text { 8. Don't know } \\
\text { 9. Refuse to answer }\end{array}$ \\
\hline $\begin{array}{l}\text { COM_Q06 } \\
\text { I do not know many agencies or organiza- } \\
\text { tions in my neighbourhood. (Read response } \\
\text { categories out except for options } 8 \text { \& 9) }\end{array}$ & $\begin{array}{l}\text { 1. Strongly agree } \\
\text { 2. Agree } \\
\text { 3. Disagree } \\
\text { 4. Strongly disagree } \\
\text { 8. Don't know } \\
\text { 9. Refuse to answer }\end{array}$ \\
\hline $\begin{array}{l}\text { COM_Q07 } \\
\text { I am part of my neighbourhood (Read re- } \\
\text { sponse categories out except for options } 8 \text { \& 9) }\end{array}$ & $\begin{array}{l}\text { 1. Strongly agree } \\
\text { 2. Agree } \\
\text { 3. Disagree } \\
\text { 4. Strongly disagree } \\
\text { 8. Don't know } \\
\text { 9. Refuse to answer }\end{array}$ \\
\hline
\end{tabular}




\begin{tabular}{l|l}
\hline COM_Q08 & 1. Strongly agree \\
$\begin{array}{l}\text { In my neighbourhood I do not count on } \\
\text { support from many people. (Read response } \\
\text { categories out except for options } 8 \text { \& 9) }\end{array}$ & $\begin{array}{l}\text { 2. Agree } \\
\text { 3. Disagree }\end{array}$ \\
\hline $\begin{array}{l}\text { 4. Strongly disagree } \\
\text { 8. Don't know } \\
\text { 9. Refuse to answer }\end{array}$ \\
\hline COM_Q09 & 1. Strongly agree \\
\hline $\begin{array}{l}\text { I feel part of a group of people in the neigh- } \\
\text { bourhood who share my attitudes and } \\
\text { beliefs. For example, prayer groups, clubs, } \\
\text { and teams. (Read response categories out } \\
\text { except for options } 8 \text { \& 9) }\end{array}$ & $\begin{array}{l}\text { 3. Disagree } \\
\text { 4. Strongly disagree }\end{array}$ \\
\hline
\end{tabular}

There are many different neighbourhood events, some sponsored by churches, governments and other groups.

\begin{tabular}{|c|c|}
\hline COM_Q10 & 1. Very often \\
\hline o vou atte & 2. Often \\
\hline or events in the neighbourhood? (Read re- & 3. Sometimes \\
\hline sponse categories out except for options 8 \& 9) & 4. Hardly ever \\
\hline & 8. Don't know \\
\hline & 9. Refuse to answer \\
\hline COM_Q11 & 1. Very often \\
\hline How often do you work with o & 2. Often \\
\hline neighbourhood to solve problems in the & 3. Sometimes \\
\hline neighbourhood? & 4. Hardly ever \\
\hline (Read response categories out e) & 8. Don't know \\
\hline tions 8 \& 9) & 9. Refuse to answer \\
\hline
\end{tabular}

Thank you very much for taking the time to participate in the survey. Ryerson University appreciates your cooperation. Your information is very important to us. We value your support and your willingness to help us meet the goals of this project. 
This edition of

Evaluation of Centres for the Integral Attention of Children in Dominican Republic (CIANIs) and Local Community

Organizations for Child Protection (LCOCP) It was printed in July 2016

Graphic workshop in Editora Búho, S.R.L.

Santo Domingo, Dominican Republic. 

